Universidade de São Paulo

Instituto de Astronomia, Geofísica e Ciências Atmosféricas

Departamento de Astronomia

Gustavo Andrés Guerrero Eraso

\title{
Estudos numéricos do dínamo Solar
}

São Paulo

2009 

Gustavo Andrés Guerrero Eraso

\section{Estudos numéricos do dínamo Solar}

Tese apresentada ao Departamento de Astronomia do Ins-

tituto de Astronomia, Geofísica e Ciências Atmosféricas da Universidade de São Paulo como parte dos requisitos para a obtenção do título de Doutor em Ciências.

Área de Concentração: Astronomia

Orientador(a): Prof. $\left({ }^{a}\right)$ Dr. $\left(^{a}\right)$ Elisabete Maria de Gouveia Dal Pino

São Paulo 

Este trabalho é dedicado às duas pessoas que fazem minha vida ter um significado maior: minha mãe e a Grá. 
Gostaria agradecer ao Instituto de Astronomía, Geofísica e Ciências Atmosféricas por ter me acolhido e permitido desenvolver os estudos de doutorado concluídos nesta tese. Agradeço também a todos os professores, especialmente à professora Zulema e ao professor Jorge. E também ao pessoal administrativo que facilita o nosso trabalho diario, especialmente à Rose e à Marina.

Aos membros da banca examinadora por aceitarem julgar essa tese.

Ao $\mathrm{CNPq}$ pelo suporte financeiro e à FAPESP pelo apoio financeiro para o projeto temático $n^{o}: 2006 / 50654-3$ que facilitou a aquisição do equipamento computacional para desenvolver estes estudos.

À Bete pelo seu ensino na sala de aula, pelas importantes discussões e o trabalho acadêmico, por seus conselhos no âmbito profissional e pessoal, por acreditar em mim e, claro, pela sua paciência. Sem a sua excelente orientação esse trabalho não teria sido possível.

A Dra. Mausumi Dikpati pelas discussões sobre dínamo solar nos vários congressos onde coincidimos e pelo seu convite para trabalhar com ela durante o verão de 2008 no High Altitude Observatory (HAO). Agradeço também o apoio financeiro do HAO durante essa viagem e a NCAR pelas facilidades computacionais no cluster bluefire onde foram feitas as simulações tridimensionais apresentadas no último Capítulo deste trabalho.

À minha família: minha mãe e meus irmãos por todo seu amor e ajuda incondicional. Tem sido mais fácil na vida fazer tudo o que eu gosto sabendo que conto com vocês.

Aos meus amigos/colegas latinos do IAG: el Compadre, Sergio, Adrian, Juan Luna, Tatiana e Fernanda. Aos meus colegas do grupo de plasmas Astrofísicos: Reinaldo, Márcia, Fernanda, Pamela, Cláudio, Luiz e Diego. Aos meus amigos del fulbito Federico, Javier, Alejandro, Jaime, Ricardo, Ives, Raul, Canijia e a aos meninos da quadra.

E, claro, agradeço à Grá, por me ajudar descobrir durante esses últimos três anos que o amor pode ser reinventado. Obrigado por tudo negrita linda, a vida é mais feliz e simples com você ao meu lado.

Esta tese/dissertação foi escrita em LATEX com a classe IAGTESE, para teses e dissertações do IAG. 


\section{Resumo}

O ciclo solar é um dos fenômenos magnéticos mais interessantes do Universo. Embora ele tinha sido descoberto há mais de 150 anos, até agora permanece um problema em aberto para a Astrofísica. Há diferentes tipos de observações que sugerem que o ciclo solar corresponde a um processo de dínamo operando em algum lugar do interior solar. Parker foi o primeiro a tentar explicar o dínamo solar como um processo hidro-magnético acerca de 50 anos atrás. Desde então, embora tenha havido avanços significativos nas observações e investigações teóricas e numéricas, uma resposta definitiva para o dínamo solar ainda não existe.

Acredita-se que no caso do Sol, pelo menos dois processos são necessários para completar o ciclo magnético observado: a transformação de um campo poloidal inicial em um campo toroidal, um processo conhecido como efeito $\Omega$, o qual se deve ao cisalhamento em grande escala ocasionado pela rotação diferencial; e a transformação do campo toroidal em um novo campo poloidal de polaridade oposta ao inicial. Esse segundo processo é menos conhecido e motivo de intensas discussões e pesquisas. Duas hipóteses principais foram formuladas para explicar a natureza deste processo, usualmente conhecido como efeito $\alpha$ : a primeira, baseada na idéia de Parker de um mecanismo turbulento onde os campos poloidais resultam de movimentos convectivos ciclônicos operando em tubos de fluxo toroidais em pequena escala. Esses modelos se depararam, no entanto, com um serio inconveniente: na fase não-linear, i.e., quando a reação dinâmica do campo magnético ao fluido torna-se importante, o efeito $\alpha$ pode ser amortecido de forma catastrófica, levando a um dínamo pouco efetivo.

A segunda hipótese é baseada nas idéias de Babcock (1961) e Leighton (1969) (BL), que propuseram que o campo poloidal forma-se devido à emergência e decaimento posterior das regiões bipolares ativas. Neste modelo a circulação meridional tem um papel fundamental pois atua como mecanismo de transporte do fluxo magnético, de tal forma que a escala de tempo advectivo deve dominar sobre a escala de tempo difusiva. Por essa razão essa classe de modelos é comumente conhecida como modelo de dínamo dominado pelo transporte de fluxo, ou dínamo advectivo.

Os modelos de dínamo dominados pelo transporte de fluxo são relativamente bem 
sucedidos em reproduzir as características em grande escala do ciclo solar, tornando-se populares entre a comunidade de Física solar, no entanto, também apresentam vários problemas amplamente discutidos na literatura. O objetivo principal deste trabalho foi identificar as principais limitações dessa classe de modelos e explorar as suas possíveis soluções. Para tal, construímos um modelo numérico bi-dimensional de dínamo cinemático baseado na teoria de campo médio e investigamos primeiro os efeitos da geometria e da espessura da tacoclina solar na amplificação do dínamo. Depois, consideramos o processo de bombeamento magnético turbulento como um mecanismo alternativo de transporte de fluxo magnético, e finalmente, incluímos a reação dinâmica do campo magnético sobre a difusividade magnética turbulenta, um processo conhecido como amortecimento de $\eta$.

Verificamos que é possível construir-se um modelo de dínamo dominado pelo transporte de fluxo capaz de reproduzir as observações ao considerar-se uma tacoclina de espessura fina localizada abaixo da zona convectiva. Isto limita a criação de intensos campos toroidais não desejados nas altas latitudes. Verificamos também ser importante considerar o bombeamento magnético, pois ele provê advecção do fluxo magnético para o equador e para a base da camada convectiva, o que resulta em uma correta distribuição latitudinal e temporal dos campos toroidais e também permite certa penetração desses campos nas regiões mais estáveis onde podem adquirir maior amplificação. Esse mecanismo é ainda importante para produzir a paridade correta do campo (anti-simétrica) nos dois hemisférios do Sol. Também encontramos que o amortecimento da difusividade magnética é um mecanismo fundamental para a formação de pequenas estruturas de campo toroidal com maior tempo de vida, identificadas com os tubos de fluxo, que acredita-se existirem na base da zona de convecção. Além do mais, os campos magnéticos formados graças ao amortecimento de $\eta$ podem ser até $\sim 2$ vezes mais intensos que as estruturas magnéticas formadas sem o seu amortecimento.

Por fim, nos últimos anos, alguns trabalhos teóricos vêm chamando a atenção para o papel da conservação da helicidade magnética no processo de dínamo, dando nova vida a modelos de dínamo turbulento, como originalmente proposto por Parker. Com o objetivo de investigar o papel da helicidade magnética e de buscar uma descrição dinâmica mais realista do mecanismo de dínamo, construímos recentemente um modelo numérico de convecção tridimensional (utilizando o código MHD, PLUTO) que tenta reproduzir o cenário 
natural do interior solar onde teria lugar o processo de dínamo. Exploramos a evolução de um campo magnético semente imposto sobre um estado convectivo estacionário. Os resultados preliminares indicam que a convecção pode facilmente excitar o efeito de dínamo, inclusive em casos sem rotação. Porém, nos casos com rotação, o dínamo parece produzir uma maior quantidade de campo magnético médio com relação aos casos sem a rotação nos quais o campo flutuante é dominante. Estes resultados suportam a existência de um dínamo turbulento y validam a teoria de campo médio, mas uma a análise mais detalhada ainda é necessária. 


\begin{abstract}
The solar cycle is one of the most interesting magnetic phenomenon in the Universe. Even though it was discovered more than 150 years ago, it remains until now as an open problem in Astrophysics. There are several observational evidences that suggest that the solar cycle corresponds to a dynamo process operating at some place of the solar interior. Parker, in 1955, was the first to try to explain the solar dynamo as hydromagnetic phenomena. Since then, although there has been important improvements in the observations, theory and numerical simulations, a definitive model for the solar dynamo is still missing.

There is common agreement that in the solar case, at least two processes are necessary to close the dynamo loop: the transformation of an initial poloidal field into a toroidal field, the so called $\Omega$ effect, which is due to a large scale shear caused by the diferential rotation, and the transformation of the toroidal field into a new poloidal field of opposite polarity, which is still a poorly understood process that has been the subject of intense debate and research. Two main hypotheses have been formulated in order to explain the nature of this effect, usually denominated $\alpha$ effect: the first one is based on Parker's idea of a turbulent mechanism where the poloidal field results from cyclonic convective motions operating at small scales in the toroidal field ropes. These models, however face an important limitation: in the non-linear regime, i.e. when the back reaction of the toroidal field on the motions becomes important, the $\alpha$ effect can be catastrophically quenched leading to an ineffective dynamo.
\end{abstract}

The second hypotheses is based on the formulation of Babcock (1961) and Leighton (1969) (BL), who proposed that the poloidal field is formed due to the emergence and decay of bipolar magnetic regions. In this model the meridional circulation plays an important role by acting as conveyor belt of the magnetic flux, so that the advection time must be dominant over the diffusion time. For this reason these models are often called fluxtransport dynamo models.

The flux-transport dynamo models has been relatively successful in reproducing the large scale features of the solar cycle, and have become popular between the solar community. However, they also present several problems that have been widely discussed in the literature. The main goal of this work was to identify the main problems concerning the flux-transport dynamo model and to explore possible solutions for them. For this aim, we 
have built a two-dimensional kinematic numerical model based on the mean-field theory in order to explore first the effects of the geometry and thickness of the solar tachocline on the dynamo amplification. Then, we considered the turbulent pumping as an alternative magnetic flux advection mechanism, and finally, we included the non-linear back-reaction of the magnetic field on the turbulent magnetic diffusivity, a process known as $\eta$-quenching.

We have found that it is possible to build a flux-transport dynamo model able to reproduce the observations as long as a thin tachocline located below the convective zone is considered. This helps to prevent the amplification of undesirable strong toroidal fields at the high latitudes. We have also found that it is important to consider the turbulent magnetic pumping mechanism, because it provides magnetic field advection both equatorward and inwards, that results in a correct latitudinal and temporal distribution of the toroidal field and also allows the penetration of the toroidal fields down into the stable layers where they can acquire further amplification. Besides, this mechanism plays an important role in reproducing the correct field parity (anti-symmetric) on both solar hemispheres. We have also found that the $\eta$-quenching may lead to the formation of long-lived small structures of toroidal field which resemble the flux-tubes that are believed to exist at the base of the convection zone. The magnetic fields that are formed thanks to the $\eta$-quenching can be up to $\sim$ twice as larger as the magnetic structures which are developed without this effect.

Finally, a number of theoretical works in the last years have called the attention to the role of magnetic helicity conservation in the dynamo processes, giving a new life to the turbulent dynamo model as proposed by Parker. With the aim to study the role of magnetic helicity and explore a more realistic dynamical description of the dynamo mechanism, we have also recently built a 3D convective numerical model (based on the MHD-Goudunov type PLUTO code) where we try to reproduce the natural scenario of the solar interior where the dynamo might take place. We have studied the evolution of a seed field embedded in an initially steady state convection layer. Our preliminary results indicate that convection can easily drive the dynamo action, even in the case without rotation. However, in the rotating cases, the dynamo appears to produce a larger amount of large scale (coherent) magnetic field when compared to the case without rotation where small scale fluctuating fields are dominant. These results support the existence of a turbulent mean field dynamo, but furthermore detailed analysis is still required. 



\section{Lista de Figuras}

2.1 Média mensal do número de manchas solares desde 1750 até o presente (Imagem extraída de http://science.msfc.nasa.gov) . . . . . . . . . . .

2.2 Duas classes diferentes de "diagramas de borboleta", tempo-latitude. O gráfico superior apresenta a latitude de surgimento de manchas individuais e grupos de manchas. A linha grossa destaca a data do mínimo solar, a linha tracejada marca a fronteira entre dois ciclos sucessivos e a linha fina mostra o local onde pequenas regiões ativas, sem manchas, aparecem nos primeiros anos do ciclo (extraída de Schrijver e Zwaan, 2000). O painel inferior apresenta a média longitudinal do campo magnético. As escalas de cor em amarelo e azul indicam campos positivos e negativos, respectivamente (extraída de http://solarscience.msfc.nasa.gov/dynamo.shtml) . . . . . . . .

2.3 Painel da esquerda: iso-contornos de velocidade angular no interior solar, extraída de Thompson et al. (2003). Painel da direita: perfil radial da velocidade angular para três latitudes diferentes, $0^{\circ}, 15^{\circ}$ e $30^{\circ}$. Nesse gráfico é evidente a camada de cisalhamento (shear) próximo à superfície (figura extraída de Brandenburg, 2005) . . . . . . . . . . . . .

2.4 Perfil de fluxo meridional obtido a partir do método de marcadores magnéticos. Para obter essa curva foram usados 514 pares de magnetogramas durante o período 1978 - 1990. As velocidades positivas (negativas) indicam que o fluxo pertence ao hemisfério norte (sul). As linhas tracejadas e pontilhadas correspondem a ajustes feitos por (Snodgrass, 1984) e (Ulrich, 1993), respectivamente. A linha sólida corresponde a um ajuste feito por Komm et al. (1993b) (imagem extraída de Komm et al., 1993b). . . . . . . . . . . 
2.5 Perfil de fluxo meridional para os hemisférios norte e sul obtidos por inversões de héliossismologia por Mitra-Kraev e Thompson (2007). As velocidades positivas (negativas) representam migração polar (equatorial) do fluxo. . . . . . . . . . . . . . . . . . . . .

3.1 Imagens esquerda e do meio: perfil de rotação diferencial no interior da camada convectiva solar obtido a partir de simulações de convecção no modelo esférico global de Miesch et al. (2008). No painel da esquerda esse perfil é exibido em contornos bi-dimensionais em dois quadrantes do Sol ao norte e ao sul do equador, em uma distribuição latitudinal e radial. Imagem à direita: mapa de contornos da circulação meridional obtido com o mesmo modelo hidrodinâmico. . . . . . . . . . . . . . . . . . .

3.2 Esquerda: representação volumétrica do campo magnético toroidal obtido em simulações numéricas 3D globais por Brun et al. (2004). As cores vermelha e azul indicam orientação positiva e negativa do campo, respectivamente. Direita: Extrapolação do campo radial no topo do domínio computacional da mesma simulação. As linhas brancas representam linhas fechadas, enquanto as linhas amarelas indicam linhas de campo abertas. . . . . . . .

3.3 Regeneração mútua dos campos toroidal e poloidal no caso de um dínamo $\alpha \Omega$. (Figura extraída de Brandenburg e Subramanian, 2005). . . . . . . . .

3.4 a) Modelo do perfil de rotação diferencial incluindo uma camada de cisalhamento radial na tacoclina e o perfil de cisalhamento latitudinal solar tal como é dado pela eq. eq. 3.40 ; b) perfil de rotação diferencial que inclui também a camada de cisalhamento radial próxima da superfície; e c) linhas de velocidade do fluxo meridional. A linha tracejada indica a posição do centro da camada de penetração (overshooting) . . . . . . . . . . . .

3.5 Perfis de difusividade magnética. O gráfico à esquerda apresenta um perfil tipo degrau separando as camadas convectiva e radiativa. O gráfico da direita apresenta um perfil com dois degraus. . . . . . . . . . . . . . . 66

3.6 Perfil radial do termo $\alpha$ num modelo de dínamo distribuído. Os valores estão normalizados ao valor máximo $\alpha_{0}$. . . . . . . . . . . . . . . . . . . 69

3.7 Perfil radial de $\alpha$ no modelo de dínamo na camada de penetração. . . . . . 70 
3.8 Valores normalizados do coeficiente $\alpha$ em função de um campo magnético inicial, $B_{0}$. As linhas tracejada e sólida representam as eqs. (3.52) e (3.56), respectivamente. Pode-se notar que a simulação reproduz o amortecimento catastrófico. (Figura extraída de Cattaneo e Hughes, 1996). . . . . . . . .

3.9 Regiões de estabilidade no plano latitude - amplitude do campo magnético, para tubos de fluxo em equilíbrio localizados nas camadas inferiores (esquerda) e superiores da da zona de overshoot. A região branca corresponde a tubos de fluxo estáveis e as regiões cinzas indicam instabilidades em diferentes modos. (Figura adaptada de Ferriz-Mas et al., 1994). . . . . . . . . 76

4.1 Representação do esquema de paralelização utilizado no código. Cada cor representa um processador diferente. A linha contínua grossa ao redor do domínio corresponde a condições de contorno física do problema, a linha contínua mais fina, dividindo os processadores é uma fronteira interna e as duas linhas tracejadas correspondem a valores de contorno internos que devem ser trocados entre processadores adjacentes.

5.1 Painel esquerdo: perfil da circulação meridional; as linhas tracejadas representam uma tacoclina de espessura $\omega_{1}=0.05 R_{\odot}$. Painéis central e direito: Perfis radial (em $\theta=\pi / 4$ ) e latitudinal (em $r=0.99 R_{\odot}$ ) do efeito $\alpha$ de Babcock-Leighton. Ele é concentrado próximo à superfície e com uma distribuição latitudinal correspondente à faixa onde aparecem as manchas solares na superfície da estrela. . . . . . . . . . . . . . . .

5.2 Diagrama de borboleta, tempo versus latitude, para um modelo de dínamo com uma tacoclina de espessura constante $\omega_{1}=0.05 R_{\odot}$. As latitudes $0^{\circ} \mathrm{e}$ $90^{\circ}$ correspondem ao Equador solar e ao Pólo, respectivamente. As linhas contínuas (tracejadas) representam as intensidades dos campos toroidais positivos (negativos), na base da zona de convecção (ou seja, no topo da tacoclina $\left.r=R_{c}+\omega_{1} / 2\right)$. As linhas são espaçadas em escala logarítmica no intervalo entre $5 \times 10^{4}-10^{5} \mathrm{G}$. O fundo em escala de cinzas representa os campos radiais positivos (em cinza claro) e negativo (em cinza escuro) na superfície do Sol. . . . . . . . . . . . . . . . . . 
5.3 Perfis de iso-rotação (esquerda) e diagramas de borboleta, tempo versus latitude (direita) para uma tacoclina prolata (superior); e uma tacoclina oblata (inferior). Os detalhes dos contornos nas imagens à direita são os mesmos que na Fig. 5.2. Nos painéis à esquerda a tacoclina é representada pelas linhas tracejadas. . . . . . . . . . . . . . . .

5.4 Amplitude dos termos de cisalhamento: a) $B_{r}\left(\frac{\partial \Omega}{\partial r}\right)$; b) $\frac{B_{\theta}}{r}\left(\frac{\partial \Omega}{\partial \theta}\right)$ na fase do ciclo na qual o campo magnético radial inverte a sua polaridade, na latitude de $60^{\circ}$ e no centro da tacoclina, e c) campo magnético toroidal $B$ na fase na qual alcança o seu máximo no topo da tacoclina, como função da espessura da tacoclina. As linhas tracejada e contínua representam dois valores diferentes da difusividade magnética turbulenta na zona de convecção, $\eta_{c}=5 \times 10^{9} \mathrm{~cm}^{2} \mathrm{~s}^{-1}$, e $2 \times 10^{10} \mathrm{~cm}^{2} \mathrm{~s}^{-1}$, respectivamente (a linha contínua corresponde ao valor da Tabela 5.1). . . . . . . . . . . . .

5.5 Máximo da componente toroidal do campo magnético no topo da tacoclina em função da difusividade (em escala logarítmica) numa latitude de $60^{\circ}$. Os diferentes tipos de linha correspondem a diferentes espessuras da tacoclina $\omega_{1}$. A linha pontilhada representa o limite entre campos magnéticos flutuantes e não flutuantes $5 \times 10^{4} \mathrm{G}$, como é explicado no texto. Só valores abaixo dessa linha aparecem nas latitudes desejadas do diagrama de borboleta. Os gráficos à esquerda e à direita correspondem a dois valores diferentes de $r_{c}$ no perfil de difusividade, $r_{c}=0.715 R_{\odot}$ (como nas figuras anteriores) e $r_{c}=0.72 R_{\odot}$, respectivamente. . . . . . . . . . . . . . . 100

5.6 Perfis de velocidade angular e diagrams de borboleta tempo versus latitude para uma tacoclina fina $\left(d_{1}=0.02 R_{\odot}, \eta_{c}=5 \times 10^{9} \mathrm{~cm}^{2} \mathrm{~s}^{-1}, r_{c}=0.72 R_{\odot}\right)$ (acima), e uma tacoclina larga $\left(d_{1}=0.08 R_{\odot}, \eta_{c}=3 \times 10^{9} \mathrm{~cm}^{2} \mathrm{~s}^{-1}, r_{c}=0.715 R_{\odot}\right)$ (embaixo). Os detalhes dos contornos nos diagramas à direita são os mesmos que na Fig. 5.2. Nos diagramas à esquerda a tacoclina é representada pelas linhas tracejadas. . . . . . . . . . . . . . . . . . . . 101 
5.7 Contornos de campo magnético toroidal positivo (negativo) apresentados em escala de azul (vermelho), juntamente com as linhas de campo poloidal positivo (negativo) apresentados nas linhas contínuas (tracejadas), para diferentes tempos no transcorrer de um meio-ciclo de 11 anos $(T / 8, T / 4,3 T / 8$ e $T / 2$ ). As imagens de acima (a), do meio (b) e embaixo (c) correspondem aos modelos com uma tacoclina de espessura fina $\left(0.02 R_{\odot}\right)$, intermediária $\left(0.06 R_{\odot}\right)$, e $\operatorname{larga}\left(0.1 R_{\odot}\right)$

6.1 Perfis radial (acima) e latitudinal (embaixo) dos termos: $\alpha$-BL (linha contínua), $\eta$ (linha pontilhada), e de pumping $\gamma_{r}$ e $\gamma_{\theta}$ (linhas tracejada e pontotracejada, respectivamente). Todos os perfis estão normalizados pelo seu máximo valor. . . . . . . . . . . . . . . . . . . . . . . . . 109

6.2 Diagrama de borboleta (a) e distribuições meridionais dos campos toroidal (b) e poloidal (c). As escalas em azul (vermelho) indicam contornos de campo toroidal positivo (negativo); as linhas contínuas e tracejadas representam campos poloidais positivos e negativos, respectivamente. Nesse modelo o período do ciclo é $T=13.6$ anos, $B_{\phi_{\max }}=4.06 \times 10^{4} \mathrm{G}$ e $B_{r_{\max }}=146.8$ G. Somente os campos toroidais maiores que $2 \times 10^{4} \mathrm{G}$ (o contorno mais externo) são apresentados nas imagens (a) e (b). O modelo começou com condições iniciais anti-simétricas (veja mais detalhes no texto). . . . . . . .

6.3 O mesmo que na Fig. 6.2, mas considerando o termo de pumping diamagnético. Nesse modelo o período do ciclo é $T=13.6$ anos, $B_{\phi_{\max }}=3.9 \times 10^{4}$ G e $B_{r_{\max }}=147.6$ G. O modelo começou com condições iniciais anti-simétricas.113

6.4 O mesmo que a Fig. 6.2 para um modelo com a contribuição geral do bombeamento obtidos a partir de simulações de magneto-convecção. Nesse modelo o período do ciclo é $T=8.2$ anos, $B_{\phi_{\max }}=4.8 \times 10^{4} \mathrm{G}$ e $B_{r_{\max }}=155.92$ G. O modelo começou com condições iniciais anti-simétricas. . . . . . . . . 115 
6.5 Linhas de fluxo meridional (acima) e diagrama de borboleta (embaixo) para um modelo incluindo as componentes de bombeamento e um perfil de circulação meridional menos profundo, com $R_{p}=0.8 R_{\odot}, U_{0}=1300 \mathrm{~cm} \mathrm{~s}^{-1}$, $\gamma_{\theta 0}=90 \mathrm{~cm} \mathrm{~s}^{-1}$ e $\gamma_{r 0}=30 \mathrm{~cm} \mathrm{~s}^{-1}$. Nesse modelo $T=10.8$ anos, $B_{\phi_{\max }}=4.5 \times 10^{4}$ G e $B_{r_{\max }}=154.9$ G. Esse modelo começou com condições iniciais antisimétricas. . . . . . . . . . . . . . . . . . .

6.6 Diagrama de borboleta para um modelo com os mesmos parâmetros da Fig. 6.2, mas incluindo o cisalhamento próximo da superfície. Neste modelo $T=15.6$ anos, $B_{\phi_{\max }}(r=0.715)=1.1 \times 10^{5} \mathrm{G}, B_{\phi_{\max }}(r=0.98)=1.9 \times 10^{4} \mathrm{G} \mathrm{e}$ $B_{r_{\max }}=131.7$ G. Este modelo começou com condições iniciais simétricas. . .

6.7 O mesmo que na Fig 6.5 mas para um modelo com cisalhamento radial próximo da superfície. Neste modelo $T=16.3$ anos, $B_{\phi_{\max }}(r=0.715)=9.7 \times$ $10^{4} \mathrm{G}, B_{\phi_{\max }}(r=0.98)=1.9 \times 10^{4} \mathrm{G}$ e $B_{r_{\max }}=164.4 \mathrm{G}$. Este modelo começou com condições iniciais simétricas.

6.8 Curvas da paridade para as três classes de modelos consideradas, i.e., (a) modelos sem bombeamento (e.g. Fig, 6.2); (b) modelos com bombeamento total (e.g., Fig. 6.5); e (c) modelos com cisalhamento próximo à superfície (e.g., Figs. 6.6 e 6.7). Nos painéis (a) e (b), as linhas contínua, tracejada e ponto-tracejada correspondem a condições iniciais simétrica, anti-simétrica e randômica, respectivamente. No painel (c), a linha contínua é utilizada para o modelo com bombeamento turbulento e a linha tracejada para o modelo sem bombeamento. . . . . . . . . . . . . . . . .

7.1 Perfis dos principais constituintes dos modelos de dínamo solar deste Capítulo. A imagem da esquerda apresenta os contornos de iso-rotação (linhas pontilhadas) juntamente com as linhas de fluxo meridional (linhas contínuas). A linha tracejada em $r=0.715 R_{\odot}$ indica o centro da camada de overshoot. A imagem central mostra a variação radial do termo $\alpha$ de BL (linha contínua) e da difusividade magnética, $\eta_{T}$ (linha pontilhada). Os valores de $\alpha$ estão normalizados ao seu valor máximo $\alpha_{0}$ e os valores de $\eta_{T}$ são indicados no eixo direito. A imagem à direita apresenta o perfil latitudinal do efeito $\alpha$ de BL. . . . . . . . . . . . . . . . . . . . 130 
7.2 Diagrama de borboleta do modelo de referência depois de atingir um estado totalmente relaxado. Os contornos em azul (vermelho) representam campos toroidais positivos (negativos). Os valores graficados correspondem a uma média radial entre $0.7 R_{\odot}$ e $0.72 R_{\odot}$ e com valores acima de $1.2 \times 10^{4} \mathrm{G}$. As linhas contínuas e tracejadas representam os campos radiais positivos e negativos na superfície, respectivamente. . . . . . . . . . . .

7.3 Solução estacionária para o modelo de referência em $0, T / 8, T / 4$ e T/2, onde $T$ é o período total do ciclo. A escala de cores obedece a mesma descrição da Fig. 7.2, mas neste caso os contornos em linhas correspondem ao campo poloidal total. . . . . . . . . . . . . . . . . .

7.4 Campo magnético toroidal máximo em função de $B_{0}$ em $r=0.7 R_{\odot}$ e $r=0.8 R_{\odot}$ (veja a função de amortecimento $\alpha$, eq. 7.4) para três latitudes diferentes $10^{\circ}$ (linha contínua, sinal positivo), $45^{\circ}$ (linha tracejada, triângulos) e $80^{\circ}$ (linha pontilhada, símbolos $X$ ). Na imagem inferior, as linhas contínua e tracejada são quase coincidentes. . . . . . . . . . . . . . .

7.5 Esquerda: Contornos do campo toroidal e linhas de campo poloidal no plano meridionais para 4 tempos diferentes $(0, T / 8, T / 4$ e $T / 2$, de acima para baixo) dentro de meio-período do ciclo da solução estacionária para $B_{q}=10^{4}$ G. Direita: Difusividade sem amortecimento (linha vermelha pontilhada), e amortecida para $10^{\circ}$ (linha contínua) e $45^{\circ}$ (linha tracejada) nos mesmos tempos dos diagramas da esquerda. . . . . . . . . . . . . . . . 139

7.6 O mesmo que na Fig. 7.5, mas para $B_{q}=10^{3}$ G. . . . . . . . . . . . . 140

7.7 Valor máximo do campo toroidal em função de $B_{q}$ (veja a eq. (7.1) para três latitudes diferentes, $10^{\circ}$ (linha contínua, sinal positivo), $45^{\circ}$ (linha tracejada, triângulos), e $80^{\circ}$ (linha pontilhada, símbolo $X$ ). Na figura inferior são apresentados unicamente os resultados para $10^{\circ}$ e $45^{\circ}$, os valores máximos de $B$ para $80^{\circ}$ são menores que $10^{4}$ G. . . . . . . . . . . . . . . . . 141 
7.8 Diagrama esquemático mostrando a forma na qual, com a ajuda do transporte advectivo descendente, o campo toroidal nas altas latitudes (normal ao laço vermelho) é amplificado na tacoclina (definida pelas linhas pontilhadas) de forma mais eficiente quando consideramos o amortecimento de $\eta$, do que quando a supressão da difusividade não é levada em conta (laço verde). Em contraste, o fluxo advectivo ascendente nas baixas latitudes faz o campo poloidal se afastar da camada de cisalhamento, de tal forma que quando a difusividade é mais suprimida o campo toroidal (normal ao laço vermelho nas baixas latitudes) permanece retido no interior da zona de convecção, enquanto no caso difusivo, sem supressão, o campo espalha-se com maior facilidade (laço verde) alcançando a camada de cisalhamento radial. . . . . 144

7.9 Diagramas de borboleta para diferentes valores de $B_{q}$. Acima: $B_{q}=10^{5} \mathrm{G}$; segundo painel (de acima para baixo): $B_{q}=10^{4} \mathrm{G}$; terceiro: $B_{q}=10^{3} \mathrm{G}$ e abaixo: $B_{q}=5 \times 10^{2}$ G. . . . . . . . . . . . . . 146

7.10 Meio-período do ciclo como função de $B_{q}$. . . . . . . . . . . . . . . 147

7.11 Meio-período do ciclo em função de $\eta_{c z}$ para $B_{q}=10^{3} \mathrm{G}$ (triângulos) e $B_{q}=10^{4}$ G (sinal positivo). . . . . . . . . . . . . . . . . . 149

7.12 Diagrama de borboleta para o modelo com $B_{q}=10^{4} \mathrm{G}$ e $\eta_{c z}=4 \times 10^{11} \mathrm{~cm}^{2}$ $\mathrm{s}^{-1}$.

8.1 Desenho esquemático das diferentes camadas utilizadas na configuração do sistema.

8.2 Esquerda: Evolução temporal da velocidade rms. Direita: Perfil vertical da densidade calculado considerando-se a média espacial bidimensional e a média temporal sob $\sim 2$ tempos de turnover. . . . . . . . . . . . . . . . . 164

8.3 Velocidade vertical, $U_{z}$ para os modelos sem rotação (parte superior), e com rotação (parte inferior), para três alturas diferentes da camada convectiva: o topo (esquerda), a metade (meio) e a base (direita) . . . . . . . . . . . 166

8.4 Média horizontal e temporal da helicidade cinética (esquerda) e do fluxo de energia cinética (direita) para os modelos C00 (linha contínua) e C01 (linha tracejada) . . . . . . . . . . . . . . . . 166 
8.5 Espectro bidimensional da energia cinética correspondente à metade da camada convectiva. As linhas contínua e tracejada correspondem aos casos com $T a=0$ (sem rotação) e $T a=5 \times 10^{5}$ (com rotação), respectivamente. A linha pontilhada com inclinação proporcional a $k^{-5 / 3}$ é mostrada como referência. . . . . . . . . . . . . . . . . . 167

8.6 Evolução temporal da densidade de energia cinética (linha contínua) e magnética multiplicada por 2 (linha tracejada) em escala linear (esquerda), e da magnitude do campo magnético em relação ao campo de equipartição $B_{e q}$ (direita).169

8.7 Médias tomadas em planos horizontais (normais a $z$ ) do campo magnético total (linha contínua), médio (linha tracejada) e flutuante (linha pontotracejada), para três fases diferentes da sua evolução: a) fase cinemática ou de crescimento; b) fase saturada 1; e c) fase saturada 2 (veja explicação no texto), para os modelos C00 (painéis superiores), e C01, (painéis inferiores). 170

8.8 Velocidade vertical, $U_{z}$ para o modelo $C 01_{h r}$, para três alturas diferentes da camada convectiva: o topo (esquerda), a metade (meio) e a base (direita). . 171

8.9 Espectro bidimensional da energia cinética correspondente à metade da camada convectiva para o modelo $C 01_{h r}$. As linhas contínua e tracejada correspondem aos passos temporais $t=0$ (sem campo magnético) e $t=120$ (com campo magnético), respectivamente. A linha pontilhada com inclinação proporcional a $k^{-5 / 3}$ é mostrada como referência. . . . . . . . . . . . . . 172

8.10 Evolução temporal da densidade de energia cinética (linha contínua) e magnética multiplicada por 10 (linha tracejada) em escala linear (esquerda), e da magnitude do campo magnético total (linha contínua), médio (linha tracejada) e flutuante (linha pontilhada), em relação ao campo de equipartição $B_{e q}$ (direita) . . . . . . . . . . . . . . . . .

8.11 Médias tomadas em planos horizontais (normais a $z$ ) do campo magnético total (linha contínua), médio (linha tracejada), e flutuante (linha pontotracejada), para duas fases diferentes da sua evolução: a) fase cinemática ou de crescimento exponencial; e b) fase de crescimento suave, para o modelo

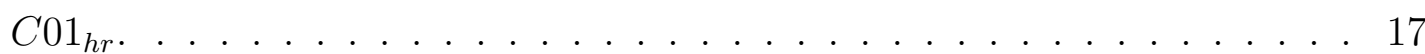


8.12 Espectro bidimensional da energia magnética correspondente à metade da camada convectiva para o modelo $C 01_{h r}$. As linhas contínua e tracejada correspondem aos passos temporais $t=40$ e $t=120$ na Fig. 8.10. A linha pontilhada com inclinação proporcional a $k^{-5 / 3}$ é mostrada como referência. 175

8.13 Componente vertical do campo magnético, $2 B_{z} / B_{e q}$, para o modelo $C 01_{h r}$, em duas alturas distintas da camada convectiva: o topo (esquerda), e a metade (direita), e para dois tempos distintos: $t=40$ (painéis superiores) e $t=120$ (painéis inferiores) . . . . . . . . . . . . . 176

A.1 Representação esquemática do mecanismo de diferenças finitas de Lax-Wendroff de dois-passos. O dois passos temporais meios, assim como os valores nos pontos intermediários da grade, marcados com $(\otimes)$ são calculados com o método de Lax da eq. eq. (A.11). Os valores atualizados $B_{j}^{n+1}$ são computados com esses dois pontos mais o ponto central original. Adaptada de Press et al. (1992). . . . . . . . . . . . . . . . . . . . . 208

A.2 Fluxograma do código DYNAMOiag indicando os passos seguidos para resolver as equações do dínamo de campo médio com os métodos de diferenças finitas e ADI para o avanço temporal. . . . . . . . . . . . . . .

B.1 Padrão de ondas emergentes típico de soluções de problemas de Riemann locais nos pontos intermediários da grade, $i-1 / 2$ e $i+1 / 2$ (figura extraída de Toro, 1997)

B.2 Fluxograma do código PLUTO indicando os passo seguidos na resolução das equações da hidrodinâmica e da magnetohidrodinâmica com um algorítmo de volumes finitos e seguindo o método de Gudunov . . . . . . . . . . . . 218 


\section{Lista de Tabelas}

2.1 Espessura e posição da tacoclina inferidas através de diferentes conjuntos de dados e técnicas. A parte superior da Tabela apresenta valores de uma média latitudinal, enquanto a parte inferior apresenta ajustes feitos no equador. O mês GONG 4 começa em 8/23/95. O fim dos meses GONG 7, 10 e 14 são 1/13/96, 4/30/96, 9/21/96, respectivamente. Os dados LOWL foram coletados durante 2/26/94 e 2/25/96 (extraída de Corbard et al., 2001). . .

3.1 Números adimensionais usados comumente em simulações HD e MHD. O valor solar é comparado com o melhor valor obtido em simulações modernas. A quarta coluna indica as escalas de tempo envolvidas em cada número. Os valores da tabela foram extraídos de Brandenburg e Subramanian (2005); Schrijver e Zwaan (2000); Brun et al. (2004); Miesch et al. (2008). . . . . . 53

3.2 Direção de propagação da onda dínamo para diferentes configurações de $\alpha$ e $\nabla \Omega$ segundo a regra do sinal de Parker-Yoshimura.

5.1 Valores dos parâmetros usados no modelo da Figura 5.2 . . . . . . . . . . 93

6.1 Valores dos parâmetros usados neste Capítulo; veja a Fig. 6.2 . . . . . . . 111

7.1 Valores dos parâmetros usados neste Capítulo, veja a Fig. 7.2 . . . . . . . 132

7.2 Parâmetros e resultados das simulações da seção 7.3.5 . . . . . . . . 151 
8.1 Valores numéricos dos parâmetros que definem o estado do sistema nas simulações de convecção turbulenta. Os números de Reynolds e de Reynolds magnético são calculados da seguinte maneira: $R e=u_{r m s} \ell / \nu$ e $R m=u_{r m s} \ell P m$, respectivamente, onde $\nu=1.16 \times 10^{-3}$ em unidades de código. $N_{x}, N_{y}$ e $N_{z}$ correspondem aos pontos de grade na direções $x, y$ e $z$, respectivamente. . 164 


\section{Sumário}

1. Introdução . . . . . . . . . . . . . . . . . . . . . . . . . . . . 27

2. Observações do ciclo magnético solar . . . . . . . . . . . . . . . . . . . . . . . . 33

2.1 Propriedades magnéticas em grande escala do ciclo solar . . . . . . . . . 33

2.1.1 Regiões magnéticas bipolares _. . . . . . . . . . . . . . 36

2.2 O campo de velocidades . . . . . . . . . . . . . . . . . . . . . . . . 39

2.2.1 Héliossismologia . . . . . . . . . . . . . . . . . . . . . . . . . . . . 39

2.2.2 Rotação diferencial . . . . . . . . . . . . . . . . . . . . . . 41

2.2.3 A tacoclina . . . . . . . . . . . . . . . . . 42

2.2.4 Circulação meridional . . . . . . . . . . . . . . . . . . . . 43

3. Magnetohidrodinâmica e teoria dínamo . . . . . . . . . . . . . . . . . . 47

3.1 Equações da MHD . . . . . . . . . . . . . . . . . . . . . . . . . . . 47

3.2 Simulação numérica e o problema da escala . . . . . . . . . . . . . . . . . 52

3.3 Simulações globais de convecção e efeito dínamo . . . . . . . . . . . . . . . 53

3.4 Teoria de dínamo de campo médio . . . . . . . . . . . . . . 55

3.5 Modelos de dínamo cinemático . . . . . . . . . . . . . . . . . . 58

3.6 Equação de indução em coordenadas esféricas . . . . . . . . . . . . . . . . 58

3.7 Os ingredientes do dínamo . . . . . . . . . . . . . . . . . . . . . 62

3.7.1 Termo fonte do campo toroidal, efeito $\Omega \ldots \ldots$. . . . . . . 62

3.7.2 Difusividade magnética . . . . . . . . . . . . . . . . . 64

3.7.3 Fonte do campo poloidal: o efeito $\alpha$ turbulento . . . . . . . . . . 67 
3.7.4 Modelos governados pelo transporte de fluxo magnético (flux transport dynamo models $\ldots \ldots \ldots$. . . . . . . . . . . 72

3.7.5 O papel da helicidade magnética em modelos de dínamo turbulento 74

3.7.6 Outras fontes de campo poloidal . . . . . . . . . . . . . 75

3.8 Modelo de dínamo de Babcock-Leighton . . . . . . . . . . . . . . 77

3.8.1 Formulação matemática do termo fonte do modelo de Babcock-Leighton 79

3.8.2 Problemas dos modelos de dínamo de BL . . . . . . . . . . . . . 80

4. Construção do modelo computacional . . . . . . . . . . . . . . . . . . . 83

4.1 Condições iniciais e de contorno . . . . . . . . . . . . . . . . . 85

4.2 Paralelização . . . . . . . . . . . . . . . . . . . . . . . 85

5. Efeitos da forma e espessura da tacoclina na geração e distribuição de campos

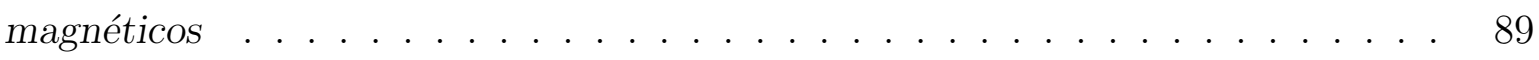

5.1 Perfis utilizados . . . . . . . . . . . . . . . . . . . . . . . 91

5.2 Resultados . . . . . . . . . . . . . . . . . . . . 93

5.2 .1 Tacoclina elipsoidal . . . . . . . . . . . . . . . 93

5.2 .2 Tacoclinas espessas e finas . . . . . . . . . . . . . . . 95

5.3 Dependência dos parâmetros . . . . . . . . . . . . . . . . . . . . . 98

5.4 Conclusões parciais e discussão f . . . . . . . . . . . . . . . . . 104

6. Bombeamento magnético turbulento

(turbulent magnetic pumping) . . . . . . . . . . . . . . . . . . 107

6.1 O modelo . . . . . . . . . . . . . . . . . . . . . 108

6.2 Perfis . . . . . . . . . . . . . . . . . . . . . 109

6.3 Resultados . . . . . . . . . . . . . . . . . . 110

6.3.1 Efeitos do bombeamento diamagnético . . . . . . . . . . . . . 111

6.3.2 Bombeamento total . . . . . . . . . . . . . . . . . 114

6.3.3 Fluxo meridional superficial . . . . . . . . . . . . . 116

6.3.4 Efeito $\Omega$ na camada próxima à superfície . . . . . . . . . . . . 118

6.4 Breve estudo do problema da paridade . . . . . . . . . . . . . . 120

6.5 Conclusões parciais deste Capítulo . . . . . . . . . . . . . . . . 122 
7. O papel do amortecimento da difusividade

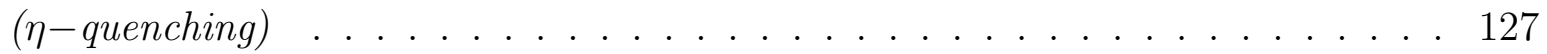

7.1 O modelo . . . . . . . . . . . . . . . . . . . . . 130

7.2 Condição inicial . . . . . . . . . . . . . . . . . . . . . . . . . 133

7.3 Resultados . . . . . . . . . . . . . . . . . . . . 134

7.3.1 Os efeitos do amortecimento $\alpha$ em modelos de dínamo de BL . . . . 134

7.3.2 Os efeitos do amortecimento de $\eta$ na evolução do campo magnético 137

7.3.3 Influência do amortecimento de $\eta$ na amplificação do campo . . . . 141

7.3.4 Influencia do amortecimento de $\eta$ no diagrama de borboleta e no período do ciclo . . . . . . . . . . . . . . . . . . . . . . 143

7.3.5 Dínamos dominados pela advecção versus dínamos dominados pela difusão . . . . . . . . . . . . . . . . . . 147

7.4 Conclusões parciais deste Capítulo . . . . . . . . . . . . . . . . 150

8. Simulações tridimensionais de efeito dínamo: resultados preliminares . . . . . . 155

8.1 O modelo . . . . . . . . . . . . . . . . . . . . . . 158

8.1.1 Condições inicial, de contorno e parâmetros do modelo . . . . . . 159

8.1 .2 O Código . . . . . . . . . . . . . . . . . . . . 162

8.2 Resultados . . . . . . . . . . . . . . . . . . . . 163

8.2.1 Solução hidrodinâmica . . . . . . . . . . . . . . . . . . . . 163

8.2 .2 Efeito dínamo . . . . . . . . . . . . . . . . . . . 167

8.2.3 Alta resolução: resultados preliminares . . . . . . . . . . . . . . . . 171

8.3 Discussão . . . . . . . . . . . . . . . . . . . . . 175

9. Conclusões gerais e Perspectivas . . . . . . . . . . . . . . . . . . . . . . . 179

9.1 Considerações finais e perspectivas . . . . . . . . . . . . . . . . . . . . 184

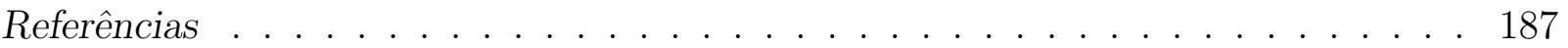

Apêndice

A. Métodos numéricos,

modelo de dínamo de campo médio 
A.1 Diferenças finitas . . . . . . . . . . . . . . . . 205

A.2 Método ADI . . . . . . . . . . . . . . . . . . . . . . . . . 208

A.3 Tratamento numérico das condições de contorno . . . . . . . . . . . . . . . 210

A.4 Fluxograma do código do dínamo de campo médio . . . . . . . . . . . . . . 211

B. O código PLUTO . . . . . . . . . . . . . . . . . . . . . 215

B.1 Método de Gudunov . . . . . . . . . . . . . . . . . 215

B.2 Fluxograma e opções do código PLUTO . . . . . . . . . . . . . . . 217

C. Efeitos da forma e espessura da tacoclina, Artigos 1 e 2 . . . . . . . . . . . . 221

D. Bombeamento magnético turbulento, Artigo $3 \ldots \ldots$. . . . . . . . . 223

E. O papel do amortecimento da difusividade, Artigo 4 . . . . . . . . . . 225 
Capítulo 1

\section{Introdução}

O Sol, como a maior parte das estrelas e galáxias, é um objeto magnético. Abaixo da sua superfície, a matéria solar, composta principalmente por hidrogênio e hélio ionizados, se encontra interagindo de uma forma complexa com um intenso campo magnético. O resultado deste processo se faz evidente na superfície solar na forma de grandes regiões escuras conhecidas como manchas solares. Voltando na história, é possível encontrar várias referências à observação de manchas solares em crônicas que pertencem às culturas chinesas e arábicas (Bray e Loughhead, 1964; Schove, 1983), no entanto, a observação sistemática delas, e portanto, o estudo da Física Solar, começou só no século XVII, logo depois da invenção do telescópio astronômico. Depois de um século de observação encontrou-se que o número de manchas segue um comportamento cíclico com um período de aproximadamente 11 anos Schwabe (1843). Depois disso, no começo do século XX, logo depois do nascimento da mecânica quântica, encontrou-se que as Manchas solares correspondem a intensas concentrações de campos magnéticos (Hale, 1908).

A variação periódica da atividade magnética solar é comumente conhecida como ciclo solar. Ele é caracterizado por períodos da atividade mínima e máxima. No mínimo, o sol parece tranqüilo e o campo magnético é predominantemente dipolar (direções $r$ e $\theta$ ); no máximo, o campo é principalmente toroidal (ou seja, orientado na direção azimuthal, $\phi)$, o número de manchas solares alcança seu máximo e vários eventos são observados na atmosfera solar, como a formação de grandes loops de plasma e violentas explosões seguidas pela expulsão das camadas mais externas do sol que são conhecidas como ejeções de massa de coronal (CMEs, pelas suas siglas em inglês).

Devido à proximidade do Sol, a atividade solar tem uma importante influência na at- 
mosfera da Terra, sendo a principal responsável pelo que é chamado de clima espacial. As partículas solares ejetadas nas CMEs, são aceleradas a velocidades relativísticas, viajam com o vento solar e colidem com a atmosfera superior da Terra. Lá, essas partículas carregadas giram ao redor do campo magnético da terra até as altas latitudes (nos hemisférios Norte e Sul) onde formam a aurora. No entanto, durante a fase de choque, elas podem penetrar as paredes das naves espaciais em órbita baixa possivelmente danificando-as, afetando desta forma os sistemas de comunicações que usamos comumente na atualidade. Os eventos mais violentos, conhecidos como tormentas geomagnéticas, são capazes de afetar tanto sistemas tecnológicos localizados na Terra, como estações de energia elétrica, assim como também algumas formas de vida. Acredita-se que outras propriedades randômicas da atividade solar, como a variação na amplitude ou no período do ciclo, estão de alguma forma relacionadas com mudanças climáticas na Terra (uma revisão deste tema pode ser encontrada em Haigh, 2007, e referências ali contidas), porém esses efeitos, atualmente em estudo, não são ainda bem compreendidos. Todos esses fatos fazem da pesquisa do ciclo magnético solar um campo de grande interesse para a ciência já que a compreensão dos processos físicos que governam estes fenômenos ajudará a construir modelos capazes de predizer os eventos associados. Importantes esforços observacionais e teóricos estão sendo desenvolvidos atualmente com a intenção de melhorar a nossa compreensão destes processos.

Por outro lado, além da escala do Sol e da sua vizinhança, conhece-se agora que diferentes classes de estrelas possuem também campos magnéticos intensos e que algumas delas apresentam sinais de variabilidade na sua superfície (veja p. ex. Baliunas et al., 1995; Berdyugina, 2005). Hoje em dia é também possível traçar as linhas do campo magnético presente em galáxias e aglomerados de galáxias (Beck, 2008) assim como determinar a importância relativa do mesmo na dinâmica destes objetos. No entanto, entender a origem e a amplificação desses campos magnéticos é ainda um problema em aberto e um grande desafio para a Astrofísica. O sol, por ser a nossa estrela mais próxima, é o melhor laboratório para o estudo geral dos campos magnéticos cósmicos.

O processo que leva à geração contínua de campos magnéticos, à sua amplificação, e que resulta nos fenômenos magnéticos observados na superfície do Sol é normalmente conhecido como dínamo Solar. Parker (1955) foi o primeiro a tentar explicá-lo como o resultado de 
um processo de hidromagnético que combina os efeitos indutivos do cisalhamento (shear) em grande escala, devido à rotação diferencial, com a turbulência helicoidal presente na pequena escala, devida às forças de Coriolis. O primeiro efeito (usualmente conhecido como efeito $\Omega$ ) transforma um campo magnético poloidal em um campo toroidal, enquanto o segundo efeito (conhecido como efeito $\alpha$ ) leva à formação de pequenos laços (ou loops) de campo magnético toroidal criando a partir deles uma componente poloidal. Esses loops devem reconectar rapidamente para formar um novo campo poloidal em grande escala com a polaridade oposta ao campo poloidal inicial, e assim sucessivamente de forma cíclica. A base matemática deste modelo foi desenvolvida formalmente alguns anos depois por Steenbeck e Krause (1969) na teoria da eletrodinâmica de campo médio a qual foi desde então a principal aproximação para modelar o dínamo solar. No entanto, devido à falta de conhecimento da teoria de turbulência, a formulação do efeito $\alpha$ nestes modelos foi normalmente feita de uma forma ad hoc, como veremos adiante.

O aumento progressivo na capacidade computacional tem permitido explorar um grande espaço de parâmetro em diferentes modelos de dínamo solar, ao mesmo tempo que se tem avançado na compreensão da dinâmica de plasmas magnetizados e fluidos turbulentos. Por outro lado, os avanços observacionais, introduzidos principalmente com a héliossismologia, impuseram importantes restrições nos modelos de dínamo, especialmente no perfil de rotação diferencial (Brown et al., 1989; Goode et al., 1991), pois a partir de então esse perfil não podia mais ser considerado um parâmetro livre dos modelos. Isto revelou que os modelos turbulentos mais aceitos até aquela data eram inconsistentes com as observações (veja p. ex. Stix, 1976). De outra parte, os avanços na teoria de dínamo no regime não linear indicaram que quando o campo magnético é bastante intenso, a turbulência e seus efeitos indutivos são amortecidos, o que resultaria num efeito $\alpha$ desprezível, produzindo então um dínamo não-cíclico (Vainshtein e Cattaneo, 1992).

Embora a compreensão da fase não linear do dínamo tenha recentemente evoluído, fazendo ressurgir os modelos turbulentos, os problemas levantados acima com o modelo de dínamo de Parker levaram à busca de outras fontes alternativas do campo poloidal. Entre elas, uma das mais notáveis é o mecanismo de Babcock (1961) - Leighton (1969) (BL), segundo o qual o campo dipolar total pode ser o resultado do decaimento observado dos pares de manchas solares (ou regiões magnéticas bipolares, BMRs, de sua sigla em 
inglês) os quais apresentam uma inclinação entre a componente principal (que se encontra na frente no sentido oeste-leste) e a sua componente secundaria, de modo a conter um momento dipolar líquido. A soma total de BMRs em um ciclo pode resultar em um campo dipolar total capaz de inverter a polaridade do campo pertencente ao ciclo prévio. Contudo, este processo requer um mecanismo de transporte de fluxo magnético para empurrar o campo dipolar das baixas latitudes na direção dos pólos e assim formar o campo polar observado, e então transportá-lo para o interior solar, onde o processo se inicia novamente. A circulação meridional de matéria, observada nas camadas mais externas do Sol, é usualmente considerada nestes modelos como o principal mecanismo de transporte de fluxo magnético. Por esta razão, esses modelos são comumente chamados de dínamo solar de Babcock-Leighton dominados pelo transporte de fluxo (flux-transport, Babcock-Leighton solar dynamo models, FTBL) (Wang et al., 1989, 1991; Choudhuri et al., 1995; Durney, 1995, 1996, 1997).

Os modelos de dínamo FTBL em geral reproduzem bem as propriedades observadas do ciclo solar (Dikpati e Charbonneau, 1999), mas apresentam vários problemas freqüentemente reportados na literatura (Brandenburg, 2005) como discutiremos adiante. Esta tese concentra-se na exploração de soluções alternativas para estes problemas com a ajuda de simulações numéricas de dínamo de campo médio (2.5D). O objetivo principal é construir um modelo de dínamo solar cujos ingredientes levem a soluções realistas. Para isto, três aproximações diferentes serão consideradas. Primeiro, exploraremos os efeitos da geometria e da espessura da tacoclina solar (i.e., a camada que separa a camada radiativa, de rotação uniforme, da camada convectiva, com rotação diferencial) nas soluções do modelo de dínamo. Segundo, examinaremos a contribuição advectiva (ou de transporte) dos efeitos turbulentos em pequena escala, em diferentes classes de modelos. Ainda neste contexto dos efeitos turbulentos, numa terceira aproximação, consideraremos a saturação da difusividade magnética em conseqüência da reação não linear do campo magnético na dinâmica dos redemoinhos turbulentos, e iremos pesquisar os seus efeitos na evolução e distribuição dos campos magnéticos. Finalmente, apresentaremos alguns resultados preliminares de simulações MHD do processo de dínamo em domínios tridimensionais representando uma fração das camadas convectiva e radiativa do Sol. A vantagem desta classe de simulações é que elas permitem o cômputo direto dos coeficientes turbulentos do dínamo os quais foram 
até agora em geral tratados de uma forma paramétrica ou sequer considerados. Além disso estas simulações levam a uma descrição totalmente dinâmica do problema.

Este manuscrito encontra-se organizado da seguinte forma: no Capítulo 2 é dada uma descrição dos fenômenos magnéticos observados na superfície solar assim como uma descrição do campo de velocidades observado. Os conceitos básicos da eletrodinâmica de campo médio e da teoria dínamo são apresentados no Capítulo 3, juntamente com uma breve descrição dos modelos de dínamo mais relevantes para explicar o ciclo solar, incluindo o modelo de dínamo FTBL. No Capítulo 4 é apresentada uma descrição detalhada do nosso modelo numérico, as suas condições de contorno e iniciais. Já os capítulos 5 a 8 apresentam os resultados desta tese e o Capítulo 9 contém as conclusões do presente trabalho e perspectivas para o futuro. 
Capítulo 2

\section{Observações do ciclo magnético solar}

Neste capítulo são apresentados os resultados observacionais mais importantes em relação ao ciclo solar. Na primeira seção iremos descrever as propriedades magnéticas em grande escala e na segunda vamos apresentar os resultados mais importantes reportados até o momento com respeito ao campo de velocidades no interior do Sol. Como veremos nos capítulos seguintes, esses dois campos encontram-se fortemente correlacionados e uma correta descrição e modelagem do magnetismo requer uma correta descrição das características do fluxo.

\subsection{Propriedades magnéticas em grande escala do ciclo solar}

A observação formal de manchas solares, e o então nascimento da Física Solar, começou nos primeiros anos do século XVII, quando elas foram observados pela primeira vez através de um telescópio. Estas observações foram feitas quase simultaneamente por quatro homens em países diferentes: Johann Goldsmith (1587-1616) na Holanda, Galileo Galilei (15641642) na Itália, Chirstopher Schneider (1575-1650) na Alemanha e Thomas Harriot (15601621) na Inglaterra. Dos quatro, o mais proeminente é Galileo, já que ele foi o primeiro a propor que as manchas solares pertencem ao sol e não são corpos distantes da sua superfície. Ele descreveu a forma e o tempo de vida de manchas individuais, assim como de grupos de manchas.

Porém, o registro diário oficial do número de manchas solares começou no observatório de Zurique somente em 1749 (Fig. 2.1), e quase um século depois Schwabe (1843) reportou a variação cíclica no número de manchas solares a cada 11 anos. A classificação diária em manchas solares individuais e grupos de manchas começou só em 1849 com o trabalho de 
R. Wolf (Schove, 1983). Durante estes primeiros dias de medição sistemática, a variação periódica na atividade solar foi expressa através do índice de manchas solares de Wolf, definido como:

$$
R \equiv k(10 g+f) \quad,
$$

onde $f$ é o número de manchas individuais, $g$ é o número de grupos (usualmente conhecidas como regiões ativas), e $k$ é um fator de correção usado para ajustar variações nas condições de observação. Embora o número de Wolf seja uma medida subjetiva, que envolve a contagem de manchas a olho, ele concorda muito bem com outras medidas quantitativas modernas da atividade solar como: o fluxo de rádio em $10.7 \mathrm{~cm}$, o fluxo magnético absoluto, a largura da linha de HeI em $10830 \AA$, ou o índice $k$ de CaII (veja uma discussão completa a respeito em Schrijver e Zwaan, 2000).
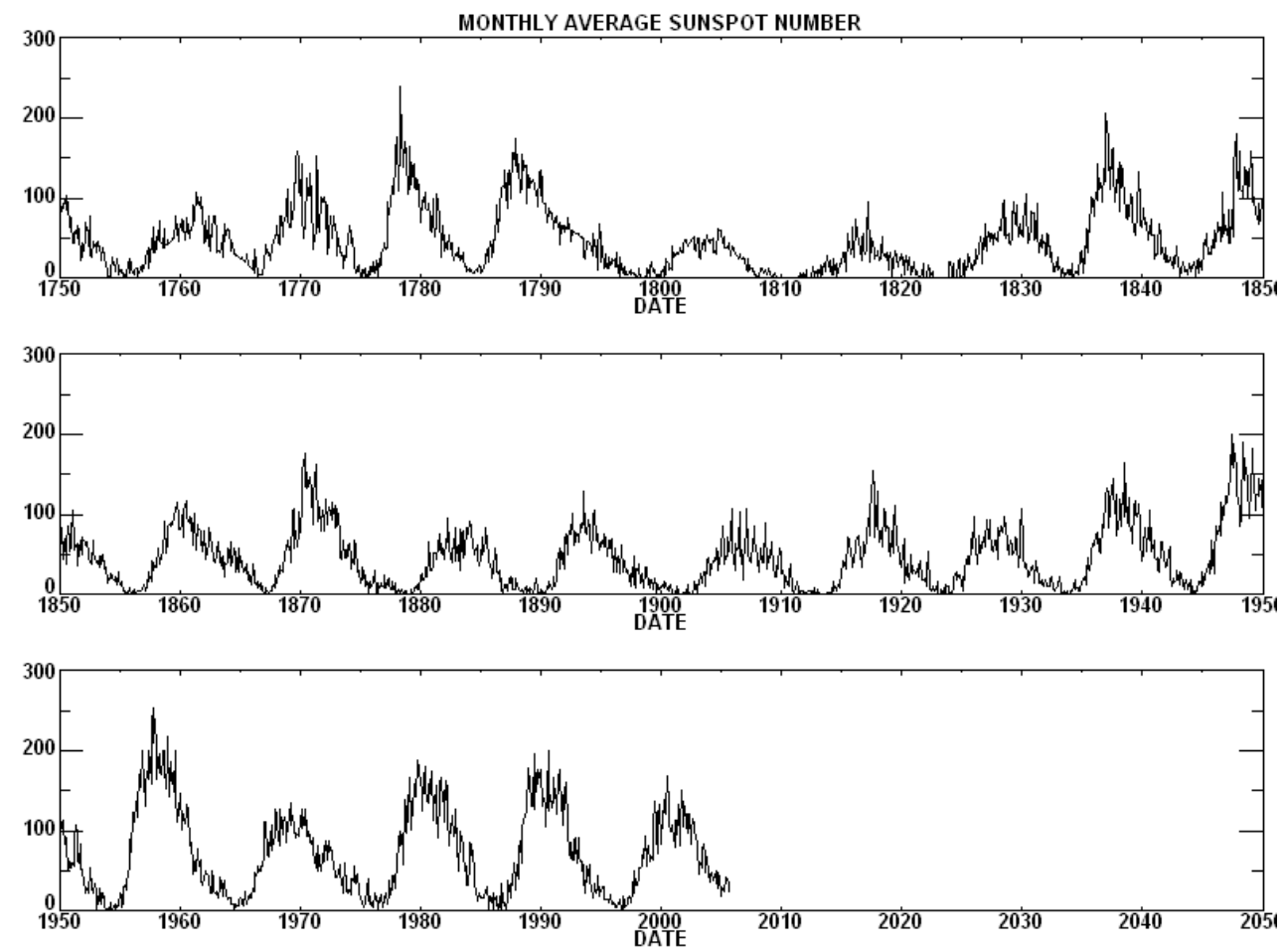

Figura 2.1: Média mensal do número de manchas solares desde 1750 até o presente (Imagem extraída de http://science.msfc.nasa.gov).

A natureza magnética das manchas solares foi descoberta por Hale (1908), que através de observações espectroscopias diárias das manchas detectou o desdobramento Zeeman nas suas linhas espectrais, evidenciando a existência do campo magnético. Depois de uma década da observação, Hale et al. (1919) e o seu grupo de colaboradores reportaram outras 
propriedades importantes das manchas solares referentes à sua polaridade anti-simétrica em ambos os hemisférios, à inversão de polaridade que acontece a cada 11 anos e também ao seu comportamento através do ciclo. O conjunto destas propriedades, bem como a variação periódica no número de manchas, são conhecidas como as propriedades em grande escala do ciclo magnético solar. Elas podem ser resumidas da seguinte forma:

1. As manchas solares aparecem unicamente numa faixa de latitudes entre $\pm 35^{\circ}$ (em ambos lados do equador solar). Esta região é conhecida como a latitude de atividade. As primeiras manchas solares de um ciclo aparecem nas latitudes médias, as manchas seguintes tendem a formar-se em latitudes progressivamente mais baixas, de tal forma que as últimas manchas do ciclo aparecem próximas do equador. Esta tendência é conhecida como lei de Spörer.

2. As manchas solares aparecem principalmente em pares nos dois lados do equador solar; a mancha principal em um par tem a polaridade oposta à mancha companheira. Além disso, as manchas (principais e companheiras) do hemisfério norte têm a polaridade oposta àquelas do hemisfério do Sul. Elas invertem a polaridade a cada 11 anos; assim o período total do ciclo de atividade magnética é de 22 anos. Esta propriedade é conhecida como lei de Hale;

3. Uma linha reta juntando as manchas principal e companheira num par apresenta sempre uma inclinação com respeito à linha equatorial. Esta inclinação vai de $\sim 30^{\circ}$ para pares de manchas nos primeiros anos do ciclo, até $\sim 10^{\circ}$ para pares de manchas nas etapas finais. Esta é conhecida como lei de Joy;

4. 1 a 2 anos após o número de manchas solares alcançar o máximo, o campo magnético nas regiões polares (ou seja, em latitudes acima de $60^{\circ}$ ) inverte a sua polaridade. As regiões polares são quase unipolares em cada hemisfério e alcançam o máximo de fluxo magnético total logo antes do mínimo de manchas solares. Isto revela uma diferença de fase de $\sim \pi / 2$ entre o campo magnético presente nas manchas, orientado na direção azimuthal, e o campo magnético presente na região polar, o qual é predominantemente dipolar.

5. O começo de um ciclo de manchas solares acontece logo antes do fim do ciclo prévio. Isto significa que as manchas solares pertencentes a dois ciclos chegam a aparecer 
simultaneamente. A sobreposição de dois ciclos sucessivos é de aproximadamente 2-3 anos.

6. A magnitude dos campos magnéticos nas manchas é ao redor de $10^{3} \mathrm{G}$. A magnitude do campo dipolar difuso é da ordem de dezenas de Gauss.

Todas estas características podem ser observadas em diagramas que contêm as latitudes de surgimento de manchas solares em função do tempo. Estes gráficos são chamados diagramas de Borboleta de Maunder. Na Fig. 2.2 são mostradas duas classes de diagramas de borboleta: o gráfico superior contém unicamente a latitude de surgimento das manchas, nele pode-se observar que nas primeiras etapas do ciclo as manchas solares aparecem ao redor dos $30^{\circ}$ e então, o lugar de surgimento migra progressivamente em direção ao equador. O gráfico inferior nele contém um mapa sinótico da componente radial do campo magnético, de tal forma que é possível acompanhar também a evolução da componente dipolar, que se encontra em oposição de fase com o campo toroidal predominante nas manchas solares.

É importante destacar que além do comportamento periódico descrito acima existe também uma componente flutuante no ciclo solar a qual se manifesta no número de manchas solares de cada ciclo (que determina a amplitude do ciclo) e na duração de cada período (ver a Fig. 2.1). De fato, o período de meio-ciclo varia entre 8 e 15 anos e a amplitude entre ciclos varia normalmente por um fator de até $\sim 3$. No entanto, já houve períodos nos quais nenhuma mancha solar foi reportada, como aquele ocorrido entre 1645 e 1715 (Maunder, 1890), conhecido como o "mínimo de Maunder"(Eddy, 1976), e também ciclos similares de atividade reduzida como o "mínimo de Spörer" por volta de 1500, ou o "Grand Minimum" no século $12^{1}$. A parte randômica do ciclo solar, a qual vem sendo estudada através da teoria do caos ou da teoria estocástica, não será discutida neste trabalho.

\subsubsection{Regiões magnéticas bipolares}

Além do conceito de mancha solar como a manifestação principal do magnetismo solar encontra-se a idéia de uma região ativa. Ela é definida como a área total contendo vários elementos magnéticos, como um grupo de manchas solares, a fécula, os filamentos e as

\footnotetext{
${ }^{1}$ Os ciclos solares anteriores à observação de manchas solares são investigados com indicadores de atividade magnética solar de longo prazo, como a razão dos isótopos $\mathrm{C}^{14} / \mathrm{C}^{12}$ encontrados em anéis sucessivos dos troncos de árvores de longa vida (Foukal, 1990)
} 

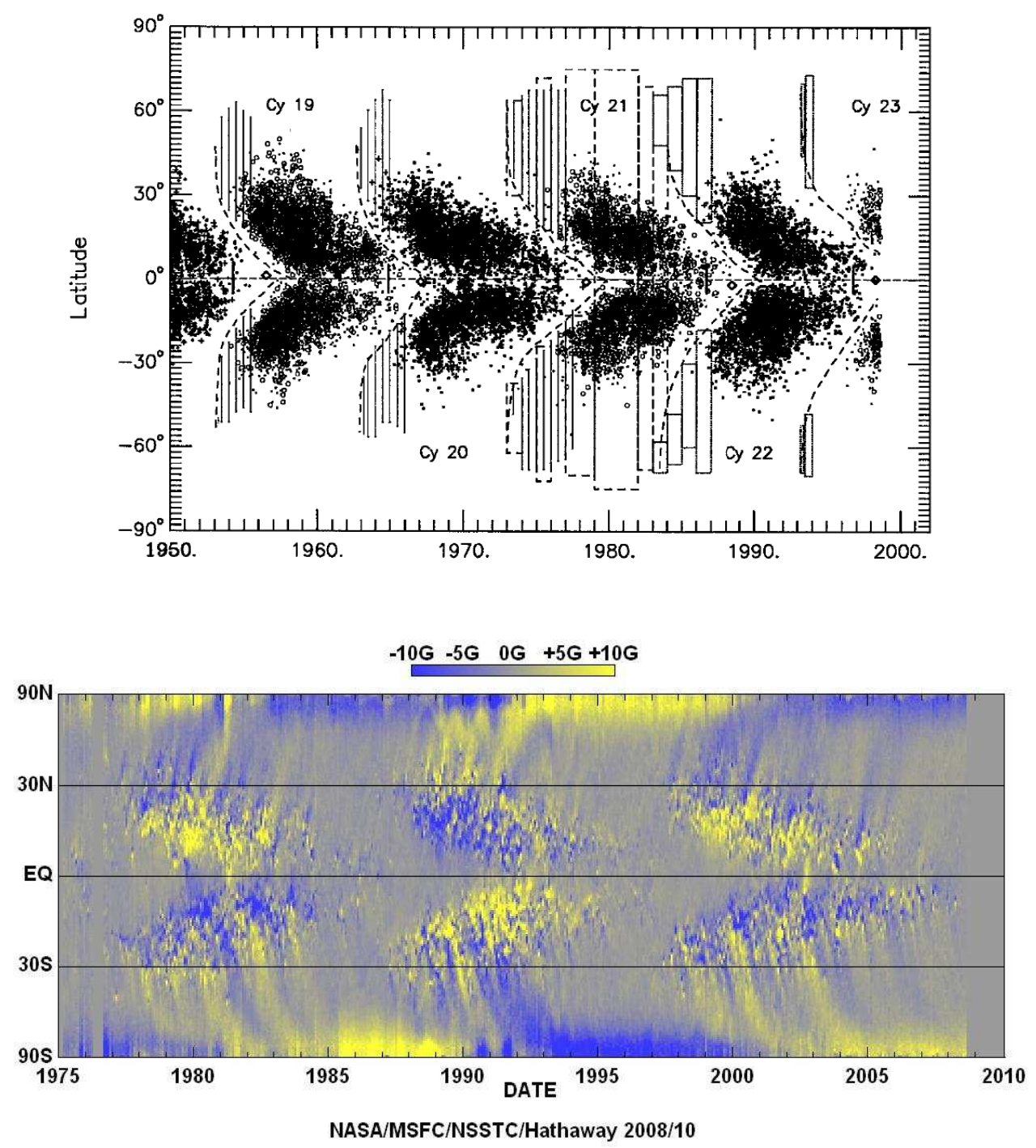

Figura 2.2: Duas classes diferentes de "diagramas de borboleta", tempo-latitude. O gráfico superior apresenta a latitude de surgimento de manchas individuais e grupos de manchas. A linha grossa destaca a data do mínimo solar, a linha tracejada marca a fronteira entre dois ciclos sucessivos e a linha fina mostra o local onde pequenas regiões ativas, sem manchas, aparecem nos primeiros anos do ciclo (extraída de Schrijver e Zwaan, 2000). O painel inferior apresenta a média longitudinal do campo magnético. As escalas de cor em amarelo e azul indicam campos positivos e negativos, respectivamente (extraída de http://solarscience.msfc.nasa.gov/dynamo.shtml).

explosões (flares) solares. A maioria das vezes, duas regiões ativas de polaridade oposta aparecem juntas, neste caso a região total é chamada região magnética bipolar (veja o Capítulo 5 de Schrijver e Zwaan, 2000). 
A parte principal de uma BMR aparece normalmente na frente e em latitudes mais baixas com respeito à parte secundária. Observa-se que as manchas solares que pertencem à componente principal são maiores do que as manchas solares da componente secundária, e ademais giram mais rápido do que o plasma circundante, o qual é uma forte indicação de que estes elementos magnéticos são provavelmente gerados abaixo da superfície solar. Por outro lado, as manchas solares secundárias das BMRs parecem retroceder ou então ficam quietas. Estes dois movimentos relativos resultam na expansão das BMRs.

A evolução total das BMRs pode levar de semanas a meses, dependendo do tamanho da região, e segue três etapas principais: i) a fase de emergência na qual as manchas solares são formadas; ii) o desenvolvimento máximo, no qual as BMRs alcançam a sua máxima expansão (entre 40 e $170 \mathrm{Mm}$ ) e iii) a fase de decaimento na qual a área total da região magnética diminui lentamente e as manchas solares decaem por fragmentação, rompendo-se em várias pequenas manchas que terminam por desaparecer.

O fluxo magnético típico das BMRs maiores, contendo várias manchas solares, está entre $5 \times 10^{21}$ e $3 \times 10^{22} \mathrm{Mx}\left(1 \mathrm{Mx}(\right.$ maxwell $\left.)=1 \mathrm{G} \mathrm{cm}^{2}\right)$, e o seu tempo de vida pode ir de algumas semanas a meses. Nas BMRs pequenas e sem manchas, o fluxo se encontra entre $1 \times 10^{20}$ e $5 \times 10^{21} \mathrm{Mx}$, e seu tempo de vida varia de dias a semanas. É importante observar que quando as regiões ativas pequenas são incluídas junto com as manchas solares nos diagramas de borboleta, as asas da borboleta começam a aparecer em latitudes ao redor de $60^{\circ}$ (veja o diagrama superior da Fig. 2.2).

O comportamento aproximadamente bem organizado do campo magnético solar, tanto no espaço quanto no tempo, que se manifesta nas propriedades descritas acima, indica que no interior do sol deve operar um processo físico capaz de induzir um campo magnético em grande escala. Esse processo compete com o outro capaz de dissipá-lo, de tal forma que a evolução temporal permanece periódica. Tal mecanismo envolve a transformação de energia mecânica devida aos movimentos convectivos e de rotação do plasma em energia magnética, e também à reação dinâmica da energia magnética sobre o campo de velocidades. Graças à semelhança com o dínamo elétrico homopolar (veja p.ex., de Gouveia Dal Pino, 1995), esse processo é comumente conhecido como dínamo. Uma grande vantagem de se estudar esses fenômenos para o caso do Sol, é que o campo de velocidades em grande escala pode ser observado através de diferentes técnicas. Em seguida são apresentados os principais 
resultados observacionais, obtidos até a presente data, acerca dos padrões de movimento na superfície e no interior solar.

\subsection{O campo de velocidades}

Nesta seção descrevemos os dados observacionais referentes ao campo de velocidades em grande escala nas camadas mais externas do sol. A direção azimuthal deste determina a rotação diferencial e os movimentos em grande escala nas direções radial e latitudinal determinam a circulação de meridional ou fluxo meridional. Três técnicas diferentes têm sido utilizadas através dos anos para a determinação dos perfis de velocidade: a primeira usa tracers ou marcadores magnéticos solares como indicadores de velocidade, o que significa que a informação é obtida da análise de imagens sucessivas; a segunda baseia-se na medição do deslocamento Doppler das linhas espectrais correspondente a regiões específicas da área solar; e a terceira baseia-se na héliossismologia com a qual é possível inferir tanto a estrutura como a velocidade a partir da medição dos modos de oscilação acústicos produzidos no interior do Sol. A diferença em relação aos outros dois métodos é que com a héliossismologia é possível obter-se informação do interior solar. Como resultado desta havido um progresso substancial na compreensão da atividade solar. Na seguinte subseção descrevemos os conceitos básicos desta técnica.

\subsubsection{Héliossismologia}

As camadas mais superficiais do sol são uma região altamente compressível, por essa razão os movimentos convectivos, que geram o padrão de granulação observado na fotosfera, são uma enorme fonte de ondas de som. Tais ondas viajam através do interior solar, refletem nas fronteiras e interferem umas com as outras para formar um padrão global de onda estacionária cujo período característico é de aproximadamente cinco minutos. A observação destas ondas sonoras é usada para inferir detalhes da estrutura interna solar de modo semelhante às ondas sísmicas usadas na sismologia para inferir a estrutura interna da Terra. Essa técnica é conhecida como héliossismologia global (veja Christensen-Dalsgaard, 2002, para uma revisão deste técnica).

Para fazer uma observação heliossismológica são necessários três passos. Primeiramente, é necessário um modelo teórico de estrutura estelar. Os modos de oscilação deste 
modelo são computados considerando-se perturbações adiabáticas lineares ao redor de um estado basico esfericamente simétrico, de tal forma que essas perturbações possam ser expressas como harmônicos esféricos $Y_{l m}$, em latitude e longitude, e em auto-funções radiais de ordem $n$. Esta parte é chamada de problema direto. O segundo elemento é a base de dados que vem da observação fotosférica de todas as variáveis dinâmicas envolvidas no modelo de estrutura. Tais imagens são decompostas em harmônicos esféricos e em séries de Fourier para as dimensões espaciais e o tempo, respectivamente. O passo final consiste em comparar os modos observados e teóricos e então, inferir as variáveis físicas. Esta comparação não é um processo trivial já que os diferentes modos de oscilação correspondem a diferentes lugares do interior solar, por exemplo, os modos $l$ altos correspondem às camadas mais superficiais e os modos $l$ baixos, às camadas mais internas já que eles são capazes de penetrar mais profundamente. No processo de inversão (ou problema inverso) é necessário considerar algumas funções para dar um peso diferente aos diferentes intervalos de freqüência, ou seja, às diferentes regiões do interior solar. Tais funções são conhecidas como núcleos (kernels) (Christensen-Dalsgaard, 2002).

Uma característica importante dos modos globais de oscilação é a sua sensibilidade à rotação. No caso não-rotacional, as auto-freqüências dos modos acústicos de um dado harmônico esférico $l$, mas diferente ordem azimuthal $m$, são idênticas, no entanto no caso rotacional, as ondas pró- e retrógradas têm velocidade relativa diferente com respeito ao observador, assim, enquanto para o sistema de referência solar os modos normais formam uma onda estacionária, no sistema do observador eles se separam em um multipleto, e no caso mais simples, em um dobleto. A Héliossismologia faz uso dessa separação para inferir informação sobre a taxa de rotação interna (Thompson et al., 2003).

Lamentavelmente, a héliossismologia global é insensível aos movimentos convectivos meridionais e não axi-simétricos, e também às componentes não-simétricas dos parâmetros solares com respeito ao equador. Outras técnicas, como as da héliossismologia local, foram desenvolvidas com o fim de obter informação sobre essas quantidades.

A héliossismologia local estuda os modos acústicos que não viajam através de toda a esfera, mas só em uma pequena região dela. É um tema de pesquisa muito interessante, já que tais modos são perturbados por variações locais da velocidade do som, por campos magnéticos ou por campos de fluxo, de tal forma que através dela é possível obter 
informações sobre esses fenômenos. No entanto, a sua principal dificuldade consiste em determinar a que processo físico corresponde cada perturbação, o que significa que é muito difícil escolher um modelo teórico apropriado. Várias técnicas de inversão têm sido implementadas para desenvolver a héliossismologia local, tais como a análise de diagramas de anéis, o método tempo-distância ou a holografia acústica. Uma descrição detalhada desses métodos pode ser encontrada em Gizon e Birch (2005).

Resultados muito interessantes acerca da evolução temporal da rotação diferencial, da circulação meridional, e também na estrutura e evolução de manchas solares individuais foram obtidos através da héliossismologia local. Mas uma limitação importante e a amplitude do sinal das ondas perturbadas que a héliossismologia local é capaz de estudar, pois elas têm um sinal mensurável só nas camadas mais externas do sol $\left(r \geq 0.97 R_{\odot}\right)$. Os resultados obtidos com essa técnica para as camadas mais profundas vêm de um sinal de baixa resolução, de tal forma que não podem ser considerados conclusivos. Atualmente, vários grupos de pesquisa empenham-se em melhorar as técnicas de observação de héliossismologia local (veja Miesch, 2005, e as referências contidas).

\subsubsection{Rotação diferencial}

As primeiras medidas da variação latitudinal da velocidade angular foram feitas através de traçadores magnéticos, tais como manchas solares de longa vida (Newton e Nunn, 1951; Balthasar et al., 1986), medindo-se o deslocamento Doppler das linhas espectrais (Snodgrass, 1984; Pierce e Lopresto, 1984) e também através de correlações em pares de magnetogramas (Komm et al., 1993b). Todas essas técnicas encontraram o mesmo padrão latitudinal na velocidade de rotação, que pode ser representado por:

$$
\Omega_{\text {sup }}=a_{0}+a_{2} \sin ^{2} \theta+a_{4} \sin ^{4} \theta
$$

onde $a_{0} \simeq 14.0$ graus dia ${ }^{-1}, a_{2} \simeq-1.5$ graus $\mathrm{dia}^{-1}$ e $a_{4} \simeq 2.6$ graus $\mathrm{dia}^{-1}$ são coeficientes livres que diferem em menos de $5 \%$ entre as técnicas enumeradas acima. Esse perfil mostra uma maior velocidade angular no equador a qual diminui lentamente em direção aos pólos. Um resultado persistente em vários anos de observação foi que a rotação diferencial obtida através de marcadores magnéticos é sempre maior que a rotação obtida através da medição do deslocamento Doppler. Isto levou a se pensar que a atividade magnética observada na fotosfera seria provavelmente produzida abaixo dela, na zona de convecção. 
Já com a héliossismologia global, graças à separação das freqüências nos modos de oscilação e ao fato de que diferentes ordens $l$ correspondem a profundidades diferentes, tornou-se possível mapear a velocidade angular nas camadas internas do sol (Brown et al., 1989; Goode et al., 1991; Tomczyk et al., 1995). A velocidade de rotação no interior da zona de convecção não muda consideravelmente daquela na superfície, e os contornos radiais seguem aproximadamente uma forma cônica até a base da zona de convecção onde a velocidade angular vira quase uniforme no núcleo radiativo (Thompson et al., 2003) (Veja a Fig. 2.3). A interface entre o núcleo de rotação uniforme (de corpo sólido) e a camada convectiva com rotação diferencial foi denominada tacoclina por Spiegel e Zahn (1992). A velocidade angular no núcleo radiativo tem valor intermediário entre as velocidades equatorial e polar no interior da zona de convecção. Isto resulta em um gradiente radial negativo (positivo) da velocidade angular em altas (baixas) latitudes.
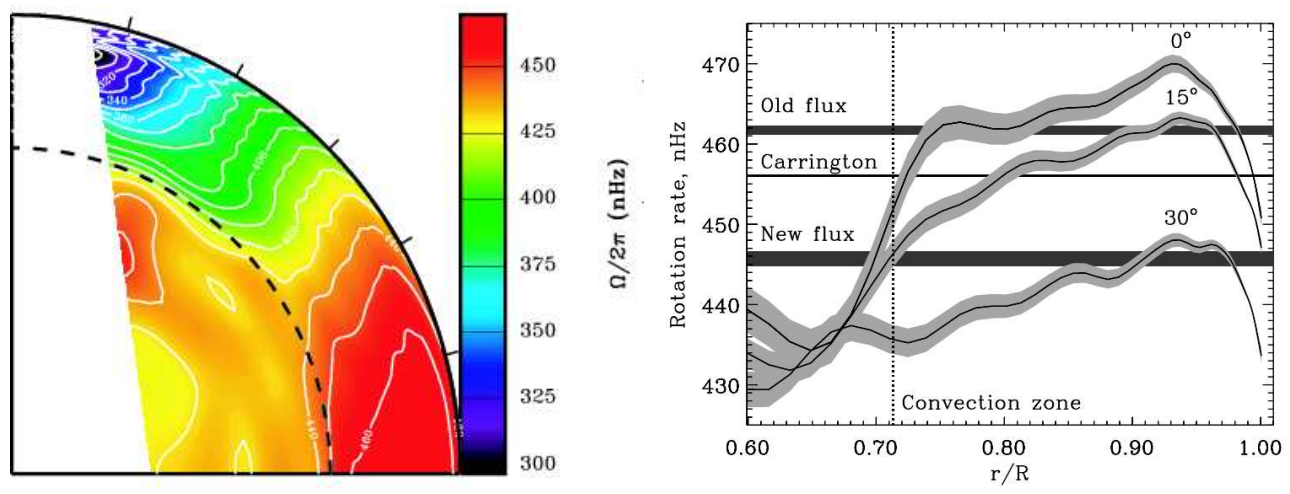

Figura 2.3: Painel da esquerda: iso-contornos de velocidade angular no interior solar, extraída de Thompson et al. (2003). Painel da direita: perfil radial da velocidade angular para três latitudes diferentes, $0^{\circ}, 15^{\circ}$ e $30^{\circ}$. Nesse gráfico é evidente a camada de cisalhamento (shear) próximo à superfície (figura extraída de Brandenburg, 2005).

Mais recentemente confirmou-se a presença de uma segunda camada de cisalhamento (shear) radial localizada próxima à superfície (Corbard e Thompson, 2002; Thompson et al., 2003). Esse shear é aparentemente negativo em quase todas as latitudes com possivelmente uma fração positiva em latitudes perto dos pólos (Veja a Fig. 2.3). 


\subsubsection{A tacoclina}

Tacoclina, como vimos, é o nome dado à interface que separa a rotação uniforme do núcleo radiativo da rotação diferencial da zona de convecção. Várias observações de héliossismologia indicaram que o centro da tacoclina encontra-se entre $0.68 R_{\odot} \leq r_{\text {tac }} \leq 0.70 R_{\odot}$ e determinaram que a sua espessura está entre $0.01 R_{\odot} \leq w_{t a c} \leq 0.09 R_{\odot}$ (veja os valores destas quantidades e as referências à literatura na Tabela 2.1, extraída de Corbard et al. (2001)).

\begin{tabular}{ccccc}
\hline Autores & $r_{t a c} / R_{\odot}$ & $w / R_{\odot}$ & Dados e método & \\
\hline Kosovichev (1996) & $0.692 \pm 0.005$ & $0.09 \pm 0.04$ & BBSO 86,88-90 & FM \\
Basu (1997) & $0.7066 \pm 0.005$ & $0.0412 \pm 0.0260$ & BBSO 86,88-90 & FM (Calibration) \\
& $0.7034 \pm 0.0056$ & $0.0490 \pm 0.0245$ & GONG 4-7 & FM (Calibration) \\
& $0.7048 \pm 0.0039$ & $0.0514 \pm 0.0177$ & GONG 4-10 & FM (Calibration) \\
Charbonneau et al. (1999) & $0.705 \pm 0.002$ & $0.053 \pm 0.015$ & LOWL 94-96 & Genetic FM \\
\hline Charbonneau et al. (1999) & $0.689 \pm 0.006$ & $0.01 \pm 0.03$ & LOWL 94-96 & Ola + Deconvolution \\
& $0.691 \pm 0.007$ & $0.07 \pm 0.03$ & LOWL 94-96 & RLS + Deconvolution \\
Corbard et al. (1998) & $0.695 \pm 0.005$ & $0.05 \pm 0.03$ & LOWL 94-96 & Ola + Deconvolution \\
Corbard et al. (1999) & $0.691 \pm 0.004$ & $0.01 \pm 0.03$ & LOWL 94-96 & Adaptative Reg. \\
Antia et al. (1998) & $0.6851 \pm 0.0077$ & $0.0230 \pm 0.0407$ & GONG 4-14 & FM (Calibration) \\
& $0.6843 \pm 0.0112$ & $0.0098 \pm 0.0093$ & GONG 4-14 & FM Simulated annealing \\
\hline \hline
\end{tabular}

Tabela 2.1 - Espessura e posição da tacoclina inferidas através de diferentes conjuntos de dados e técnicas. A parte superior da Tabela apresenta valores de uma média latitudinal, enquanto a parte inferior apresenta ajustes feitos no equador. O mês GONG 4 começa em 8/23/95. O fim dos meses GONG 7, 10 e 14 são 1/13/96, 4/30/96, 9/21/96, respectivamente. Os dados LOWL foram coletados durante 2/26/94 e 2/25/96 (extraída de Corbard et al., 2001).

Os resultados de Antia et al. (1998); Charbonneau et al. (1999) indicaram que a tacoclina poderia ter uma forma prolata, com a diferença de $\Delta r_{t a c}=0.024 R_{\odot}$ na posição do raio central entre o equador e uma latitude de $60^{\circ}$. A origem física desta prolaticidade é até agora incerta, porém, acredita-se que pode ser uma consequência dos intensos campos magnéticos que podem ser formados nesse lugar. Esses resultados indicam que, ao menos na região equatorial, a tacoclina encontra-se abaixo da zona convectiva. A sua posição deve em parte coincidir com a camada de overshoot ${ }^{2}$, a qual por suas características termodinâmicas é considerada uma camada estável, cujo centro está localizado em $r_{c} \sim 0.713$

\footnotetext{
${ }^{2}$ A camada de overshoot corresponde à interface entre a zonas radiativa, na qual a energia é transportada por radiação, e convectiva, na qual o transporte e predominantemente convectivo. Formalmente pode definir-se como a região entre $r_{r z}$, o local no qual o gradiente da temperatura, $\nabla=d \ln T / d \ln p=\nabla_{r}$, tem valor radiativo, e $r_{c z}$, que corresponde à fronteira que define o começo da zona convectivamente instável onde o gradiente da temperatura iguala-se ao gradiente adiabático $\nabla=\nabla_{a d}$.
} 
e com uma espessura aproximada de $0.01 R_{\odot}$ (Basu, 1997).

\subsubsection{Circulação meridional}

No estado atual das técnicas observacionais existe um conjunto de medidas independentes da circulação meridional (a componente $r$ e $\theta$ do campo de velocidades) que confirmam um fluxo superficial em direção aos pólos, ao redor de $20 \mathrm{~m} \mathrm{~s}^{-1}$, com máxima amplitude em $\sim 40^{\circ}$ (Komm et al., 1993b; Hathaway, 1996; Hathaway et al., 1996; Snodgrass e Dailey, 1996; Latushko, 1996; Giles et al., 1997; Braun e Fan, 1998) (veja a Fig. 2.4). Tem-se encontrado que esse fluxo meridional pode estar relacionado com a atividade magnética, pois apresenta magnitudes maiores durante os mínimos de atividade magnética e amplitudes menores durante os mínimos solares (Komm et al., 1993b).

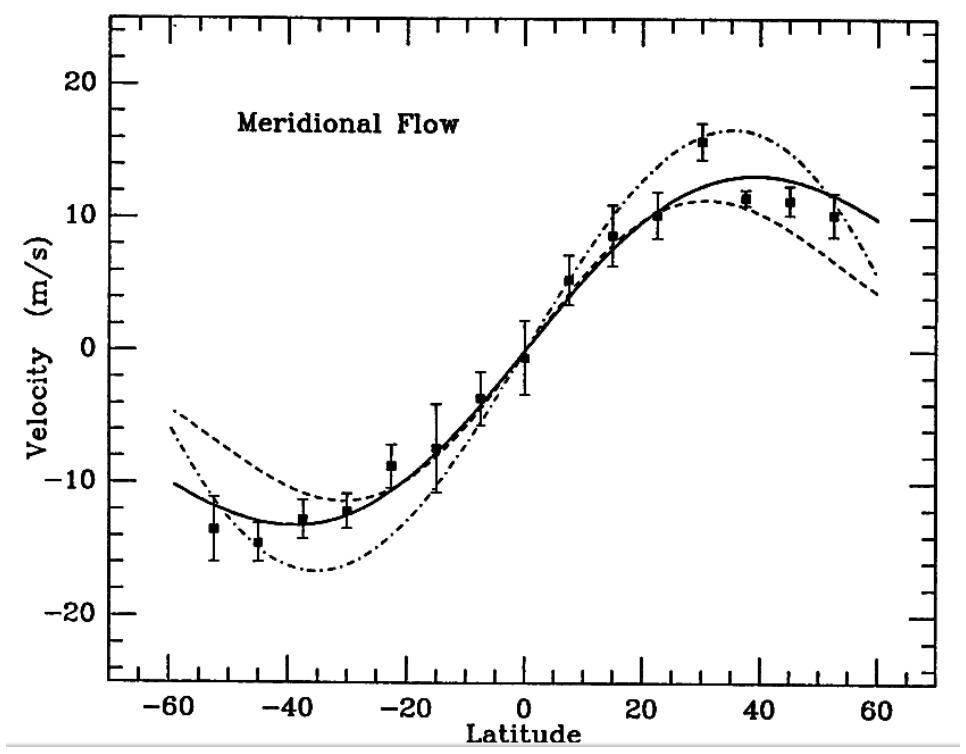

Figura 2.4: Perfil de fluxo meridional obtido a partir do método de marcadores magnéticos. Para obter essa curva foram usados 514 pares de magnetogramas durante o período 1978 1990. As velocidades positivas (negativas) indicam que o fluxo pertence ao hemisfério norte (sul). As linhas tracejadas e pontilhadas correspondem a ajustes feitos por (Snodgrass, 1984) e (Ulrich, 1993), respectivamente. A linha sólida corresponde a um ajuste feito por Komm et al. (1993b) (imagem extraída de Komm et al., 1993b).

A amplitude das perturbações induzidas pelo fluxo meridional nos modos globais de oscilação é pequena quando comparada com perturbações induzidas pela rotação ou pelo campo magnético, de tal forma que observações de héliossismologia desta componente do 
fluxo são factíveis unicamente com héliossismologia local. Isto significa que só as camadas mais superficiais podem ser resolvidas. Recentes tentativas neste sentido (Giles et al., 1997; Braun e Fan, 1998; Haber et al., 2002; Zhao e Kosovichev, 2004) encontraram que o fluxo na direção polar persiste até $\sim 0.85 R_{\odot}$. Nestes trabalhos não existe nenhuma referência ao fluxo meridional de retorno (nas camadas mais profundas), a exceção de Haber et al. (2002) que reportaram que em 1999 observou-se uma célula de convecção na direção contrária.

Em um trabalho mais recente Mitra-Kraev e Thompson (2007) sugerem que o ponto de retorno da circulação meridional pode estar em $\sim 0.95 R_{\odot}$ e que nas regiões abaixo de $0.8 R_{\odot}$, poderia existir uma segunda célula de convecção mais fraca em amplitude, ou então um fluxo meridional em grande escala nulo (veja a Fig. 2.5). Além deste trabalho, não existe nenhum outro recente com medidas do fluxo de retorno. De fato, Braun e Birch (2008) fizeram uma análise da razão sinal-ruído na base da zona de convecção e concluíram que para se detectar esse fluxo, com a técnica de héliossismologia tempo-distância (timedinstance helioseismology), seria necessário mais de uma década de medições.

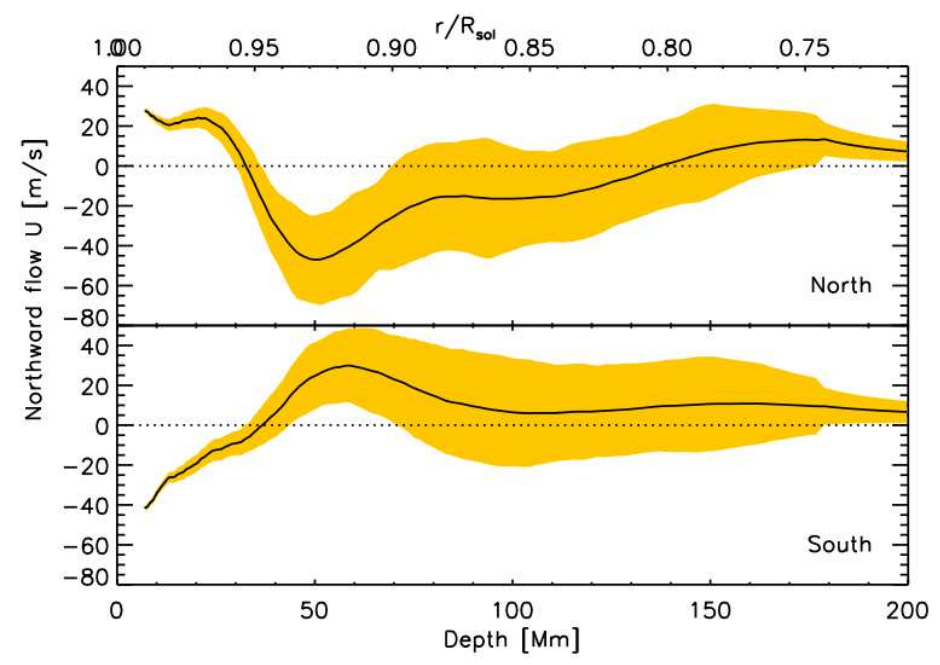

Figura 2.5: Perfil de fluxo meridional para os hemisférios norte e sul obtidos por inversões de héliossismologia por Mitra-Kraev e Thompson (2007). As velocidades positivas (negativas) representam migração polar (equatorial) do fluxo.

Efetuado este levantamento dos aspectos observacionais do ciclo solar, no próximo Capítulo apresentaremos os fundamentos matemáticos que ajudarão a descrever esse processo. 
Capítulo 3

\section{Magnetohidrodinâmica e teoria dínamo}

Neste Capítulo iremos tentar descrever os princípios físicos nos quais estão baseados os modelos de Dínamo solar. Na primeira seção apresentamos as equações gerais do magnetohidrodinâmica (MHD), seguida dos modelos globais que tentam resolver de uma forma ab initio o problema de Dínamo solar. Posteriormente, apresentamos as bases da teoria de dínamo de campo médio, que é a ferramenta apropriada para descrever a evolução cinemática do campo magnético solar em grande escala, quando o campo de velocidades é conhecido, a priori, a partir de observações. Finalmente, apresentaremos os principais elementos que devem ser considerados na construção de um modelo numérico de dínamo, revisando de forma crítica os modelos mais relevantes e tentando mostrar o desenvolvimento da teoria de dínamo em ordem cronológica. A seção final deste capítulo é dedicada à descrição do modelo de Dínamo solar de Babcock-Leighton, destacando as suas vantagens e limitações.

\subsection{Equações da MHD}

Os padrões temporais de campo magnético observados na atmosfera solar indicam que essa estrutura magnética forma-se abaixo da superfície pela interação do campo com os fluxos de matéria em grande escala. No sol, bem como na maioria dos objetos Astrofísicos, o gás se encontra total ou parcialmente ionizado em um estado conhecido como plasma. O movimento do gás cria correntes elétricas capazes de induzir campos magnéticos. Por sua vez, a reação dinâmica do campo magnético sobre o gás, devida à força de Lorentz, modifica o movimento. A evolução macroscópica deste fluxo magnetizado é descrita pelas equações da magnetohidrodinâmica, as quais combinam as equações de Maxwell com as 
equações de Navier-Stokes (hidrodinâmicas) do fluido.

Em unidades cgs, as equações de Maxwell apresentam a seguinte forma:

$$
\begin{aligned}
\nabla \times \mathbf{B} & =\frac{1}{c} \frac{\partial \mathbf{E}}{\partial t}+\frac{4 \pi}{c} \mathbf{J} \\
\nabla \cdot \mathbf{B} & =0 \\
\nabla \times \mathbf{E} & =-\frac{1}{c} \frac{\partial \mathbf{B}}{\partial t} \\
\nabla \cdot \mathbf{E} & =4 \pi \rho_{e},
\end{aligned}
$$

onde $\mathbf{B}$ e $\mathbf{E}$ são os campos magnético e elétrico, respectivamente, J é a densidade de corrente $c$ é a velocidade da luz e $\rho_{e}$ é a densidade de carga. As equações acima são complementadas pela lei de Ohm generalizada de um fluido total ou parcialmente ionizado:

$$
\mathbf{J}=\sigma\left(\mathbf{E}+\frac{1}{c} \mathbf{U} \times \mathbf{B}\right)
$$

onde $\mathbf{U}$ é o campo de velocidades e a quantidade escalar $\sigma$ é a condutividade elétrica. É possível combinar as eqs. (3.5) e (3.3) para eliminar J da eq. (3.1) e obter:

$$
\frac{1}{c} \frac{\partial \mathbf{E}}{\partial t}+\frac{1}{\eta}(c \mathbf{E})=\nabla \times \mathbf{B}-\frac{1}{\eta}(\mathbf{U} \times \mathbf{B})
$$

aqui, introduzimos a difusividade magnética Ohmica $\eta=\frac{c^{2}}{4 \pi \sigma}$. Se na eq. (3.6), a velocidade do fluido é pequena comparada com a velocidade da luz $(U<<c)$, a derivada temporal do campo elétrico, também conhecida como corrente de deslocamento, pode ser desprezada e, então, tomando-se o rotacional da eq. (3.6) e usando a eq. (3.3), obtem-se uma única equação para descrever a evolução do campo magnético num meio com velocidade $\mathbf{U}$, a equação de indução:

$$
\frac{\partial \mathbf{B}}{\partial t}=\nabla \times(\mathbf{U} \times \mathbf{B}-\eta \nabla \times \mathbf{B})
$$

Uma análise dimensional da eq. (3.7) ajuda a entender o seu significado físico. Considerando $\hat{t}$ e $\ell$ como unidades de tempo e comprimento características do sistema, temos:

$$
\left[\frac{B}{\hat{\mathrm{t}}}\right] \simeq\left[\frac{U B}{\ell}\right]+\left[\frac{\eta B}{\ell^{2}}\right],
$$

Nessa equação $\ell / U$ e $\ell^{2} / \eta$ dão os tempos de adveção e de difusão, respectivamente, e a sua razão resulta em:

$$
\mathrm{Rm}=\frac{U \ell}{\eta}
$$


o qual é conhecido como o número de Reynolds magnético. No caso em que $R m<<1$, o segundo termo do lado direito da equação de indução (3.7) domina sobre o primeiro e, assim, a evolução do campo magnético é governada por uma equação de difusão,

$$
\frac{\partial \mathbf{B}}{\partial t}=\eta \nabla^{2} \mathbf{B}
$$

onde se assumiu que $\eta=$ cte. Por outro lado, se $R m>>1$, a evolução do campo magnético é governada pelo primeiro termo da eq. (3.7), $\nabla \times(\mathbf{U} \times \mathbf{B})$, que é usualmente conhecido como o termo indutivo. O papel real deste termo torna-se mais claro se o reescrevemos como segue:

$$
\nabla \times(\mathbf{U} \times \mathbf{B})=-\mathbf{U} \cdot \nabla \mathbf{B}+\mathbf{B} \cdot \nabla \mathbf{U}-\mathbf{B} \nabla \cdot \mathbf{U}
$$

onde foi considerado o fato de que $\nabla \cdot \mathbf{B}=0$. O primeiro termo do lado direito da equação acima tem um efeito advectivo, o segundo é um termo que estica ou alonga o campo magnético podendo amplificá-lo exponencialmente a uma taxa que depende do gradiente local do campo de velocidades. Finalmente, o terceiro termo tem efeito compressivo. Assim o termo indutivo da eq. 3.7 pode desempenhar três papéis diferentes na evolução de $\mathbf{B}$ : transporte, amplificação e compressão.

No caso em que os efeitos indutivos do campo de velocidades sejam capazes de amplificar um campo magnético semente e sustentá-lo contra a dissipação Ohmica (veja o segundo termo de eq. (3.7)), o processo é conhecido como efeito dínamo (Cowling, 1976). No Sol, o problema do dínamo consiste em encontrar a configuração apropriada do campo de velocidades e da difusividade magnética que sejam capazes de garantir o comportamento periódico do campo magnético, tal como foi descrito no Capítulo anterior.

No entanto, para resolver o problema do Dínamo solar de uma forma totalmente consistente, não é suficiente resolver-se a eq. (3.7), mas ela deve ser complementada com as equações de continuidade, momento e energia do fluido, as quais podem ser escritas como segue: 


$$
\begin{aligned}
\frac{\partial \rho}{\partial t}= & -\nabla \cdot(\rho \mathbf{U}) \\
\frac{\partial \rho \mathbf{U}}{\partial t}= & -\nabla \cdot(\rho \mathbf{U} \mathbf{U})-\nabla p+\nabla \cdot \tau-2 \rho \Omega \times \mathbf{U} \\
& +\frac{1}{c}(\mathbf{J} \times \mathbf{B})+\rho \mathbf{g} \\
\frac{\partial e}{\partial t}= & -\nabla \cdot(e \mathbf{U})-p \nabla \cdot \mathbf{U}+Q_{v i s}+\nabla \cdot(\kappa \nabla T) \\
& +\frac{1}{c}|\nabla \times \mathbf{B}|^{2}
\end{aligned}
$$

onde $\rho, e, p, T$ e g são a densidade de massa, densidade de energia, pressão do gás, temperatura e aceleração da gravidade, respectivamente. $\Omega$ é a freqüência de rotação do sistema e o termo $2 \rho \Omega \times \mathbf{U}$ corresponde à densidade da força de Coriolis. $\kappa$ é o coeficiente de condução térmica e $\tau$ é o tensor de estresse viscoso cujas componentes são dadas por:

$$
\tau_{\mathbf{i j}}=\nu \rho\left(\nabla \mathbf{U}_{i j}+\nabla \mathbf{U}_{j i}-\frac{2}{3} \nabla \cdot \mathbf{U} \delta_{i j}\right),
$$

onde $\nu$ é o coeficiente de viscosidade cinemática. O aquecimento associado a esta força viscosa é dado por:

$$
Q_{v i s}=\sum_{i j} \tau_{\mathbf{i j}} \nabla \mathbf{U}_{i j}
$$

As variáveis termodinâmicas acima devem estar relacionadas através de uma equação de estado. Se assumimos que o fluido corresponde a um gás ideal, então:

$$
p=\rho e(\gamma-1)
$$

onde $\gamma=c_{p} / c_{v}=5 / 3$ é a razão entre o calor específico sob pressão constante e o calor específico em volume constante para um gás monoatômico ideal.

As eqs. (3.12) a (3.14) correspondem às equações de Navier-Stokes complementadas com a força magnética (força de Lorentz), 1/c $(\mathbf{J} \times \mathbf{B})$, e a densidade de energia magnética $1 / c|\nabla \times \mathbf{B}|^{2}$, as quais descrevem os efeitos do campo magnético na dinâmica do sistema. O conjunto de equações (3.12) - (3.14) e (3.7) é conhecido como equações da MHD.

Se desprezarmos os termos magnéticos e de Coriolis na equação de movimento (3.13) e tomarmos o rotacional da mesma, obtemos a equação da vorticidade $(\omega=\nabla \times \mathbf{U})$, que é formalmente similar à equação de indução (3.7). Uma análise dimensional da equação da 
vorticidade do fluido, similar àquela efetuada para a eq. (3.7) dá a razão entre o tempo de advecção e o tempo viscoso, usualmente conhecida como o número de Reynolds do fluido:

$$
\operatorname{Re}=\frac{U l}{\nu}
$$

Se $R e<<1$, a força viscosa domina sobre o termo advectivo. Neste caso, o fluido é chamado de laminar. Por outro lado, se $R e>>1$, o fluido será turbulento com turbilhões em grande escala transferindo energia a turbilhões cada vez menores até chegar à escala viscosa (ou seja, aquela onde $\nu$ torna-se importante).

As magnitudes relativas entre o coeficiente de condução térmica e a viscosidade, e entre a difusividade magnética e a viscosidade são dadas pelos números de Prandtl cinético e magnético, respectivamente:

$$
\begin{aligned}
\operatorname{Pr} & =\frac{\nu}{\chi} \\
\operatorname{Pm} & =\frac{\nu}{\eta}
\end{aligned}
$$

onde $\chi=\kappa \rho / c_{p}$.

Veremos mais adiante que esses números adimensionais $(R m, \operatorname{Re}, \operatorname{Pr}$ e $\operatorname{Pm})$ são parâmetros chave para definir a evolução dos campos magnéticos. Além deles, há outros números adimensionais que descrevem outras propriedades do fluido e cuja definição será útil mais adiante neste trabalho (especialmente no Capítulo 8). Por exemplo, em um sistema que é convectivamente instável, como a camada de convecção do interior solar, a ação da instabilidade convectiva num caso hidrodinâmico puro é determinada pelo Número de Rayleigh:

$$
\mathrm{Ra}=\frac{g}{T} \frac{l^{4}}{\nu \chi}\left(\frac{d T}{d z}-\frac{g}{c_{p}}\right) .
$$

É possível demonstrar-se que para a convecção operar, o número de Rayleigh do sistema deve exceder o valor crítico $\sim 10^{3}$ (Chandrasekhar, 1961). A influência da rotação na convecção é caracterizada pelo número de Taylor:

$$
\mathrm{Ta}=\frac{4 \Omega^{2} \ell^{4}}{\nu^{2}}
$$

E finalmente, a disputa entre as pressões do gás e magnética é controlada pelo parâmetro $\beta_{\text {plasma }}$, definido como:

$$
\beta_{\text {plasma }}=\frac{8 \pi p}{B^{2}}
$$


Se $\beta_{\text {plasma }}>>1$ o sistema é dominado pela pressão térmica do gás, e o campo magnético não tem nenhuma influência importante na dinâmica do sistema, enquanto que para $\beta_{\text {plasma }}<<1$, é a pressão magnética quem domina a dinâmica do sistema.

\subsection{Simulação numérica e o problema da escala}

Resolver o conjunto completo de equações MHD para o estudo do dínamo solar dinâmico é um problema complexo, analiticamente não solúvel. Contudo, é possível aproximar-se da solução real através de simulações numéricas.

Porém, em sistemas Astrofísicos onde a turbulência desempenha um papel importante, como é o caso da zona de convecção solar, onde se acredita que está operando o dínamo, existem grandes diferenças entre as várias camadas. De fato, há regiões onde $R m<<1$ (e $R e<<1$ ) de modo que os termos dissipativos dominam na dinâmica do sistema, e outras regiões onde acontece a situação oposta e desenvolvem-se estruturas turbulentas. Nestes casos a energia é transferida da grande escala (escala de injeção) à pequena escala (escala de difusão), de acordo com o formalismo de Kolmogorov (Frisch, 1995). Esta situação pode ser muito difícil de se considerar matematicamente já que lida com sistemas onde as estruturas abrangem várias ordens de magnitude em escala, de tal forma que para chegarse a uma solução realista do problema é necessário utilizar uma resolução numérica muito grande. De fato, uma simulação hidrodinâmica de n-dimensões capaz de descrever todas as escalas relevantes deve ter pelo menos $N=R e^{3 n / 4}$ pontos de grade (Frisch, 1995). No caso da camada convectiva do Sol e também de outros objetos astrofísicos, isto constitui um importante inconveniente já que o número de Reynolds nesses casos é maior que $10^{6}$, de tal forma que uma simulação $3 \mathrm{D}$ deve ter $N \sim 10^{3 \times 4.5}$ pontos de grade, a qual é uma resolução impensável atualmente, inclusive para os supercomputadores mais modernos. Esse problema é conhecido como o problema da escala.

Para ilustrar melhor esse problema, na tabela 3.2 são apresentados os valores solares de alguns dos parâmetros adimensionais descritos na seção anterior, comparados com o valor dos mesmos atingidos nas simulações numéricas mais modernas. É claro que os modelos numéricos mais realistas estão ainda longe de abranger todas as escalas, tanto para estruturas puramente hidrodinâmicas, nas quais o número relevante é o número Reynolds, quanto para estruturas magnéticas, nas quais o número relevante é o número Reynolds 
magnético. Contudo, essas tentativas de desenvolver simulações numéricas globais autoconsistentes de convecção solar e do efeito dínamo em domínios esféricos, têm resultado em informações que nos aproximam do comportamento físico desses sistemas, o qual é impossível de ser observado diretamente. Na seguinte seção apresentaremos alguns desses modelos. No Capítulo 8 voltaremos às simulações numéricas tridimensionais, porém que não abrangem a esfera completa, mas apenas uma pequena fração das camadas convectiva e radiativa.

\begin{tabular}{cccc}
\hline Símbolo & Valor solar & Valor no modelo & Escalas de tempo envolvidas \\
\hline$M=\frac{v}{c_{s}}$ & $\leq 1$ & $0.01-1$ & Velocidade do som \\
$\operatorname{Pr}=\frac{\nu}{\chi}$ & $10^{-7}$ & $0.1-1$ & Condução térmica sobre dissipação viscosa \\
$\operatorname{Ra}=\frac{g}{T} \frac{l^{4}}{\nu \chi}\left(\frac{d T}{d z}-\frac{g}{c_{p}}\right)$ & $10^{16}-10^{20}$ & $\leq 10^{7}$ & média geométrica de condução sobre empuxo viscoso \\
$\operatorname{Re}=\frac{u \ell}{\nu}$ & $\geq 10^{11}$ & $\leq 10^{3}$ & dissipação viscosa sobre adveção \\
\hline $\operatorname{Ta}=\frac{4 \Omega l}{\nu^{2}}$ & $10^{19}-10^{27}$ & $\leq 10^{7}$ & dissipação viscosa sobre rotação \\
\hline$\beta=\frac{{ }^{2}}{B^{2}}$ & $10^{-6}-10^{-4}$ & $0.1-1$ & diffusividade magnética sobre dissipação viscosa \\
$\operatorname{Pm}=\frac{\nu}{\eta}$ & $10^{6}-10^{9}$ & $\leq 10^{3}$ & difusão do campo sobre adveção \\
$\mathrm{Rm}=\frac{u \ell}{\eta}$ & &
\end{tabular}

Tabela 3.1 - Números adimensionais usados comumente em simulações HD e MHD. O valor solar é comparado com o melhor valor obtido em simulações modernas. A quarta coluna indica as escalas de tempo envolvidas em cada número. Os valores da tabela foram extraídos de Brandenburg e Subramanian (2005); Schrijver e Zwaan (2000); Brun et al. (2004); Miesch et al. (2008).

\subsection{Simulações globais de convecção e efeito dínamo}

Os primeiros modelos globais do dínamo solar (Gilman e Miller, 1981; Gilman, 1983; Glatzmaier, 1985a,b) foram capazes de reproduzir a formação da componente toroidal do campo magnético como resultado do alongamento das linhas de um campo poloidal. Eles verificaram também a formação de um novo campo poloidal criado possivelmente como resultado de movimentos helicoidais em pequena escala devidos à rotação (efeito $\alpha$ ). Porém, nos seus resultados os deslocamentos radial e latitudinal do campo magnético não concordam com aqueles observados. Esses autores concluíram que, mesmo com a melhor resolução numérica disponível naquele tempo, era impossível obter um perfil de rotação diferencial que satisfizesse as observações e atribuíram a isso a discordância encontrada nas magnitudes e distribuições dos campos magnéticos.

Mais recentemente, os modelos hidrodinâmicos, empregando a aproximação inelástica (Miesch, 2005; Miesch et al., 2008), com uma grade computacional de até $256 \times 1024 \times$ 
2048 pontos, foram capazes de alcançar altos valores do número de Reynolds $(\sim 400)$. Nos seus resultados verificaram a formação de grandes células de convecção térmica cujas componentes da velocidade média avaliadas temporalmente durante vários meses, resultam em um perfil de rotação diferencial que concorda muito bem com as observações, tal como se pode ver na Fig. 3.1 (compare com a Fig. 2.3). Na imagem à direita dessa figura observa-se o perfil de fluxo meridional o qual mostra um movimento em direção ao pólo nas camadas mais superficiais e um movimento em direção ao equador nas camadas mais profundas. Também encontraram que para algumas médias temporais, desenvolvem-se mais de uma célula de fluxo meridional em cada quadrante (painel direito da Fig. 3.1).
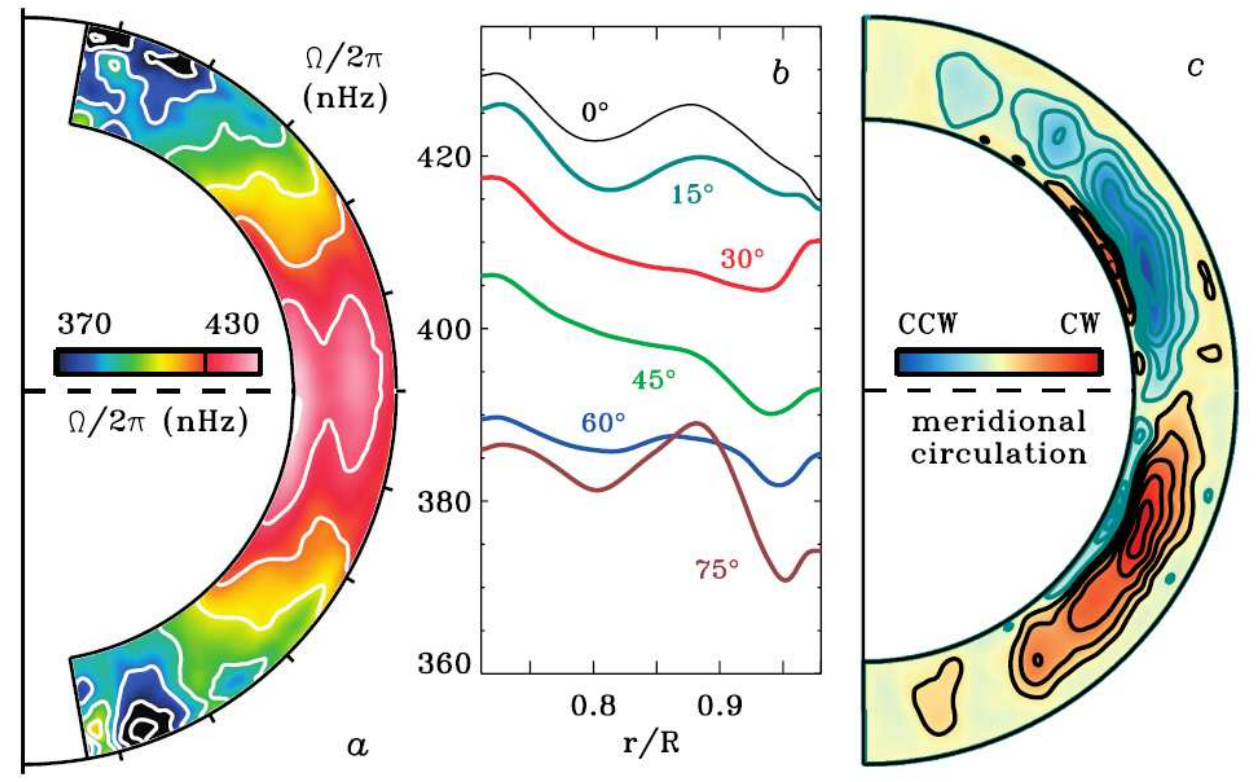

Figura 3.1: Imagens esquerda e do meio: perfil de rotação diferencial no interior da camada convectiva solar obtido a partir de simulações de convecção no modelo esférico global de Miesch et al. (2008). No painel da esquerda esse perfil é exibido em contornos bi-dimensionais em dois quadrantes do Sol ao norte e ao sul do equador, em uma distribuição latitudinal e radial. Imagem à direita: mapa de contornos da circulação meridional obtido com o mesmo modelo hidrodinâmico.

No caso MHD (Brun et al., 2004) conseguiram uma máxima resolução numérica de $125 \times 512 \times 1024$ pontos de grade, que levam a um Número de Reynolds de $\sim 150$ e a um número de Reynolds magnético de $\sim 500$. Brun et al. (2004) encontraram a formação de intensos campos toroidais e poloidais em grande escala (veja a Fig. 3.2), mas sem obter a migração equatorial do fluxo magnético nem as reversões de polaridade. Além disso, 
a proporção entre as componentes dos campos poloidal e toroidal é $\sim 1$ e não $\sim 100$ como observado. Eles comentam que esse resultado pode se relacionar com a ausência de um cisalhamento (shear) muito intenso, já que suas simulações não incluem nem a tacoclina nem a camada de cisalhamento próxima da superfície (veja o Capítulo 2). No entanto, esse resultado pode se dever também ao valor do número de Prandtl magnético que eles consideram $(\sim 1)$, pois com este se define uma escala dissipativa maior do que o esperada para o Sol, o qual poderia resultar na criação de campos magnéticos turbulentos em pequena escala à mesma taxa de criação dos campos na grande escala, tal como foi apontado por Brandenburg (2005).
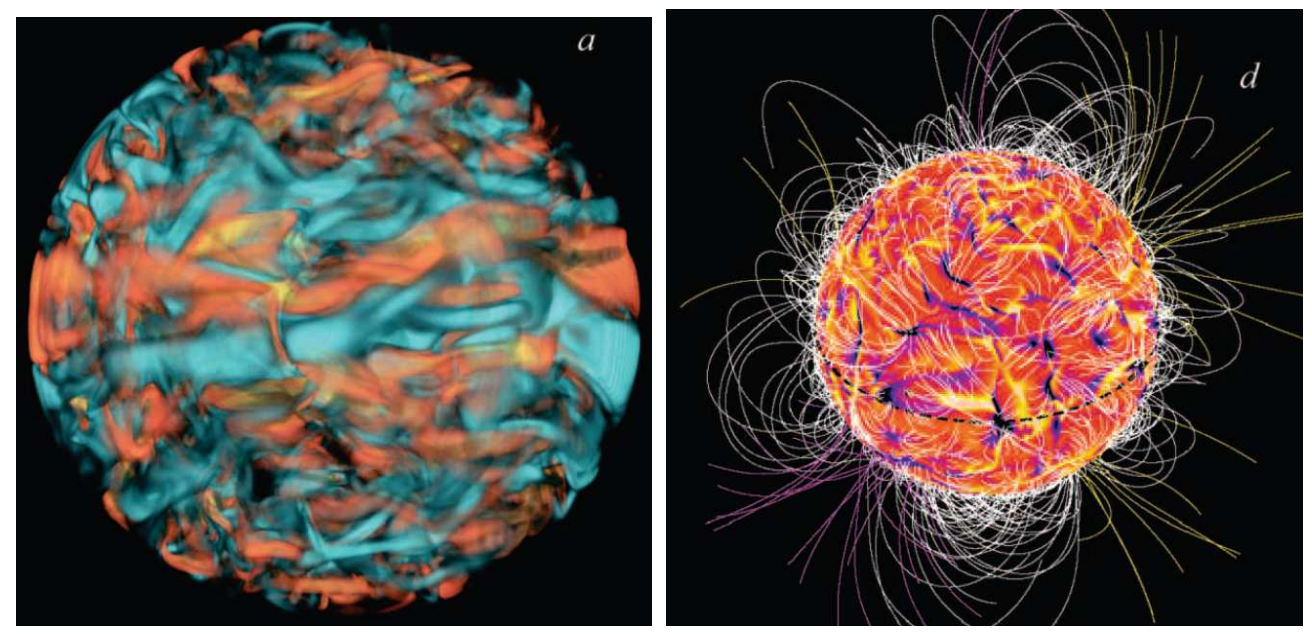

Figura 3.2: Esquerda: representação volumétrica do campo magnético toroidal obtido em simulações numéricas 3D globais por Brun et al. (2004). As cores vermelha e azul indicam orientação positiva e negativa do campo, respectivamente. Direita: Extrapolação do campo radial no topo do domínio computacional da mesma simulação. As linhas brancas representam linhas fechadas, enquanto as linhas amarelas indicam linhas de campo abertas.

\subsection{Teoria de dínamo de campo médio}

As equações MHD (3.7, 3.12 a 3.17) descrevem o comportamento e evolução das quantidades físicas totais de um sistema, ou seja das suas componentes tanto em pequena quanto em grande escala, por isso, a sua solução numérica pode vir a sofrer o problema das escalas descrito acima. Uma aproximação alternativa para resolver o problema de dínamo é a teoria de campo médio. Ela foi introduzida por Parker (1955) para investigar o dínamo solar. 
Ele propôs um efeito indutivo turbulento, $\alpha$, que produz um campo magnético médio $B$. Depois de Parker, Steenbeck e Krause (1969) desenvolveram a teoria com uma rigorosa base matemática.

A teoria de campo médio permite separar as estruturas finas das estruturas em grande escala, de tal forma que qualquer quantidade física, $Q$, pode ser decomposta em uma componente média, $Q_{0}$, e em uma componente flutuante, $q$, cuja média é zero. Então é possível escrever as quantidades físicas das equações MHD como segue:

$$
\mathbf{U}=\mathbf{U}_{\mathbf{0}}+\mathbf{u}, \quad \mathbf{B}=\mathbf{B}_{\mathbf{0}}+\mathbf{b}, \quad \mathbf{E}=\mathbf{E}_{\mathbf{0}}+\mathbf{e} \quad \text { and } \quad \mathbf{J}=\mathbf{J}_{\mathbf{0}}+\mathbf{j} .
$$

No entanto, para se poder considerar a média para a qual a decomposição acima seja válida, as quantidades consideradas devem obedecer às leis das médias de Reynolds:

$$
\begin{array}{r}
\overline{\bar{Q}}=\bar{Q}, \quad \overline{Q_{1}+Q_{2}}=\overline{Q_{1}}+\overline{Q_{2}}, \quad \overline{Q_{1} \overline{Q_{2}}}=\overline{Q_{1} Q_{2}} \\
\overline{Q_{1} Q_{2}}=\overline{Q_{1}} \quad \overline{Q_{2}}+\overline{q_{1} q_{2}}, \quad \frac{\partial Q}{\partial t}=\frac{\partial \bar{Q}}{\partial t}, \quad \overline{\frac{\partial Q}{\partial x}}=\frac{\partial \bar{Q}}{\partial x}, \quad \bar{c}=c
\end{array}
$$

onde $Q_{1}$ e $Q_{2}$ são funções de $x$ e $t$, e $c$ é uma constante. Como a média da componente flutuante é zero, $(\bar{b}=0)$, então $\bar{B}=B_{0}$, a qual é chamada de campo médio, e $\bar{U}=U_{0}$ é chamado de fluxo médio. Podemos ainda substituir as eqs. (3.24) na eq. (3.7) e assim obter a equação de indução do campo magnético médio $\bar{B}$ :

$$
\frac{\partial \overline{\mathbf{B}}}{\partial t}=\nabla \times(\overline{\mathbf{U}} \times \overline{\mathbf{B}}+\mathcal{E}-\eta \nabla \times \overline{\mathbf{B}})
$$

Aqui, $\mathcal{E}=\overline{\mathbf{u} \times \mathbf{b}}$ é a força electromotriz devida às flutuações do campo de velocidades, ou, em outras palavras, é a contribuição dos movimentos em pequena escala às grandes escalas. O cálculo de $\mathcal{E}$ é o ponto mais problemático na construção da teoria de campo médio devido ao pobre conhecimento que temos atualmente sobre turbulência. Porém, usando as eqs. (3.7) e (3.26) é possível obter uma equação de indução para o campo flutuante, b, que deve ser uma função de $\overline{\mathbf{U}}, \mathbf{u}$ e $\overline{\mathbf{B}}$. Então, é possível assumir que $\mathcal{E}$ é também função das mesmas variáveis. Supondo-se que todas as componentes de $\mathcal{E}$ são função de $\overline{\mathbf{B}}$, e que $\overline{\mathbf{B}}$ varia suavemente no espaço e no tempo, de tal forma que $\mathcal{E}$ depende unicamente de $\overline{\mathbf{B}}$ e de suas derivadas, temos então:

$$
\mathcal{E}=a_{i j} \bar{B}_{j}+b_{i j k} \frac{\partial \bar{B}}{\partial x_{k}}
$$


onde $a_{i j}$ e $b_{i j k}$ são tensores de segunda e terceira ordem, respectivamente. Depois de algumas operações de álgebra tensorial, separando as componentes simétrica e anti-simétrica dos tensores $a, b$ e $\frac{\partial \bar{B}}{\partial x_{k}}$ (Raedler, 1980), é possível escrever a eq. (3.27) como:

$$
\mathcal{E}=\alpha \overline{\mathbf{B}}-\gamma \times \overline{\mathbf{B}}-\beta(\nabla \times \overline{\mathbf{B}})-\delta \times(\nabla \times \overline{\mathbf{B}})-\kappa\left(\nabla \overline{\mathbf{B})^{(s)}}\right.
$$

onde $\alpha$ e $\beta$ são tensores de segunda ordem, $\gamma$ e $\delta$ são vetores, e $\kappa$ é um tensor de terceira ordem. O termo $(\nabla \overline{\mathbf{B}})^{(s)}$ representa as componentes simétricas do gradiente de $\overline{\mathbf{B}}$. Finalmente, podemos substituir $\mathcal{E}$ em eq. (3.26) pela eq. (3.28) e obter:

$$
\frac{\partial \overline{\mathbf{B}}}{\partial t}=\nabla \times[(\overline{\mathbf{U}}+\gamma) \times \overline{\mathbf{B}}+\alpha \overline{\mathbf{B}}-(\eta+\beta) \nabla \times \overline{\mathbf{B}}],
$$

Note que por simplicidade só os três primeiros termos da expansão de força electromotriz estão sendo considerados na eq. (3.29). Iremos descrever o papel de cada um desses termos para entender melhor o significado físico destas contribuições turbulentas. O vetor $\gamma$ é um termo advectivo conhecido como bombeamento magnético turbulento ou magnetic pumping. O tensor $\alpha_{i j}$ contém uma parte indutiva de campo magnético dada pelos seus elementos diagonais, $\alpha^{D}$, e uma parte advectiva dada pelos elementos não diagonais $\alpha^{N D}$ (desconsiderados daqui por diante, por simplicidade). $\beta_{i j}$ é o tensor de difusividade magnética turbulenta que, sob a hipótese de turbulência homogênea e isotrópica pode reduzir-se a um escalar, $\beta$ (como será discutido em §3.7.2). O valor de $\beta$ é normalmente maior do que o coeficiente de difusão Ohmica, $\eta$. Por essa razão, a partir de agora chamaremos todos os termos difusivos de $\eta_{T}=\eta+\beta$.

A eq. (3.29) pode ser aplicada para modelar o campo magnético do sol e outras estrelas, assim como de outros corpos astrofísicos, como planetas e galáxias. O tipo de dínamo que deve operar em cada caso depende dos parâmetros $\overline{\mathbf{U}}$ e $\mathcal{E}$, e das suas importâncias relativas em cada sistema. Graças à proximidade do sol, somos capazes de observar o campo de velocidades solar com algum grau de detalhe, de tal forma que este pode ser considerado como um parâmetro conhecido a priori nos modelos que são normalmente denominados de cinemáticos, pois só resolvem a equação de indução (3.29). Porém, não é este o caso da força electromotriz $(\mathcal{E})$, que é uma quantidade menos conhecida e a maioria dos modelos é obrigada a considerá-la como um parâmetro livre, sem nenhuma contrapartida observacional ou teórica realmente consistente, com excepção de algumas aproximações numéricas recentes. Na próxima seção iremos estudar o formalismo teórico 
dos modelos cinemáticos em uma geometria esférica e logo depois vamos descrever os principais elementos necessários nestes modelos. Finalizaremos este capítulo revisando os modelos existentes de dínamo solar no formalismo de campo médio.

\subsection{Modelos de dínamo cinemático}

Graças aos recentes desenvolvimentos observacionais da héliossismologia (veja §2.2.1), agora temos acesso a um perfil preciso e detalhado da rotação diferencial em toda a extensão da zona de convecção solar (§2.2.2) e, embora a observação do fluxo meridional de matéria seja uma tarefa muito mais difícil, agora conhecemos pelo menos a sua forma aproximada nas camadas mais superficiais (§2.2.4). A análise temporal destes perfis indica que não existem variações temporais importantes no comportamento do fluido em grande escala. Assim, pelo menos do ponto de vista observacional, podemos dizer que as mudanças no movimento do plasma devidas à reação dinâmica do campo magnético são pequenas, ou então que elas são rapidamente restauradas em tempos muito menores do que o período do ciclo solar. Isto torna legítimo o emprego da aproximação cinemática de dínamo, a qual reduz o problema à solução da equação de indução do campo magnético unicamente, considerando-se os perfis observados do campo de velocidades como parâmetros livres do modelo.

\subsection{Equação de indução em coordenadas esféricas}

Como foi dito acima, o problema do dínamo solar consiste em encontrar o conjunto apropriado de elementos indutivos e difusivos que levem a uma solução periódica do campo magnético apresentando as características do ciclo solar descritas em $§ 2.1$. Para esse fim, as observações sugerem que são necessários dois processos principais: a transformação de um campo poloidal inicial em um campo toroidal, seguida pela reconstrução do campo poloidal de polaridade oposta ao inicial. Para entender melhor a natureza destes processos criadores de campo magnético é interessante escrever a equação de indução de campo médio usando coordenadas esféricas para reproduzir as camadas pertencentes à zona de convecção e uma parte da camada radiativa, como caroços esféricos, em um ou dois hemisférios.

Antes de mais nada, iremos assumir simetria azimuthal $(\partial / \partial \phi=0)$, e separar as com- 
ponentes médias dos campos de velocidade e magnético nas suas componentes poloidal e toroidal:

$$
\begin{aligned}
& \overline{\mathbf{U}}=(\Omega r \sin \theta) \hat{e}_{\phi}+\mathbf{u}_{p} \\
& \overline{\mathbf{B}}=B \hat{e}_{\phi}+\nabla \times\left(A \hat{e}_{\phi}\right),
\end{aligned}
$$

onde $B$ é o campo magnético toroidal, $A$ é um potencial vetorial, tal que o seu rotacional dá o campo magnético poloidal $\mathbf{B}_{p}=\nabla \times\left(A \hat{e}_{\phi}\right)$, $\Omega$ é a velocidade angular e $\mathbf{u}_{p}$ é a velocidade na direção meridional (ou poloidal). Então, podemos substituir essas variáveis na eq. (3.29) para obter:

$$
\begin{aligned}
\frac{\partial B}{\partial t} & =-\frac{1}{r}\left[\frac{\partial}{\partial r}\left[r\left(u_{r}+\gamma_{r}\right) B\right]+\frac{\partial}{\partial \theta}\left[\left(u_{\theta}+\gamma_{\theta}\right) B\right]\right]+r \sin \theta\left(\mathbf{B}_{p} \cdot \nabla\right) \Omega \\
& -\left[\nabla \eta_{T} \times\left(\nabla \times B \hat{e}_{\phi}\right)\right]_{\phi}+\eta_{T}\left(\nabla^{2}-\frac{1}{s^{2}}\right) B+\left[\nabla \times\left(\alpha^{D} \overline{\mathbf{B}}\right)\right]_{\phi}, \\
\frac{\partial A}{\partial t} & =-\frac{1}{s}\left[\left(\mathbf{u}_{p}+\gamma_{p}\right) \cdot \nabla\right](s A)+\eta_{T}\left(\nabla^{2}-\frac{1}{s^{2}}\right) A+\left(\alpha^{D} B\right)_{\phi},
\end{aligned}
$$

onde, $\gamma_{p}=\gamma_{r}+\gamma_{\theta}$ é a componente poloidal do vetor de bombeamento magnético $\gamma, \alpha^{D}$ corresponde às componentes diagonais do tensor $\alpha_{i j}$, e $\eta_{T}=\eta+\beta$. O sistema de equações (3.31) e (3.32) será o foco central deste trabalho já que a maior parte das simulações que apresentaremos nos capítulos seguintes envolvem a sua solução. Por esse motivo, a seguir descreveremos em detalhe cada uma das suas componentes.

O primeiro grupo entre colchetes do lado direito da eq. (3.31) possui termos advectivos e compressivos que transportam e organizam o fluxo do campo magnético toroidal na direção meridional ( $r$ e $\theta)$ a uma taxa dada pelas velocidades de circulação meridional e de bombeamento magnético. O segundo termo no lado direito da eq. (3.31) é a contribuição indutiva do campo de velocidades, a qual depende do gradiente da velocidade angular, ou rotação diferencial, operando sobre a componente poloidal do campo magnético. A ação indutiva deste termo é conhecida como efeito $\Omega$. O terceiro termo transporta campo magnético toroidal nas regiões onde existe um gradiente da difusividade magnética total; o quarto termo corresponde ao decaimento resistivo do campo magnético toroidal, e finalmente o último termo é uma fonte de campo toroidal devido às contribuições da pequena escala, esse efeito indutivo é conhecido como efeito $\alpha$, e em conjunto com o termo de $\Omega$ formam a base do processo de dínamo. Os termos do lado direito da eq. (3.32) são termos 
advectivo, difusivo e indutivo, respectivamente. É importante notar que a única fonte de campo poloidal vem do efeito $\alpha$.

A importância dos termos de cisalhamento e $\alpha$ relativa ao termo difusivo e dado pelos seguintes números adimensionais:

$$
C_{\Omega}=\frac{\Omega_{0} R_{\odot}^{2}}{\eta_{0}}, \quad C_{\alpha}=\frac{\alpha_{0} R_{\odot}}{\eta_{0}}
$$

onde $\Omega_{0}, \alpha_{0}$ e $\eta_{0}$ são valores característicos destas quantidades. A contribuição de cada uma destas quantidades pode determinar-se pela razão $C_{\Omega} / C_{\alpha}$. Da mesma forma, a importância da advecção relativa à difusão é dada por:

$$
C_{U}=\frac{U_{0} R_{\odot}}{\eta_{0}}
$$

onde $U_{0}$ é um valor característico da velocidade na direção meridional (note que esse número é o número de Reynolds magnético correspondente à velocidade na direção meridional em grande escala). Finalmente, esses números adimensionais são complementados com uma unidade de tempo característica dada pelo tempo de difusão: $t^{\prime}=R_{\odot}^{2} / \eta_{0}$.

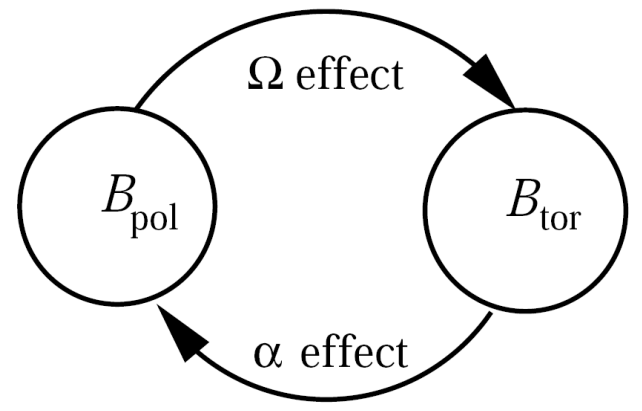

Figura 3.3: Regeneração mútua dos campos toroidal e poloidal no caso de um dínamo $\alpha \Omega$.

(Figura extraída de Brandenburg e Subramanian, 2005).

No caso mais geral das eqs. (3.31) e (3.32), o efeito $\alpha$ aparece como fonte das duas componentes do campo magnético, por essa razão um modelo de dínamo funcionando dessa forma é conhecido como dínamo $\alpha^{2} \Omega$. No entanto, é possível encontrar soluções da equação de indução para sistemas onde não existe uma componente de rotação diferencial (cisalhamento) em grande escala e o dínamo funciona exclusivamente devido aos coeficientes turbulentos. Esse tipo de modelo é conhecido como dínamo $\alpha^{2}$. Acredita-se que os dínamos que operam no interior dos planetas correspondem a esse tipo. Nos casos 
onde o cisalhamento em grande escala tem valores consideráveis, tal que $C_{\Omega}>>C_{\alpha}$ (como acontece na zona de convecção solar), o termo $\alpha$ na eq. (3.31) pode ser desprezado e as soluções resultantes são conhecidas como dínamo $\alpha \Omega$ (veja um esquema deste processo na Fig. 3.3). Neste último caso as equações de indução reduzem-se a:

$$
\begin{aligned}
\frac{\partial B}{\partial t} & =-\frac{1}{r}\left[\frac{\partial}{\partial r}\left[r u_{r} B\right]+\frac{\partial}{\partial \theta}\left[u_{\theta} B\right]\right]+r \sin \theta\left(\mathbf{B}_{p} \cdot \nabla\right) \Omega \\
& -\left[\nabla \eta_{T} \times\left(\nabla \times B \hat{e}_{\phi}\right)\right]_{\phi}+\eta_{T}\left(\nabla^{2}-\frac{1}{s^{2}}\right) B, \\
\frac{\partial A}{\partial t} & =-\frac{1}{s}\left[\mathbf{u}_{\mathbf{P}} \cdot \nabla\right](s A)+\eta_{T}\left(\nabla^{2}-\frac{1}{s^{2}}\right) A+\alpha_{\phi \phi} B,
\end{aligned}
$$

onde, para simplificar, desprezamos também os termos de bombeamento magnético (esses termos serão considerados novamente no Capítulo 6).

O objetivo final ao se resolverem as equações do dínamo acima é encontrar soluções periódicas das mesmas uma vez que os elementos do dínamo (discutidos abaixo) são considerados como conhecidos. Isto pode ser feito admintindo-se soluções da forma:

$$
\begin{aligned}
B(r, \theta, t) & =f_{B}(r, \theta) \exp (\lambda t) \\
A(r, \theta, t) & =f_{A}(r, \theta) \exp (\lambda t)
\end{aligned}
$$

onde $f_{B}$ e $f_{A}$ são auto-funções associadas aos auto-valores $\lambda$. A parte real das soluções, $\sigma=\operatorname{Re}(\lambda)$, corresponde a uma taxa de crescimento exponencial, e a parte imaginária, $\omega=\operatorname{Im}(\lambda)$, corresponde a uma freqüência de oscilação. As soluções onde $\sigma$ é menor, igual o maior que 0 são conhecidas como sub-críticas, críticas e super-críticas, respectivamente. O valor de $\sigma$ depende do valor do produto $C_{\Omega} C_{\alpha}$, conhecido como eficiência do dínamo (Brandenburg e Subramanian, 2005).

É também importante notar que as soluções do dínamo tipo $\alpha \Omega$ são ondulatórias, e que o sinal do produto $\alpha \nabla \Omega$ dá a direção de propagação da onda. Este comportamento foi inicialmente estudado por Parker (1955) e Yoshimura (1975), razão pela qual é conhecido como a regra do sinal de Parker-Yoshimura (PY). Tal regra manifesta que a onda dínamo se propaga através de superfícies de iso-rotação. Em sistemas onde o termo de cisalhamento tem componentes em mais de uma direção (como no caso da rotação diferencial do Sol) a sua forma geral pode ser escrita como:

$$
\operatorname{sign}\left(v_{p h}\right)=\alpha \nabla \Omega \times \hat{e}_{\phi}
$$


Na tabela 3.2 foram resumidas as direções de propagação da onda dínamo para diferentes configurações dos termos $\alpha$ e $\nabla \Omega$ em uma geometria esférica segundo a regra do sinal de PY.

\begin{tabular}{ccc|ccc}
\hline$\alpha$ & $\partial_{r} \Omega$ & Propagação da onda & $\alpha$ & $\partial_{\theta} \Omega$ & Propagação da onda \\
\hline+ & + & Polar & + & + & Ascendente \\
+ & - & Equatorial & + & - & Descendente \\
- & + & Equatorial & - & + & Descendente \\
- & - & Polar & - & - & Ascendente \\
\hline
\end{tabular}

Tabela 3.2 - Direção de propagação da onda dínamo para diferentes configurações de $\alpha$ e $\nabla \Omega$ segundo a regra do sinal de Parker-Yoshimura.

Acredita-se que a migração na direção equatorial das manchas solares observada nos diagramas de borboleta encontra-se relacionada à viagem de uma onda dínamo (Parker, 1955; Stix, 1976), ao mesmo tempo que a diferença de fase observada nas freqüências dos campos toroidal e poloidal é devida à diferença de fase das componentes das suas respectivas ondas. No entanto, o padrão de migração pode ser consideravelmente mais complexo quando são considerados perfis realistas da velocidade angular solar e do efeito $\alpha$, como será visto nos Capítulos 5, 6 e 7.

\subsection{Os ingredientes do dínamo}

Já se mostrou que o dínamo solar pode ser explicado como um modelo de dois passos: a transformação de um campo poloidal em um campo toroidal (efeito $\Omega$ ) e a reconstrução do campo poloidal, mas com polaridade oposta à inicial (através do efeito $\alpha$ ) (Fig. 3.3). Após a fase de crescimento dos campos magnéticos segue-se uma fase não-linear, na qual a ação indutiva dos dois processos acima é saturada, e o campo magnético decresce devido à difusividade magnética. Nesta seção vamos descrever os perfis destes diferentes processos, aqui denominados de ingredientes, usados nos principais modelos numéricos de dínamo. 


\subsubsection{Termo fonte do campo toroidal, efeito $\Omega$}

A partir da eq. (3.35) é claro que a fonte do campo toroidal depende dos gradientes da componente azimuthal do campo de velocidades, $\Omega$. Um perfil detalhado do padrão de velocidade angular no interior do Sol foi descrito em $§ 2.2 .2$. Um perfil analítico deste resultado obtido com héliossismologia (Brown et al., 1989; Goode et al., 1991) foi introduzido por Charbonneau e MacGregor (1997) e tem sido usado em vários modelos de dínamo (Dikpati e Charbonneau, 1999; Bonanno et al., 2002; Guerrero e Muñoz, 2004). Neste trabalho usaremos a mesma expressão usada por Dikpati e Charbonneau (1999):

$$
\Omega(r, \theta)=\Omega_{c}+\frac{1}{2}\left[1+\operatorname{erf}\left(2 \frac{r-R_{c}}{\omega_{1}}\right)\right]\left(\Omega_{s}(\theta)-\Omega_{c}\right),
$$

onde $\Omega_{c} / 2 \pi=432.8 \mathrm{nHz}$ é a velocidade angular uniforme (ou de corpo sólido) do caroço radiativo, $\Omega_{s}(\theta)=\Omega_{e q}+a_{2} \cos ^{2} \theta+a_{4} \cos ^{4} \theta$ é a rotação diferencial latitudinal na superfície tendo uma velocidade angular $\Omega_{e q} / 2 \pi=460.7 \mathrm{nHz}$ no equador, e onde $a_{2} / 2 \pi=-62.9 \mathrm{nHz}$ e $a_{4} / 2 \pi=-67.13 \mathrm{nHz}$. erf $(x)$ é uma função de erro que confina o cisalhamento radial à tacoclina ( $(2.2 .3)$ localizada em $R_{c}=0.7 R_{\odot}$ e de espessura $\omega_{1}$ (veja a imagem à esquerda da Fig. 3.4).
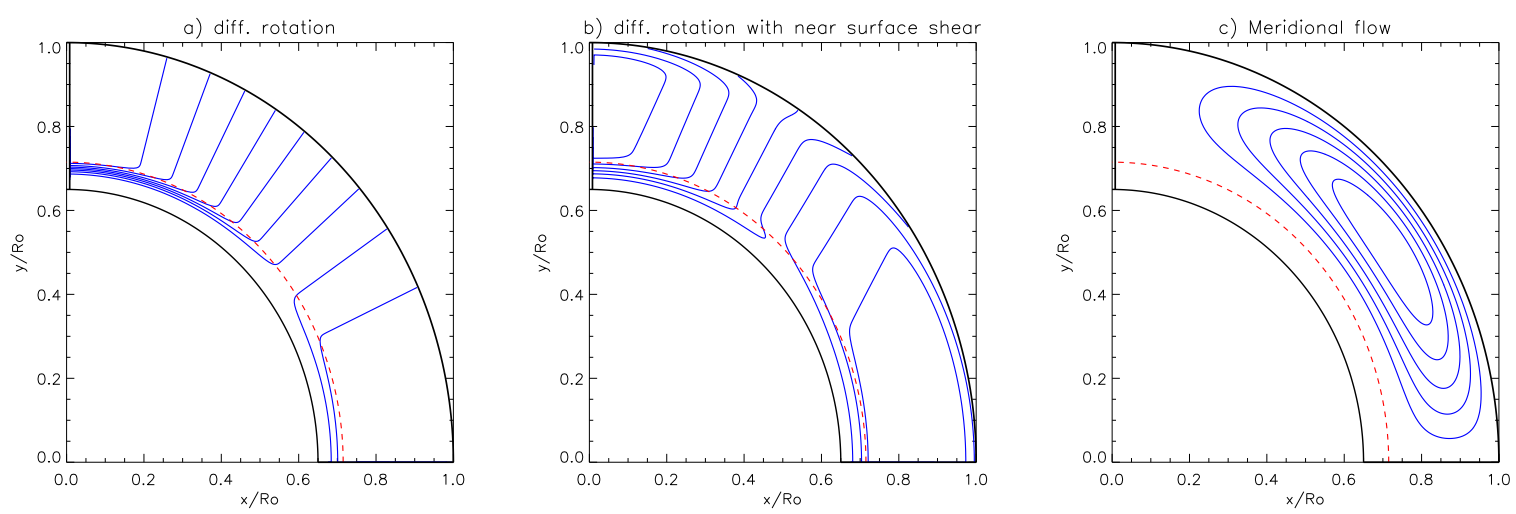

Figura 3.4: a) Modelo do perfil de rotação diferencial incluindo uma camada de cisalhamento radial na tacoclina e o perfil de cisalhamento latitudinal solar tal como é dado pela eq. eq. 3.40 ; b) perfil de rotação diferencial que inclui também a camada de cisalhamento radial próxima da superfície; e c) linhas de velocidade do fluxo meridional. A linha tracejada indica a posição do centro da camada de penetração (overshooting).

Como foi discutido em $\S 2.2 .3$, até o presente não há um consenso quanto à posição exata e a espessura da tacoclina (veja tabela 2.1). No Capítulo 5 iremos apresentar a 
influência destes parâmetros nos modelos de dínamo.

A eq. 3.40 não inclui a camada de cisalhamento superficial encontrada nas recentes inversões de héliossismologia de Corbard e Thompson (2002). Quando incorporamos essa camada ao perfil de rotação diferencial, a eq. (3.40) pode ser substituída por (e.g. Dikpati et al., 2002):

$$
\Omega(r, \mu)=A_{1}(r, \mu)+\phi_{t a c}(r)\left(\Omega_{c z}-\Omega_{0}+a_{2} \mu^{2}+a_{4} \mu^{4}\right)
$$

onde

$$
\begin{aligned}
A_{1}(r, \mu) & =\Omega_{0}+\phi_{c z}\left[\alpha(\mu)\left(r-r_{c z}\right)\right]+\phi_{r} \\
& \times\left[\Omega_{e q}-\Omega_{c z}-\beta(\mu)\left(r-R_{\odot}\right)-\alpha(\mu)\left(r-r_{c z}\right)\right] \\
\alpha(\mu) & =\frac{\Omega_{e q}-\Omega_{c z}+\beta(\mu)\left(R_{\odot}-r_{s}\right)}{r_{s}-r_{c z}} \\
\phi_{t a c(c z, s)} & =\frac{1}{2}\left\{1+\operatorname{erf}\left[\frac{2\left(r-r_{t a c(c z, s)}\right)}{w_{t a c}(c z, s)}\right]\right\}
\end{aligned}
$$

e onde $\Omega_{e q}=452.5 \mathrm{nHz}, \Omega_{0}=435 \mathrm{nHz}, r_{t a c}=0.69 R_{\odot}, r_{c z}=0.71 R_{\odot}, a_{2}=-61 \mathrm{nHz}, a_{4}=-73.5$ $\mathrm{nHz}, w_{t a c}=w_{c z}=w_{s}=0.05 R_{\odot}$ e $\beta=\beta_{0}+\beta_{6} \mu^{6}, \operatorname{com} \beta_{0}=437 \mathrm{nHz}, \beta_{6}=-1445 \mathrm{nHz}$ e $\mu=\cos \theta$. Uma representação gráfica deste perfil de $\Omega$ é mostrada no painel central da Fig. 3.4. Na tacoclina, ele apresenta o mesmo padrão de rotação diferencial da eq. (3.40), mas na superfície apresenta-se um novo cisalhamento positivo em latitudes próximas aos pólos e um cisalhamento negativo nas baixas latitudes. O perfil acima também será empregado nesta tese, como se verá adiante (Capítulo 6).

\subsubsection{Difusividade magnética}

O termo de difusividade magnética, $\eta_{T}$, nas eqs. (3.35) e (3.36), resulta da adição da difusividade Ohmica, $\eta$, com a difusividade turbulenta, $\beta$. A difusividade Ohmica é inversa à condutividade do plasma, $\sigma$, que pode ser estimada por:

$$
\sigma \sim \frac{\left(k_{B} T\right)^{3 / 2}}{m_{e}^{1 / 2} \pi Z e^{2} \ln \Lambda}
$$

onde só são consideradas as colisões entre elétrons e íons. Na eq. (3.45) $k_{B}$ é a constante de Boltzmann, $m_{e}$ é a massa dos elétrons, $Z$ é número de carga, e é a carga do elétron e $\ln \Lambda$ é o logarítmo de Coulomb, usualmente considerando no intervalo entre 5 e 20 em meios e sistemas Astrofísicos. De tal forma que uma estimativa aproximada de $\eta$ (considerando 
$\left.\eta=c^{2} / 4 \pi \sigma\right)$ é dada por:

$$
\eta=10^{4}\left(\frac{T}{10^{6} \mathrm{~K}}\right)^{-3 / 2}\left(\frac{\ln \Lambda}{20}\right) \mathrm{cm}^{2} \mathrm{~s}^{-1} .
$$

Como se pode notar $\eta$ depende unicamente da temperatura (grandes temperaturas significam grandes valores do caminho livre médio entre colisões, larga condutividade e, portanto, pequena difusividade). Esta assume na parte superior da zona de convecção (onde $T \sim 10^{4}$ K) $\eta \sim 10^{7} \mathrm{~cm}^{2} \mathrm{~s}^{-1}$, e na parte inferior da zona de convecção (onde $T \sim 10^{6} \mathrm{~K}$ ) $\eta \sim 10^{4} \mathrm{~cm}^{2} \mathrm{~s}^{-1}$.

Já o valor da difusividade turbulenta, $\beta$, é estimado através de técnicas analíticas como FOSA (first order smoothing approximation; veja p. ex., Krause e Raedler, 1980) ou MTA (minimal tau approximation; p. ex., Blackman e Field, 2002), as quais tentam calcular os coeficientes da força electromotriz, $\mathcal{E}$, assumindo que a turbulência é homogênea e isotrópica de tal forma que os tensores $\alpha$ e $\beta$ (veja eq. 3.28) são reduzidos a escalares. Na fase cinemática, na qual o campo magnético não é dinamicamente importante, verifica-se que (Krause e Raedler, 1980):

$$
\beta \simeq-\frac{1}{3} \tau \overline{\mathbf{u}^{2}}
$$

onde $\tau$ é o tempo de correlação dos movimentos turbulentos (ou tempo de turnover), ou seja, o tempo requerido para que estruturas de um tamanho determinado sofram mudanças significativas devido ao movimento relativo das suas componentes, e $\overline{\mathbf{u}^{2}}$ é a média do quadrado da componente flutuante da velocidade. Na maioria das vezes u é estimada a partir de modelos de comprimento de mistura na camada convectiva, os quais resultam em valores de $\beta$ entre $10^{11} \mathrm{~cm}^{2} \mathrm{~s}^{-1}$ e $10^{13} \mathrm{~cm}^{2} \mathrm{~s}^{-1}$ (logo, muito maiores que o valor de $\eta$ da eq. 3.46). Esses valores concordam com os observados de difusão do fluxo magnético na fotosfera, também conhecida como difusão supergranular (veja a tabela 6.2 de Schrijver e Zwaan, 2000).

A dependência radial da difusividade magnética é pouco conhecida no interior solar. Os movimentos turbulentos de fato existem pelo menos até a parte inferior da zona de convecção, porém a dependência da intensidade da turbulência com a profundidade é ainda incerta (veja, porém, o recente trabalho de Käpylä et al., 2008a), o que levou a que, em geral, somente valores aproximados da difusividade sejam adotados nos modelos de dínamo. O perfil mais comumente considerado é uma função de um degrau radial, separando o valor da difusividade no interior da zona de convecção, de um valor (Ohmico) 
da difusão na zona radiativa, como segue:

$$
\eta_{T}(r)=\eta_{r z}+\frac{\eta_{c z}}{2}\left[1+\operatorname{erf}\left(\frac{r-r_{c}}{d_{2}}\right)\right],
$$

onde $\eta_{r z}$ é o valor da difusividade microscópica (Ohmica) na camada radiativa. Um valor realista para essa quantidade deve estar entorno de $\leq 10^{5} \mathrm{~cm}^{2} \mathrm{~s}^{-1}$, no entanto, para não lidar com gradientes numéricos muito intensos, usualmente é considerado um valor de $10^{9} \mathrm{~cm}^{2} \mathrm{~s}^{-1}$ (veja o gráfico esquerdo da Fig. 3.5). Como o tempo de difusão é inversamente proporcional à difusividade magnética, considerar um valor maior de $\eta_{r z}$ ajuda a chegar-se no modelo numérico a um estado estacionário mais rapidamente sem, no entanto, afetar os resultados da evolução do dínamo na camada convectiva. A separação entre as zonas convectiva e radiativa acontece na camada conhecida como zona de penetração ou overshooting, localizada em $r_{c} \simeq 0.713$ e de espessura $d_{2} \simeq 0.01 R_{\odot}$ (Corbard et al., 2001). Como já foi dito, o valor inferido dos modelos de comprimento de mistura da difusividade turbulenta na zona convectiva, $\eta_{c z}=\beta$, encontra-se entre $\sim 10^{11} \mathrm{~cm}^{2} \mathrm{~s}^{-1}$ e $10^{14} \mathrm{~cm}^{2} \mathrm{~s}^{-1}$, contudo, como demonstraremos adiante, se valores maiores que $5 \times 10^{11} \mathrm{~cm}^{2} \mathrm{~s}^{-1}$ são considerados nos modelos numéricos para toda a camada convectiva, o período do ciclo magnético resultante é muito pequeno (veja §7.3.5). Por essa razão usualmente adota-se $\eta_{c z}=10^{11} \mathrm{~cm}^{2} \mathrm{~s}^{-1}$.
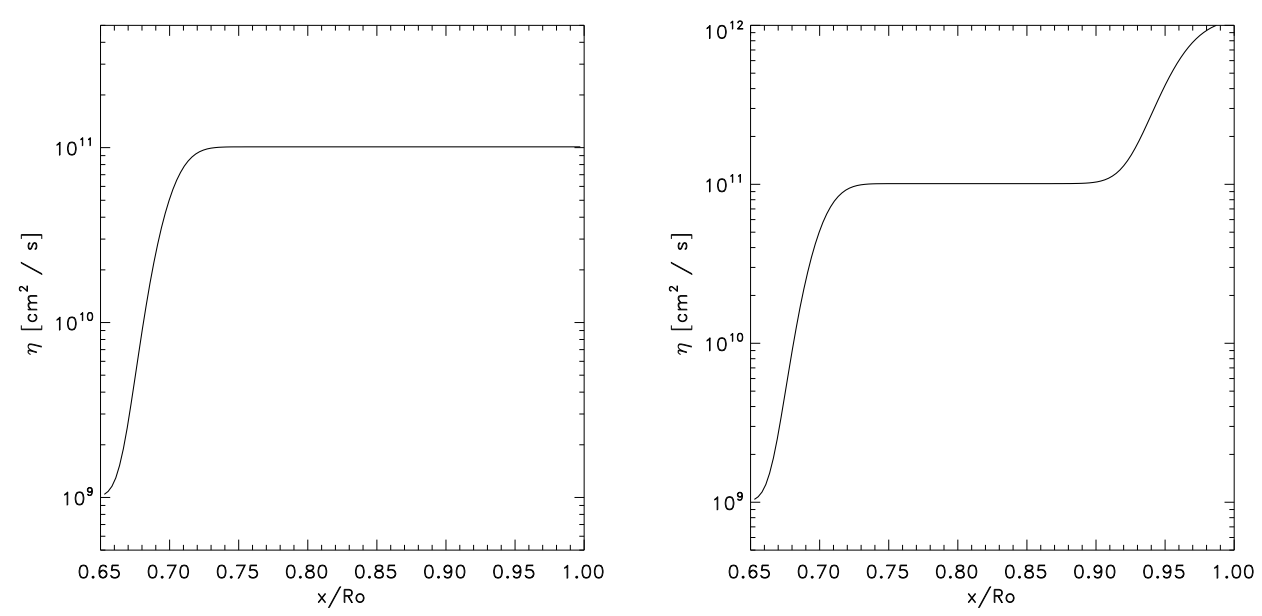

Figura 3.5: Perfis de difusividade magnética. O gráfico à esquerda apresenta um perfil tipo degrau separando as camadas convectiva e radiativa. O gráfico da direita apresenta um perfil com dois degraus.

Outra possibilidade, proposta por Dikpati et al. (2004), é considerar um perfil com dois degraus radiais, um deles separando as camadas convectiva e radiativa, como no caso 
acima, e outro, localizado em $r_{c 1}=0.95 R_{\odot}$, e com uma espessura de $d_{3}=0.05 R_{\odot}$ separando a zona de convecção das camadas superficiais supergranulares onde $\eta_{S}=10^{12} \mathrm{~cm}^{2} \mathrm{~s}^{-1}$ (veja gráfico direito da Fig. 3.5). A forma algébrica deste perfil é dada por:

$$
\eta(r)=\eta_{r z}+\frac{\eta_{c z}}{2}\left[1+\operatorname{erf}\left(\frac{r-r_{c}}{d_{2}}\right)\right]+\frac{\eta_{S}}{2}\left[1+\operatorname{erf}\left(\frac{r-r_{c 1}}{d_{3}}\right)\right] .
$$

A maior parte dos modelos numéricos é especialmente sensível à variação da difusividade entre o caroço radiativo e a zona convectiva, pois a quantidade de fluxo magnético que é capaz de penetrar na região estável (radiativa) depende da inclinação do perfil na transição entre essas duas camadas. Nesta tese ambos os perfis de difusividade acima descritos são empregados (veja os Caps. 5, 6 e 7.)

Na fase não-linear, quando o campo magnético alcança os valores máximos, entende-se que o nível da turbulência diminui, de tal forma que o valor da difusividade turbulenta deve ser amortecido. Os efeitos deste processo em um modelo de dínamo cinemático, são estudados no Capítulo 7.

\subsubsection{Fonte do campo poloidal: o efeito $\alpha$ turbulento}

A reconstrução do campo poloidal a partir de um campo toroidal, o efeito $\alpha$, é um processo pouco compreendido e tema de intensos debates e pesquisas. Devido a isso, várias hipóteses já foram formuladas para tentar explicar a natureza desse efeito. Uma delas é baseada na idéia de Parker de um mecanismo turbulento, no qual o campo poloidal é conseqüência de movimentos convectivos ciclônicos (helicoidais) que operam em pequenos tubos de fluxo magnético emergentes orientados na direção toroidal, os quais sofrem torções (ou twists). Esses pequenos loops devem reconectar-se rapidamente para formar um campo dipolar em grande escala.

Com argumentos similares àqueles usados para calcular a difusividade turbulenta, $\beta$, aproximações analíticas como FOSA ou MTA encontraram para o efeito $\alpha$ a seguinte relação (Krause e Raedler, 1980; Blackman e Field, 2002):

$$
\alpha=-\frac{1}{3} \tau \overline{\mathbf{u} \cdot w}
$$

onde $w=\nabla \times \mathbf{u}$ é a vorticidade e $\overline{\mathbf{u} \cdot w}$ é uma quantidade conhecida como helicidade cinématica, a qual, quando atua nas linhas de campo toroidal, induz um campo poloi- 
dal em concordância com a idéia de Parker. No entanto, os perfis radial e latitudinal de $\alpha$ não podem ser obtidos através das aproximações FOSA ou MTA.

O fato de o conhecimento sobre esse tema ser insuficiente obriga, em geral, a adoção de perfis analíticos de $\alpha$ em função de $r$ e $\theta$, de tal forma que os resultados dos modelos sejam capazes de reproduzir o melhor possível as observações. A seguinte equação resume algumas das várias possibilidades encontradas na literatura, um perfil auto-similar:

$$
\alpha(r, \theta)=\alpha_{0} \Lambda_{r}(r) \Lambda_{\theta}(\theta) f(\overline{\mathbf{B}})
$$

onde $\Lambda_{r}(r)$ e $\Lambda_{\theta}(\theta)$ são os perfis radial e latitudinal, respectivamente. A máxima amplitude do efeito $\alpha, \alpha_{0}$, é geralmente calculada considerando-se a ordem de magnitude dos coeficientes escalares na base da zona de convecção, no caso: $\alpha_{0} \sim \Omega \ell \sim 10^{3} \mathrm{~cm} \mathrm{~s}^{-1}$, onde $\Omega$ é a velocidade de rotação e $\ell \sim 10^{9} \mathrm{~cm}$ é a escala de comprimento característico dos turbilhões dominantes nessa região (Charbonneau, 2005).

Quando a energia magnética é comparável à energia dos movimentos turbulentos, o crescimento do campo poloidal deve saturar ao redor do valor de equipartição com o movimento turbulento $B_{e q} \simeq \sqrt{4 \pi \rho_{e}} \overline{\mathbf{u}}$. Esse efeito é levado em conta no termo:

$$
f(\overline{\mathbf{B}})=\frac{1}{1+\overline{\mathbf{B}}^{2} / B_{e q}^{2}},
$$

o qual embora tenha sido derivado empiricamente (Stix, 1972; Yoshimura, 1978b,a; Deluca e Gilman, 1986; Brandenburg et al., 1989), funciona da forma correta nos modelos de dínamo, fazendo-se $\alpha \rightarrow 0$, quando $B$ começa a se aproximar de $B_{e q}$.

A variação latitudinal vem sendo considerada por vários autores seguindo um perfil $\Lambda_{\theta}=\cos \theta$, já que esse é o perfil da variação da força de Coriolis, responsável pela helicidade (Choudhuri et al., 1995; Chatterjee et al., 2004). Outros autores tem usado $\Lambda_{\theta}=\cos \theta \sin ^{2} \theta$ (Küker et al., 2001), o qual tem uma amplitude máxima nas latitudes onde aparecem as manchas solares.

Por outro lado, a distribuição radial de $\alpha$ tem sido considerada com diferentes perfis que por sua vez têm dado lugar a diferentes modelos de dínamo turbulento. Nos próximos parágrafos iremos descrever esses modelos. 


\section{Dínamo distribuído (distributed dynamo)}

Nos modelos de dínamo distribuído, $\Lambda_{r}$ (i.e., o perfil radial do efeito $\alpha$ ) é distribuído ao longo de toda a zona de convecção. A sua variação é estimada a partir da velocidade flutuante $\overline{\mathbf{u}}$, que por sua vez é calculada em modelos de comprimento de mistura (Brandenburg e Tuominen, 1988). Mais recentemente, esse perfil vem sendo avaliado numericamente em simulações de magnetoconvecção (veja o Capítulo 8), a partir das quais são calculados os coeficientes do dínamo (Ossendrijver et al., 2001, 2002; Käpylä et al., 2006, 2008a). Em ambos os casos, o sinal de $\alpha$ resulta ser positivo no hemisfério norte (o sinal contrário da helicidade cinemática) e reverter-se ou cancelar-se na base da zona de convecção. Uma representação analítica simples deste perfil é dada por (veja Fig. 3.6):

$$
\Lambda_{r}(r)=\frac{1}{2}\left[1+\operatorname{erf}\left(\frac{r-r_{c}}{d_{2}}\right)\right] .
$$

Se $\alpha$ é positivo no hemisfério norte, considerando-se o sinal do cisalhamento radial na tacoclina (positivo nas baixas latitudes e negativo nas altas latitudes), segundo a regra do sinal de Parker-Yoshimura (PY), o campo magnético toroidal deveria migrar na direção equatorial nos pólos, e na direção polar no equador, ou seja, exatamente da forma contrária ao que é observado. Uma forma de resolver esse problema é considerar que o sinal de $\alpha$ se reverte abaixo da camada de overshooting, de tal forma que a migração do campo toroidal na tacoclina comporta-se de acordo com as observações. No interior da camada convectiva, onde a componente principal do cisalhamento é latitudinal e positiva, segundo a regra de PY a onda dínamo viaja em direção ascendente (veja a Tabela 3.2).

\section{Dínamo na camada de penetração (Overshoot dynamo)}

Outra possibilidade consiste em concentrar o efeito $\alpha$ ao redor da camada de penetração (ou de overshooting) (Ruediger e Brandenburg, 1995), com um perfil radial dado por:

$$
\Lambda_{r}(r)=\frac{1}{2}\left[1+\operatorname{erf}\left(\frac{r-r_{c}}{d_{2}}\right)\right]\left[1-\operatorname{erf}\left(\frac{r-r_{c 1}}{d_{2}}\right)\right] .
$$

onde $r_{c 1}$ é um parâmetro variável da ordem de $0.72 R_{\odot}$. Como $\alpha$ se encontra concentrado em uma camada de pequena espessura, a migração radial da onda dínamo estará restrita a um pequeno raio. Isto resulta na formação de um perfil magnético composto por várias ilhas de campo toroidal, cada uma delas com a polaridade oposta a das ilhas vizinhas. Ruediger 


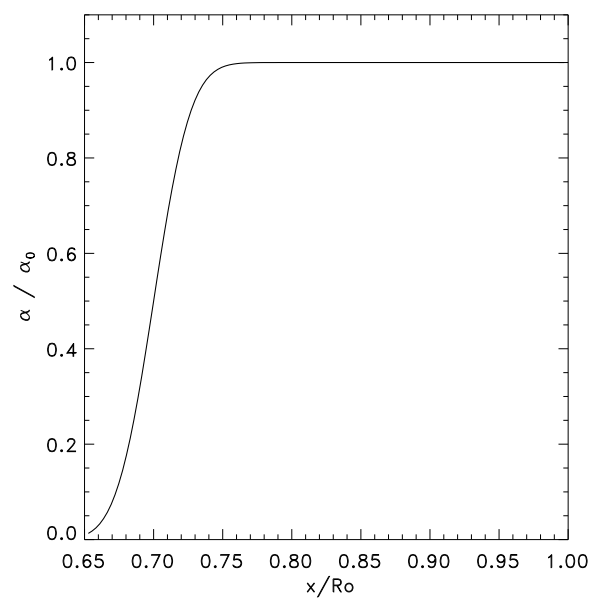

Figura 3.6: Perfil radial do termo $\alpha$ num modelo de dínamo distribuído. Os valores estão normalizados ao valor máximo $\alpha_{0}$.

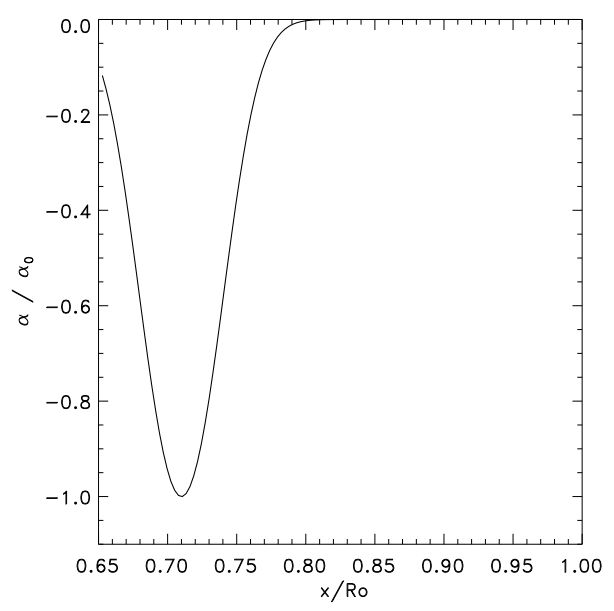

Figura 3.7: Perfil radial de $\alpha$ no modelo de dínamo na camada de penetração.

e Brandenburg (1995) utilizaram um efeito $\alpha$ com sinal negativo para obter a migração apropriada do campo magnético toroidal no interior dessa camada. Eles encontraram também que os seus resultados eram altamente sensíveis ao perfil de cisalhamento utilizado e à espessura da camada de penetração.

Os dois modelos descritos acima têm importantes limitações com respeito à natureza da fonte do campo poloidal. Por um lado, estimativas da ordem de grandeza mostram que se a energia mecânica da turbulência é transformada em energia magnética, os campos magnéticos resultantes seriam da ordem de $10^{3} \mathrm{G}$ (para $\overline{\mathbf{u}} \sim 10^{3} \mathrm{~cm} \mathrm{~s}^{-1}$ ). A tensão 
magnética associada às linhas de um campo magnético de tal magnitude é o suficientemente grande para resistir a deformação causada pelo efeito turbulento helicoidal, $\alpha$. Além disso Vainshtein e Cattaneo (1992) notaram que para grandes números de Reynolds (como no caso da zona de convecção solar, veja a Tabela 3.2), o campo magnético em pequena escala, b, se amplifica e alcança o valor de equipartição, mais rapidamente que a componente em grande escala, $\overline{\mathbf{B}}$. Neste caso, a eq. (3.52) não deve ser mais computada para o campo médio, mas sim para o campo em pequena escala, o qual resulta em:

$$
f(\overline{\mathbf{b}})=\frac{1}{1+\overline{\mathbf{b}^{2}} / B_{e q}^{2}},
$$

Como para grandes valores de $R m$, o campo magnético encontra-se aproximadamente congelado com o fluido, a compressão de um campo de larga escala num campo de pequena escala leva à razão $\overline{\mathbf{B}}^{2} / \overline{\mathbf{b}}^{2}=\mathrm{Rm}^{-1}$, a qual pode ser substituída na eq. (3.55) para obter:

$$
f(\overline{\mathbf{B}})=\frac{1}{1+\mathrm{Rm}_{\mathbf{B}^{2} / B_{e q}^{2}}},
$$

Neste caso para $R m>>0$, o valor de $\alpha$ é desprezível, mesmo para baixos valores de $\overline{\mathbf{B}}$, de tal forma que esse mecanismo resulta ser ineficaz para produzir campos magnéticos nas escalas observadas no Sol. Esse problema é conhecido como amortecimento catastrófico e foi verificado numericamente em simulações de magneto-convecção em pequenos domínios com fronteiras periódicas (Cattaneo e Hughes, 1996; Ossendrijver et al., 2001), nas quais observa-se (veja Fig. 3.8) que o decaimento de $\alpha$ como função de $B$ segue rigorosamente a eq. (3.56):

\section{Dínamo de interface (Interface dynamo)}

Nos modelos anteriores, as fontes das componentes toroidal e poloidal do campo magnético compartilham o mesmo espaço, o que significa que o crescimento do efeito $\alpha$ é catastroficamente saturado com o aumento da amplitude do campo toroidal nesses casos. Uma forma simples de resolver-se esse inconveniente foi proposta por Parker (1993) supondo que a principal fonte do campo toroidal estaria localizada na camada de cisalhamento radial (ou seja, na tacoclina), enquanto que a fonte de campo poloidal encontrar-se-ia afastada dessa região, de tal forma que ambas as regiões fonte estariam separadas por uma forte descontinuidade da difusividade magnética, isto é, uma descontinuidade no número de Reynolds 


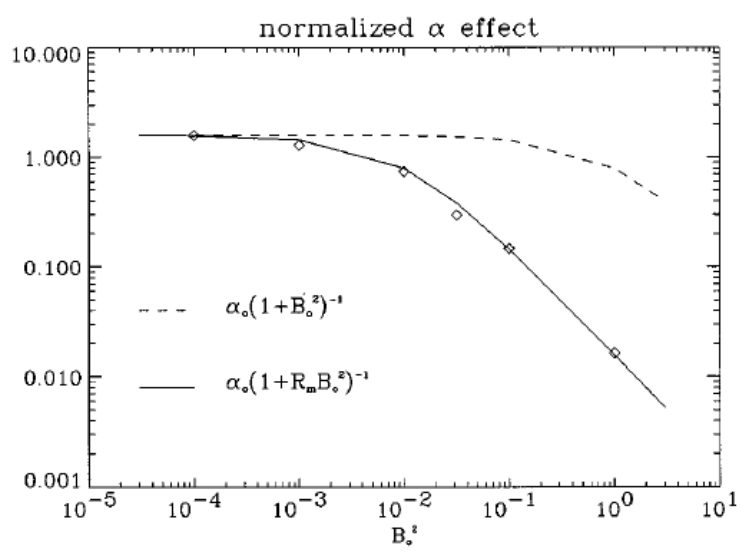

Figura 3.8: Valores normalizados do coeficiente $\alpha$ em função de um campo magnético inicial, $B_{0}$. As linhas tracejada e sólida representam as eqs. (3.52) e (3.56), respectivamente. Pode-se notar que a simulação reproduz o amortecimento catastrófico. (Figura extraída de Cattaneo e Hughes, 1996).

magnético (Charbonneau e MacGregor, 1996; Tobias, 1996). Estes modelos resultam em ondas de dínamo que viajam pela fronteira (ou interface) dessa descontinuidade. Modelos desse tipo funcionam relativamente bem em uma geometria cartesiana (Charbonneau e MacGregor, 1996; Tobias, 1996), pois fornecem a migração equatorial do campo magnético toroidal resolvendo, ao mesmo tempo, o problema do decaimento catastrófico do dínamo. Porém, em uma geometria esférica, esta classe de dínamo produz um comportamento oscilatório quando se considera unicamente o cisalhamento radial. Quando o cisalhamento latitudinal também é considerado, a solução não é mais oscilatória (Charbonneau e MacGregor, 1997; Markiel e Thomas, 1999).

\subsubsection{Modelos governados pelo transporte de fluxo magnético (flux transport dynamo models)}

Os modelos de dínamo discutidos acima não incluem nem o os termos advectivos, nem os termos compressivos das equações de indução (3.35) e (3.36), no entanto, como já foi discutido no Capítulo 2, a componente em grande escala do fluxo meridional existe de fato e foi observada nas camadas superiores da zona de convecção solar (Hathaway, 1996; Hathaway et al., 1996; Giles et al., 1997; Komm et al., 1993a; Braun e Fan, 1998). O fluxo meridional de retorno, que deve ocorrer nas camadas mais profundas, é mais difícil 
de se observar, inclusive pela héliossismologia. No entanto, considerando-se a conservação de massa é possível predizer um fluxo equatorial localizado na base da zona de convecção com uma velocidade de alguns metros por segundo, formando assim uma única célula de convecção por quadrante meridional. Simulações hidrodinâmicas em um domínio esférico global (Miesch et al., 2008), são compatíveis com essa aproximação para o fluxo meridional (veja acima §3.3).

Esse fluxo meridional tem sido modelado supondo-se um campo escalar de velocidades da forma (van Ballegooijen e Choudhuri, 1988; Holzwarth et al., 2006):

$$
\Psi=\frac{1}{r \sin \theta} R_{\odot}^{2} \rho_{e}(r) F(r) G(\theta)
$$

onde

$$
\begin{aligned}
F(r) & =\left(-\frac{1}{m+1}+\frac{c_{1}}{2 m+1} \zeta^{m}-\frac{c_{2}}{2 m+p+1} \zeta^{m+p}\right) \zeta \\
G(r) & =\sin ^{q+1} \theta \cos \theta
\end{aligned}
$$

tal que

$$
\rho \mathbf{u}_{p}=\nabla \times\left(\Psi \hat{e}_{\phi}\right)
$$

Assim, as componentes radial e latitudinal da velocidade meridional são dadas por:

$$
\begin{aligned}
u_{r}(r, \theta) & =U_{0}\left(\frac{R_{\odot}}{r}\right)^{2} \times\left[-\frac{1}{m+1}+\frac{c_{1}}{2 m+1} \zeta^{m}-\frac{c_{2}}{2 m+p+1} \zeta^{m+p}\right] \\
& \times \zeta \sin ^{q} \theta\left[(q+2) \cos ^{2} \theta-\sin ^{2} \theta\right] \\
u_{\theta}(r, \theta) & =U_{0}\left(\frac{R_{\odot}}{r}\right)^{3}\left[-1+c_{1} \zeta^{m}-c_{2} \zeta^{m+p}\right] \sin ^{q+1} \theta \cos \theta,
\end{aligned}
$$

onde

$$
\begin{aligned}
c_{1} & =\frac{(2 m+1)(m+p)}{(m+1) p} \zeta_{b}^{-m}, \\
c_{2} & =\frac{(2 m+p+1) m}{(m+1) p} \zeta_{b}^{m+p}, \\
\zeta(r) & =\frac{R_{\odot}}{r}-1, \\
\zeta_{b}(r) & =\frac{R_{\odot}}{r_{p}}-1,
\end{aligned}
$$

a amplitude máxima do fluxo meridional é definida por $U_{0}$ e a profundidade de penetração desse fluxo é definida pelo parâmetro $r_{p}$. Os perfis latitudinais são determinados pelos valores de $m, p$ e $q$. Nas simulações que apresentaremos nos capítulos seguintes, consideramos os valores usados por Dikpati e Charbonneau (1999), $m=0.5, p=0.25$ e $q=0$. 
Algumas formulações diferentes foram consideradas na literatura para a função de corrente $\Psi$ (Dikpati e Choudhuri, 1995; Jouve et al., 2008; Nandy e Choudhuri, 2001). Elas diferem ligeiramente da função dada pelas eqs. (3.57), (3.58) e (3.59), mas apresentam o mesmo padrão em grande escala.

Em modelos de dínamo como aqueles descritos acima, os quais consideram um efeito $\alpha$ turbulento, a circulação meridional é importante para transportar o fluxo magnético e gerar os perfis migratórios observados, sem a necessidade de que o sistema obedeça à regra de Parker-Yoshimura. Isto significa que o sinal do efeito $\alpha$ não seria tão importante, já que o sentido da migração é o resultado da comparação entre a velocidade da onda de dínamo e a velocidade de circulação (Choudhuri et al., 1995). Porém, para que a direção do fluxo meridional seja dominante é necessário que o sistema obedeça a uma restrição física: o tempo de advecção, $\ell / U$, deve dominar sobre o tempo de difusão, $\ell^{2} / \eta$, ou em outras palavras, o número de Reynolds magnético da velocidade de circulação, $C_{U}=\frac{U \ell}{\eta_{T}}$, deve ser $>>1$. Na base da zona de convecção, onde $\ell \sim 0.3 R_{\odot}$ e $U \sim 100$ $\mathrm{cm} \mathrm{s}^{-1}$, considerando-se um número de Reynolds magnético de, por exemplo, $\sim 10$, um dínamo dominado pelo transporte do fluxo requer que $\eta_{T} \leq 2 \times 10^{11} \mathrm{~cm}^{2} \mathrm{~s}^{-1}$, i.e., um valor aproximadamente uma a duas ordens de grandeza menor que o valor esperado para a difusividade turbulenta no interior da camada convectiva (veja §3.7.2). No entanto, devese notar que $\eta_{T}=10^{11} \mathrm{~cm}^{2} \mathrm{~s}^{-1}$ é ainda um valor consideravelmente maior que a viscosidade magnética Ohmica da ordem de $\sim 10^{4} \mathrm{~cm}^{2} \mathrm{~s}^{-1}$ (Charbonneau, 2007).

Nos modelos que incluem o fluxo meridional, as fontes dos campos toroidal e poloidal podem estar separadas espacialmente já que a circulação age como um mecanismo transportador (conveyor belt) que leva o fluxo magnético de um lugar a outro. Usualmente, esses modelos concentram o efeito $\alpha$ nas camadas superiores da zona de convecção (Choudhuri et al., 1995; Küker et al., 2001), no entanto Bonanno et al. (2002) consideraram também o efeito $\alpha$ distribuído em toda a zona de convecção (como no caso do dínamo distribuído), ou concentrado unicamente na camada de overshoot (como no caso do dínamo na camada de penetração), com o fim de estudar os efeitos do local e espessura do perfil radial de $\alpha$ na paridade das soluções do modelo. Eles encontraram que um efeito $\alpha$ concentrado próximo da superfície, ou distribuído na zona convectiva, tem a tendência de produzir soluções simétricas ao redor do equador (ou seja, a polaridade do campo magnético toroi- 
dal é a mesma nos dois hemisférios), em desacordo com as observações. Por outro lado, os dínamos operando na camada de overshoot, incluindo circulação meridional, resultam soluções com a paridade anti-simétrica apropriada.

Também vêm sendo estudados modelos de dínamo que incluem perfis de circulação meridional que apresentam mais de uma célula de convecção em cada hemisfério (Bonanno et al., 2006; Jouve e Brun, 2007), contudo esses modelos resultam diagramas de borboleta que não concordam com o observado.

\subsubsection{O papel da helicidade magnética em modelos de dínamo turbulento}

Utilizando soluções aproximadas das equações MHD, Pouquet et al. (1976) mostraram que a força electromotriz não depende somente da helicidade cinemática, como na eq. (3.50), mas também da helicidade magnética, $h_{m}=A \cdot B$. A segunda, ao contrário da primeira, é uma quantidade conservativa em magnetohidrodinâmica. Pouquet et al. (1976) verificaram que na fase não-linear, a helicidade magnética em grande escala aumenta e transfere energia das pequenas para as grandes escalas em um processo de cascateamento turbulento inverso. Porém, ao mesmo tempo, para conservar o seu valor total, a helicidade magnética em pequena escala aumenta, mas com o sinal contrário, o que finalmente leva à saturação do crescimento do campo magnético. Estudos recentes da fase não-linear do processo de dínamo (Blackman e Field, 2001; Field e Blackman, 2002; Blackman e Field, 2002), recuperaram esse resultado e mostraram que o amortecimento catastrófico de $\alpha$ da eq. (3.56) acontece unicamente no caso estacionário e em domínios periódicos (ou infinitos). Já quando a força electromotriz é avaliada consistentemente num domínio com fronteiras finitas, ela não é amortecida de forma catastrófica e permite a amplificação do campo magnético até valores próximos do valor de equipartição de energia.

Brandenburg (2001) demonstrou esse resultado através de simulações numéricas tridimensionais de um fluido com turbulência helicoidal forçada. Ele verificou que condições de contorno periódicas saturam rapidamente o crescimento do campo magnético. Já fronteiras abertas (que permitem um fluxo finito de helicidade magnética em pequena escala para o exterior do domínio) facilitam o crescimento do campo em grande escala.

Em objetos Astrofísicos reais, acredita-se que o fluxo de helicidade magnética em pequena escala escapa de forma significativa através das fronteiras externas de tais objetos. 
No caso das estrelas, isso pode ocorrer através das ejeções de massa coronal. Em escalas galácticas, pode ocorrer através de ventos (veja uma revisão completa deste tema em Brandenburg e Subramanian, 2005).

Esses resultados recentes podem levar, possivelmente, a uma nova mudança de paradigma na explicação do processo de dínamo solar, revivendo o cenário de dínamo turbulento. Porém, esses resultados são ainda controversos. Não obstante, a possibilidade de se gerar campo magnético médio (i.e. em grande escala) em uma região turbulenta convectiva será examinada no Capítulo 8.

\subsubsection{Outras fontes de campo poloidal}

Os problemas teóricos relacionados ao efeito $\alpha$ turbulento, têm levado à procura de outras fontes possíveis de campo magnético poloidal no interior solar. De fato, é possível que diferentes fontes possam estar agindo ao mesmo tempo e provavelmente em diferentes escalas. Como as propriedades magnéticas observadas correspondem a um campo magnético em grande escala, as fontes que contribuem nessa escala devem ter maior importância para os objetivos do presente estudo.

Outras fontes do efeito $\alpha$ estão relacionadas a instabilidades que se desenvolvem nos tubos de campo magnético toroidal depositados em algum ponto abaixo da base da zona de convecção. Ferriz-Mas et al. (1994) encontraram que ondas desenvolvendo-se ao longo desses tubos têm a capacidade de induzir uma força electromotriz azimuthal, $\langle u \times b\rangle_{\phi}$, que por sua vez pode gerar um efeito $\alpha$. Ferriz-Mas et al. (1994) estudaram as latitudes nas quais essas perturbações se desenvolvem com maior facilidade em tubos de fluxo com magnitudes entre 60-150 kG. Essas regiões foram identificadas em diagramas de estabilidade, como os apresentados na Fig. 3.9, para diferentes localizações radiais dos tubos de fluxo. Como se pode observar, as instabilidades nos tubos de fluxo acontecem preferencialmente nas baixas latitudes, assim, essa fonte de campo poloidal é um mecanismo natural para explicar o desenvolvimento da atividade solar nessas latitudes. Com base nesse resultado foram feitas algumas poucas tentativas para incluir esse mecanismo fonte do efeito $\alpha \mathrm{em}$ modelos de dínamo de campo médio (Schmitt et al., 1996; Ossendrijver, 2000). Porém, a migração encontrada nas ramificações magnéticas resultou ser em direção aos pólos, já que o sinal deste efeito $\alpha$ é positivo (negativo) no hemisfério norte (sul). 

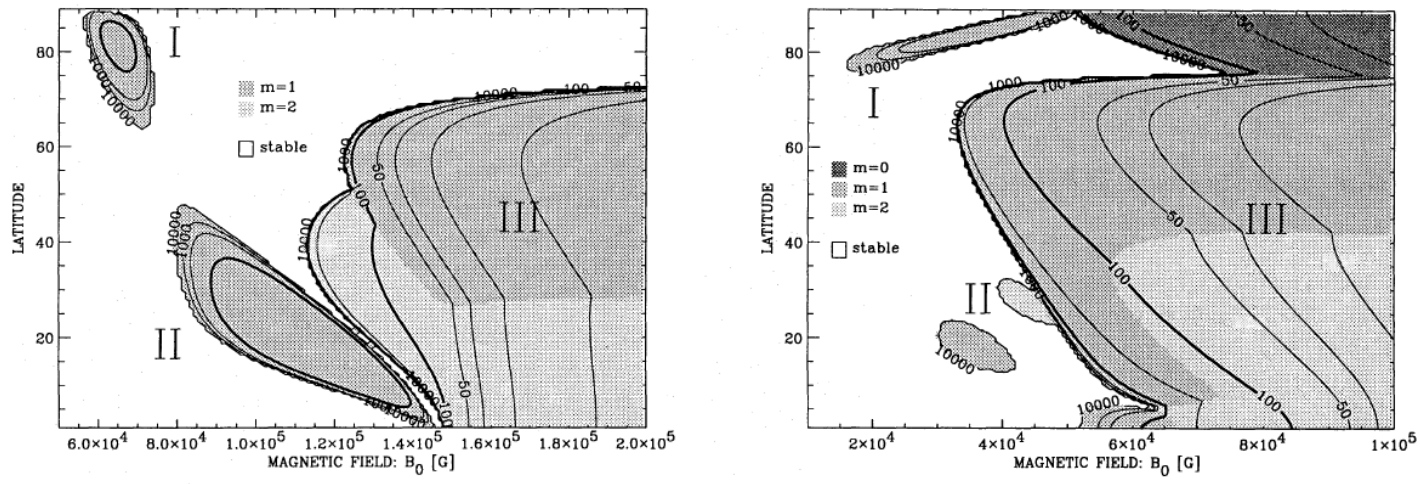

Figura 3.9: Regiões de estabilidade no plano latitude - amplitude do campo magnético, para tubos de fluxo em equilíbrio localizados nas camadas inferiores (esquerda) e superiores da da zona de overshoot. A região branca corresponde a tubos de fluxo estáveis e as regiões cinzas indicam instabilidades em diferentes modos. (Figura adaptada de Ferriz-Mas et al., 1994).

Uma aproximação diferente ao efeito $\alpha$ foi proposta por Dikpati e Gilman (2001a) que calcularam a instabilidade hidrodinâmica global da rotação diferencial na tacoclina. Esta deve-se à grande extensão latitudinal quando comparada à espessura radial, o que permite a formação de instabilidades de superfície como em águas rasas (shallow water). Dikpati e Gilman (2001a) verificaram que os modos normais instáveis propagam-se em longitude criando vários vórtices que por sua vez produzem uma helicidade cinemática liquida e assim um efeito $\alpha$.

De forma similar ao efeito $\alpha$ calculado através de aproximações de primeira ordem da teoria de campo médio (FOSA ou MTA), neste caso também considera-se que $\alpha$ tem o sinal oposto à helicidade cinemática, com o qual Dikpati e Gilman (2001a) encontram que $\alpha$ é positivo em latitudes intermediárias, e negativo nos pólos, resultando assim numa migração das ramificações dos campos magnéticos contrária à solar. Eles resolvem esse problema incluindo a circulação meridional em seu modelo de dínamo. Esta fonte de campo poloidal é uma interessante alternativa para se tentar resolver o problema do dínamo solar, no entanto, nos cálculos da instabilidade Dikpati e Gilman (2001a) não consideram os efeitos dos campos magnéticos. Vários outros trabalhos que estudaram essas instabilidades do ponto de vista MHD foram recentemente publicados (Dikpati et al., 2003; Cally et al., 2003; Arlt et al., 2007), porém até o momento não existe uma nova proposta de efeito $\alpha$ a partir desses trabalhos. 
Finalmente, outra forma possível de se reconstruir o campo poloidal é baseada nas idéias de Babcock (1961) e Leighton (1964) (BL), segundo os quais o decaimento randômico das regiões bipolares (BMRs) inclinadas é capaz de neutralizar o campo poloidal existente e substituí-lo por um novo campo com polaridade oposta. Essa proposta de modelo foi esquecida por vários anos, durante o período de ouro da teoria de dínamo de campo médio, mas, em vista das incertezas com o efeito $\alpha$ turbulento, foi recentemente recuperada e demonstrou ser eficaz o suficiente para descrever e reproduzir as observações solares.

Como os resultados desta tese se referem a modelos que seguem esse mecanismo, dedicaremos a seguinte seção a descrever em detalhe o modelo de dínamo de BL, assim como os resultados mais importantes obtidos com esse modelo e os inconvenientes que ele apresenta, discutidos atualmente na literatura.

\subsection{Modelo de dínamo de Babcock-Leighton}

O modelo de dínamo de Babcock-Leighton não é unicamente um formalismo que explica a formação da componente poloidal do campo magnético, mas oferece um cenário fenomenológico completo para explicar o ciclo magnético solar. Seguindo Babcock (1961), o ciclo completo pode descrever-se em cinco passos, partindo de um campo magnético dipolar.

1. Efeito $\Omega$ : da mesma forma que nos modelos de dínamo descritos acima, o campo magnético toroidal neste caso é formado pelo esticamento das linhas do campo dipolar difuso, devido à rotação diferencial, acontecendo em algum local no interior da zona de convecção.

2. Formação e emergência de tubos de fluxo: acredita-se que o campo magnético toroidal coalesça na forma de tubos de fluxo altamente intermitentes. Estes são pacotes de linhas de campo magnético contendo uma quantidade fixa de fluxo magnético e separados de seu meio ambiente menos magnetizado por uma interface estreita (Schüssler, 2005). Os tubos de fluxo formados no meio da zona convectiva são altamente instáveis à ação das forças de empuxo e rapidamente começam a emergir à superfície ainda com baixas magnitudes. Porém, espera-se que esses tubos de fluxo toroidal sejam torcidos (twisted) pela força de Coriolis durante a sua emergência até 
a superfície, onde devem formar regiões bipolares obedecendo à lei de Joy. Estudos numéricos da emergência de tubos de fluxo (D'Silva e Choudhuri, 1993; Fan et al., 1993; Caligari et al., 1995, 1998; Fan e Fisher, 1996) têm mostrado que tanto a latitude, quanto o ângulo de inclinação apropriados são obtidos para tubos de fluxo com intensidades entre $5 \times 10^{4}$ e $10^{5} \mathrm{G}$, os quais emergem da base da zona de convecção. Recentemente, outras simulações mais elaboradas (Fan, 2008) mostraram que as linhas de campo magnético de um tubo de fluxo precisam ter uma certa taxa de enrolamento para que o tubo possa emergir à superfície sem perder a coesão. Fan (2008) encontrou também que a força de Coriolis opera de forma assimétrica sobre o tubo de fluxo, de tal forma que as partes principal e secundária de uma região bipolar ativa terminam com diferentes intensidades de campo, em boa concordância com as observações (veja o Capítulo 2) ${ }^{1}$.

3. Decaimento difusivo das BMRs (efeito $\alpha$ de $B L$ ): no modelo de BL, a fonte de campo poloidal vem da inclinação existente entre as partes principal e secundária das BMRs. Enquanto o ciclo avança, a difusão supergranular (turbulenta) faz uma região bipolar magnética decair, empurrando a parte principal na direção do equador e a parte secundária em direção aos pólos. Esse processo amplifica um novo campo poloidal que finalmente destrói o campo poloidal do ciclo anterior. A parametrização matemática deste efeito é apresentada em $§ 3.8 .1$.

4. Transporte do fluxo do novo campo poloidal: como o decaimento difusivo das BMRs acontece na superfície e nas latitudes de emergência das manchas (sempre $\leq 30^{\circ}$ ), é necessária a presença de um mecanismo de transporte capaz de conduzir o fluxo de campo poloidal às altas latitudes para formar o campo magnético polar observado. A circulação meridional, com uma única célula convectiva em cada hemisfério, é aparentemente o mecanismo mais atraente e simples para desempenhar essa função, embora até o presente ainda não disponhamos de nenhuma evidência observacional

\footnotetext{
${ }^{1}$ Além do Sol, a idéia da emergência de tubos de fluxo foi aplicada a outras estrelas de tipo solar, i.e., contendo um caroço radiativo circundado por uma camada convectiva. Esta idéia é bastante satisfatória para explicar a distribuição de manchas em estrelas de diferentes idades, taxas de rotação e profundidade da camada convectiva (Schuessler et al., 1996; Granzer et al., 2000), bem como as grandes manchas estelares que aparecem nas regiões polares de estrelas com alta taxa de rotação (Schuessler e Solanki, 1992)
} 
direta desse fluxo nas camadas inferiores da zona de convecção, como destacado anteriormente. Contudo, os mapas sinóticos do campo magnético fotosférico tomados durante os ciclos 21 e 22 constituem uma boa evidência de que a inversão do campo poloidal superficial é governada pelo decaimento difusivo das BMRs e que o campo polar é formado pela migração para os pólos de uma fração desse campo (veja p.ex. a Figura 1 de Wang et al., 1989). Além disso, simulações numéricas unidimensionais da evolução do campo poloidal confirmaram que o fluxo meridional (de $\sim 10 \mathrm{~m} \mathrm{~s}^{-1}$ ) é capaz de transportar tal fluxo magnético e formar o campo polar (Wang e Sheeley, 1991; Wang et al., 1991).

5. O último passo consiste em transportar esse campo polar à base da zona de convecção onde se formarão os tubos de fluxo toroidais do novo ciclo, fechando assim o ciclo do dínamo. O principal mecanismo de transporte nessa fase é novamente o fluxo meridional, que, como foi encontrado por Dikpati e Charbonneau (1999), parece ser o parâmetro mais importante na determinação do período do ciclo. No entanto, como discutiremos no Capítulo 6, os efeitos do transporte turbulento (ou turbulent pumping), i.e., o termo $\gamma$ nas eqs. (3.31) e (3.32), também podem agir de forma importante nesse processo.

\subsubsection{Formulação matemática do termo fonte do modelo de Babcock-Leighton}

Com o fim de parametrizar o mecanismo fonte do campo poloidal no modelo de BL, é necessário representar matematicamente a emergência flutuante dos tubos de fluxo magnético, tal como descrito no passo 3 acima. Uma forma de se considerar esse efeito é usando um termo $\alpha$ não-local como segue:

$$
\alpha_{B L}(r, \theta, B)=\Lambda_{r}(r) \Lambda_{\theta}(\theta) f\left(B_{r_{c}}\right)
$$

onde para $\Lambda_{\theta}$, podem ser usados os perfis $\cos \theta$ ou $\cos \theta \sin ^{2} \theta$ e, assumindo-se que a formação do campo poloidal acontece nas camadas superiores do Sol, $\Lambda_{r}$ é concentrado nas camadas fotosféricas, assim:

$$
\Lambda_{r}(r)=\frac{1}{2}\left[1+\operatorname{erf}\left(\frac{r-r_{s 1}}{d_{2}}\right)\right]\left[1-\operatorname{erf}\left(\frac{r-r_{s 2}}{d_{2}}\right)\right],
$$


com $r_{s 1}=0.95 R_{\odot}$ e $r_{s 2}=0.98 R_{\odot}$. O termo de saturação, $f\left(B_{r_{b c}}\right)$, tem a mesma forma que na eq. (3.52), mas depende do valor de $B$ na base da zona de convecção, $B\left(r_{b c}\right)$ :

$$
f\left(B_{r_{b c}}\right)=\frac{1}{1+\frac{B\left(r_{b c}\right)^{2}}{B_{0}^{2}}} .
$$

É possível considerar também uma média radial em torno de $r_{b c}$.

Como iremos discutir em detalhe em $\S 7.3 .1$, o valor $B_{0}$ na última equação não corresponde exatamente ao valor de equipartição de energia entre o campo magnético e o movimento do fluido (como na eq. 3.52). Ao invés disso, ele é tomado como um artefacto numérico que permite limitar o crescimento do campo toroidal aos valores que nos interessam para os tubos de fluxo, ou seja entre $10^{4}$ e $10^{5} \mathrm{G}$. Isto nos garante que iremos transportar numericamente tubos de fluxo das amplitudes certas desde a base da camada de convecção até a fotosfera. Utilizar essa não-localidade no termo $\alpha$ é considerado, às vezes, como uma aproximação inapropriada que pode afetar a operação do dínamo. Porém, esse não é o caso já que enquanto as inversões de polaridade acontecem a cada 11 anos, as simulações de tubos de fluxo (veja por exemplo Fan, 2008) indicam que a emergência dos mesmos acontece em apenas alguns dias.

\subsubsection{Problemas dos modelos de dínamo de $B L$}

Vários grupos de pesquisa têm modelado o dínamo solar considerando o mecanismo de BL com o fim de reproduzir a evolução dos campos poloidais na superfície (Wang et al., 1991), considerando unicamente o cisalhamento radial na tacoclina (Durney, 1995, 1996, 1997), ou ainda perfis realistas da rotação diferencial e do fluxo meridional (Dikpati e Charbonneau, 1999; Nandy e Choudhuri, 2001; Guerrero e Muñoz, 2004). Esses modelos têm sido relativamente bem sucedidos ao produzir diagramas de borboleta teóricos bastante realistas, no entanto, eles apresentam vários problemas os quais vêm sendo discutidos na literatura (Brandenburg, 2005; Charbonneau, 2007). Podemos resumir essas limitações como segue:

1. Onde funciona o dínamo? É necessário que os tubos de fluxo magnético na base da zona de convecção sejam da ordem de $10^{5} \mathrm{G}$ a fim de que a sua emergência à superfície tenha a magnitude e a inclinação apropriadas (Choudhuri, 2003; Schüssler, 
2005; Gilman e Rempel, 2005). Um cálculo simples, considerando-se o termo de esticamento na equação de indução,

$$
B \simeq r \sin \theta\left(\mathbf{B}_{p} \cdot \nabla\right) \Omega
$$

permite estimar o campo toroidal resultante na tacoclina, onde o cisalhamento é predominantemente radial, assim:

$$
B \simeq r \sin \theta B_{r} \frac{\nabla \Omega}{\nabla r} \tau
$$

onde $\tau$ é um tempo característico desse esticamento. O campo poloidal observado, o qual será a semente do campo toroidal, é da ordem de 10 G. A partir do valor do perfil de rotação diferencial para a velocidade angular do caroço radiativo, $\Omega_{c} / 2 \pi=432.8$ $\mathrm{nHz}$, e a velocidade angular na parte superior da tacoclina, $\Omega_{e q} / 2 \pi=460.7 \mathrm{nHz}$, considerando-se uma espessura da tacoclina da ordem de $\omega_{1} \sim 0.05 R_{\odot}$, e assumindo que o termo $r \sin \theta \sim 0.7 R_{\odot}$, temos $(r \sin \theta) \Delta \Omega \sim 122.5 R_{\odot} \mathrm{nHz}$, e $\Delta r \sim 0.04 R_{\odot}$. Logo, considerando-se que os tubos de fluxo são amplificados durante $\tau \sim 10$ anos, obtemos:

$$
B \sim 10^{4} \mathrm{G} \quad .
$$

Embora esse valor seja otimista, pois supusemos que toda a energia mecânica é convertida em energia magnética, os tubos de fluxo com tal intensidade não são capazes de emergir à fotosfera com a inclinação e coerência observadas. Dessa forma, espera-se que algum outro mecanismo esteja contribuindo para a amplificação desses campos magnéticos (Gilman e Rempel, 2005) ou que, talvez, o local onde opera o dínamo não seja a base da zona de convecção (Brandenburg, 2005).

2. Como se explicam as latitudes onde se observa a atividade Solar? Na tacoclina, o cisalhamento radial se estende a todas as latitudes, no entanto, o termo $\nabla \Omega$ é maior nos pólos do que no equador. Por essa razão os modelos de dínamo solar que incluem um perfil realista da rotação diferencial obtêm resultados com intensos campos magnéticos nas altas latitudes (Choudhuri et al., 1995; Dikpati e Charbonneau, 1999; Nandy e Choudhuri, 2001; Jouve e Brun, 2007), contradizendo as observações.

3. Porque a paridade do campo solar é assimétrica? Os modelos de dínamo dominados pelo transporte do fluxo (ou dínamos dominados pela advecção) e que consideram 
o efeito $\alpha$ concentrado nas camadas mais externas do Sol, resultam diagramas de borboleta com paridade simétrica do campo magnético toroidal ao invés da antisimetria observada (Dikpati e Gilman, 2001a; Bonanno et al., 2002; Chatterjee et al., 2004; Charbonneau, 2007).

4. Qual o verdadeiro papel do fluxo meridional e qual é o valor da difusividade? Como os modelos dominados pelo transporte de fluxo requerem que o sistema esteja no regime advectivo, é necessário considerar valores $\leq 2 \times 10^{11} \mathrm{~cm}^{2} \mathrm{~s}^{-1}$ para a difusividade turbulenta no centro da zona de convecção (como vimos). Esses valores são uma a duas ordens de grandeza menores do que os valores observados para difusão supergranular (Veja valores e referências na Tabela 6.2 de Schrijver e Zwaan, 2000) e do que os valores obtidos em simulações de fluidos turbulentos (Yousef et al., 2003). Por outro lado, os modelos no regime difusivo resultam em períodos muito curtos comparados com o período do ciclo solar.

Várias propostas têm sido feitas na tentativa de encontrar respostas consistentes aos problemas acima. Nos capítulos 5-7 discutiremos com maior detalhe cada um desses problemas, revisando as possíveis soluções propostas na literatura e apresentando soluções alternativas para esses problemas. Mas, antes disso, no próximo Capítulo apresentamos os detalhes da construção do modelo computacional de dínamo de campo médio construído nesta tese, incluindo-se os métodos numéricos e as condições iniciais e de fronteira. 
Capítulo 4

\section{Construção do modelo computacional}

A evolução do campo magnético no interior de um plasma é dada pelas eqs. (3.31) e (3.32), as quais são equações diferenciais parciais acopladas com termos de advecção e difusão. A construção de um modelo computacional de dínamo solar na aproximação cinemática consiste em levar essas equações a uma forma discreta que permita encontrar uma solução numérica das variáveis $B$ e $A$, nas coordenadas $\theta$ e $r$, e então acompanhar a evolução temporal dessas variáveis. As outras quantidades físicas que aparecem nas equações, como $\mathbf{u}_{p}, \Omega, \eta$ e $\alpha$ são consideradas como conhecidas a priori. O primeiro que deve ser feito é escrever-se eqs. (3.31) e (3.32) em uma forma adimensional para evitar considerar valores numéricos muito grandes ou muito pequenos. Para isso assumimos que cada quantidade física é igual a um valor característico multiplicado por um valor numérico. Por exemplo, para a coordenada radial temos que $r=r_{0} r^{\prime}$, onde $r$ é o valor da variável em unidades físicas, $r_{0}$ é um comprimento característico do sistema, também em unidades físicas, e $r^{\prime}$ é um valor numérico adimensional. Fazendo isto para todas as quantidades, as equações (3.31) e (3.32) ficam:

$$
\begin{aligned}
\frac{\partial B^{\prime}}{\partial t^{\prime}} & =\frac{C_{U}}{r^{\prime}}\left[\frac{\partial}{\partial r^{\prime}}\left(r^{\prime} u_{r}^{\prime} B^{\prime}\right)+\frac{\partial}{\partial \theta}\left(u_{\theta}^{\prime} B^{\prime}\right)\right]+C_{\Omega} r^{\prime} \sin \theta\left(\mathbf{B}_{p}^{\prime} \cdot \nabla^{\prime}\right) \Omega^{\prime} \\
& -\left[\nabla^{\prime} \eta_{T}^{\prime} \times \nabla^{\prime} \times B^{\prime} \hat{e}_{\phi}\right]_{\phi}+\eta^{\prime}\left(\nabla^{\prime 2}-\frac{1}{s^{\prime 2}}\right) B^{\prime} \\
\frac{\partial A^{\prime}}{\partial t^{\prime}} & =-\frac{C_{U}}{s^{\prime}}\left(\mathbf{u}^{\prime} \cdot \nabla^{\prime}\right)\left(s^{\prime} A^{\prime}\right)+\eta^{\prime}\left(\nabla^{\prime 2}-\frac{1}{s^{\prime 2}}\right) A^{\prime}+C_{\alpha} \alpha^{\prime} B^{\prime} .
\end{aligned}
$$

Onde os números adimensionais, $C_{\Omega}, C_{\alpha}$ e $C_{U}$, definidos pelas eqs. (3.33) e (3.34), são:

$$
C_{\Omega}=\frac{\Omega_{e q} R_{\odot}^{2}}{\eta_{c z}}, \quad C_{U}=\frac{U_{0} R_{\odot}}{\eta_{c z}}, \quad \text { and } \quad C_{\alpha}=\frac{\alpha_{0} R_{\odot}}{\eta_{c z}} .
$$

Nessas equações escolhemos o raio solar, $R_{\odot}$, a velocidade angular no equador, $\Omega_{e q}$, a 
amplitude máxima do efeito $\alpha, \alpha_{0}$, a velocidade do fluxo meridional na superfície, $U_{0}$, e a difusividade magnética no interior da zona de convecção $\eta_{c z}$ como unidades de normalização. Como unidade de tempo escolhemos o tempo de dissipação, $t^{\prime}=R_{\odot}^{2} / \eta_{c z}$.

Agora podemos escrever as eqs. eqs. 4.1 e 4.2 em termos dos operadores das variáveis $r$ e $\theta$ como segue:

$$
\begin{aligned}
& \frac{\partial B^{\prime}}{\partial t^{\prime}}=\left(L_{r}+L_{\theta}\right) B^{\prime}+S_{1}^{\prime} \\
& \frac{\partial A^{\prime}}{\partial t^{\prime}}=\left(L_{r}+L_{\theta}\right) A^{\prime}+S_{2}^{\prime}
\end{aligned}
$$

onde

$$
\begin{aligned}
L_{r} B & =-C_{U} u_{r}^{\prime} \frac{\partial B^{\prime}}{\partial r^{\prime}}-C_{U} \frac{u_{r}^{\prime}}{r^{\prime}} B^{\prime}-C_{U} \frac{\partial u_{r}^{\prime}}{\partial r^{\prime}} B^{\prime}-\frac{\eta^{\prime}}{2 r^{\prime 2} \sin ^{2} \theta} B^{\prime}+\frac{2 \eta^{\prime}}{r^{\prime}} \frac{\partial B^{\prime}}{\partial r^{\prime}} \\
& +\eta^{\prime} \frac{\partial^{2} B^{\prime}}{\partial r^{\prime 2}}+\frac{\partial \eta^{\prime}}{\partial r^{\prime}}\left(\frac{B^{\prime}}{r^{\prime}}+\frac{\partial B^{\prime}}{\partial r^{\prime}}\right) \\
L_{\theta} B & =C_{U}-\frac{1}{r^{\prime}} \frac{\partial u_{\theta}^{\prime}}{\partial \theta} B^{\prime}-C_{U} \frac{u_{\theta}^{\prime}}{r^{\prime}} \frac{\partial B^{\prime}}{\partial \theta}-\frac{\eta^{\prime}}{2 r^{\prime 2} \sin ^{2} \theta} B^{\prime} \\
& +\frac{\eta^{\prime}}{r^{\prime 2}} \cot \theta \frac{\partial B^{\prime}}{\partial \theta}+\frac{\eta^{\prime}}{r^{\prime 2}} \frac{\partial^{2} B^{\prime}}{\partial \theta^{2}} . \\
L_{r} A & =-C_{U} \frac{u_{r}^{\prime}}{r^{\prime}} A^{\prime}-C_{U} u_{r}^{\prime} \frac{\partial A^{\prime}}{\partial r^{\prime}}-\frac{\eta^{\prime}}{2 r^{\prime 2} \sin ^{2} \theta} A^{\prime}+\frac{2 \eta^{\prime}}{r^{\prime}} \frac{\partial A^{\prime}}{\partial r^{\prime}}+\eta^{\prime} \frac{\partial^{2} A^{\prime}}{\partial r^{\prime 2}} \\
L_{\theta} A & =-C_{U} \frac{1}{r^{\prime}} \cot \theta u_{\theta}^{\prime} A^{\prime}-C_{U} \frac{u_{\theta}^{\prime}}{r^{\prime}} \frac{\partial A^{\prime}}{\partial \theta}-\frac{\eta^{\prime}}{2 r^{\prime 2} \sin ^{2} \theta} A^{\prime} \\
& +\frac{\eta^{\prime}}{r^{\prime 2}} \cot \theta \frac{\partial A^{\prime}}{\partial \theta}+\frac{\eta^{\prime}}{r^{\prime 2}} \frac{\partial^{2} A^{\prime}}{\partial \theta^{2}},
\end{aligned}
$$

e $S_{1}^{\prime}$ e $S_{2}^{\prime}$ são os termos fonte dos campos magnéticos toroidal e poloidal, respectivamente, dados por:

$$
\begin{aligned}
S_{1}^{\prime} & =C_{\Omega} r^{\prime} \sin \theta\left(B_{p}^{\prime} \cdot \nabla\right) \Omega^{\prime} \\
& =C_{\Omega} \frac{1}{r^{\prime}} \frac{\partial \Omega^{\prime}}{\partial \theta} \sin \theta\left(-A^{\prime}-r^{\prime} \frac{\partial A^{\prime}}{\partial r^{\prime}}\right)+C_{\Omega} \sin \theta \frac{\partial \Omega^{\prime}}{\partial r^{\prime}}\left(A^{\prime} \cot \theta+\frac{\partial A^{\prime}}{\partial \theta}\right) . \\
S_{2}^{\prime} & =C_{\alpha} \alpha^{\prime} B^{\prime} .
\end{aligned}
$$

Finalmente, resolvemos as eqs.(4.5) e (4.4) para $A^{\prime}$ e $B^{\prime}$ considerando que $r$ encontra-se no intervalo espacial $0.6 R_{\odot} \leq r \leq R_{\odot}$, o qual se inclui a parte mais externa da zona radiativa, a camada de overshoot, a tacoclina, a zona de convecção e a superfície. A coordenada $\theta$ pode abranger um $(0 \leq \theta \leq \pi / 2)$ ou dois $(0 \leq \theta \leq \pi)$ hemisférios. Para levar as eqs. (4.5) e (4.4) 
a uma forma totalmente discreta utilizamos o esquema de diferencias finitas; o método de Lax-Wendroff (Press et al., 1992) para os termos na primeira derivada e o método das diferencias finitas centradas (Press et al., 1992) para as segundas derivadas. A evolução temporal é feita utilizando o método semi-implícito ADI (alternating direction implicit method). No apêndice A fazemos uma descrição detalhada de cada um desses métodos numéricos.

\subsection{Condições iniciais e de contorno}

Nos métodos de diferenças finitas (veja o apêndice A) o valor numérico de uma variável num ponto no interior da grade computacional é calculado a partir dos valores em seus pontos vizinhos. Para calcular os valores numéricos nos pontos integráveis mais externos da grade é necessário definir-se os valores das variáveis nos pontos correspondentes aos contornos ou fronteiras. Nas simulações de dínamo que apresentaremos nos capítulos seguintes, utilizaremos as seguintes condições de contorno: no pólo norte (e também no pólo sul no caso de simulações abrangendo os dois hemisférios), $A=0$ e $B=0$; no equador (só em casos abrangendo um hemisfério), $B=0$ mas $A$ deve acoplar-se de forma simétrica com o hemisfério sul, então fazemos $\frac{\partial}{\partial \theta}(r \sin \theta A)=0$. Na fronteira radial inferior usamos $A=\frac{\partial}{\partial r}(r B)=0$, e finalmente, na fronteira radial superior onde $r=R_{\odot}$, consideramos um campo potencial, ou seja, $B=0$ e $A$ acopla-se a um campo magnético externo no vácuo que obedece à equação $\left(\nabla^{2}+1 / s\right) A=0$. O tratamento numérico dessas condições de contorno é explicado no Apêndice A.

As condições iniciais que serão geralmente utilizadas consistem em definir $A(t=0)=0$ e um campo toroidal anti-simétrico $B(t=0)=\sin (2 \theta)$. Porém, como a paridade da solução (tema que estudaremos no Capítulo 6) deve ser independente da simetria da condição inicial, nos modelos que abrangem os dois hemisférios iremos considerar condições iniciais anti-simétrica como acima, simétrica, $B(t=0)=\sin (\theta)$; e randômica com $B(t=0)=Q$, onde $Q$ varia aleatoriamente entre -1 e 1 . 

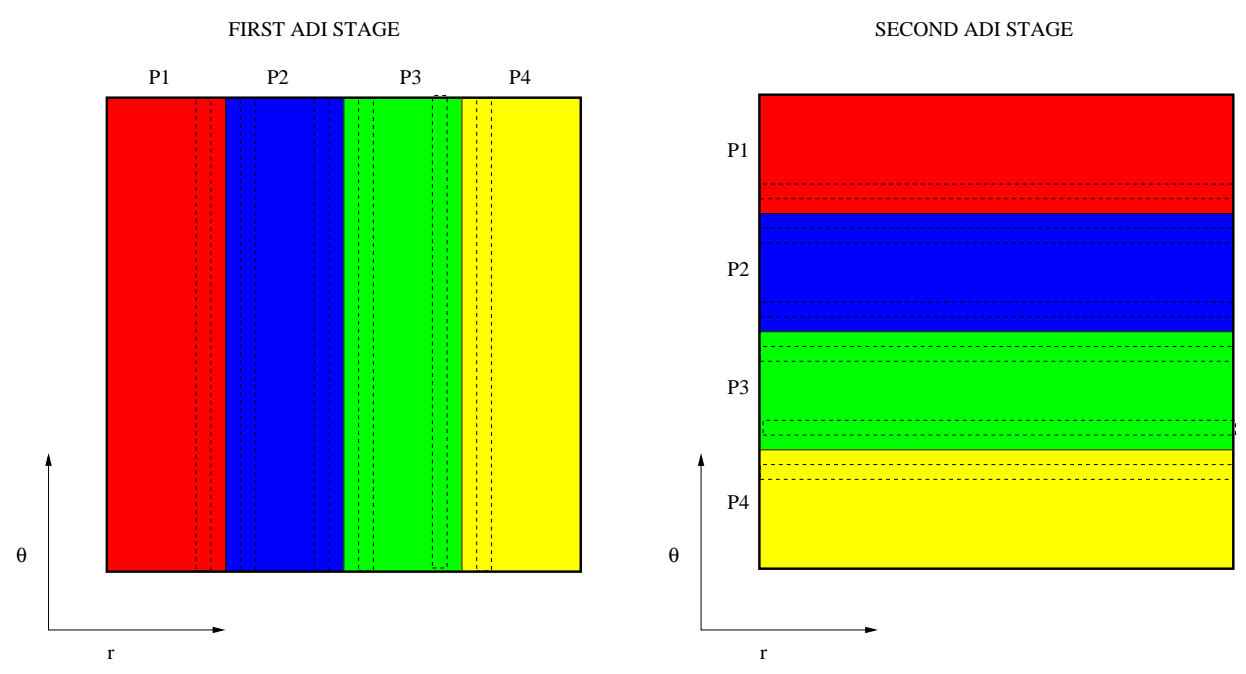

Figura 4.1: Representação do esquema de paralelização utilizado no código. Cada cor representa um processador diferente. A linha contínua grossa ao redor do domínio corresponde a condições de contorno física do problema, a linha contínua mais fina, dividindo os processadores é uma fronteira interna e as duas linhas tracejadas correspondem a valores de contorno internos que devem ser trocados entre processadores adjacentes.

\subsection{Paralelização}

Grande parte dos avanços recentes na Física de plasmas e na Astrofísica numérica tornaram-se possíveis somente graças ao rápido aumento da capacidade dos computadores. Atualmente, existem enormes "clusters" de processadores ou mesmo computadores pessoais com dois ou quatro núcleos de processamento. Essas novas arquiteturas permitem dividir o domínio computacional das simulações numéricas entre os vários processadores, acelerando o tempo de computação e diminuindo a carga de memória de cada computador. Nossos modelos de dínamo cinématico, os quais resolvem as equações de campo médio são modelos 2.5D, isto é, consideram 2 dimensões e meia pois integram as equações do dínamo em 2 dimensões espaciais independentes $(r$ e $\theta)$ e assumem simetria azimuthal (na terceira dimensão, $\phi)$, de tal forma que as três componentes do campo podem ser computadas. Essas simulações podem ser executadas inclusive em computadores com um único processador, porém nesse caso podem levar muito tempo de integração já que necessitamos deixar o sistema evoluir desde as condições iniciais até um estado estacionário. Este, normalmente é proporcional ao tempo de decaimento do campo magnético na zona radiativa, onde a difusividade Ohmica é baixa: $t_{r e l a x} \simeq d_{r c}^{2} / \eta_{r c}$, sendo $d_{r c}$ a espessura da camada ra- 
diativa considerada. Isto garante que não existam campos magnéticos remanescentes da condição inicial em nenhum lugar do domínio.

Por essa razão, no código que utilizamos nas simulações deste trabalho aproveitamos a ferramenta de paralelismo utilizando as livrarias MPI (message passage interface). A idéia básica é separar o número de pontos de grade em uma dada direção espacial $(r$ ou $\theta)$ no número de processadores disponíveis a cada meio passo temporal (veja o esquema na Fig. 4.1), e compartilhar os dois últimos pontos de grade, ou contornos internos, de cada subdomínio entre núcleos processadores adjacentes, já que esses valores são requeridos para calcular, com segunda ordem de precisão, as primeiras e segundas derivadas das variáveis do primeiro (ou ultimo) ponto de grade de cada núcleo. Na segunda metade do passo temporal é efetuado o mesmo procedimento, mas na outra direção. Ao final o processador principal reúne a informação e escreve os arquivos de resultados.

A aceleração do processo (ou speedup), definida como $S=T_{s} / T_{p}$, onde $T_{s}$ é o tempo de execução do algorítmo de forma serial, e $T_{p}$ é o tempo de execução do algorítmo de modo paralelo em $p$ processadores, é em torno de 3 em um computador de 4 núcleos processadores. 
Capítulo 5

\section{Efeitos da forma e espessura da tacoclina na geração e distribuição de campos magnéticos}

Como mencionado (Capitulo 3) os modelos de dínamo dominados pelo transporte de fluxo que consideram um perfil realista da rotação diferencial, são capazes de reproduzir a maior parte das características do ciclo magnético solar em grande escala, descritas em $\S 2.1$. Contudo, possuem limitações serias, pois falham em produzir uma correta distribuição latitudinal do campo toroidal, apresentando intensos fluxos de campo magnético em altas latitudes, o que resultaria na formação de manchas solares próximas dos pólos, em clara discordância com as observações. Nandy e Choudhuri (2002) encontraram uma possível solução para esse problema assumindo que o fluxo meridional poderia penetrar abaixo da zona convectiva, na zona radiativa. Com essa hipótese, o fluxo magnético ficaria confinado em uma camada sub-adiabática e seria transportado pelo fluxo meridional em direção ao equador e emergiria somente nas latitudes desejadas (baixas latitudes, como observado). Porém, essa hipótese cria uma nova dificuldade referente à quantidade de fluxo meridional que poderia penetrar abaixo da tacolina. Por um lado, em um trabalho recente Chatterjee et al. (2004), considerando a mesma hipótese, foram capazes de reproduzir as características do ciclo solar incluindo a simetria observada (a lei de Hale). Por outro lado, simulações numéricas que consideraram um fluxo meridional penetrando em um meio sub-adiabático como a camada radiativa (Gilman e Miesch, 2004) revelaram que os efeitos dinâmicos do fluido (sem incluir o campo magnético) não permitiriam uma penetração superior a $5 \%$ na tacoclina. Assim, no caso que o fluxo pudesse penetrar de alguma forma na zona radiativa, essa penetração seria de apenas alguns quilômetros. Mais recentemente, Rüdiger et al. (2005) confirmaram esse resultado. Além disso, outro problema que surge quando 
se considera a penetração do fluido na zona radiativa é a queima excessiva de elementos leves associada a regiões tão quentes, contradizendo modelos numéricos de mistura de elementos, que se baseiam em medições de héliossismologia da velocidade do som e do perfil de densidade. Estes indicam um máximo de mistura do 5\% no interior da tachclina (Brun et al., 2002). Para testar essa hipótese, Guerrero e Muñoz (2004) desenvolveram um modelo de dínamo cinemático no qual utilizaram o um perfil da rotação diferencial compatível com as observações, o perfil de velocidade meridional sugerido por Nandy e Choudhuri (2002), e o termo $\alpha$ empregado por Dikpati e Charbonneau (1999). Verificaram que um fluxo meridional penetrando a camada radiativa resolveria só parcialmente o problema da distribuição dos campos toroidais na região polar. Já Dikpati et al. (2004) combinaram o efeito $\alpha$ de Babcock-Leighton, localizado nas camadas superiores do Sol com um efeito $\alpha$ devido a instabilidades hidrodinâmicas na tacoclina, e encontraram uma distribuição de campos magnéticos no diagrama de borboleta teórico compatível com a observada. No entanto, até agora não há um mecanismo ou condição física que possa explicar claramente o fato de as manchas solares aparecerem concentradas unicamente nas baixas latitudes.

Neste Capítulo, investigaremos a possível influência que a forma e a espessura da tacoclina podem exercer na distribuição latitudinal dos campos magnéticos e das manchas solares. Mudar esses dois parâmetros significa alterar as contribuições das componentes radial e latitudinal do cisalhamento na produção dos campos magnéticos no interior solar. Desse modo, iremos examinar aonde, e qual componente indutiva de cisalhamento, é responsável pela produção dos campos magnéticos toroidais mais importantes. Os resultados desse estudo, que descreveremos a seguir, foram publicados em dois trabalhos (Guerrero e de Gouveia Dal Pino, 2007a,b, veja também o Apéndice C).

Nas próximas seções, apresentaremos primeiramente os perfis que utilizamos para o campo de velocidades, a difusividade magnética e o efeito $\alpha$ de Babcock-Leighton. Depois, apresentaremos como possíveis formas prolata e oblata da tacoclina afetam o diagrama de borboleta. Em seguida, efetuamos uma detalhada análise da produção de campos toroidais pelas duas componentes de cisalhamento, separadamente, examinando a dependência destes com o valor da difusividade magnética na zona de convecção. Finalmente apresentaremos as conclusões desses estudos. 


\subsection{Perfis utilizados}

\section{Rotação diferencial}

Nas simulações apresentadas neste Capítulo consideramos um perfil da rotação diferencial compatível com o observado, dado pela eq. (3.40) e mostrado no painel esquerdo da Fig. 3.4. Este inclui um caroço radiativo girando de forma uniforme, uma camada de cisalhamento radial na tacoclina e rotação diferencial latitudinal na zona de convecção. Inicialmente, não consideraremos a segunda camada de cisalhamento radial próxima à superfície (painel central da mesma figura).

\section{Circulação meridional}

Para a circulação meridional usamos a prescrição analítica introduzida por trabalhos anteriores (Dikpati e Choudhuri, 1994; Choudhuri et al., 1995; Nandy e Choudhuri, 2002; Guerrero e Muñoz, 2004), e discutida em $§ 3.7 .4$, considerando (eq. 3.57):

$$
\rho(r) \mathbf{u}=\nabla \times\left[\psi(\mathbf{r}, \theta) \mathbf{e}_{\phi}\right]
$$

onde $\psi$ é a função de corrente dada por:

$$
\begin{aligned}
\psi r \sin \theta & =\left(r-R_{p}\right) \psi_{0} \sin \left[\frac{\pi\left(r-R_{p}\right)}{\left(R_{\odot}-R_{p}\right)}\right] \\
& \times\left(1-e^{-\beta_{1} \theta^{\epsilon}}\right)\left(1-e^{\beta_{2}(\theta-\pi / 2)}\right) \\
& \times e^{[(r-r o) / \Gamma]^{2}},
\end{aligned}
$$

e $\rho(r)$ é o perfil de densidade para uma esfera adiabática com razão de calores específicos $\gamma=5 / 3$ (ou seja, índice politrópico $m=1.5$ ), assim:

$$
\rho(r)=C\left(\frac{R_{\odot}}{r}-0.95\right)^{m} .
$$

Os valores de $\psi_{0}$ e $C$ são escolhidos de tal forma que a amplitude máxima da velocidade meridional, $u_{\theta}$, nas latitudes intermediárias seja $U_{0}=\psi_{0} / C=2500 \mathrm{~cm} \mathrm{~s}^{-1}$. Os valores dos demais parâmetros são: $\beta_{1}=6.06 \times 10^{9} \mathrm{~cm}^{-1}, \beta_{2}=4.6 \times 10^{9} \mathrm{~cm}^{-1}, \epsilon=2.0000001, r_{o}=\left(R_{\odot}-\right.$ $\left.R_{\text {min }}\right) / 4.0$, e $\Gamma=3.47 \times 10^{10} \mathrm{~cm} . R_{\min }$ é o raio da base da zona convectiva e $R_{p}=0.69$ é o raio de máxima penetração do fluido. Consideramos uma leve penetração devida aos efeitos naturais de mistura na interface entre a zona convectiva e a radiativa (camada de 
overshooting, Rogers et al., 2006). O painel esquerdo da Fig. 5.1 apresenta o perfil de circulação meridional acima.

\section{Difusividade magnética}

Para a difusividade magnética consideramos um perfil de dois degraus com a forma analítica dada pela eq. (3.49), representada na imagem da direita na Fig. 3.5, e com os seguintes valores: $\eta_{r z}=2.2 \times 10^{8} \mathrm{~cm}^{2} \mathrm{~s}^{-1}, \eta_{c z}=5 \times 10^{9} \mathrm{~cm}^{2} \mathrm{~s}^{-1}, \eta_{s}=10^{12} \mathrm{~cm}^{2} \mathrm{~s}^{-1}$, e $d_{2}=d_{3}=0.01 R_{\odot}$.

\section{O termo $\alpha$}

Iremos considerar um termo fonte de campo poloidal, $\alpha$, seguindo o mecanismo de Babcock-Leighton como foi discutido em §3.8.1, conforme a eq. (3.67). O perfil radial é semelhante à eq. (3.68) e para a variação latitudinal vamos considerar, seguindo Dikpati et al. (2004), um perfil concentrado na região de surgimento das manchas, assim:

$$
\Lambda(\theta)=\sin \theta \cos \theta\left[\frac{1}{1+e^{\gamma_{1}(\pi / 4-\theta)}}\right],
$$

e, como já foi discutido, o termo $\alpha$ é considerado proporcional ao campo toroidal na base da zona de convecção em $r_{b c}=R_{c}+\omega_{1} / 2$, onde $\omega_{1}$ é a espessura da tacoclina. Nos painéis central e direito da Fig. 5.1 apresentamos os perfis radial e latitudinal, respectivamente, desse efeito $\alpha$.
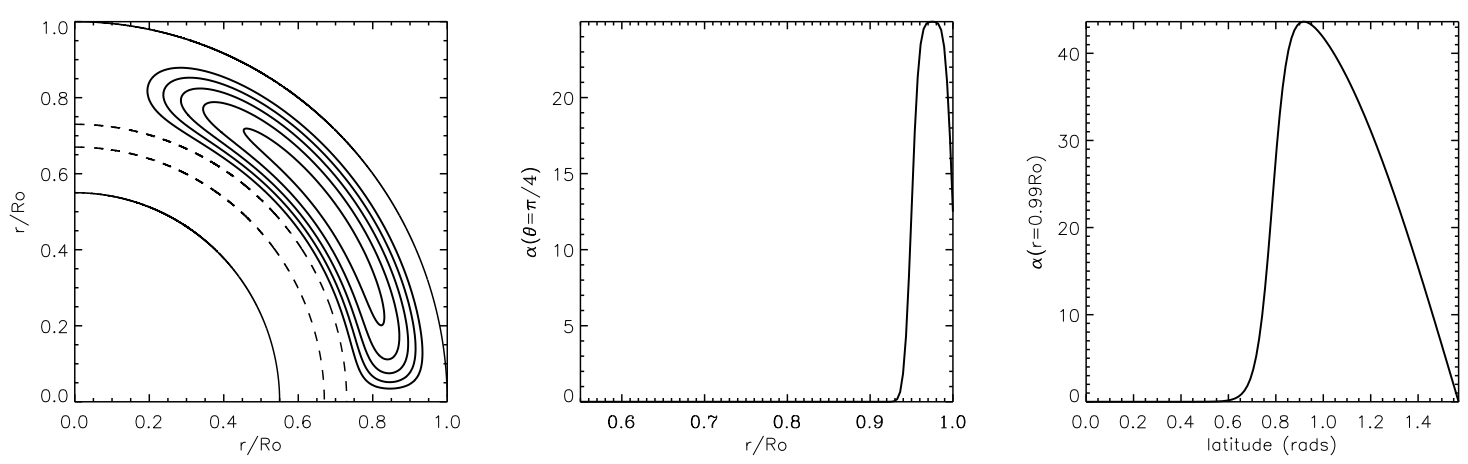

Figura 5.1: Painel esquerdo: perfil da circulação meridional; as linhas tracejadas representam uma tacoclina de espessura $\omega_{1}=0.05 R_{\odot}$. Painéis central e direito: Perfis radial (em $\theta=\pi / 4$ ) e latitudinal (em $r=0.99 R_{\odot}$ ) do efeito $\alpha$ de Babcock-Leighton. Ele é concentrado próximo à superfície e com uma distribuição latitudinal correspondente à faixa onde aparecem as manchas solares na superfície da estrela. 
Tabela 5.1 - Valores dos parâmetros usados no modelo da Figura 5.2

\begin{tabular}{lc}
\hline PARÂMETRO & VALOR \\
\hline$\Omega_{E q}$ & $2 \pi \times 460.7 \mathrm{nHz}$ \\
$R_{c}$ & $0.7 R_{\odot}$ \\
$\omega_{1}$ & $0.05 R_{\odot}$ \\
\hline$U_{0}$ & $2500 \mathrm{~m} \mathrm{~s}^{-1}$ \\
$R_{p}$ & $0.69 R_{\odot}$ \\
\hline$\eta_{r z}$ & $2.2 \times 10^{8} \mathrm{~cm}^{2} \mathrm{~s}^{-1}$ \\
$\eta_{c z}$ & $5.0 \times 10^{9} \mathrm{~cm}^{2} \mathrm{~s}^{-1}$ \\
$\eta_{s}$ & $1.0 \times 10^{12} \mathrm{~cm}^{2} \mathrm{~s}^{-1}$ \\
\hline$\alpha_{0}$ & $130 \mathrm{~cm} \mathrm{~s}^{-1}$ \\
\hline$C_{\Omega}=\Omega_{e q} R_{\odot}^{2} / \eta_{c z}$ & $1.4 \times 10^{5}$ \\
$C_{\alpha}=\alpha_{0} R_{\odot} / \eta_{c z}$ & $1.8 \times 10^{3}$ \\
$C_{U}=U_{0} R_{\odot} / \eta_{c z}$ & $3.5 \times 10^{4}$ \\
\hline
\end{tabular}

\subsection{Resultados}

Utilizando a parametrização da Tabela 5.1 e os perfis descritos acima no código 2.5D descrito no Capítulo 4, construímos o modelo apresentado no diagrama de borboleta da Fig. 5.2. Veja que nesse caso consideramos uma tacoclina de espessura constante $\omega_{1}=0.05 R_{\odot}$. Ele reproduz algumas das características do ciclo magnético solar, como por exemplo, a periodicidade do ciclo magnético, a magnitude dos campos toroidais próximos do equador, bem como os campos radiais mais difusos e fracos perto do pólo, e a diferença de fase entre esses campos. No entanto, pode-se notar que os campos toroidais intensos persistem acima dos $45^{\circ}$ sugerindo que as manchas iriam aparecer também nessas latitudes, o qual não é observado. Nas seções seguintes iremos buscar soluções para esse problema, mudando a forma e a espessura da tacoclina.

\subsubsection{Tacoclina elipsoidal}

Como foi discutido em $§ 2.2 .3$, até agora não existe um valor preciso para a localização e a espessura da tacoclina (veja também a Tabela 2.1 extraída de Corbard et al., 2001). 


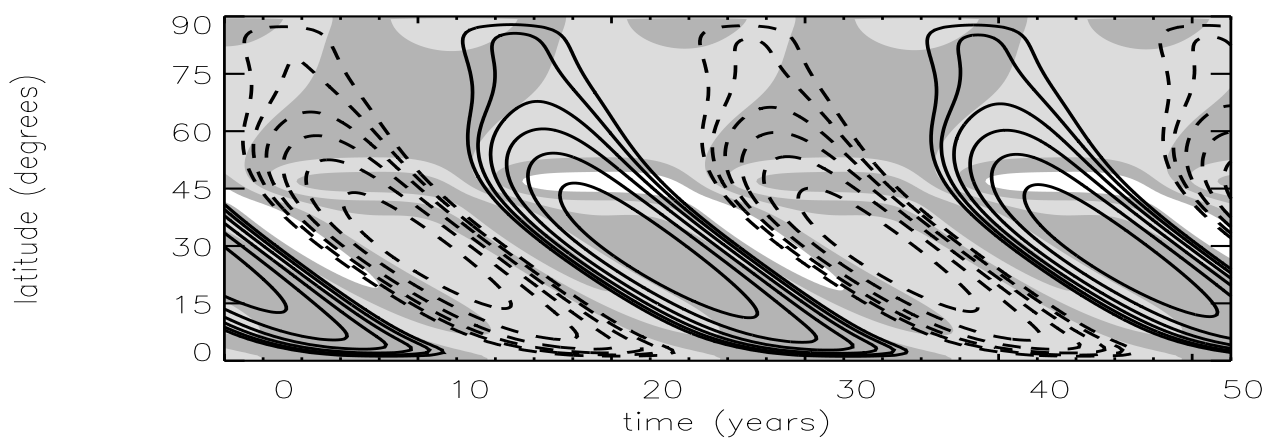

Figura 5.2: Diagrama de borboleta, tempo versus latitude, para um modelo de dínamo com uma tacoclina de espessura constante $\omega_{1}=0.05 R_{\odot}$. As latitudes $0^{\circ}$ e $90^{\circ}$ correspondem ao Equador solar e ao Pólo, respectivamente. As linhas contínuas (tracejadas) representam as intensidades dos campos toroidais positivos (negativos), na base da zona de convecção (ou seja, no topo da tacoclina $r=R_{c}+\omega_{1} / 2$ ). As linhas são espaçadas em escala logarítmica no intervalo entre $5 \times 10^{4}-10^{5} \mathrm{G}$. O fundo em escala de cinzas representa os campos radiais positivos (em cinza claro) e negativo (em cinza escuro) na superfície do Sol.

Além disso, existem certas evidências observacionais que indicam que a tacoclina poderia ter uma forma prolata (Antia et al., 1998; Charbonneau et al., 1999). Porém, esses resultados poderiam dever-se a incertezas observacionais ou então às técnicas de inversão de héliossismologia utilizadas na análise dos dados (Corbard et al., 2001). As simulações numéricas de Dikpati e Gilman (2001b) mostram que uma tensão magnética (devida a um campo de intensidade $B>10^{5} \mathrm{G}$ ) poderia empurrar a matéria nos pólos aumentando a densidade e assim a espessura da tacoclina nesse ponto. Isto poderia explicar a forma prolata da tacoclina, porém, como um campo magnético bem intenso existe somente na fase de máxima atividade do ciclo, a tacoclina poderia mudar de forma com o percurso do ciclo, virando aproximadamente prolata durante o máximo, mas essa variação ainda não foi observada.

Contudo, para avaliar os efeitos de uma tacoclina possivelmente prolata em um modelo de dínamo de Babcock-Leighton, introduzimos uma variação latitudinal na espessura da tacoclina na eq. (3.40), fazendo-a variar de $\omega_{1}$ (pólo) $=0.07 R_{\odot}$ a $\omega_{1}$ (equador) $=0.02 R_{\odot}$ (como se pode observar no painel esquerdo da Fig. 5.3). Essa mudança faz reduzir o cisalhamento radial, $\partial \Omega / \partial r$, nas altas latitudes. Assim, se o surgimento dos campos toroidais intensos nessas regiões fosse sensível à quantidade de cisalhamento radial, então deveríamos esperar que uma diminuição de $\partial \Omega / \partial r$ nessas latitudes reduziria a amplificação de campos 

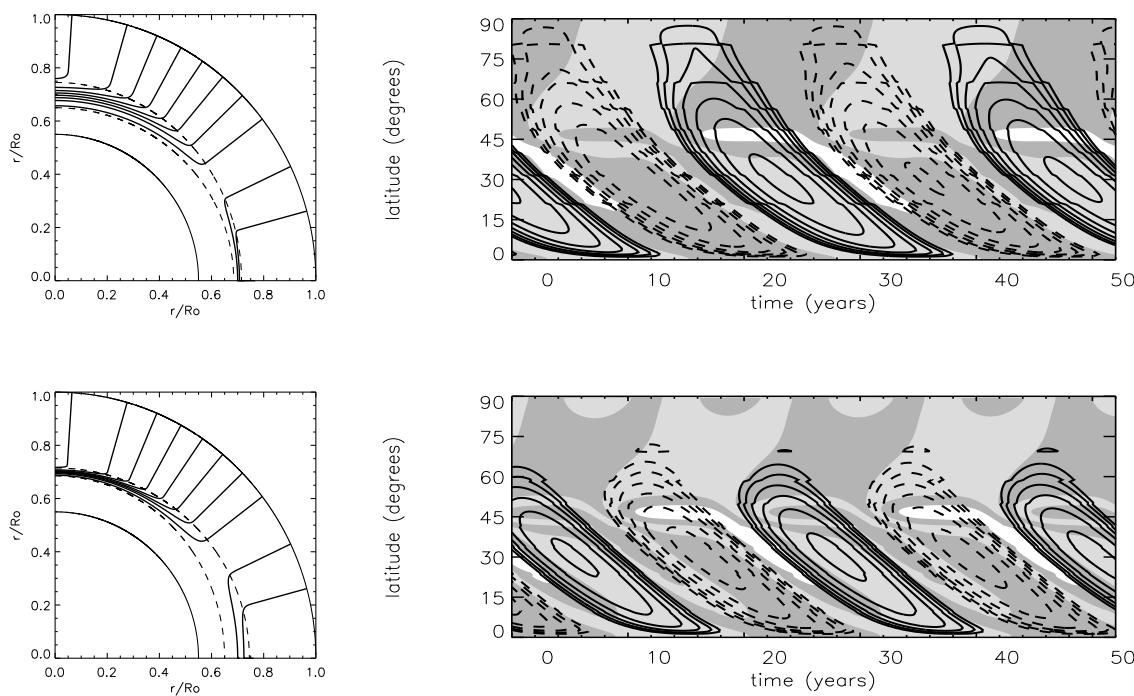

Figura 5.3: Perfis de iso-rotação (esquerda) e diagramas de borboleta, tempo versus latitude (direita) para uma tacoclina prolata (superior); e uma tacoclina oblata (inferior). Os detalhes dos contornos nas imagens à direita são os mesmos que na Fig. 5.2. Nos painéis à esquerda a tacoclina é representada pelas linhas tracejadas.

toroidais aí. No entanto, o diagrama de borboleta mostrado na Fig. 5.3 (superior), calculado com uma tacoclina prolata, não apresenta mudanças significativas com respeito ao diagrama da Fig. 5.2, calculado para uma tacoclina homogênea. Por outro lado, quando consideramos uma tacoclina oblata (painel esquerdo inferior na Fig. 5.3), vemos que o campo toroidal é amplificado a seu máximo valor só em latitudes abaixo dos $60^{\circ}$. Em outras palavras, para uma tacoclina oblata, na qual o cisalhamento radial aumenta nas altas latitudes, encontramos uma inibição na geração de campos toroidais nessas regiões, contrariando as nossas expectativas, porém, concordando melhor com as observações. Além disso, nos dois casos acima, com tacoclinas prolata ou oblata, a geração de campos toroidais nas baixas latitudes permanece praticamente inalterada, o que sugere que o termo $\partial \Omega / \partial r$ não influencia a formação desses campos na região equatorial.

\subsubsection{Tacoclinas espessas e finas}

Dos resultados anteriores (Fig. 5.3) podemos notar duas características interessantes. Primeiro, é aparentemente impossível reproduzir um diagrama de borboleta considerando uma tacoclina prolata. Segundo, encontramos que a contribuição do cisalhamento radial à 
amplificação da componente toroidal do campo magnético é aparentemente muito pequena.

Para investigar os motivos desse aparente paradoxo iremos considerar novamente uma tacoclina esférica, de espessura homogênea, e calcular os termos indutivos no lado direito da eq. (4.1), $\left(\mathbf{B}_{\mathbf{p}} \cdot \nabla\right) \Omega=B_{r} \partial \Omega / \partial r+B_{\theta} / r \partial \Omega / \partial \theta$, e compará-los com o campo magnético toroidal $(B)$ no instante do ciclo no qual o campo magnético radial $\left(B_{r}\right)$ inverte a sua polaridade, na latitude $\theta=60^{\circ}$ e raio $r=R_{c}$ (ou seja, no centro da tacoclina onde o cisalhamento radial é máximo). Nessa fase do ciclo, a ação do termo de cisalhamento sobre o campo magnético poloidal gera as ramificações do campo toroidal e estabelece a morfologia das mesmas para as fases seguintes do ciclo. As quantidades acima são computadas como função da espessura da tacoclina $\left(\omega_{1}\right)$ para a qual consideramos valores possíveis dentro do intervalo dado pelas observações de héliossismologia $\left(0.01 R_{\odot} \leq d_{1} \leq 0.1 R_{\odot} ;\right.$ Corbard et al., 2001, veja também a Tabela 2.1). Os resultados são apresentados na Fig. 5.4.

Na Figura vemos que a componente radial, $B_{r}\left(\frac{\partial \Omega}{\partial r}\right)$ (Fig. 5.4a), de fato decresce com o aumento da espessura da tacoclina, tal como era esperado. No entanto, mais importante é o fato de que o seu valor é ao redor de duas ordens de magnitude menor que aquele da componente latitudinal, $\frac{B_{\theta}}{r}\left(\frac{\partial \Omega}{\partial \theta}\right)$ (Fig. 5.4b). Assim, quando um novo campo toroidal começa a ser gerado, o seu crescimento é dominado pelo cisalhamento latitudinal na eq. (4.1). Outros experimentos numéricos para diferentes latitudes revelaram o mesmo efeito. Além disso, confirmamos esse fato na Fig. $5.4 c$ que indica que a magnitude do campo toroidal gerado nas altas latitudes varia com a largura da tacoclina de uma forma similar ao termo de cisalhamento latitudinal (Fig. 5.4b), atingindo um valor máximo para uma largura da tacoclina, $\omega_{1}$, que depende do valor assumido para a difusividade magnética. Esse último resultado será estudado com maior detalhe nos próximos parágrafos.

Os resultados acima levantam duas novas questões. Já que o cisalhamento radial não parece ser importante na amplificação da componente toroidal do campo magnético, inclusive nas altas latitudes, será que a tacoclina está realmente participando no processo de dínamo? E, em caso afirmativo, qual é a sua verdadeira espessura?

No presente modelo, o tacoclina não é unicamente a interface onde o cisalhamento radial, $\partial \Omega / \partial r$, é máximo, mas também o local para onde o fluxo meridional empurra os campos poloidais e os tubos de fluxo toroidais são armazenados e amplificados antes de emergir às camadas exteriores graças ao empuxo das linhas. Dessa forma a nossa resposta 

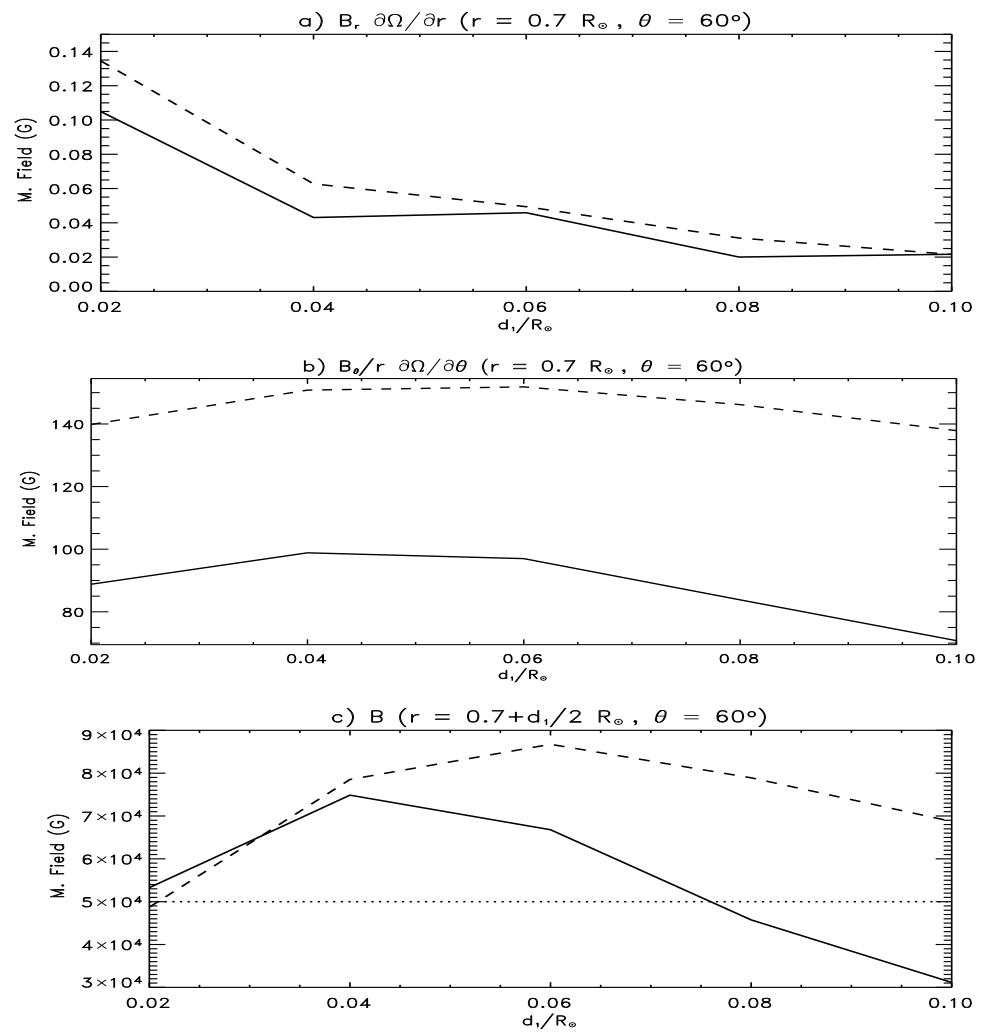

Figura 5.4: Amplitude dos termos de cisalhamento: a) $B_{r}\left(\frac{\partial \Omega}{\partial r}\right)$; b) $\frac{B_{\theta}}{r}\left(\frac{\partial \Omega}{\partial \theta}\right)$ na fase do ciclo na qual o campo magnético radial inverte a sua polaridade, na latitude de $60^{\circ}$ e no centro da tacoclina, e c) campo magnético toroidal $B$ na fase na qual alcança o seu máximo no topo da tacoclina, como função da espessura da tacoclina. As linhas tracejada e contínua representam dois valores diferentes da difusividade magnética turbulenta na zona de convecção, $\eta_{c}=5 \times 10^{9} \mathrm{~cm}^{2} \mathrm{~s}^{-1}$, e $2 \times 10^{10} \mathrm{~cm}^{2} \mathrm{~s}^{-1}$, respectivamente (a linha contínua corresponde ao valor da Tabela 5.1).

à primeira pergunta é sim.

Para responder à segunda pergunta, podemos examinar com mais atenção a amplitude do campo toroidal gerado na latitude $60^{\circ}$, na base da zona de convecção (Fig. 5.4c). Ela indica que para valores de $\omega_{1} \lesssim 0.02 R_{\odot}$ e $\omega_{1} \gtrsim 0.08 R_{\odot}{ }^{1}$ não há formação de campos toroidais intensos nas altas latitudes, como é requerido pelas observações. Mas determinar qual dentre esses é o valor mais realista de $\omega_{1}$ é uma tarefa difícil, já que os valores dos campos magnéticos dependem também do perfil da difusividade magnética adotado. Para se obter uma resposta definitiva, teremos ainda que aguardar melhores resultados observacionais da héliossismologia, porém, uma análise detalhada dos parâmetros da difusividade magnética,

\footnotetext{
${ }^{1} \mathrm{Na}$ seção $\S 5.3$ mostraremos que esse resultado é valido somente para valores de $\eta_{c}<2 \times 10^{10} \mathrm{~cm}^{2} \mathrm{~s}^{-1}$.
} 
como os mostrados na próxima seção, podem nos oferecer informações a esse respeito.

\subsection{Dependência dos parâmetros}

Já que o nosso modelo utiliza um grande número de parâmetros, realizamos alguns testes para verificar a sensibilidade dos resultados acima à variação desses parâmetros. A circulação meridional, definida nas eqs. (5.1) - (5.3), possui dois parâmetros livres, a amplitude do fluxo meridional na superfície, $U_{0}$, e a profundidade de penetração do fluxo meridional, $R_{p}$. O primeiro não afeta significativamente a intensidade dos campos magnéticos gerados (embora esse parâmetro seja muito importante para estabelecer o período do ciclo), no entanto o segundo parâmetro é capaz de mudar as latitudes de formação dos campos magnéticos intensos, como foi estudado por Nandy e Choudhuri (2002). Contudo, já que em nossa análise estamos assumindo um regime de pouca penetração, verificamos que pequenas variações ao redor do valor representado na Tabela 5.1 não modificam de forma significativa os resultados acima mencionados. Além disso, em Guerrero e de Gouveia Dal Pino (2007b) trocamos o perfil de velocidade das eqs. (5.1) (5.3) pelo perfil usado em Dikpati e Charbonneau (1999), dado nas eqs. (3.61) e (3.62), e verificamos que os resultados acima são robustos mesmo com a mudança desses perfis.

O termo $\alpha$, cujo perfil semi-empírico foi escolhido para reproduzir melhor as observações (Fig 5.1), possui apenas um parâmetro livre, a amplitude, $\alpha_{0}$ (na eq. 3.67). Este determina a quantidade de campo poloidal que vai ser gerado para manter o ciclo. Em nossos testes verificamos que o nossos resultados são geralmente insensíveis às suas variações.

Em relação aos termos difusivos da eq. (3.49), é possível estabelecer alguns vínculos para os diferentes regimes. Para a camada mais externa, na parte superior da zona convectiva, , adotamos um valor da difusividade obtido a partir das observações, de tal forma que fixamo-lo em todas as simulações. No entanto os resultados acima podem tornar-se bastante sensíveis ao valor da difusividade turbulenta na zona de convecção $\left(\eta_{c z}\right)$, como o indica a diferença nas linhas contínua e tracejada da Fig. 5.4, e também ao valor do gradiente radial da difusividade entre as regiões radiativa e convectiva. Para estudar a forma em que esses parâmetros afetam os resultados, fixamos o valor da difusividade na zona radiativa e escolhemos um valor apropriado de $\eta_{c z}$ baseados no período do ciclo e na magnitude dos campos gerados, pois se o valor de $\eta_{c z}$ for muito grande, o sistema sai do 
regime advectivo e entra em um regime dominado pela difusão, reduzindo o período do ciclo nos diagramas de borboleta. Por outro lado, se $\eta_{c z}$ for pequeno demais, os campos magnéticos na zona de convecção irão sobreviver por muito tempo nessa região e também terão grandes magnitudes nos pólos.

Na Figura 5.5, graficamos o máximo campo magnético toroidal na base da zona de convecção, em uma latitude de $60^{\circ}$ (tal como na Fig. 5.4c), em função da difusividade $\eta_{c z}$, no intervalo de valores apropriados para obter soluções realistas. Os diferentes estilos de linha correspondem a valores diferentes da espessura da tacoclina. A linha pontilhada em $5 \times 10^{4} \mathrm{G}$ indica o limite entre os tubos de fluxo flutuantes e não flutuantes. Se a curva se localiza acima deste limite, no diagrama de borboleta irão aparecer contornos de campo magnético toroidal acima de $60^{\circ}$, o qual não é desejado. A Fig. 5.5 contém o resultado para dois valores diferentes do parâmetro $r_{c}$ do perfil de difusividade magnética (eq. 3.49). Esse parâmetro indica o raio de transição entre um regime turbulento intenso e um regime estável, no centro da camada de overshoot. Embora o seu valor tenha sido determinado a partir de observações com grande precisão $\left(r_{c}=0.715 R_{\odot}\right)$, deslocamos a sua localização em $0.5 \%$ para verificar a sensibilidade dos resultados a esse parâmetro. No painel esquerdo, $r_{c}=0.715 R_{\odot}$ é o mesmo adotado nas figuras anteriores. No painel direito, $r_{c}=0.72 R_{\odot}$, o que significa que uma fração maior da tacoclina vai permanecer em um meio menos turbulento (sub-adiabático). Contudo, ambos os painéis indicam um comportamento similar para diferentes valores da largura da tacoclina, mas com um ligeiro deslocamento das curvas no diagrama direito para valores maiores da difusividade, que são permitidos unicamente se a zona de convecção (turbulenta) é menor.

O diagrama esquerdo mostra que uma tacoclina com uma largura de $\sim 2 \%$ ou menos do raio solar produzirá diagramas de borboleta realistas para quase todo o intervalo da difusividade. Larguras intermediárias, $\omega_{1} \simeq 0.04 R_{\odot}-0.06 R_{\odot}$, produzem valores não permitidos para qualquer difusividade, e grandes espessuras, entre $\sim 0.08 R_{\odot}$ e $\sim 0.1 R_{\odot}$, produziram também diagramas de borboleta concordando com as observações para $\eta_{c z}$, de $2 \times 10^{9} \mathrm{~cm} \mathrm{~s}^{-2}$ até $1 \times 10^{10} \mathrm{~cm} \mathrm{~s}^{-2}$. O painel direito também indica que as larguras intermediárias $\left(\omega_{1} \simeq 0.04 R_{\odot}-0.06 R_{\odot}\right)$ produzem diagrams de borboleta inapropriados, enquanto que tacoclinas suficientemente finas $\left(\omega_{1} \lesssim 0.02 R_{\odot}\right)$ produzem diagramas de borboleta similares ao solar para o intervalo inteiro de difusividades apropriadas. Já tacoclinas 

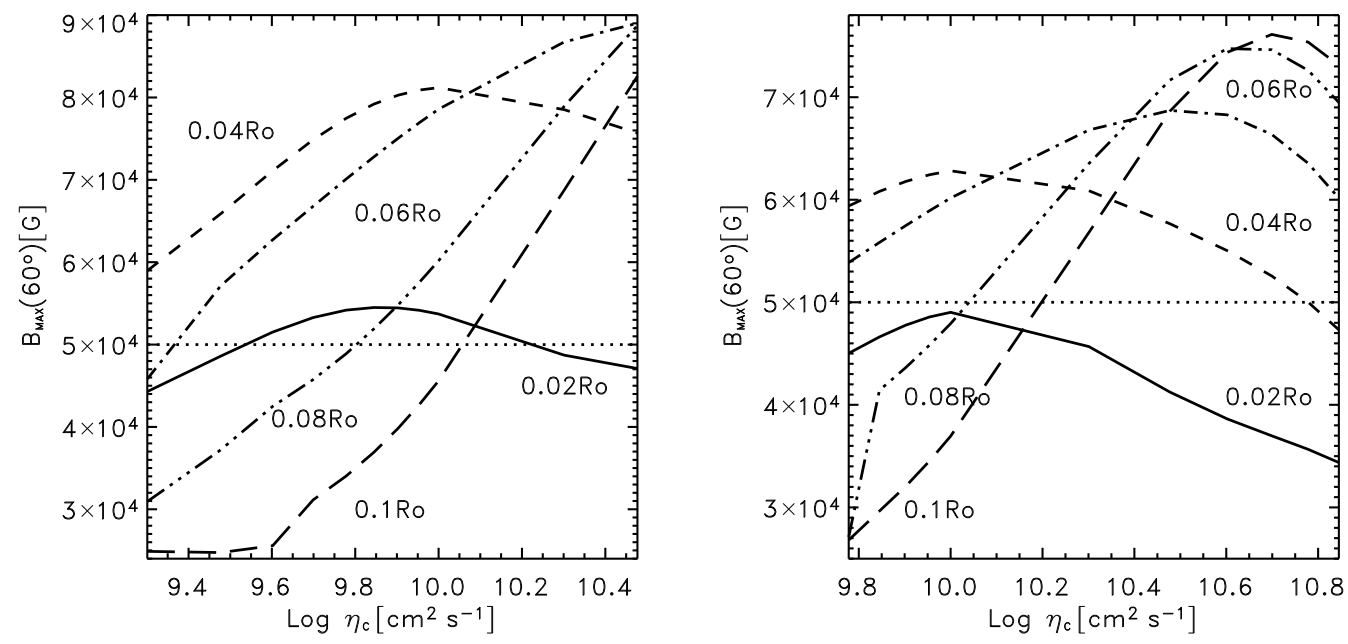

Figura 5.5: Máximo da componente toroidal do campo magnético no topo da tacoclina em função da difusividade (em escala logarítmica) numa latitude de $60^{\circ}$. Os diferentes tipos de linha correspondem a diferentes espessuras da tacoclina $\omega_{1}$. A linha pontilhada representa o limite entre campos magnéticos flutuantes e não flutuantes $5 \times 10^{4} \mathrm{G}$, como é explicado no texto. Só valores abaixo dessa linha aparecem nas latitudes desejadas do diagrama de borboleta. Os gráficos à esquerda e à direita correspondem a dois valores diferentes de $r_{c}$ no perfil de difusividade, $r_{c}=0.715 R_{\odot}$ (como nas figuras anteriores) e $r_{c}=0.72 R_{\odot}$, respectivamente.

largas, $\omega_{1} \simeq 0.08 R_{\odot}-0.1 R_{\odot}$, produzem diagramas de borboleta similares ao observado unicamente para difusividades no intervalo $6 \times 10^{9}-1.6 \times 10^{10} \mathrm{~cm}^{2} \mathrm{~s}^{-1}$. Outros experimentos feitos com $r_{c}=0.71 R_{\odot}$ revelaram um comportamento similar, com um ligeiro deslocamento das curvas para menores valores da difusividade com respeito ao diagrama correspondente a $r_{c}=0.715$ (Fig. 5.5, esquerda). Os diagramas de borboleta da Figura 5.6, construídos considerando-se tacoclinas esféricas, uma com uma largura estreita $\left(\omega_{1}=0.02 R_{\odot}, \eta_{c}=5 \times 10^{9}\right.$ $\left.\mathrm{cm}^{2} \mathrm{~s}^{-1}, r_{c}=0.72 R_{\odot}\right)$ e a outra com uma largura grande $\left(\omega_{1}=0.08 R_{\odot}, \eta_{c}=3 \times 10^{9} \mathrm{~cm}^{2} \mathrm{~s}^{-1}\right.$, $\left.r_{c}=0.715 R_{\odot}\right)$, são os que melhor reproduzem as observações.

Note-se também que os resultados acima são aplicáveis a tacoclinas prolata e oblata e explicam naturalmente os resultados da Fig. 5.3. De fato, já que uma tacoclina prolata tem uma largura maior nas latitudes altas (Painel superior da Fig 5.3), os contornos do campo toroidal com intensidades entre $5 \times 10^{4} \mathrm{G}$ e $1 \times 10^{5} \mathrm{G}$ desenvolvem-se no hemisfério inteiro devido ao cisalhamento latitudinal (que domina sobre o radial em todas as latitudes). Por 

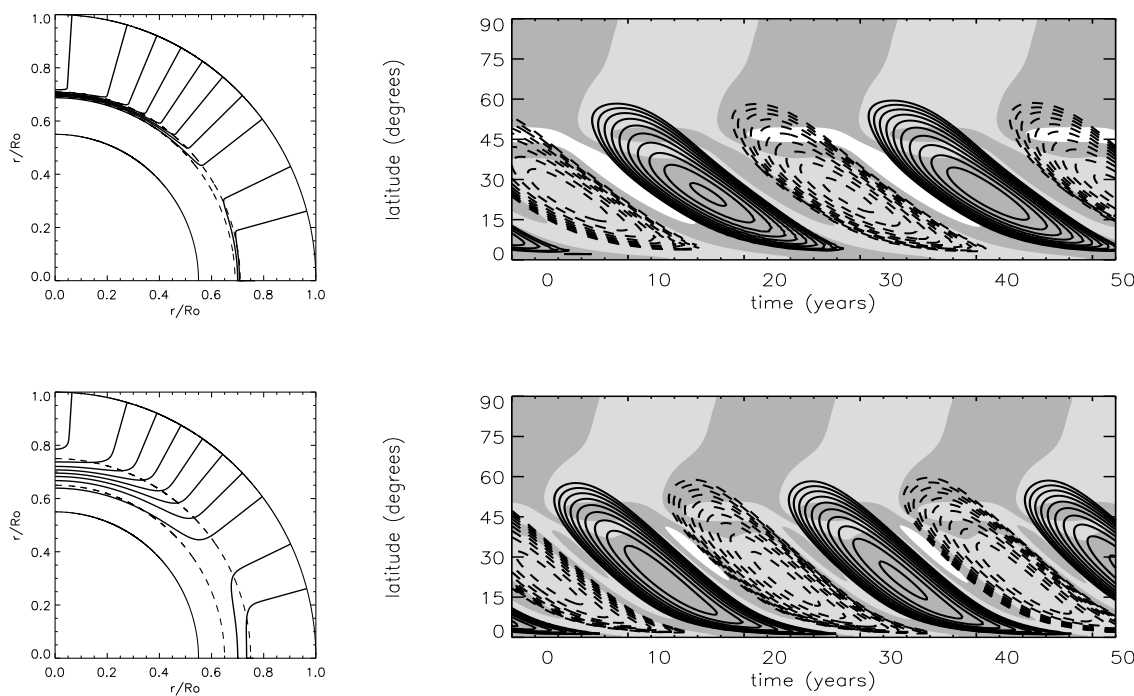

Figura 5.6: Perfis de velocidade angular e diagrams de borboleta tempo versus latitude para uma tacoclina fina $\left(d_{1}=0.02 R_{\odot}, \eta_{c}=5 \times 10^{9} \mathrm{~cm}^{2} \mathrm{~s}^{-1}, r_{c}=0.72 R_{\odot}\right)($ acima $)$, e uma tacoclina larga $\left(d_{1}=0.08 R_{\odot}, \eta_{c}=3 \times 10^{9}\right.$ $\left.\mathrm{cm}^{2} \mathrm{~s}^{-1}, r_{c}=0.715 R_{\odot}\right)$ (embaixo). Os detalhes dos contornos nos diagramas à direita são os mesmos que na Fig. 5.2. Nos diagramas à esquerda a tacoclina é representada pelas linhas tracejadas.

outro lado, no caso da tacoclina oblata (diagrama inferior da Fig. 5.3), onde a largura é menor nas latitudes mais altas, a formação de campos toroidais é suprimida devido a uma menor contribuição do cisalhamento latitudinal, resultando assim numa distribuição concentrada nas baixas latitudes. Contudo, a espessura da tacoclina na qual o cisalhamento radial tem seu valor máximo ou mínimo depende do perfil de difusividade magnética. Para aquele considerado na Fig. 5.3, um valor mínimo é obtido para uma tacoclina mais fina (como na Fig. 5.6, acima) e por isso a configuração oblata é a que melhor reproduz as observações, mas esse cenário poderia mudar se adotássemos um valor diferente para a difusividade na zona de convecção daquele considerado na Fig. 5.3. Note-se que os parâmetros usados no modelo da tacoclina prolata $\left(\omega_{1}=0.07 R_{\odot}\right.$ nos pólos, $\eta_{c}=5 \times 10^{9} \mathrm{~cm}^{2}$ $\mathrm{s}^{-1}$ ) pertencem à região proibida da Fig. 5.5. Se por exemplo, em concordância com o diagrama esquerdo da Fig. 5.5, adotássemos $\eta_{c z}$ entre $2 \times 10^{9} \mathrm{~cm}^{2} \mathrm{~s}^{-1}$ e $1 \times 10^{10} \mathrm{~cm}^{2}$ $\mathrm{s}^{-1}$, então, uma configuração prolata com uma largura $\omega_{1}$ nos pólos entre $0.08 R_{\odot}$ e $0.1 R_{\odot}$ deveria produzir um diagrama de borboleta apropriado já que nesse caso, ainda nas altas latitudes, onde a tacoclina é larga, a contribuição do cisalhamento latitudinal seria pequena o suficiente para não admitir campos toroidais intensos nesse ponto (tal como no painel 

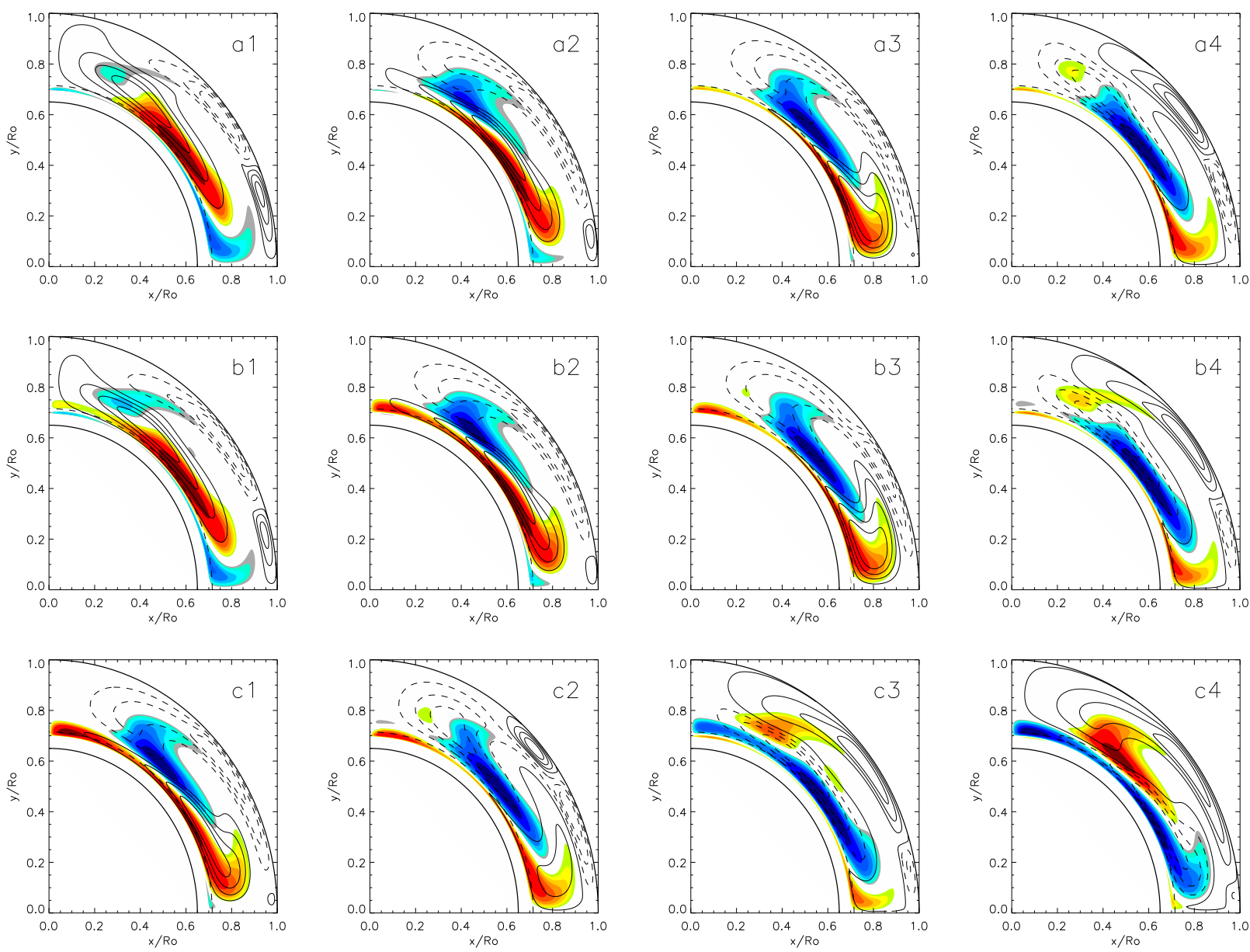

Figura 5.7: Contornos de campo magnético toroidal positivo (negativo) apresentados em escala de azul (vermelho), juntamente com as linhas de campo poloidal positivo (negativo) apresentados nas linhas contínuas (tracejadas), para diferentes tempos no transcorrer de um meio-ciclo de 11 anos $(T / 8, T / 4$, $3 T / 8$ e $T / 2$ ). As imagens de acima (a), do meio (b) e embaixo (c) correspondem aos modelos com uma tacoclina de espessura fina $\left(0.02 R_{\odot}\right)$, intermediária $\left(0.06 R_{\odot}\right)$, e larga $\left(0.1 R_{\odot}\right)$.

inferior da Fig. 5.6).

Contudo, o resultado acima não é simples de interpretar e é de certa forma ambíguo ao dar preferência a dois intervalos diferentes de espessuras da tacoclina. Porém, uma melhor compreensão desse resultado pode ser obtida se examinamos simultaneamente a distribuição radial e latitudinal dos campos magnéticos, como apresentado na Fig. 5.7. Nessa figura são mostrados mapas de contorno do campo magnético no plano meridional $(r, \theta)$, em quatro estágios diferentes do ciclo $(T / 8, T / 4,3 T / 8$ e $T / 2)$ e para três larguras diferentes da tacoclina, $0.02 R_{\odot}, 0.06 R_{\odot}$ e $0.1 R_{\odot}$. Vemos que quando a tacoclina é fina, o campo magnético gerado nos pólos, mantém-se confinado a uma camada muito estreita, no 
interior da camada de overshoot ou abaixo desta, fazendo assim com que esse campo seja mais estável às forças de empuxo. Além disso, já que toda a tacoclina encontra-se abaixo da interface da difusividade (que ocorre em $r=0.715 R_{\odot}$ ), o fluxo de campo poloidal que consegue ser transportado através dessa descontinuidade é muito baixo, o que implica em uma baixa amplitude do campo toroidal nessas latitudes. Já o campo toroidal, formado pelo cisalhamento latitudinal alcança amplitudes máximas nas latitudes intermediárias e baixas (veja os contornos mais intensos nas imagens superiores da Fig. 5.7).

Para a largura intermediária, uma fração da tacoclina pertence à região instável, onde o fluxo poloidal é maior. Assim, forma-se uma camada mais larga e intensa de campo magnético toroidal. Isso também acontece para a tacoclina de largura grande. No entanto, neste caso o campo toroidal mais intenso é formado aproximadamente no centro da tacoclina e se difunde por toda a sua espessura, de tal forma que no ponto radial onde estamos considerando que os tubos de fluxo começam a emergir $\left(r=R_{c}+\omega_{1} / 2\right)$, o campo assume amplitudes no intervalo permitido. Mas se a emergência dos tubos de fluxo fosse considerada a partir do valor de $B$ no centro da camada de overshoot, por exemplo, ou de uma média radial do campo toroidal em toda a extensão da tacoclina, os diagramas de borboleta apresentariam novamente campos toroidais intensos indesejados nos pólos.

O comportamento primeiro crescente e depois decrescente do campo toroidal encontrado na Fig. 5.5, indica que o valor do campo $B$ depende também do gradiente da difusividade, $\nabla \eta$, na zona de overshoot. Notamos que existe a competição entre três efeitos: a penetração do campo toroidal na zona estável devida gradiente na difusividade (i.e. terceiro termo da eq. 3.31), a amplificação do campo na tacoclina e a dissipação do mesmo na zona convectiva onde a difusividade é maior. Para maiores valores de $\nabla \eta$, maior será a fracção de campo $B$ penetrando na região de cisalhamento e por isso as curvas apresentam um comportamento inicialmente crescente. Existe um valor de $\eta$ para o qual o campo toroidal produzido é máximo. Esse valor é diferente para distintas espessuras da tacoclina. Então, para os maiores valores de $\eta$ a curva torna-se decrescente, indicando que os efeitos difusivos têm-se tornado dominantes. Os dois gráficos da Fig. 5.5 indicam que para espessuras $\lesssim 0.04 R_{\odot}$ e grandes valores de $\nabla \eta$ existe a tendência à formação de campos toroidais com intensidades no intervalo permitido. Isto sugere que, se a formação dos campos toroidais que observamos na superfície têm uma origem profunda (na base da 
zona convectiva), a tacoclina deve ser fina o suficiente e estar, preferivelmente, contida na região estável, abaixo da interface entre as zonas convectiva (turbulenta) e radiativa.

\subsection{Conclusões parciais e discussão}

Neste Capítulo exploramos os efeitos que variações na forma e na espessura da tacoclina solar têm sobre os resultados de um dínamo cinemático dominado pelo transporte de fluxo. Primeiramente, adotando valores o mais realistas possíveis para os parâmetros da difusão e do efeito $\alpha$, e considerando uma tacoclina de espessura constante $\omega_{1}=0.05 R_{\odot}$, reproduzimos apropriadamente as principais características do ciclo solar de 11 anos (Fig. 5.2). No entanto, nosso modelo sofre de um problema freqüente neste tipo de aproximação, que é a persistência de campos toroidais intensos nas altas latitudes.

Considerando-se então, uma tacoclina prolata (com uma espessura maior na região polar, como mostrado no diagrama superior da Fig. 5.3), o que significa um cisalhamento radial menor nas altas latitudes, obtemos um diagrama de borboleta similar ao obtido com uma tacoclina homogênea (Fig. 5.2). Por outro lado, quando consideramos uma tacoclina oblata (diagrama inferior da Fig. 5.3), obtemos um campo toroidal com uma distribuição latitudinal que concorda melhor com as observações, já que evita a formação de campos toroidais em latitudes maiores que $60^{\circ}$.

Em vista desse resultado um tanto surpreendente, calculamos o campo toroidal e as componentes radial e latitudinal do termo de cisalhamento na equação (4.1) os quais são os responsáveis pela amplificação da componente toroidal do campo, $\left(\mathbf{B}_{\mathbf{p}} \cdot \nabla\right) \Omega=B_{r} \partial \Omega / \partial r+$ $B_{\theta} / r \partial \Omega / \partial \theta$, como função da espessura, $\omega_{1}$, da tacoclina em uma latitude alta e em um tempo no qual $\partial \Omega / \partial r$ deve ser máximo. Os resultados sugerem que a componente latitudinal do cisalhamento domina sobre a componente radial na amplificação de campos toroidais.

Encontramos também que esses resultados são muito sensíveis ao perfil de difusividade adotado. Um diagrama do campo toroidal a uma latitude de $60^{\circ}$ em função da difusividade da camada convectiva, para tacoclinas com diferentes larguras, indica que os campos toroidais são eliminados nas altas latitudes para tacoclinas com $\omega_{1} \gtrsim 0.08 R_{\odot}$ (para $\eta_{c z}=2 \times 10^{9}-1 \times 10^{10} \mathrm{~cm}^{2} \mathrm{~s}^{-1}$, e $r_{c}=0.715 R_{\odot} ;$ e para $\eta_{c z}=6 \times 10^{9}-1.6 \times 10^{10} \mathrm{~cm}^{2} \mathrm{~s}^{-1} \mathrm{e}$ $r_{c}=0.72 R_{\odot}$ ) e para tacoclinas com $\omega_{1} \lesssim 0.02 R_{\odot}$ (praticamente para qualquer valor de $\eta_{c z}$ 
nesse caso). Para larguras intermediárias $\omega_{1} \simeq 0.04-0.06 R_{\odot}$, campos toroidais intensos persistem nas altas latitudes do diagrama de borboleta, fazendo com que essas larguras sejam não aceitáveis. É também importante o local onde se dá a medição do campos toroidais, para sua posterior emergência à superfície. Uma análise detalhada da distribuição dos campos no plano meridional e em diferentes estágios do ciclo, indicou por fim que as configurações mais favoráveis correspondem a uma tacoclina fina, localizada abaixo da camada de overshoot.

Verificamos que graças ao perfil de difusividade com dois degraus (um deles com valor similar à difusividade supergranular observada na superficie), a magnitude dos campos poloidais é reproduzida corretamente com exceção de uma ramificação de intenso campo radial que migra para o equador (veja as áreas brancas nos contornos em escala de cinzas em todos os diagramas de borboleta). A formação dessa ramificação deve-se à nossa implementação não-local do termo $\alpha$.

Os resultados deste Capítulo indicam que é possível encontrar-se um conjunto de parâmetros que reproduzem bastante bem os diagramas de borboleta observados. Note, porém, que nos melhores modelos obtidos neste Capítulo, ainda existem campos toroidais intensos em latitudes intermediárias, até $\lesssim 60^{\circ}$. É necessário notar ainda que existem outras dificuldades no cenário descrito. Quando são feitas considerações dinâmicas (não levadas em conta no modelo cinemático aqui discutido), verifica-se que a transformação da energia mecânica dos vários movimentos para energia magnética é insuficiente para produzir campos da ordem de $10^{5} \mathrm{G}$ nas latitudes observadas. Dessa forma, outros processos que podem ajudar à amplificação do campo podem também estar presentes no ciclo solar. Alguns desses processos serão examinados nos Capítulos seguintes. 
Capítulo 6

\section{Bombeamento magnético turbulento}

\section{(turbulent magnetic pumping)}

Em nosso modelo fenomenológico de dínamo solar, a formação do campo poloidal fundamenta-se na formação e emergência à superfície de tubos de fluxo magnético orientados na direção toroidal. Esse modelo de Babcock-Leighton (BL) ganhou força nas décadas de 1980 e 1990 devido às sérias limitações do modelo de dínamo turbulento $\alpha \Omega$ propriamente dito (i.e., aquele no qual o efeito $\alpha$ vem da contribuição das componentes flutuantes dos campos de velocidades e magnético em pequena escala, $\overline{\mathbf{u} \times \mathbf{b}}$ ). Conforme vimos nos Capítulos 3 e 5, os modelos de BL apresentam boa concordância com as observações. No entanto, conforme descrito em $\S 3.4$, o primeiro termo da força electromotriz, o tensor $a_{i j}$ na eq. (3.27), contribui na equação de indução com componentes simétricas (o tensor $\alpha$ ) e com componentes anti-simétricas (o vetor $\gamma$ ) (veja a eq. 3.28). As componentes simétricas têm um efeito indutivo, enquanto que as anti-simétricas possuem um efeito de advecção do campo magnético.

Esse último efeito, conhecido como bombeamento magnético turbulento (turbulent magnetic pumping), corresponde ao transporte do fluxo magnético nas direções radial, latitudinal e longitudinal, devido à presença de intensos gradientes na densidade (empuxo magnético turbulento) e/ou no nível de turbulência (diamagnetismo turbulento). O bombeamento magnético foi predito pela teoria de campo médio (Kichatinov e Ruediger, 1992), e exaustivamente estudado em simulações numéricas tridimensionais de convecção magnética turbulenta (Tobias et al., 1998, 2001; Ziegler e Rüdiger, 2003; Dorch e Nordlund, 2001). Porém, praticamente desconsiderado em modelos de dínamo axi-simétricos, como o nosso. 
Uma primeira aproximação mostrando a importância do pumping no ciclo solar foi feita por Brandenburg et al. (1992); e desde então somente alguns trabalhos o tem incorporado como um termo proporcional ao gradiente da difusividade que provê uma velocidade em direção ao interior solar (Küker et al., 2001; Bonanno et al., 2002, 2006). Mais recentemente, Käpylä et al. (2006) implementaram simulações de dínamo de campo médio no regime distribuído (§3.7.3), incluindo todos os coeficientes do tensor $\alpha_{i j}$ calculados em simulações de magneto-convecção (Ossendrijver et al., 2002; Käpylä et al., 2006). Eles obtém diagramas de borboleta que se parecem aos observados. No entanto, até agora, nenhum trabalho investigou os efeitos do pumping no comportamento dos campos em um plano meridional, no interior da zona de convecção, nem em um modelo de dínamo que siga uma descrição de BL.

Neste Capítulo, examinaremos os efeitos do bombeamento turbulento na formulação do dínamo de BL, usando versões modificadas do modelo apresentado no Capítulo 5. Em uma primeira aproximação, incluiremos a velocidade radial diamagnética na equação de indução tal como descrita por Kichatinov e Ruediger (1992). Em seguida incluiremos os termos de pumping calculados em simulações de magneto-convecção (Ossendrijver et al., 2002; Käpylä et al., 2006). Essa segunda aproximação inclui a contribuição do bombeamento tanto na direção radial, quanto na direção latitudinal. Iremos discutir também as implicações do pumping quando incluímos a camada de cisalhamento radial próxima à superfície (veja §2.2.2, e também Corbard e Thompson, 2002). Por fim, revisaremos brevemente o problema da paridade observada do campo magnético solar em modelos que incluem o transporte turbulento. Os resultados deste Capítulo foram publicados no artigo Guerrero e de Gouveia Dal Pino (2008), apresentado no Apêndice D.

\subsection{O modelo}

Tal como no Capítulo anterior, vamos resolver a equação de indução em coordenadas esféricas, eqs. (4.1) e (4.2), mas dessa vez incluiremos dois termos da expansão da força electromotriz (eq. 3.28), isto é:

$$
\mathcal{E}=\gamma \times \mathbf{B}-\beta \nabla \times \mathbf{B}
$$

onde não incluímos nenhuma componente do tensor $\alpha$ (veja eq. 3.28), já que neste trabalho 
adotamos uma formulação alternativa para o termo fonte do campo poloidal (veja §3.8.1). Vale a pena notar que outros efeitos indutivos, como o efeito $\alpha$ turbulento, ou aqueles provenientes de instabilidades nos tubos de fluxo, ou de instabilidades hidrodinâmicas na tacoclina, discutidos em $§ 3.7 .6$, podem de fato existir no interior da zona de convecção, ou na tacoclina, e participar de alguma forma no processo de dínamo. A nossa escolha do efeito $\alpha$ de BL baseia-se, como vimos, na hipótese da formação de campo poloidal a partir do decaimento de BMRs na superfície solar (veja §3.8).

Neste Capítulo, iremos considerar os intervalos espaciais $\left[0.6 R_{\odot}-R_{\odot}\right]$ e $[0-\pi]$, para as coordenadas $r$ e $\theta$, respectivamente, e utilizaremos uma resolução de $200 \times 200$ pontos de grade. Abrangeremos, portanto, os dois hemisférios do Sol. Isso nos permitirá estudar, mesmo que brevemente, o problema da simetria dos campos nos dois hemisférios.
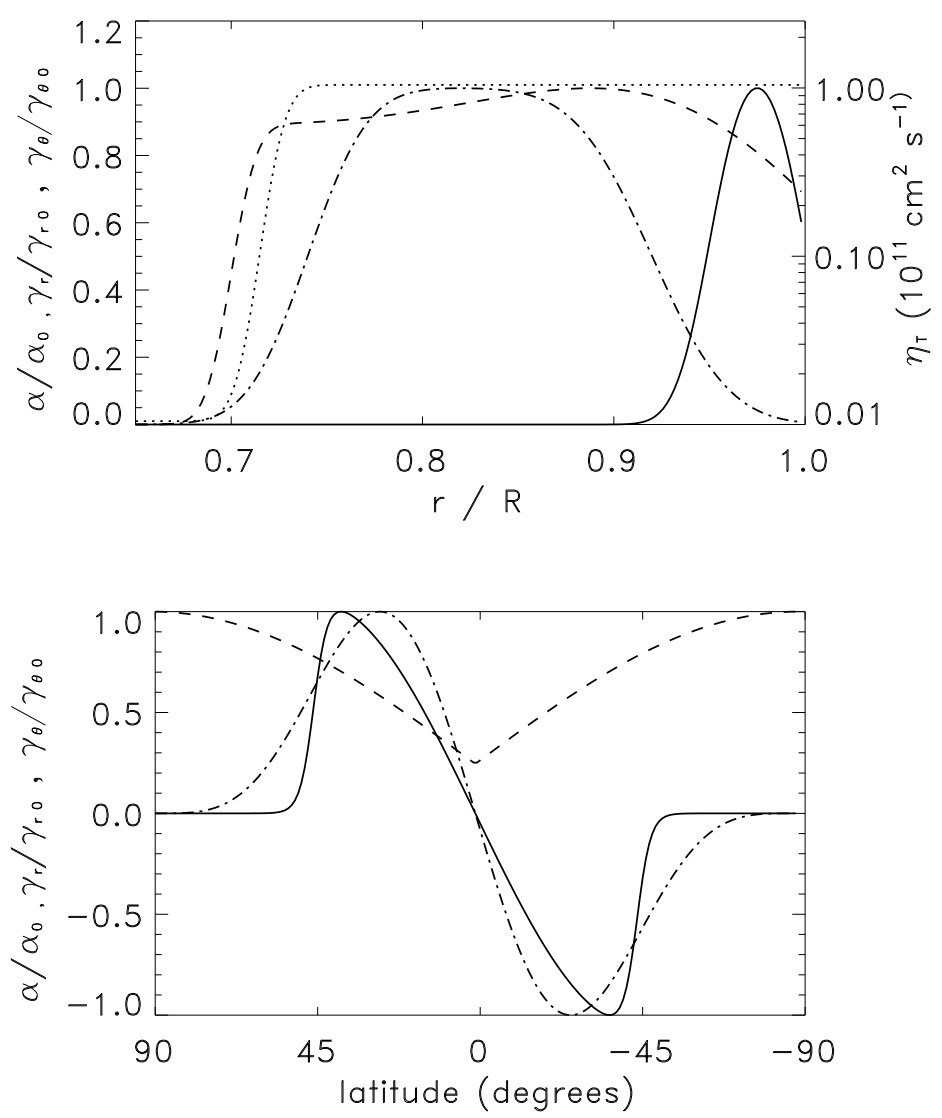

Figura 6.1: Perfis radial (acima) e latitudinal (embaixo) dos termos: $\alpha$-BL (linha contínua), $\eta$ (linha pontilhada), e de pumping $\gamma_{r}$ e $\gamma_{\theta}$ (linhas tracejada e ponto-tracejada, respectivamente). Todos os perfis estão normalizados pelo seu máximo valor. 


\subsection{Perfis}

\section{Rotação diferencial}

Inicialmente, tal como no capítulo anterior, iremos utilizar o perfil de rotação dado pela eq. (3.40) e mostrado na Fig. 3.4 (painel esquerdo). Porém, no presente caso iremos considerar unicamente uma espessura fina para a tacoclina: $\omega_{1}=0.02 R_{\odot}$.

\section{Circulação meridional}

Para o perfil de circulação meridional utilizaremos o perfil analítico usado em Dikpati e Charbonneau (1999), dado nas eqs. (3.61) e (3.62) e mostrado na Fig. 3.4 (painel direito). No entanto, agora, já que os efeitos do bombeamento magnético levam a uma maior penetração do campo magnético, iremos reduzir o parâmetro que define a penetração do fluido em relação as análises do Capítulo $5, R_{p}=0.71 R_{\odot}$.

\section{Difusividade magnética}

Nos modelos apresentados neste Capítulo iremos considerar unicamente um gradiente de difusividade (eq. 3.48) localizado em $r_{c}$, separando a região radiativa estável (com $\left.\eta_{r z}=10^{9} \mathrm{~cm} \mathrm{~s}^{-2}\right)$ da região convectiva turbulenta $\left(\operatorname{com~} \eta_{c z}=10^{11} \mathrm{~cm} \mathrm{~s}^{-2}\right.$ ) (veja a linha pontilhada na imagem superior da Fig. 6.1).

\section{O termo $\alpha$}

O termo $\alpha$ nos modelos deste Capítulo é o mesmo do Capítulo anterior: dado pelas eqs. (3.67), (3.68) e (5.4).

O valor dos parâmetros utilizados é resumido na Tabela 6.1.

\subsection{Resultados}

Na Figura 6.2, os efeitos do bombeamento magnético não foram considerados. Como foi encontrado no Capítulo anterior, neste caso a contribuição mais importante ao campo toroidal vem do termo de cisalhamento latitudinal. Assim, o campo responsável pela atividade observada começa a ser formado no interior da zona de convecção. Por outro lado, 
Tabela 6.1 - Valores dos parâmetros usados neste Capítulo; veja a Fig. 6.2

\begin{tabular}{lc}
\hline PARÂMETRO & VALOR \\
\hline$\Omega_{e q}$ & $2 \pi \times 460.7 \mathrm{nHz}$ \\
$R_{c}$ & $0.7 R_{\odot}$ \\
$\omega_{1}$ & $0.02 R_{\odot}$ \\
\hline$U_{0}$ & $1000 \mathrm{~cm} \mathrm{~s}^{-1}$ \\
$R_{p}$ & $0.71 R_{\odot}$ \\
\hline$\eta_{r z}$ & $1 \times 10^{9} \mathrm{~cm}^{2} \mathrm{~s}^{-1}$ \\
$\eta_{c z}$ & $1 \times 10^{11} \mathrm{~cm}^{2} \mathrm{~s}^{-1}$ \\
$\alpha_{0}$ & $17 \mathrm{~cm} \mathrm{~s}^{-1}$ \\
\hline$C_{\Omega}=\Omega_{e q} R_{\odot}^{2} / \eta_{c z}$ & $1.4 \times 10^{5}$ \\
$C_{\alpha}=\alpha_{0} R_{\odot} / \eta_{c z}$ & 11.8 \\
$C_{U}=U_{0} R_{\odot} / \eta_{c z}$ & 695.5 \\
\hline
\end{tabular}

como diminuímos o parâmetro $R_{p}$, a penetração do campo na camada estável (radiativa) é muito baixa, porém a velocidade equatorial do fluido é grande, de modo que o tempo que o campo toroidal leva para amplificar aos valores desejados pelas simulações de tubos de fluxo, é provavelmente curto. A Fig. 6.2 (painel superior) apresenta o diagrama de borboleta resultante deste modelo. São evidentes algumas diferenças com respeito aos modelos do Capítulo anterior, as quais devem-se à mudança de alguns parâmetros, especialmente, dos perfis de circulação meridional e difusividade. Para garantir que chegasse ao estado estacionário esse modelo foi integrado por $3.3 \times 10^{4}$ anos. Nesse tempo, o campo toroidal apresenta uma paridade aproximadamente anti-simétrica (ou seja, ele possui o mesmo sinal nos dois lados do equador), contradizendo a lei de Hale. Nos modelos de dínamo solar, esse problema é conhecido como o problema da paridade. Discutiremos esse problema mais adiante (§6.4). Nas próximas seções iremos considerar o bombeamento magnético como um mecanismo de penetração do fluxo magnético, alternativo ao fluxo meridional.

\subsubsection{Efeitos do bombeamento diamagnético}

Os coeficientes de bombeamento turbulento foram calculados segundo a teoria de campo médio na aproximação FOSA por Kichatinov e Ruediger (1992). Eles encontraram que a 

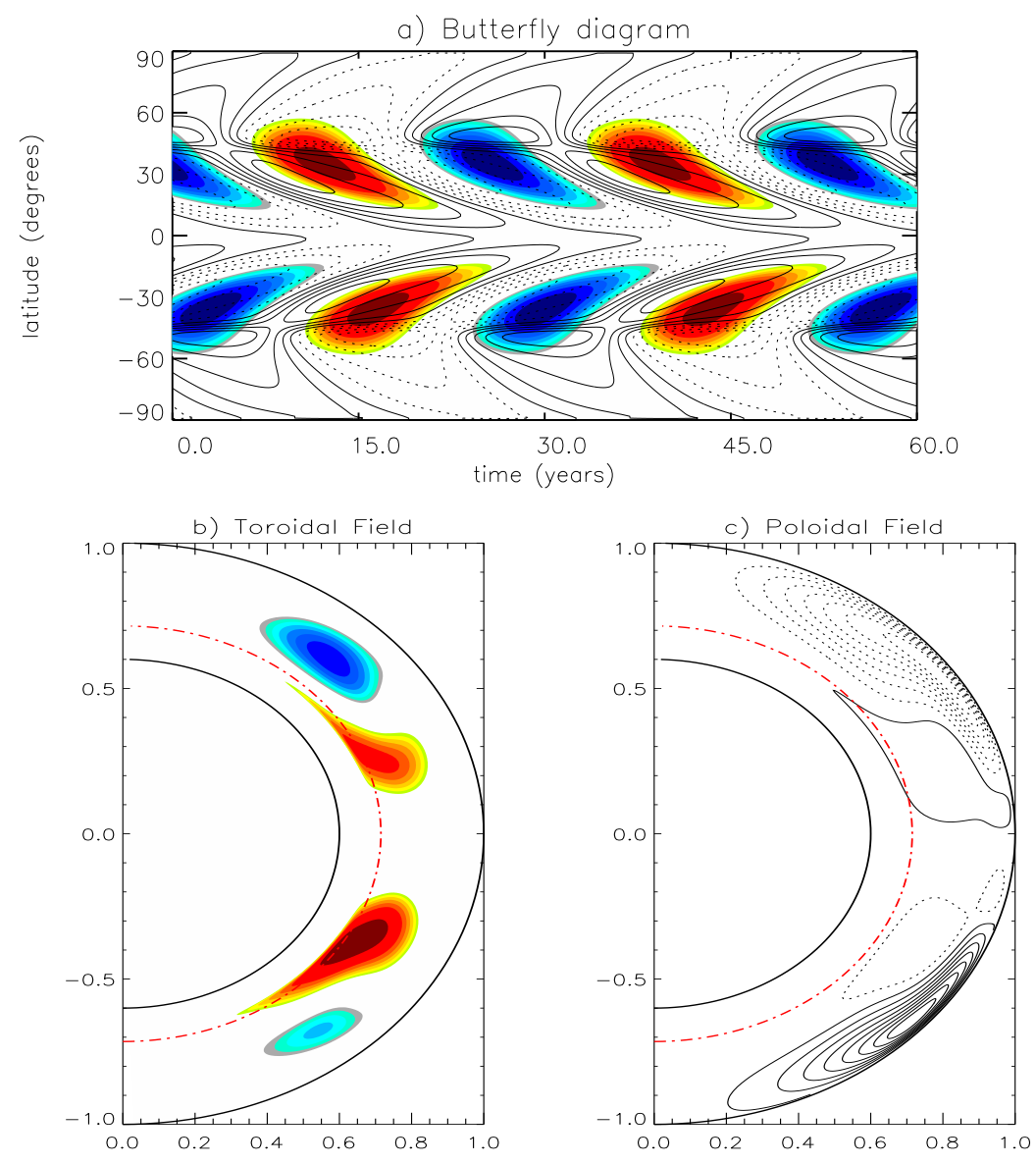

Figura 6.2: Diagrama de borboleta (a) e distribuições meridionais dos campos toroidal (b) e poloidal (c). As escalas em azul (vermelho) indicam contornos de campo toroidal positivo (negativo); as linhas contínuas e tracejadas representam campos poloidais positivos e negativos, respectivamente. Nesse modelo o período do ciclo é $T=13.6$ anos, $B_{\phi_{\max }}=4.06 \times 10^{4} \mathrm{G}$ e $B_{r_{\max }}=146.8 \mathrm{G}$. Somente os campos toroidais maiores que $2 \times 10^{4} \mathrm{G}$ (o contorno mais externo) são apresentados nas imagens (a) e (b). O modelo começou com condições iniciais anti-simétricas (veja mais detalhes no texto).

parte advectiva de $\mathcal{E}$ tem duas componentes:

$$
\gamma=U_{b u o}+U_{\text {dia }}
$$

onde o primeiro termo no lado direito da equção acima, é proporcional às variações na densidade, já que reproduz a tendência de o campo magnético ocupar as regiões menos densas. Ele tem a forma:

$$
U_{b u o}=\Psi(\Omega, \overline{\mathbf{B}}) \eta \frac{\nabla \log \rho}{2}
$$

e é conhecido como empuxo turbulento (turbulent buoyancy). No interior de uma camada em equilíbrio hidrostático, o sinal positivo desse termo indica que o empuxo dirige-se às 
regiões menos densas (Kichatinov, 1991; Kichatinov e Ruediger, 1992), ou seja, às camadas mais externas.

O segundo termo à direita da eq. (6.2) deve-se às variações no nível da turbulência no interior do fluido. Ele descreve a tendência de o campo magnético escapar das regiões onde existem variações no nível de turbulência. Na aproximação linear (FOSA) verifica-se que:

$$
U_{d i a}=-\Phi(\Omega, \overline{\mathbf{B}}) \frac{\nabla \eta}{2}
$$

o que mostra que variações no nível de turbulência implicam em variações no valor da difusividade. Devido à sua dependência com $\eta, U_{\text {dia }}$ é conhecido como bombeamento diamagnético. O sinal negativo indica que se $\eta$ tem um gradiente radial com valores maiores nas camadas mais externas, o campo magnético é transportado para o interior (Kichatinov, 1991; Kichatinov e Ruediger, 1992). As funções $\Psi$ e $\Phi$ indicam que o bombeamento magnético depende da rotação do sistema e do campo magnético, sendo amortecido para grandes valores de $\overline{\mathbf{B}}$.

Já que a densidade não é uma variável independente no nosso modelo, não é possível introduzir os efeitos de empuxo. No entanto, o bombeamento diamagnético pode ser introduzido trocando o termo $\eta \nabla \times \mathbf{B}$ por $\eta \nabla \times \mathbf{B}+\nabla \eta \times \mathbf{B} / 2$ nas eqs. (4.1) e (4.2). Esse novo termo incrementa o fluxo de campo poloidal que penetra na camada de overshoot (Fig. 6.3) e, como consequência, mais campo toroidal é produzido em todas as latitudes. O campo toroidal formado na zona de convecção também penetra na camada estável onde continua sendo amplificado pelo cisalhamento radial na tacoclina. A velocidade equatorial do fluxo magnético no interior da camada estável é bem menor que a velocidade logo acima da camada de overshoot, de tal forma que se os efeitos latitudinais do bombeamento não são considerados, o campo toroidal deve permanecer um tempo mais longo nessa camada. A velocidade radial correspondente ao bombeamento magnético ao redor da camada de overshoot (onde há um gradiente no perfil da difusividade), é $U_{d i a}=-\nabla \eta / 2 \simeq 47 \mathrm{~cm} \mathrm{~s}^{-1}$, pois temos considerado uma variação de duas ordens de magnitude em uma região fina de espessura $0.015 R_{\odot}$ (veja a linha pontilhada no painel superior da Fig 6.1). 

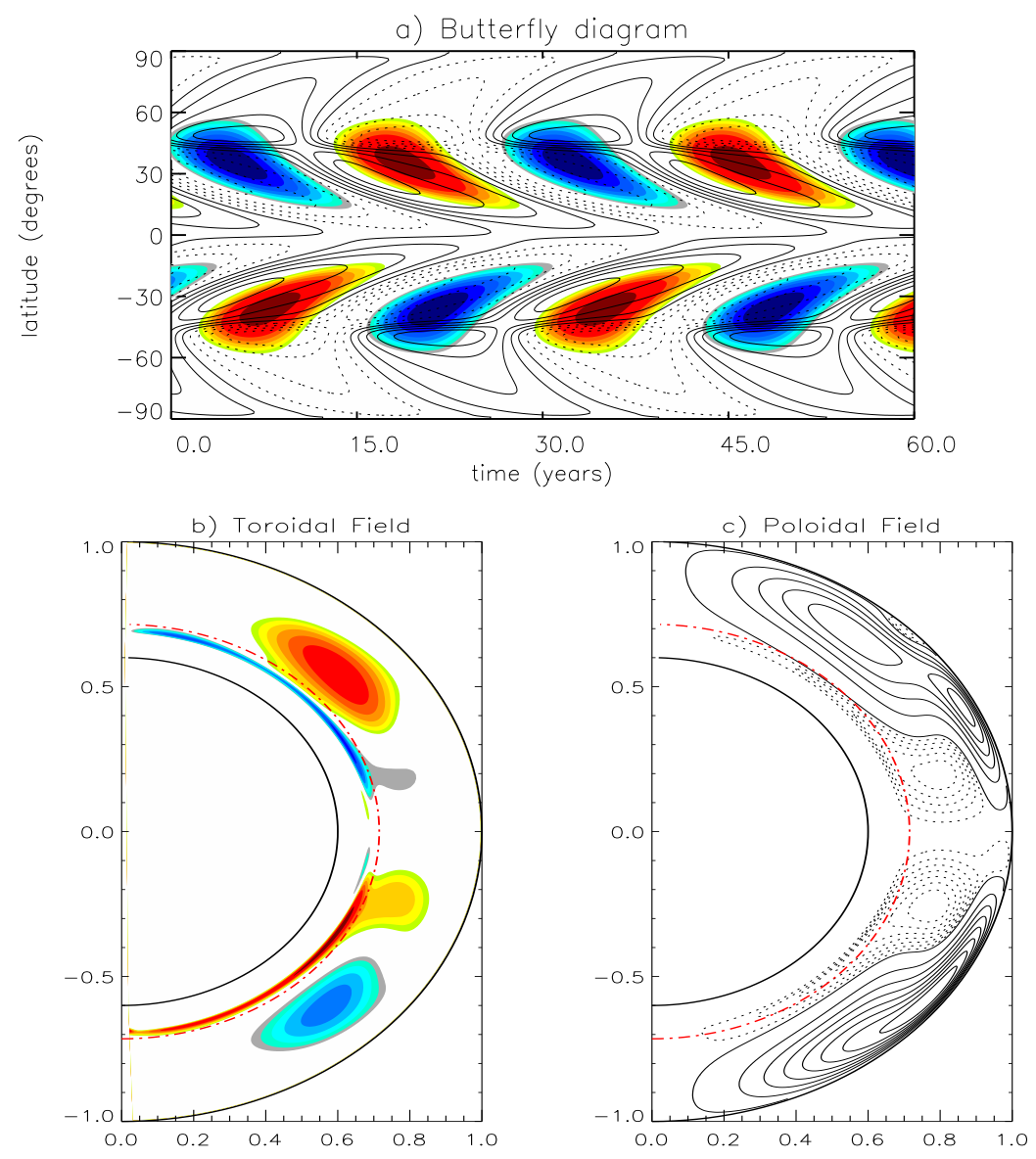

Figura 6.3: O mesmo que na Fig. 6.2, mas considerando o termo de pumping diamagnético. Nesse modelo o período do ciclo é $T=13.6$ anos, $B_{\phi_{\max }}=3.9 \times 10^{4} \mathrm{G}$ e $B_{r_{\max }}=147.6 \mathrm{G}$. O modelo começou com condições iniciais anti-simétricas.

\subsubsection{Bombeamento total}

Como se observou anteriormente, em uma camada de plasma convectivamente instável, o campo magnético é transportado em todas as direções devido à combinação dos efeitos do bombeamento. Dessa forma, por exemplo, o transporte central do bombeamento diamagnético pode ser balanceado pelos efeitos de empuxo. Assim, para investigar de forma geral os efeitos advectivos da turbulência, nesta seção iremos considerar as contribuições radial e latitudinal do vetor $\gamma$ (eq. 3.28), calculadas numericamente em simulações de magnetoconvecção (Ossendrijver et al., 2002; Käpylä et al., 2006). Os perfis dessas componentes são ajustados a partir dos resultados dessas simulações numéricas. Seguindo 
Käpylä et al. (2006), temos:

$$
\begin{aligned}
\gamma_{\theta} & =\gamma_{0 \theta}\left[1+\operatorname{erf}\left(\frac{r-0.8}{0.55}\right)\right] \\
& \times\left[1-\operatorname{erf}\left(\frac{r-0.98}{0.025}\right)\right] \\
& \times \cos \theta \sin ^{4} \theta \\
\gamma_{r} & =-\gamma_{0 r}\left[1+\operatorname{erf}\left(\frac{r-0.715}{0.015}\right)\right] \\
& \times\left[1-\operatorname{erf}\left(\frac{r-0.97}{0.1}\right)\right] \\
& \times\left[\exp \left(\frac{r-0.715}{0.015}\right)^{2} \cos \theta+1\right]
\end{aligned}
$$

onde $\gamma_{0 \theta}$ e $\gamma_{0 r}$ definem as amplitudes máximas dos coeficientes de bombeamento latitudinal e radial, respectivamente. O bombeamento latitudinal é zero na camada de overshoot e tem valores positivos (negativos) na zona de convecção no hemisfério norte (sul); ele é zero nos pólos e no equador, com uma amplitude máxima de $100 \mathrm{~cm} \mathrm{~s}^{-1}$ ao redor de $\sim 15^{\circ}$ (veja a linha ponto-tracejada da Fig. 6.1). O bombeamento radial, $\gamma_{r}$, é negativo na zona de convecção. Isso indica que há transporte central até $r=0.7 R_{\odot}$ (ou seja, até uma profundidade inferior ao centro da camada de overshoot) e se anula abaixo dessa profundidade. A sua máxima amplitude é $40 \mathrm{~cm} \mathrm{~s}^{-1}$ (veja a linha tracejada na Fig. 6.1). Não iremos considerar a contribuição longitudinal do bombeamento já que essa é muito pequena comparada com o termo de velocidade longitudinal $u_{\phi}$.

A Figura 6.4 mostra que os termos de bombeamento, além de transportar o campo para a região estável, resultam uma melhor distribuição latitudinal dos campos toroidais, comparada com àquelas das Figs. 6.2 e 6.3. Os gradientes de difusividade e densidade geram o bombeamento do campo magnético nas direções central e equatorial. Esse resultado é importante para os modelos de dínamo já que sugere que o bombeamento pode ajudar a formar a distribuição latitudinal de campos, tal como observado, além de empurrar o fluxo magnético para a camada estável onde os campos toroidais podem ser armazenados e ganhar maior amplificação.

\subsubsection{Fluxo meridional superficial}

Como o bombeamento e o fluxo meridional são termos advectivos e em algumas regiões dentro da zona de convecção as suas componentes têm o mesmo sinal, ao considerarmos 

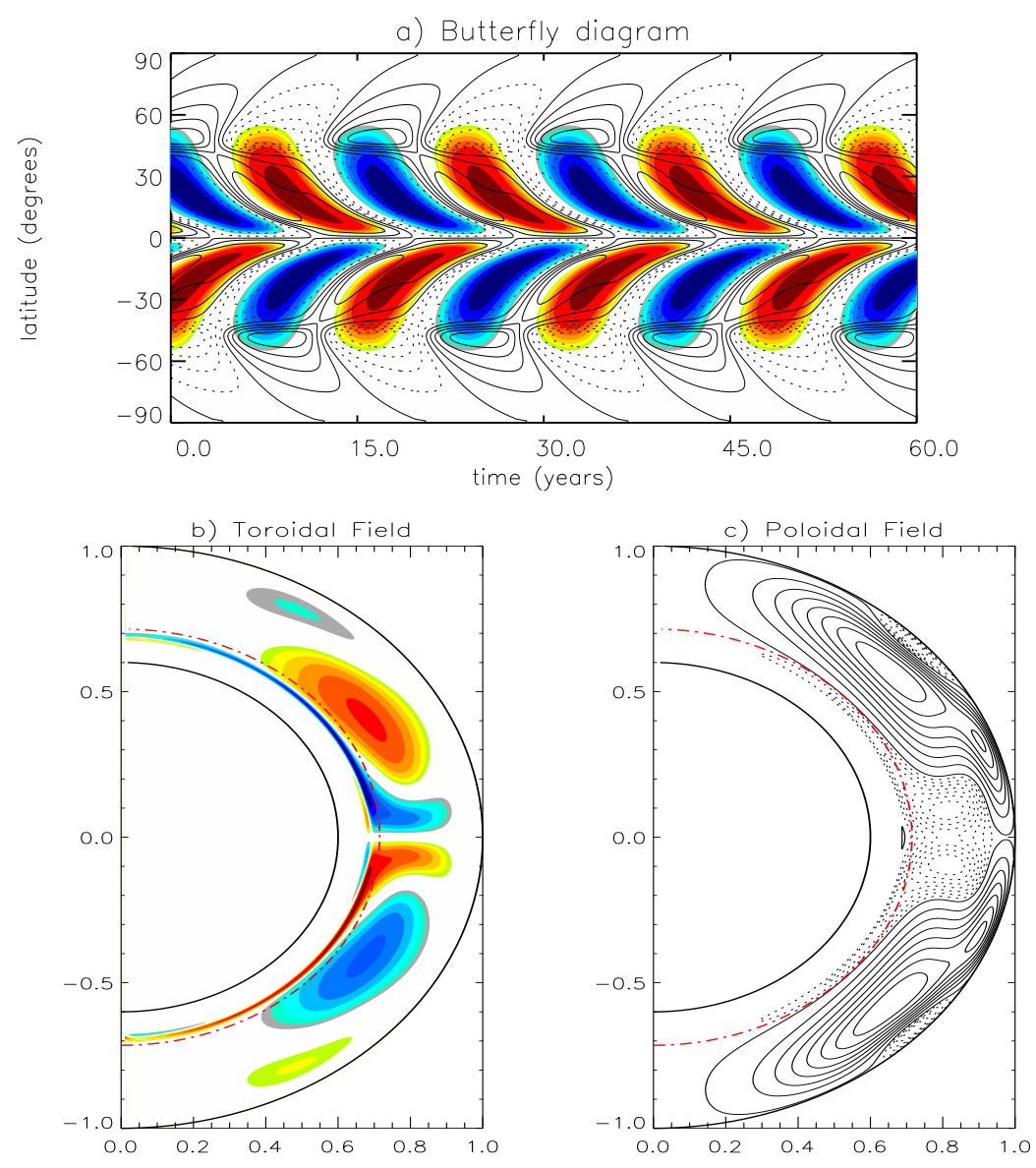

Figura 6.4: O mesmo que a Fig. 6.2 para um modelo com a contribuição geral do bombeamento obtidos a partir de simulações de magneto-convecção. Nesse modelo o período do ciclo é $T=8.2$ anos, $B_{\phi_{\max }}=4.8 \times 10^{4}$ G e $B_{r_{\max }}=155.92$ G. O modelo começou com condições iniciais anti-simétricas.

todos os termos de bombeamento o período do ciclo passa a ser fortemente afetado. Ele vai de 13.6 anos nos modelos das Figs. 6.2 e 6.3 (sem bombeamento), a 8.2 anos no modelo da Fig. 6.4 (com bombeamento). Uma forma de reproduzir novamente o período observado no ciclo solar é reduzir o valor da difusividade na zona convectiva, mas essa possibilidade não é muito realista já que a difusividade supergranular é, na verdade, uma a duas ordens de grandeza maior do que o valor assumido neste caso. Outra possibilidade é diminuir a profundidade de penetração do fluxo meridional. Essa opção é consistente com resultados recentes de héliossismologia (Mitra-Kraev e Thompson, 2007), que sugerem que o ponto do retorno do fluxo (onde a direção da velocidade começa a apontar para o equador) pode estar em torno de $\sim 0.95 R_{\odot}$. Nas regiões mais profundas, abaixo de $\sim 0.8 R_{\odot}$, poderia existir uma segunda célula de fluxo meridional com menor amplitude de velocidade, ou ainda 
completa ausência de fluxo meridional em grande escala. Na imagem superior da Fig. 6.5, apresentamos o perfil de fluxo meridional quando a profundidade de penetração é reduzida para $0.8 R_{\odot}$. Na imagem inferior apresentamos o diagrama de borboleta para um modelo que utiliza esse perfil. Verifica-se que o período recobra o valor observado, ao mesmo tempo que os campos toroidais aparecem mais concentrados nas baixas latitudes. Se diminuímos ainda mais a profundidade de penetração, a concentração equatorial dos campos toroidais é ainda maior e o período mais longo. A razão para esse comportamento é que, nesse caso, não há fluxo magnético movimentando-se na direção dos pólos na metade inferior da zona convectiva, já que esse movimenta-se na direção do equador com a velocidade de bombeamento. Esse resultado confirma a hipótese de Ossendrijver et al. (2002) que sugerem que o movimento equatorial observado na atividade magnética poderia não ser produto do movimento do fluxo meridional, mas sobretudo do bombeamento latitudinal do campo magnético toroidal. Uma análise dos parâmetros das simulações efetuadas nessas condições leva a um período:

$$
T \simeq 181.2(\text { anos }) U_{0}^{-0.12} \gamma_{r 0}^{-0.51} \gamma_{\theta_{0}}^{-0.05},\left\{\begin{array}{l}
500 \leq U_{0} \leq 3000 \mathrm{~cm} \mathrm{~s}^{-1} \\
60 \leq \gamma_{\theta 0} \leq 140 \mathrm{~cm} \mathrm{~s}^{-1} \\
20 \leq \gamma_{r 0} \leq 120 \mathrm{~cm} \mathrm{~s}^{-1}
\end{array}\right.
$$

o qual indica que os termos de bombeamento regulam o período do ciclo, levando a uma classe diferente de modelos de dínamo, que são dominados pelos termos advectivos turbulentos, ao invés de pelo fluxo meridional. Na Fig. 6.5 ajustamos os valores do fluxo meridional e do bombeamento magnético que resultam em um diagrama de borboleta compatível com o observado, com um período de 10.8 anos e a diferença de fase apropriada entre as componentes do campo.

\subsubsection{Efeito $\Omega$ na camada próxima à superfície}

Recentemente, Brandenburg (2005) discutiu a possibilidade de um dínamo operando nas camadas mais externas do sol, excitado pelo cisalhamento radial detectado em observações de héliossismologia nessa região (Corbard e Thompson, 2002).

As características mais atraentes de um modelo de dínamo de tipo $\alpha \Omega$ operando nessa região seriam: (i) a intensidade dos tubos de fluxo magnético internos não precisariam alcançar intensidades tão altas quanto $10^{5} \mathrm{G}$ para originarem as manchas solares na su- 

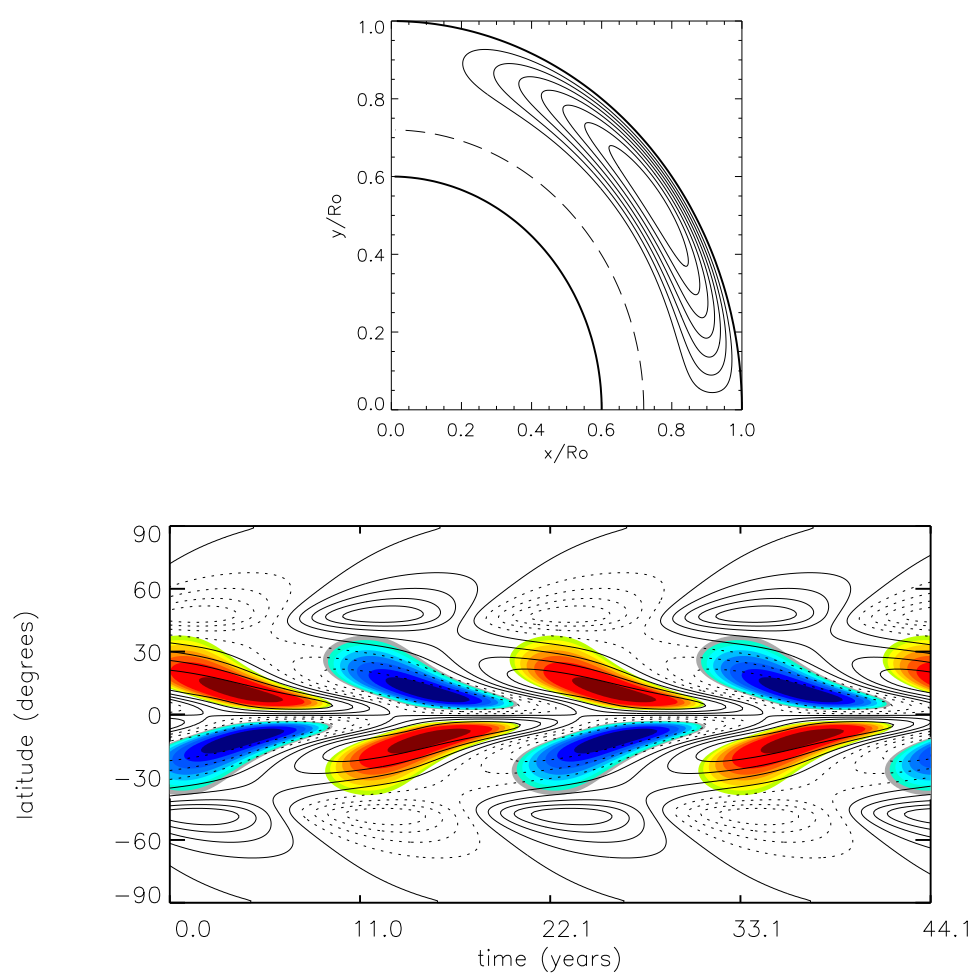

Figura 6.5: Linhas de fluxo meridional (acima) e diagrama de borboleta (embaixo) para um modelo incluindo as componentes de bombeamento e um perfil de circulação meridional menos profundo, com $R_{p}=0.8 R_{\odot}, U_{0}=1300 \mathrm{~cm} \mathrm{~s}^{-1}, \gamma_{\theta 0}=90 \mathrm{~cm} \mathrm{~s}^{-1} \mathrm{e} \gamma_{r 0}=30 \mathrm{~cm} \mathrm{~s}^{-1}$. Nesse modelo $T=10.8$ anos, $B_{\phi_{\max }}=4.5 \times$ $10^{4} \mathrm{G}$ e $B_{r_{\max }}=154.9$ G. Esse modelo começou com condições iniciais anti-simétricas.

perfície com a magnitude de campo magnético observada. Campos da ordem de $10^{3} \mathrm{G}$ já seriam suficientes; e (ii) com um efeito $\Omega$ operando próximo à superfície seria possível explicar a coincidência da velocidade angular das manchas solares na fotosfera com a velocidade angular em $r=0.95 R_{\odot}$, bem como a desconexão aparente entre a parte fotosférica das manchas e as suas bases encontrada por Kosovichev (2002).

A contribuição do cisalhamento radial próximo à superfície já foi estudada em modelos de dínamos de interface (§3.7.3) por Mason et al. (2002), em dínamos do tipo distribuído (§3.7.3) com um efeito $\alpha$ turbulento por Käpylä et al. (2006), e também em dínamos dominados pela advecção, como o que estudamos neste trabalho (§3.8), por Dikpati et al. (2002). Neste último caso descartou-se a possibilidade da operação do dínamo próximo à superfície, pois nos diagramas de borboleta produzidos por eles o campo toroidal positivo ajuda formar um campo radial negativo, o qual é exatamente oposto ao observado.

Nesta seção consideraremos o cisalhamento radial próximo da superfície juntamente 
com o bombeamento magnético. Para tal, substituiremos o perfil de rotação diferencial da eq. (3.40) por aquele usado por Dikpati et al. (2002), dado pelas eqs. (3.41) a (3.44), e apresentado na Fig. 3.4 (centro). Esse perfil contém um cisalhamento radial negativo em latitudes abaixo de $45^{\circ}$ e um cisalhamento radial positivo acima dessa latitude ${ }^{1}$.

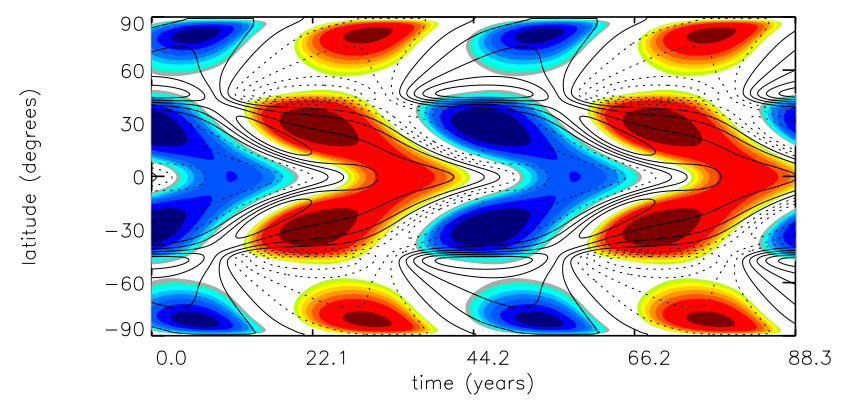

Figura 6.6: Diagrama de borboleta para um modelo com os mesmos parâmetros da Fig. 6.2, mas incluindo o cisalhamento próximo da superfície. Neste modelo $T=15.6$ anos, $B_{\phi_{\max }}(r=0.715)=1.1 \times 10^{5}$ $\mathrm{G}, B_{\phi_{\max }}(r=0.98)=1.9 \times 10^{4} \mathrm{G}$ e $B_{r_{\max }}=131.7 \mathrm{G}$. Este modelo começou com condições iniciais simétricas.

Assumindo que as manchas solares são formadas nas camadas superiores, o efeito $\alpha$ de Babcock-Leighton, que se concentra acima de $r=0.95 R_{\odot}$, não precisa mais ser considerado de forma não-local com o campo toroidal, pois o acoplamento entre os dois processos, $\alpha$ e $\Omega$, se dá na mesma região. Pela mesma razão os resultados mostrados no diagrama de borboleta correspondem dessa vez ao mesmo ponto radial, $r=0.98 R_{\odot}$, tanto para o campo radial quanto para o campo toroidal. Assim, usando os mesmos perfis que no modelo da Fig. 6.2, mas considerando o cisalhamento próximo da superfície, os resultados da Fig. 6.6 mostram duas ramificações principais do campo toroidal no diagrama de borboleta. Uma delas está migrando em direção aos pólos (em altas latitudes) e a outra está migrando em direção ao equador (em latitudes abaixo de $45^{\circ}$ ). Esse é o resultado que se espera se a regra do sinal de Parker-Yoshimura (eq. 3.39) for considerada. Observamos também que a paridade resultante é quadrupolar ou simétrica, porém com uma diferença de fase apropriada entre os campos. Contudo, a amplitude dos campos toroidais nos pólos é grande o suficiente para provocar o surgimento de manchas não desejadas nessas latitudes. Além disso, verifica-se que o período do ciclo aumenta para 15.6 anos, devido ao fato de que a velocidade do fluxo meridional aponta na direção contraria à velocidade da onda de

\footnotetext{
${ }^{1}$ O perfil da rotação diferencial usado por Käpylä et al. (2006) é ligeiramente diferente do usado neste trabalho já que eles consideram um cisalhamento radial negativo em todas as latitudes.
} 
dínamo, a qual é dominante nessa região.

Na Fig. 6.7 usamos os mesmos parâmetros da Fig. 6.5, mas dessa vez incluímos o cisalhamento radial superficial. Já que o bombeamento radial tem maior amplitude perto dos pólos (veja as linhas tracejadas na Fig. 6.1), os campos toroidais criados nesse ponto são eficientemente empurrados na direção central antes deles alcançarem uma amplitude grande, de tal forma que sobrevivem unicamente campos toroidais abaixo de $45^{\circ}$. Esse cenário requer que o bombeamento diamagnético seja dominante sobre o empuxo nas altas latitudes. Por outro lado, a diferença de fase entre $B_{r}$ e $B_{\phi}$, obtida no modelo da Fig. 6.7, parece coincidir com aquela observada, pelo menos nas latitudes de máxima atividade. No entanto, apresenta-se uma sobreposição dos campos de um ciclo e do seguinte que é ligeiramente maior do que aquela observada. Devemos notar, porém, que resultados realistas podem ser obtidos se os parâmetros acima forem ajustados com maior precisão.
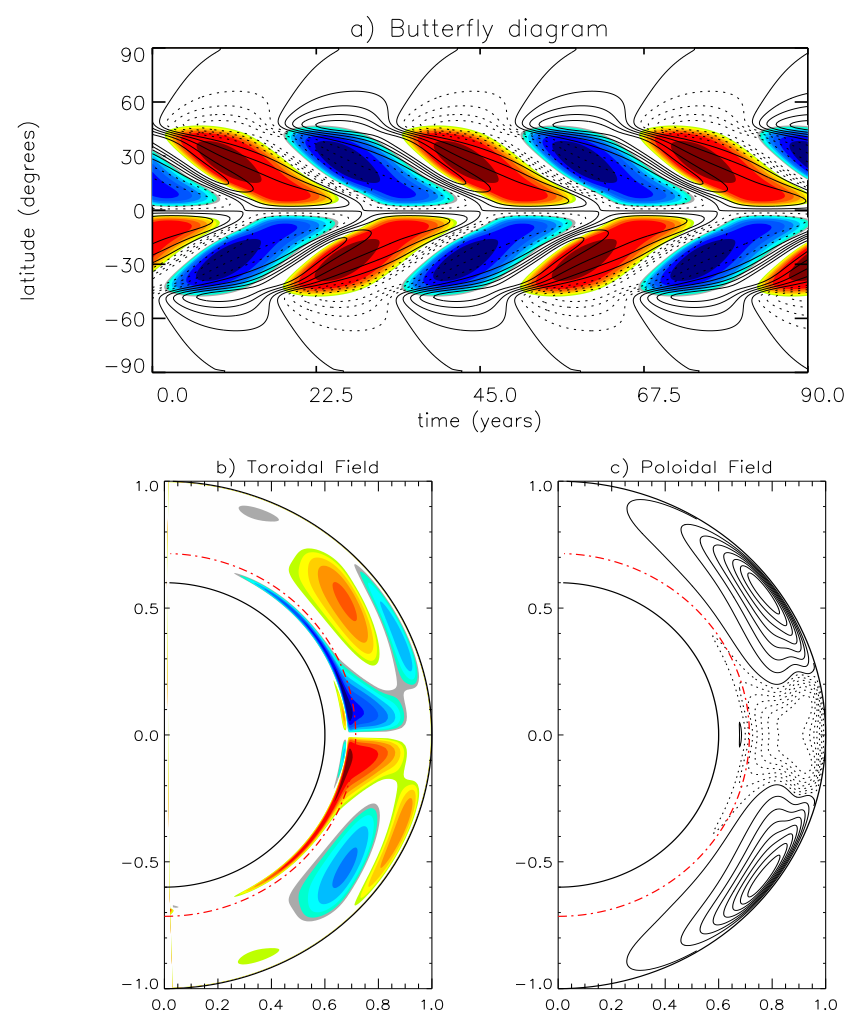

Figura 6.7: O mesmo que na Fig 6.5 mas para um modelo com cisalhamento radial próximo da superfície. Neste modelo $T=16.3$ anos, $B_{\phi_{\max }}(r=0.715)=9.7 \times 10^{4} \mathrm{G}, B_{\phi_{\max }}(r=0.98)=1.9 \times 10^{4} \mathrm{G}$ e $B_{r_{\max }}=164.4 \mathrm{G}$. Este modelo começou com condições iniciais simétricas.

Vale a pena notar, que modelos que incluem o cisalhamento radial superficial e uma célula de fluxo meridional penetrando até $r=0.71 R_{\odot}$, tal como no modelo da Fig. 6.4, 
precisam que a amplitude do efeito $\alpha$ seja incrementada. Esse resultado concorda com o modelo de Käpylä et al. (2006).

\subsection{Breve estudo do problema da paridade}

Embora já tenha sido estudada por vário autores, a anti-simetria (paridade dipolar) dos campos magnéticos toroidais através do equador solar ainda constitui um dos maiores problemas na teoria do dínamo solar. Isto deve-se principalmente ao fato de que a paridade resultante em um modelo é muito sensível a um grande número de parâmetros, o que significa que pequenas variações no espaço de parâmetros podem trocar uma solução dipolar para uma quadrupolar. A paridade observada (anti-simétrica) pode resultar de um eficaz acoplamento difusivo dos campos poloidais nos dois hemisférios, como foi apontado por Chatterjee et al. (2004), mas pode também depender do perfil radial do efeito $\alpha$ (Dikpati e Gilman, 2001a; Bonanno et al., 2002), ou ainda ser o resultado da assinatura quadrupolar que o fluxo meridional imprime no campo magnético poloidal, como é argumentado por Charbonneau (2007). Embora o objetivo principal deste Capítulo não seja o estudo do problema da paridade, e sim a contribuição do bombeamento magnético turbulento, iremos aproveitar os resultados dos modelos apresentados acima para analisar como o bombeamento afeta a paridade.

Todas as simulações apresentadas neste Capítulo evoluíram $10^{7}$ passos temporais até alcançarem $\sim 10^{4}$ anos. As condições iniciais do campo toroidal empregadas foram ora anti-simétricas (A), ora simétricas (S), mas também realizamos alguns testes usando um campo toroidal randômico $(\mathrm{R})$ como condição inicial. A paridade da solução é calculada a partir da seguinte equação (Chatterjee et al., 2004):

$$
P(t)=\frac{\int_{-T / 2}^{T / 2}\left(B_{N}(t)-\bar{B}_{N}\right)\left(B_{S}(t)-\bar{B}_{S}\right) d t}{\sqrt{\int_{-T / 2}^{T / 2}\left(B_{N}(t)-\bar{B}_{N}\right)^{2} d t} \sqrt{\int_{-T / 2}^{T / 2}\left(B_{S}(t)-\bar{B}_{S}\right)^{2} d t}},
$$

onde $B_{N}$ e $B_{S}$ são os valores do campo magnético toroidal em $r=0.715 R_{\odot}$, e $\theta=25^{\circ}$ e $-25^{\circ}$, respectivamente. $\bar{B}_{N}$ e $\bar{B}_{S}$ correspondem a médias temporais sobre um período. O valor de $P$ deve estar entre +1 (solução simétrica) e -1 (solução anti-simétrica), dependendo da paridade do campo. Os resultados de nossos experimentos numéricos com respeito à paridade podem ser resumidos como segue: 
- Os resultados dos modelos sem bombeamento (e.g Fig. 6.2), e aqueles com bombeamento diamagnético (Fig. 6.3) têm uma paridade simétrica (quadrupolar). Quando a sua condição inicial é anti-simétrica (dipolar), eles levam muitos anos até trocar de simetria, como indica a Fig. 6.8a.

Note-se que esse resultado é um pouco diferente do obtido por Dikpati e Gilman (2001a) ou Chatterjee et al. (2004), já que nos modelos desses autores a mudança de paridade acontece mais rápido, depois de apenas 500 anos, indicando uma grande sensibilidade da paridade resultante aos parâmetros iniciais de cada modelo. Ao mesmo tempo, essa divergência é um indicador de que a paridade observada hoje em dia no Sol poderia vir a mudar com o tempo, pelo menos no caso em que o bombeamento turbulento não seja realmente relevante para o dínamo.

- Já os modelos que incluem os termos de bombeamento, $\gamma_{r}$ e $\gamma_{\theta}$ (e.g Fig. 6.5), conservam a paridade da condição inicial, seja ela simétrica ou anti-simétrica, como indicado na Fig. 6.8b. No entanto, quando a condição inicial é do tipo randômico, o sistema tende rapidamente a escolher a paridade simétrica (quadrupolar), mas depois tende a mudar para uma paridade anti-simétrica (linha ponto-tracejada da Fig. $6.8 b)$, o que sugere que a assinatura altamente quadrupolar do fluxo meridional pode ser apagada quando o bombeamento magnético é considerado.

- Por outro lado, os modelos que incluem os termos de bombeamento juntamente com a camada de cisalhamento superficial (e.g. Fig. 6.7), tendem a uma paridade dipolar desde os primeiros anos de evolução do modelo, como mostra a linha contínua da Fig. 6.8c. Nesses modelos, o acoplamento dos campos toroidais nos dois hemisférios é mais efetivo, provavelmente devido ao fato de que nesses casos o termo $\alpha$ opera localmente. Por exemplo, Chatterjee et al. (2004) obtém uma solução dipolar em um modelo onde consideram um efeito $\alpha$ concentrado na superfície (agindo localmente), combinado com um mecanismo numérico de erupção dos tubos de fluxo e uma alta difusividade na zona de convecção. No entanto, o efeito $\alpha$ local por si só não é suficiente para assegurar a paridade dipolar, como confirma a Fig. 6.6 e a linha tracejada da Fig. 6.8c. Aparentemente, o fator determinante para isso é eliminar a assinatura quadrupolar que o fluxo meridional imprime no campo poloidal dos dois 
hemisférios e permitir o acoplamento difusivo do mesmo na latitude equatorial. Isto pode ser alcançado de várias formas, por exemplo, considerando-se um efeito $\alpha$ na base da zona convectiva (Dikpati e Gilman, 2001a; Bonanno et al., 2002), com o emprego de uma alta difusividade (Chatterjee et al., 2004), ou ainda, como o indica a linha contínua da Fig. 6.8c, considerando-se outros mecanismos de transporte do campo magnético, como o bombeamento turbulento (Guerrero e de Gouveia Dal Pino, 2008).
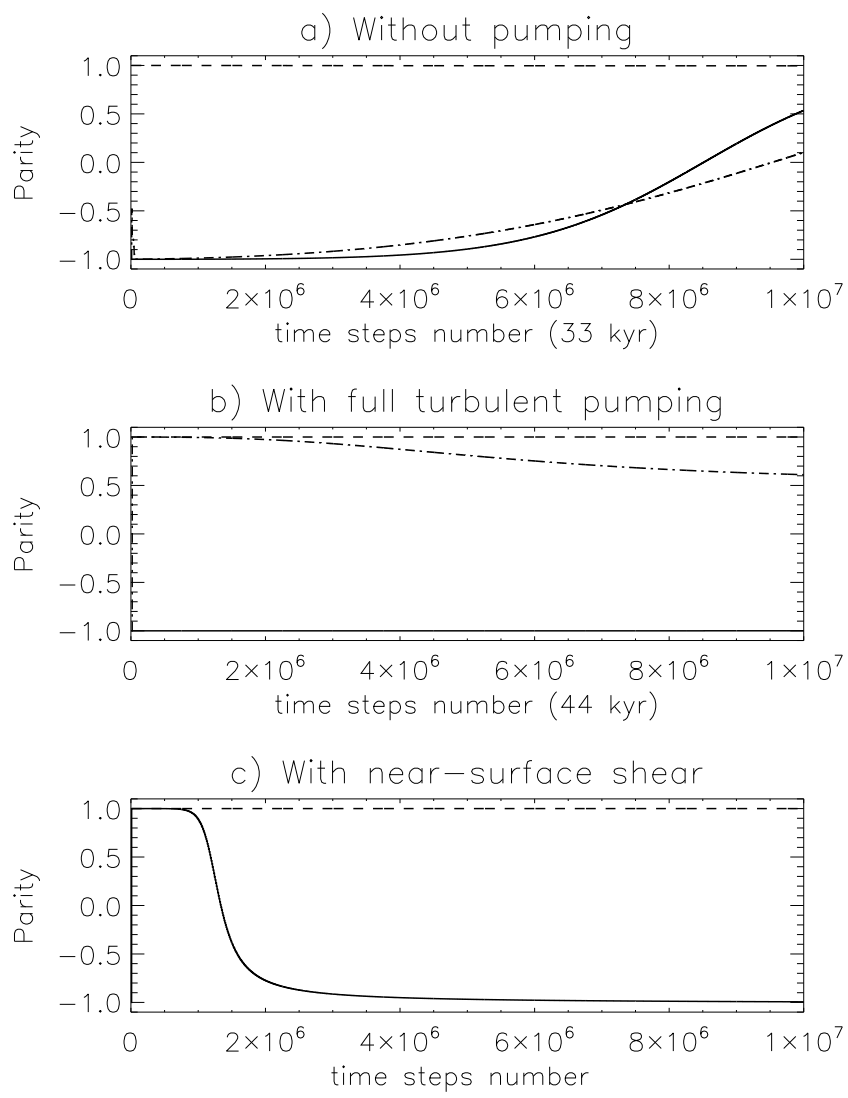

Figura 6.8: Curvas da paridade para as três classes de modelos consideradas, i.e., (a) modelos sem bombeamento (e.g. Fig, 6.2); (b) modelos com bombeamento total (e.g., Fig. 6.5); e (c) modelos com cisalhamento próximo à superfície (e.g., Figs. 6.6 e 6.7). Nos painéis (a) e (b), as linhas contínua, tracejada e ponto-tracejada correspondem a condições iniciais simétrica, anti-simétrica e randômica, respectivamente. No painel (c), a linha contínua é utilizada para o modelo com bombeamento turbulento e a linha tracejada para o modelo sem bombeamento. 


\subsection{Conclusões parciais deste Capítulo}

Neste Capítulo realizamos simulações numéricas de um modelo de dínamo de campo médio dominado pelo transporte de fluxo, com um efeito $\alpha$ de tipo BL, mas incluindo o efeito de bombeamento magnético turbulento. Nosso primeiro conjunto de simulações utilizou um perfil realista da rotação diferencial, porém, sem incluir o cisalhamento radial superficial. Os resultados mostram que os efeitos de transporte do bombeamento turbulento são, sem dúvida, relevantes nas simulações de dínamo solar, já que podem ajudar a resolver dois importantes problemas amplamente discutidos na literatura: o problema do armazenamento do campo toroidal na camada estável (sob a zona convectiva) e o de sua distribuição latitudinal (como discutido no Capítulo anterior).

Propusemos um novo cenário para o dínamo solar, no qual o fluxo meridional é importante, unicamente nas camadas mais externas, para fazer operar os efeitos de transporte de fluxo requeridos pelo mecanismo de BL. Já nas camadas mais internas, a advecção do campo é dominada pela velocidade de bombeamento. Nossos resultados suportam a idéia de que a migração equatorial da atividade solar observada deve-se ao bombeamento latitudinal do campo, tanto na camada de overshoot, quanto na zona convectiva. Outra característica importante deste cenário é que um fluxo meridional coerente durante todo o tempo (aliás, uma coerência difícil de se observar e de se explicar teoricamente) não é mais exigido para fazer o dínamo operar.

Em um segundo grupo de simulações incluímos a camada de cisalhamento superficial detectada em observações mais recentes de héliossismologia, nos últimos $35 \mathrm{Mm}$ do Sol (Corbard e Thompson, 2002). Os resultados mostram a formação de uma segunda camada de campos toroidais intensos próxima à superfície do Sol quando as componentes de bombeamento não são consideradas. As ramificações desse campo obedecem à lei de Parker-Yoshimura para um efeito $\alpha$ positivo, i.e., movimentam-se em direção aos pólos nas altas latitudes e em direção ao equador abaixo de $45^{\circ}$. O papel do bombeamento nesta classe de modelos é também interessante já que reduz a amplitude dos campos toroidais nos pólos, empurrando-os em direção ao centro (Fig. 6.7). Esses modelos funcionam melhor se o perfil de circulação meridional for raso. Ao contrário, se permitirmos um fluxo meridional profundo chegando até a tacoclina, torna-se difícil excitar o dínamo para valores baixos (mais realistas) do efeito $\alpha$. 
Com respeito ao problema da paridade, os nossos resultados indicam que um modelo simples de dínamo $\alpha \Omega$, com o efeito $\alpha$ concentrado na superfície, termina com uma paridade quadrupolar. Os modelos com bombeamento conservam a paridade inicial, e quando a mesma é randômica, o sistema tende à paridade como observada (dipolar). As soluções de todos os modelos que combinam bombeamento turbulento e cisalhamento superficial levam também à paridade dipolar.

Resumindo, nossos resultados demonstram a importância do bombeamento no dínamo solar e sugerem que esse efeito deve ser incluído nos estudos futuros, mesmo naqueles que consideram múltiplas células de conveç̧ão (Bonanno et al., 2006; Jouve e Brun, 2007). Além disso, o bombeamento diminui a importância do fluxo meridional em dois aspectos importantes: no período do ciclo e na distribuição latitudinal dos campos. Por outro lado, nossos resultados indicam também que na presença do transporte turbulento existem duas alternativas possíveis para a questão acerca do verdadeiro local onde funciona o efeito $\Omega$ no dínamo solar: isto pode ocorrer na zona de convecção e na camada de overshoot de onde emergiriam os tubos de fluxo, ou, pode ser também, na camada de cisalhamento superficial, no topo da zona de convecção. As duas possibilidades apresentam vantagens e desvantagens, porém o modelo cinemático que utilizamos acima não é suficiente para chegar-se a uma resposta definitiva a essa questão.

Já sabemos que o campo toroidal pode alcançar a camada de overshoot com a ajuda do bombeamento, porém, ao desprezarmos os efeitos dinâmicos no campo magnético, não podemos determinar com certeza se o campo irá alcançar ali a amplitude requerida pelas simulações de tubos de fluxo, a fim de emergir, atingindo a superfície de forma coerente, tal como observado. Do contrário, ele pode tornar-se instável e difundir-se pelo caminho através da zona convectiva antes de atingir a superfície. No Capítulo a seguir continuaremos utilizando os modelos cinemáticos, mas exploraremos outros efeitos não-lineares da turbulência sobre a amplificação e a estabilidade do campo. 
Capítulo 7

\section{O papel do amortecimento da difusividade}

$$
\text { ( } \text {-quenching) }
$$

Uma das questões mais difíceis presente em todos os cenários possíveis para o dínamo solar, descritos no Capítulo 3, refere-se à reação dinâmica que o campo magnético, na fase não-linear do processo de dínamo, exerce sobre as componentes média e turbulenta do fluido.

No cenário da eletrodinâmica de campo médio (§3.4), o mecanismo mais estudado é a reação dos campos magnéticos sobre a parte indutiva da força electromotriz, isto é, sobre o efeito $\alpha$, pois esse mecanismo pode determinar a saturação no crescimento do campo magnético (Stix, 1972). Nessa questão, os avanços teóricos têm levado a importantes mudanças. Acreditava-se antes que o efeito $\alpha$ turbulento poderia ser catastroficamente amortecido, dependendo do valor do número de Reynolds magnético, o que levaria à impossibilidade de um dínamo turbulento (Vainshtein e Cattaneo, 1992; Cattaneo e Hughes, 1996). Porém, atualmente acredita-se que o fator fundamental no processo de saturação é a conservação da helicidade magnética. Espera-se que na fase de amplificação do campo magnético, o crescimento da helicidade magnética em grande escala permita a transferência de energia dos campos magnéticos em pequena escala para os campos em grade escala. No entanto, na fase saturada, quando o campo magnético alcança o valor de equipartição, desenvolve-se também helicidade magnética na pequena escala, mas com sinal contrario, amortecendo finalmente o termo $\alpha$ (Blackman e Field, 2002; Brandenburg, 2001; Brandenburg e Subramanian, 2005).

Por outro lado, a reação dinâmica que o campo magnético pode exercer sobre a componente difusiva da força electromotriz, $\beta$, foi bem menos estudada na literatura. Essa 
reação do campo magnético deve reduzir o nível de turbulência, diminuindo, dessa forma, a difusividade magnética. Por essa razão conhece-se esse efeito como amortecimento de $\eta$ ( $\eta$-quenching) (Roberts e Soward, 1975).

O papel do amortecimento de $\eta$ no processo de dínamo já foi investigado por Ruediger et al. (1994) e Tobias (1996) no contexto de dínamo de campo médio. Os primeiros incorporaram o amortecimento de $\eta$ em um modelo unidimensional de tipo $\alpha \Omega$ e em um modelo bidimensional de tipo $\alpha^{2} \Omega$. Em regimes supercríticos (isto é, $C_{\Omega} C_{\alpha}>0$ ), Ruediger et al. (1994) encontraram que em modelos unidimensionais o amortecimento de $\eta$ contribui pouco para aumentar a magnitude do campo, enquanto que o período do ciclo decresce significativamente. Por outro lado, nos seus modelos bidimensionais encontraram que o campo aumenta de forma significativa, com um fator de amplificação de aproximadamente 2, mas sem mudanças consideráveis no período do ciclo. Enquanto que a amplificação do campo é esperada intuitivamente, a mudança no período do ciclo, $T$, depende da forma como $T$ é determinado em diferentes tipos de modelos de dínamo. Por exemplo, no interior da zona de convecção, em dínamos de tipo $\alpha \Omega$ a freqüência do ciclo $(1 / T)$ segue a relação $1 / T \propto \Omega^{0.5} \eta^{0.5}$, a qual sugere um aumento do período do ciclo devido ao amortecimento de $\eta$.

Em um modelo de dínamo de interface (§3.7.3), Tobias (1996) encontrou que para campos magnéticos fracos, a difusividade é pouco suprimida e o resultado do modelo é pouco afetado pela presença do termo de amortecimento. Já no caso de campos magnéticos intensos, eles mostraram que na base da zona de convecção a difusividade turbulenta pode ser tão fortemente amortecida que os campos poderiam ficar presos na interface entre as camadas convectiva e radiativa sem poder emergir para a superfície.

Em simulações mais recentes, Gilman e Rempel (2005) resolveram a equação de indução da componente toroidal do campo magnético incluindo a reação dinâmica do campo sobre a difusividade e sobre os termos de cisalhamento. Mostraram, então, que existe uma competição entre a amplificação do campo, devido ao amortecimento de $\eta$, e a diminuição do mesmo, devido ao deslocamento da camada de cisalhamento latitudinal pela força de Lorentz para longe das latitudes intermediárias. Contudo, Gilman e Rempel (2005) argumentam que uma amplificação ainda considerável pode ser possível se o cisalhamento latitudinal for restaurado novamente em uma escala de tempo curta comparada com o 
período do ciclo solar.

Em todos os estudos discutidos acima existe o efeito comum da amplificação líquida do campo magnético devido ao amortecimento da difusividade. No entanto, a influência desse efeito não-linear nas características do ciclo solar, ou seja, no diagrama de borboleta e no padrão de evolução temporal do campo magnético na zona de convecção e na tacoclina, não foi estudado em detalhe até o presente.

Nosso objetivo, nos estudos numéricos deste Capítulo, apresentados no trabalho (Guerrero et al., 2009, veja também o Apêndice E), é usar o modelo de dínamo de BabcockLeighton, incluindo a reação dinâmica do campo magnético tanto no termo indutivo, quanto no termo difusivo da força electromotriz (i.e. incluindo o amortecimento de $\alpha$ e o amortecimento de $\eta$ ). Especificamente, procuraremos respostas às seguintes questões, que formam parte das limitações dos modelos de dínamo:

1. Qual é o valor característico da amplificação do campo magnético devido ao amortecimento de $\eta$ em um modelo de dínamo de Babcock-Leighton dominado pela advecção?

2. Como se modifica o diagrama de borboleta devido ao amortecimento de $\eta$ ?

3. Em qual região do domínio de integração o amortecimento da difusividade exerce seus efeitos mais significativos?

4. Como fica o transporte do campo pelo fluxo meridional quando a difusividade, $\eta$, é progressivamente amortecida?

5. De que modo a supressão de $\eta$ afeta o período do ciclo que nesta classe de modelos é determinado, principalmente, pela circulação meridional?

6. Dado que o amortecimento de $\alpha$ satura o crescimento do campo magnético e o amortecimento de $\eta$ funciona como mecanismo amplificador do campo, como se comporta o dínamo na presença simultânea desses dois mecanismos?

7. O amortecimento de $\eta$ pode converter um modelo de dínamo dominado pela difusão em um dominado pela advecção?

Os detalhes do modelo com o qual tentaremos responder a essas perguntas são apresentados na próxima seção. Em seguida, apresentamos nossos resultados de forma detalhada e finalizamos com as conclusões parciais, referentes a este Capítulo. 

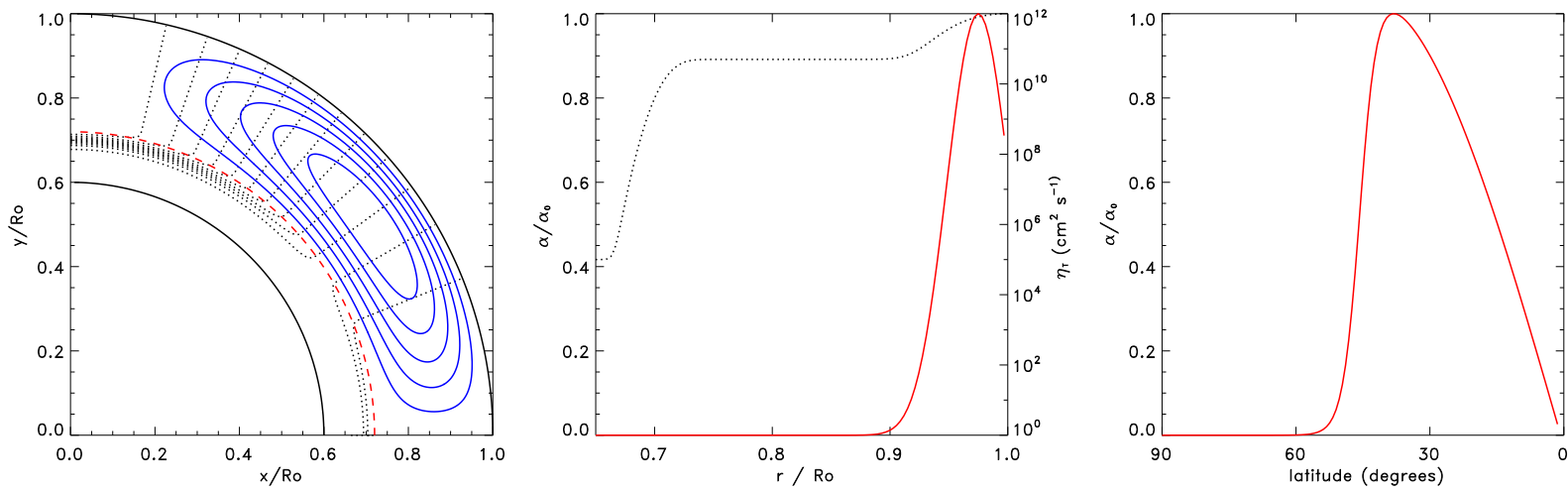

Figura 7.1: Perfis dos principais constituintes dos modelos de dínamo solar deste Capítulo. A imagem da esquerda apresenta os contornos de iso-rotação (linhas pontilhadas) juntamente com as linhas de fluxo meridional (linhas contínuas). A linha tracejada em $r=0.715 R_{\odot}$ indica o centro da camada de overshoot. A imagem central mostra a variação radial do termo $\alpha$ de BL (linha contínua) e da difusividade magnética, $\eta_{T}$ (linha pontilhada). Os valores de $\alpha$ estão normalizados ao seu valor máximo $\alpha_{0}$ e os valores de $\eta_{T}$ são indicados no eixo direito. A imagem à direita apresenta o perfil latitudinal do efeito $\alpha$ de BL.

\subsection{O modelo}

As simulações numéricas que apresentaremos neste Capítulo foram obtidas a partir da resolução das eqs. (3.35) e (3.36) no intervalo espacial $0.6 R_{\odot} \leq r \leq R_{\odot}$ e $0 \leq \theta \leq \pi / 2$, com as condições de contorno descritas em $§ 4.1$ e em A.3. Os perfis considerados são descritos abaixo:

\section{Campo de velocidades}

Seguindo os resultados de trabalhos anteriores (Dikpati e Charbonneau, 1999; Guerrero e de Gouveia Dal Pino, 2007b, 2008) e dos Capítulos precedentes, consideraremos o perfil de rotação diferencial dado pela eq. (3.40), assim como o perfil de circulação meridional dado pelas eqs. (3.61) e (3.62). Para todas as simulações iremos considerar uma profundidade de penetração de $r_{p}=0.7 R_{\odot}$ e uma tacoclina centrada em $0.7 R_{\odot}$, com uma espessura $\Omega_{1}=0.03 R_{\odot}$ (veja o Capítulo 5 e também Guerrero e de Gouveia Dal Pino, 2007a,b). Esses perfis são apresentados na imagem esquerda da Fig. 7.1. 


\section{Difusividade magnética}

Consideraremos o perfil de difusividade de dois degraus, dado pela eq. (3.49), com os seguintes valores: $\eta_{r z}=10^{5} \mathrm{~cm}^{2} \mathrm{~s}^{-1}, \eta_{c z}=5 \times 10^{10} \mathrm{~cm}^{2} \mathrm{~s}^{-1}$ e $\eta_{s}=10^{12} \mathrm{~cm}^{2} \mathrm{~s}^{-1}$. A transição entre as camadas radiativa e convectiva é localizada em $r_{c}=0.715 R_{\odot}$ com $d_{2}=0.015 R_{\odot}$ e a transição entre a zona convectiva turbulenta e a camada de difusão super-granular localizase em $r_{c 1}=0.96 R_{\odot}$ e tem uma largura $d_{3}=0.03 R_{\odot}$. Veja a linha pontilhada do painel central da Fig. 7.1.

Equações do dínamo com amortecimento de $\eta$

Como dito anteriormente, o principal objetivo deste Capítulo é estudar os efeitos do amortecimento da difusividade turbulenta devido à presença de campos magnéticos intensos. Para esse fim, por simplicidade admitiremos que o amortecimento irá afetar unicamente os campos toroidais. Assim, na equação de B (eq. 3.35) substituímos $\eta_{T}$ por

$$
\eta=\frac{\eta_{T}}{1+\left(B / B_{q}\right)^{2}}
$$

que é a mesma forma algébrica usada por Gilman e Rempel (2005). Na equação acima, $B_{q}$ corresponde ao valor do campo magnético no qual $\eta_{T}$ começa a ser amortecido. Em simulações numéricas tridimensionais de um fluido magnético com turbulência forçada, Yousef et al. (2003) encontraram que a supressão da difusividade magnética segue a forma: $\eta \simeq \eta_{T 0} /\left(1+a \mathbf{B}^{2} / B_{e q}^{2}\right)$, onde o valor de $a$ depende da geometria do campo magnético inicial (i.e. se ele é helicoidal ou não). Mais recentemente, Käpylä et al. (2008a) verificaram a partir de simulações MHD com turbulência helicoidal forçada, que o amortecimento de $\eta_{T}$ pode seguir a mesma equação ou então pode ser proporcional a $a \mathbf{B} / B_{e q} \operatorname{com} a=0.3$. No presente caso, adotamos uma formulação similar (eq. 7.1), mas com $B_{q}$ sendo um parâmetro livre do modelo.

Vale ressaltar que quando o termo de amortecimento é incorporado na eq. (3.35), $\eta$ não é mais uma função que depende apenas de $r$, mas de $B(r, \theta, t)$ e, portanto, $\eta$ é agora uma função de $r, \theta$ e $t$. Devido a essa dependência adicional, a componente $\theta$ do termo $\nabla \eta \times\left(\nabla \times B \hat{e}_{\phi}\right)$, dá lugar a dois novos termos na equação de indução. Assim, a eq. (3.35) 
fica:

$$
\begin{array}{r}
\frac{\partial B}{\partial t}+\frac{1}{r}\left[\frac{\partial}{\partial r}\left[r u_{r} B\right]+\frac{\partial}{\partial \theta}\left[u_{\theta} B\right]\right]=r \sin \theta\left(\mathbf{B}_{\mathbf{p}} \cdot \nabla\right) \Omega \\
-\left[\frac{\partial \eta_{T}}{\partial r}\left(\frac{\partial B}{\partial r}-\frac{B}{r}\right)+\frac{1}{r^{2}} \frac{\partial \eta_{T}}{\partial \theta}\left(B \cot \theta+\frac{\partial B}{\partial \theta}\right)\right]_{\phi} \\
+\eta_{T}\left(\nabla^{2}-\frac{1}{s^{2}}\right) B,
\end{array}
$$

\section{O termo $\alpha$}

Da mesma forma que nos Capítulos anteriores, para as simulações deste Capítulo o termo $\alpha$ é dado pelas eqs. (3.67), (3.68) e (5.4), mas dessa vez $\alpha_{B L}$ não é mais proporcional ao valor do campo $B$ no ponto $r_{c}$. Ao invés disso utilizamos:

$$
\alpha_{B L}(r, \theta, B)=\alpha_{0} \Lambda_{r}(r) \Lambda_{\theta}(\theta) f\left(\overline{B_{r_{c}}}\right)
$$

onde $\overline{B_{r_{c}}}$ corresponde a uma média radial de $B$ entre $r=0.7 R_{\odot}$ e $r=0.72 R_{\odot}$. Esta permite computar de forma mais realista o valor do campo na região de formação dos tubos de fluxo. Desta forma, o amortecimento do termo fonte do campo poloidal é dado por:

$$
f_{Q}(B)=\left(1+\left[\frac{\left.\overline{B_{r_{c}}}, \theta\right)}{B_{0}}\right]^{2}\right)^{-1},
$$

e a sua função é limitar o crescimento do campo poloidal quando a média radial do campo toroidal na base da zona de convecção esteja ao redor de $B_{0} \sim 10^{4} \mathrm{G}$.

Um resumo dos principais parâmetros usados neste Capítulo aparece na Tabela 7.1

\subsection{Condição inicial}

Como a nossa intenção é explorar a forma em que o amortecimento de $\eta$ afeta um campo magnético com um comportamento bem organizado no espaço e no tempo, uma possível escolha da condição inicial para as simulações é uma solução totalmente relaxada (i.e., estacionária) do sistema antes de introduzir o amortecimento de $\eta$. Para tal, consideramos como condição inicial para as componentes do campo magnético:

$$
\begin{aligned}
& A= \begin{cases}\sin \theta / r^{2} & r>0.715 \\
0 & r<0.715\end{cases} \\
& B=0
\end{aligned}
$$


Tabela 7.1 - Valores dos parâmetros usados neste Capítulo, veja a Fig. 7.2

\begin{tabular}{lc}
\hline PARÂMETRO & VALOR \\
\hline$\Omega_{e q}$ & $2 \pi \times 460.7 \mathrm{nHz}$ \\
$R_{c}$ & $0.7 R_{\odot}$ \\
$\omega_{1}$ & $0.03 R_{\odot}$ \\
\hline$U_{0}$ & $1500 \mathrm{~cm} \mathrm{~s}^{-1}$ \\
$R_{p}$ & $0.70 R_{\odot}$ \\
\hline$\eta_{r z}$ & $1 \times 10^{5} \mathrm{~cm}^{2} \mathrm{~s}^{-1}$ \\
$\eta_{c z}$ & $5 \times 10^{10} \mathrm{~cm}^{2} \mathrm{~s}^{-1}$ \\
$\eta_{s}$ & $1 \times 10^{12} \mathrm{~cm}^{2} \mathrm{~s}^{-1}$ \\
$\alpha_{0}$ & $50 \mathrm{~cm} \mathrm{~s}^{-1}$ \\
\hline$C_{\Omega}=\Omega_{e q} R_{\odot}^{2} / \eta_{c z}$ & $1.4 \times 10^{5}$ \\
$C_{\alpha}=\alpha_{0} R_{\odot} / \eta_{c z}$ & 70 \\
$C_{U}=U_{0} R_{\odot} / \eta_{c z}$ & 2086.5 \\
\hline
\end{tabular}

e permitimos, então, que o sistema evolua por $10^{4}$ anos com o termo de amortecimento não incluído na eq. (7.2).

A Figura 7.2 mostra o diagrama de borboleta tempo-latitude para os últimos 60 anos de evolução do sistema acima. Ele mostra em escalas de cores os contornos da média radial dos campos toroidais, $\overline{B_{r_{c}}}$, positivos (azuis) e negativos (vermelhos), em escala logarítmica e para valores acima de $12 \mathrm{kG}$, juntamente com os contornos dos campos radiais, $B_{r}$, na superfície. Pode-se observar que as máximas amplitudes dos campos toroidais estão localizadas abaixo de $45^{\circ}$ e satisfazem à diferença de fase de $\pi / 2$ com respeito ao campo poloidal, tal como é observado. O máximo valor do campo toroidal é $\overline{B_{r_{c}}}=22.9 \mathrm{kG}$, e o máximo valor do campo radial é 86.6 G. O período do ciclo completo é 21.2 anos.

Os diagramas da Fig. 7.3 mostram o mesmo modelo da Fig. 7.2, mas em um plano meridional. Vemos que os campos toroidais mais intensos começam a formar-se nas latitudes médias, na zona de conveç̧ão $\left(r \sim 0.8 R_{\odot}\right)$. O campo toroidal penetra ligeiramente na camada de overshoot somente nas baixas latitudes, porém, ele não é amplificado substancialmente nesse ponto. Isto acontece por duas razões: primeiro, como o fluxo meridional não pode penetrar na camada de overshoot, não existe uma grande quantidade de campo 


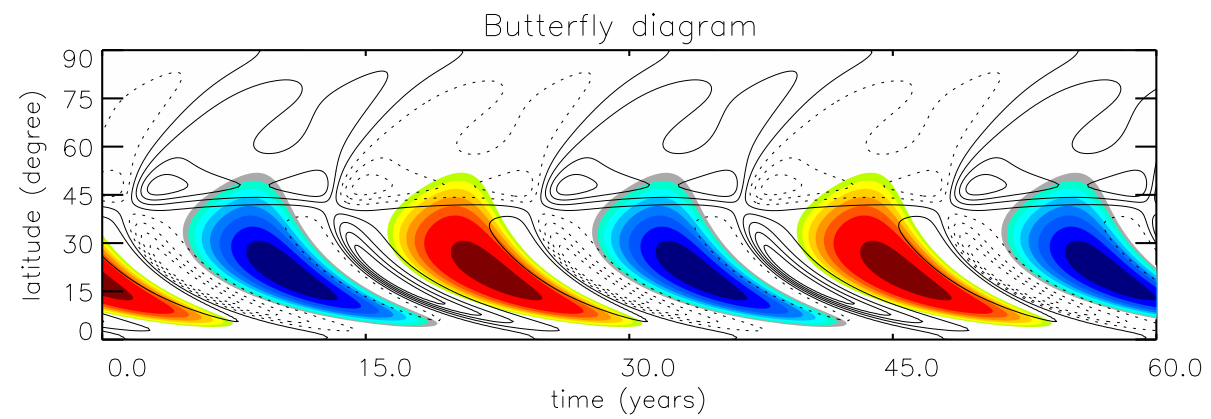

Figura 7.2: Diagrama de borboleta do modelo de referência depois de atingir um estado totalmente relaxado. Os contornos em azul (vermelho) representam campos toroidais positivos (negativos). Os valores graficados correspondem a uma média radial entre $0.7 R_{\odot}$ e $0.72 R_{\odot}$ e com valores acima de $1.2 \times 10^{4}$ G. As linhas contínuas e tracejadas representam os campos radiais positivos e negativos na superfície, respectivamente.
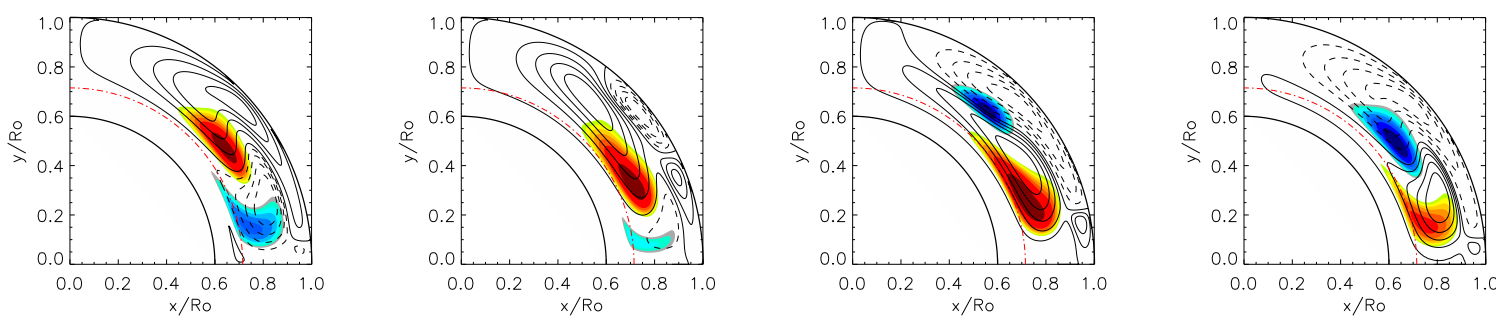

Figura 7.3: Solução estacionária para o modelo de referência em $0, T / 8, T / 4$ e $T / 2$, onde $T$ é o período total do ciclo. A escala de cores obedece a mesma descrição da Fig. 7.2, mas neste caso os contornos em linhas correspondem ao campo poloidal total.

poloidal (fonte do campo toroidal) descendo para a camada de cisalhamento. Segundo, o campo toroidal líquido produzido pela componente radial do cisalhamento é muito menor que a componente produzida pelo cisalhamento latitudinal, como foi discutido no Capítulo 5 (Guerrero e de Gouveia Dal Pino, 2007a,b). A Fig. 7.3 revela, também, que os campos poloidais positivos e negativos são produzidos na superfície, em latitudes intermediárias, e viajam em direção ao pólo seguindo o fluxo de plasma.

Consideramos a solução acima, sem amortecimento de $\eta$, mostrada nas Figs. 7.2 e 7.3, como a configuração inicial $(t=0)$ das simulações que incluem tal amortecimento e evoluímos o sistema por mais 200 anos. Os resultados são apresentados na próxima seção. 


\subsection{Resultados}

\subsubsection{Os efeitos do amortecimento $\alpha$ em modelos de dínamo de $B L$}

O amortecimento do termo $\alpha$ é aplicado geralmente em quase todos os modelos de dínamo e os resultados básicos são bem conhecidos. Em um dínamo do tipo cinemático, o máximo valor que o campo toroidal pode alcançar depende da quantidade de campo poloidal gerado pelo efeito $\alpha$ de Babcock-Leighton, que por sua vez depende dos valores $\alpha_{0}$ e $B_{0}$ nas eqs. (7.3) e (7.4). Assim, para explorar a influência do amortecimento de $\alpha$ com um pouco mais de detalhe e comparar essa influência com aquela obtida implementandose o amortecimento de $\eta$, nesta seção examinaremos como os campos toroidais máximos produzidos em diferentes latitudes variam com o parâmetro de amortecimento, $B_{0}$. O valor de $\alpha_{0}$, que define o número adimensional $C_{\alpha}=\alpha_{0} R_{\odot} / \eta_{c z}=70$ para $\alpha_{0}=50 \mathrm{~cm} \mathrm{~s}^{-1} \mathrm{e}$ $\eta_{c z}=5 \times 10^{10} \mathrm{~cm}^{2} \mathrm{~s}^{-1}$, permanece constante durante todas as simulações mostradas abaixo. Isto garante que a eficiência do dínamo $C_{\Omega} C_{\alpha}$ seja sempre a mesma. Variamos, então, o valor de $B_{0}$ na eq. (7.4) entre $5 \times 10^{2} \mathrm{G}$ e $\times 10^{5} \mathrm{G}$ e computamos o valor máximo que o campo toroidal alcança no domínio computacional durante meio-período (11 anos). Intuitivamente, poderíamos pensar que o valor de $B_{\max }$ deveria ser maior que $B_{0}$.

A Fig. 7.4 apresenta $B_{\max }$ em função de $B_{0}$ para duas posições radiais diferentes $r=0.7 R_{\odot}$ e $r=0.8 R_{\odot}$, e para três latitudes diferentes, $10^{\circ}, 45^{\circ}$ e $80^{\circ}$. Essa figura revela imediatamente que o campo toroidal máximo gerado em diferentes latitudes e profundidades muda linearmente com o valor do campo de amortecimento; quanto maior a magnitude do campo de amortecimento, maior o campo toroidal gerado pelo dínamo. Isto significa que a não-linearidade introduzida no modelo pelo termo de saturação de $\alpha$ é muito fraca, pelo menos até um campo de amortecimento $B_{0}=10^{5} \mathrm{G}$, de tal forma que o dínamo comporta-se como se estivesse operando no regime linear.

Também encontramos que para baixas latitudes $\left(<45^{\circ}\right)$, o máximo campo toroidal é da mesma ordem, tanto na zona de convecção $\left(r=0.8 R_{\odot}\right)$, quanto na tacoclina $\left(r=0.7 R_{\odot}\right)$. Isto se deve ao fato de que os maiores campos toroidais no dínamo de Babcock-Leighton são produzidos principalmente pelo cisalhamento latitudinal operando sobre os campos poloidais, mais que pela ação do cisalhamento radial na tacoclina operando sobre campos radiais. Isto confirma o resultado do Capítulo anterior (Guerrero e de Gouveia Dal Pino, 
b) $r=0.7 R$

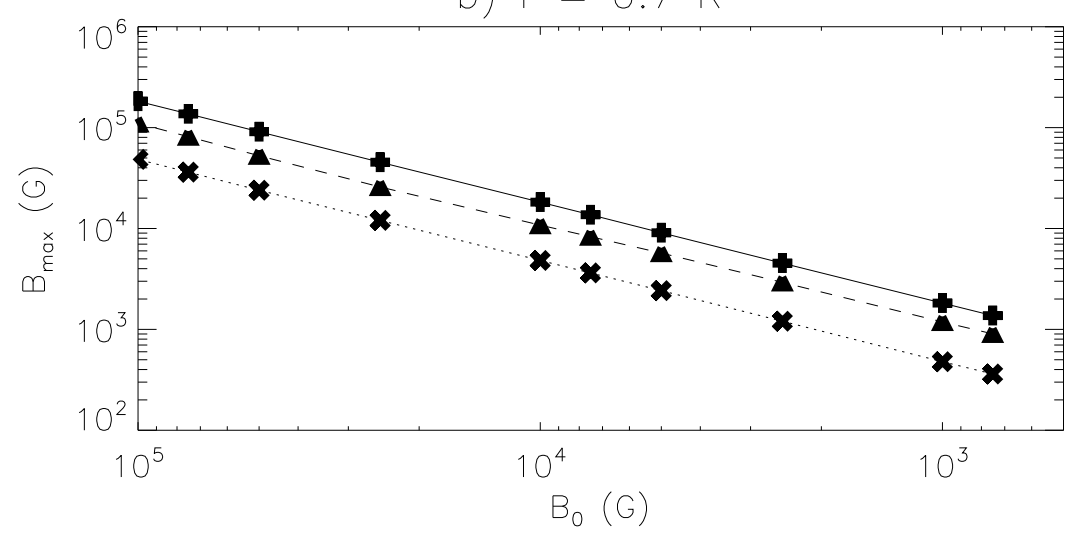

b) $r=0.8 R$

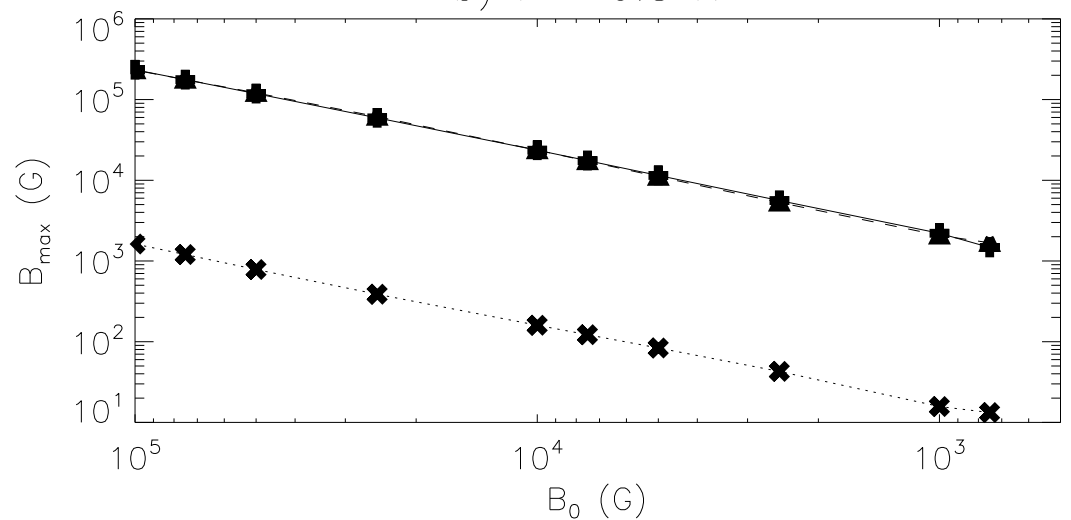

Figura 7.4: Campo magnético toroidal máximo em função de $B_{0}$ em $r=0.7 R_{\odot}$ e $r=0.8 R_{\odot}$ (veja a função de amortecimento $\alpha$, eq. 7.4) para três latitudes diferentes $10^{\circ}$ (linha contínua, sinal positivo), $45^{\circ}$ (linha tracejada, triângulos) e $80^{\circ}$ (linha pontilhada, símbolos $X$ ). Na imagem inferior, as linhas contínua e tracejada são quase coincidentes. 
2007a,b) e também os resultados obtidos pelos modelos de outros autores (Rempel, 2006; Dikpati et al., 2006). Já que não há transporte advectivo até abaixo da base da zona de convecção, há muito pouco campo poloidal disponível para ser amplificado nessa região. No entanto, a situação poderia ser diferente se os campos magnéticos fossem transportados por causa da penetração do fluido (overshooting) ou por bombeamento magnético e ganhassem uma amplificação adicional na camada de cisalhamento radial, tal como discutiu-se no Capítulo anterior (Guerrero e de Gouveia Dal Pino, 2008).

\subsubsection{Os efeitos do amortecimento de $\eta$ na evolução do campo magnético}

Em modelos de dínamo unidimensionais do tipo $\alpha \Omega$, em modelos bidimensionais do tipo $\alpha^{2} \Omega$ e em dínamos de interface, notou-se que o amortecimento da difusividade devido à reação dinâmica do campo magnético é um mecanismo provável para dar uma amplificação adicional ao campo magnético final. Nesta subsseção, iremos explorar primeiro os detalhes da evolução dos campos magnéticos em um modelo de dínamo de BL que inclui o termo de supressão da difusividade, partindo da solução ou estado de referência descrito acima. Posteriormente, iremos apresentar estimativas quantitativas da amplificação do campo e da mudança no período do ciclo devido ao amortecimento de $\eta$.

Para o caso de $\alpha$ fizemos simulações para $5 \times 10^{2} \mathrm{G} \leq B_{0} \leq 5 \times 10^{5} \mathrm{G}$. Agora, iremos considerar o mesmo intervalo de valores de $B_{q}$ para o estudo da supressão de $\eta: 5 \times 10^{2} \mathrm{G} \leq$ $B_{q} \leq 5 \times 10^{5} \mathrm{G}$. Todos os outros parâmetros permanecem iguais àqueles do modelo de referência descrito acima (\$7.2) e consideraremos como condição inicial a solução deste modelo (Figs. 7.2 e 7.3), mas agora incluiremos o termo de amortecimento de $\eta$, rodando a simulação numérica por mais 200 anos. Nesse intervalo de tempo o sistema alcança um novo estado estacionário com variações cíclicas de $A, B$ e $\eta$.

Espera-se que para menores valores de $B_{q}$, mais rapidamente $\eta_{T}$ seja amortecido, levando à amplificação do campo magnético. As Figs. 7.5 e 7.6 mostram a evolução temporal dos campos toroidal e poloidal em um plano meridional (equador - pólo), para quatro tempos sucessivos em um meio-ciclo (diagramas esquerdos) e para dois valores representativos de $B_{q}\left(10^{4} \mathrm{G}\right.$ e $\left.10^{3} \mathrm{G}\right)$. Essas são soluções após 200 anos de evolução. Os diagramas da direita mostram a variação de $\eta$ devido à ação do amortecimento para duas latitudes diferentes, $10^{\circ}$ (linha contínua) e $45^{\circ}$ (linha tracejada). O perfil não amortecido de $\eta$ é 
graficado também para comparação (linha vermelha pontilhada).

As características comuns dos dois casos (veja Figs. 7.5 e 7.6) são que ambos mostram um decréscimo da difusividade nos locais onde o campo magnético toroidal tem uma amplitude considerável. Esse amortecimento pode ser de até três ordens de magnitude, como se pode observar na Fig. 7.6 para $B_{q}=10^{3}$ G. Porém, essa supressão de $\eta$ não é uniforme em nenhuma das duas direções. Comparando os diagramas à esquerda e à direita das Fig. 7.5 e 7.6, vemos que as cristas e vales da difusividade estão anti-correlacionadas com a distribuição espacial das amplitudes do campo toroidal. Já que as figuras mostram a solução já relaxada, as mudanças observadas em $\eta$ repetem-se nos ciclos sucessivos.

Nos dois casos, aparecem intensos gradientes de difusividade tanto em latitude quanto em raio, levando a um processo de amplificação mais eficiente nessas regiões e, portanto, à formação de pequenas concentrações de campo magnético toroidal. Comparando as Figs. 7.5 e 7.6 com a Fig. 7.3, podemos ver o aumento de campos magnéticos inclusive em regiões onde a simulação sem amortecimento não exibe campos toroidais intensos.

A formação dessas pequenas regiões de concentração de fluxo no domínio computacional pode ser entendida considerando-se que, em média, o tempo de difusão $\left(\ell^{2} / \eta\right)$ dos campos magnéticos em cada fração do domínio onde $\eta$ é fortemente amortecido, é vários anos maior que em outras regiões onde o amortecimento não é tão efetivo. Assim, nas regiões de grande amortecimento de $\eta$ os campos podem sofrer uma amplificação prolongada e alcançar maiores valores do que nas regiões vizinhas onde $\eta$ é maior.

Uma outra característica interessante que notamos na Fig. 7.6 é a formação de padrões de campos magnéticos no interior da tacoclina (veja os painéis à esquerda). Isto está associado com a variação de $\eta$ em função da profundidade como consequência do acoplamento não-linear entre $B_{q}$ e $\eta$. Assim, para menores $B_{q}$, mais rápidas e inclinadas as variações presentes no perfil de $\eta$, o qual produz uma maior segregação de campos magnéticos. Devido à supressão da difusividade nas camadas de overshoot e tacoclina, o fluxo toroidal que produzirá as manchas solares permanece ancorado nesses pontos, particularmente no caso da Fig. 7.6. Ao mesmo tempo, no interior da zona convectiva, dois processos estão competindo: a amplificação prolongada do campo toroidal devido à rotação diferencial, e a advecção das linhas pelo fluxo meridional. Se o ancoramento dos campos devido ao amortecimento de $\eta$ vence parcialmente essa disputa em algumas regiões do espaço, essas 

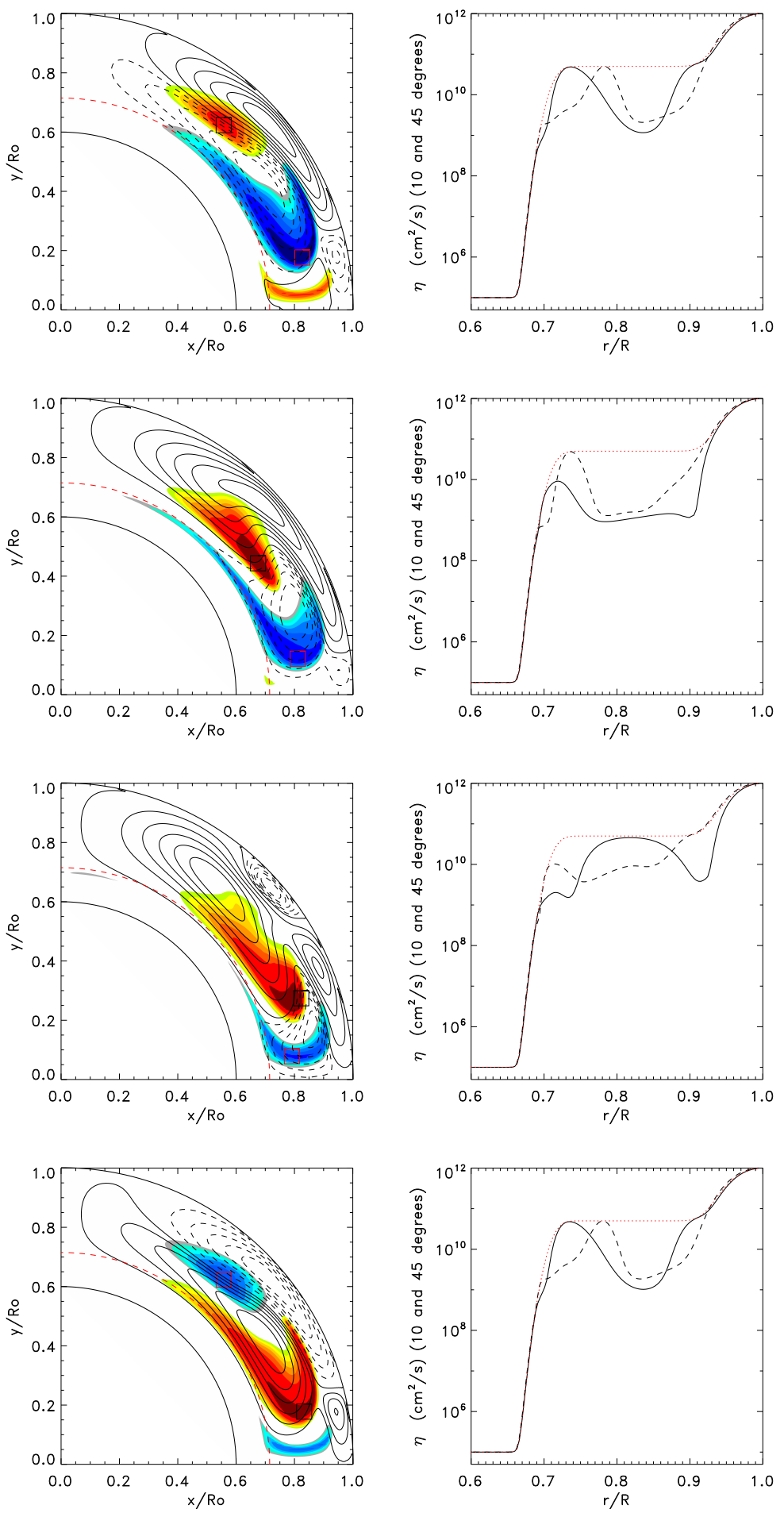

Figura 7.5: Esquerda: Contornos do campo toroidal e linhas de campo poloidal no plano meridionais para 4 tempos diferentes $(0, T / 8, T / 4$ e $T / 2$, de acima para baixo) dentro de meio-período do ciclo da solução estacionária para $B_{q}=10^{4} \mathrm{G}$. Direita: Difusividade sem amortecimento (linha vermelha pontilhada), e amortecida para $10^{\circ}$ (linha contínua) e $45^{\circ}$ (linha tracejada) nos mesmos tempos dos diagramas da esquerda. 

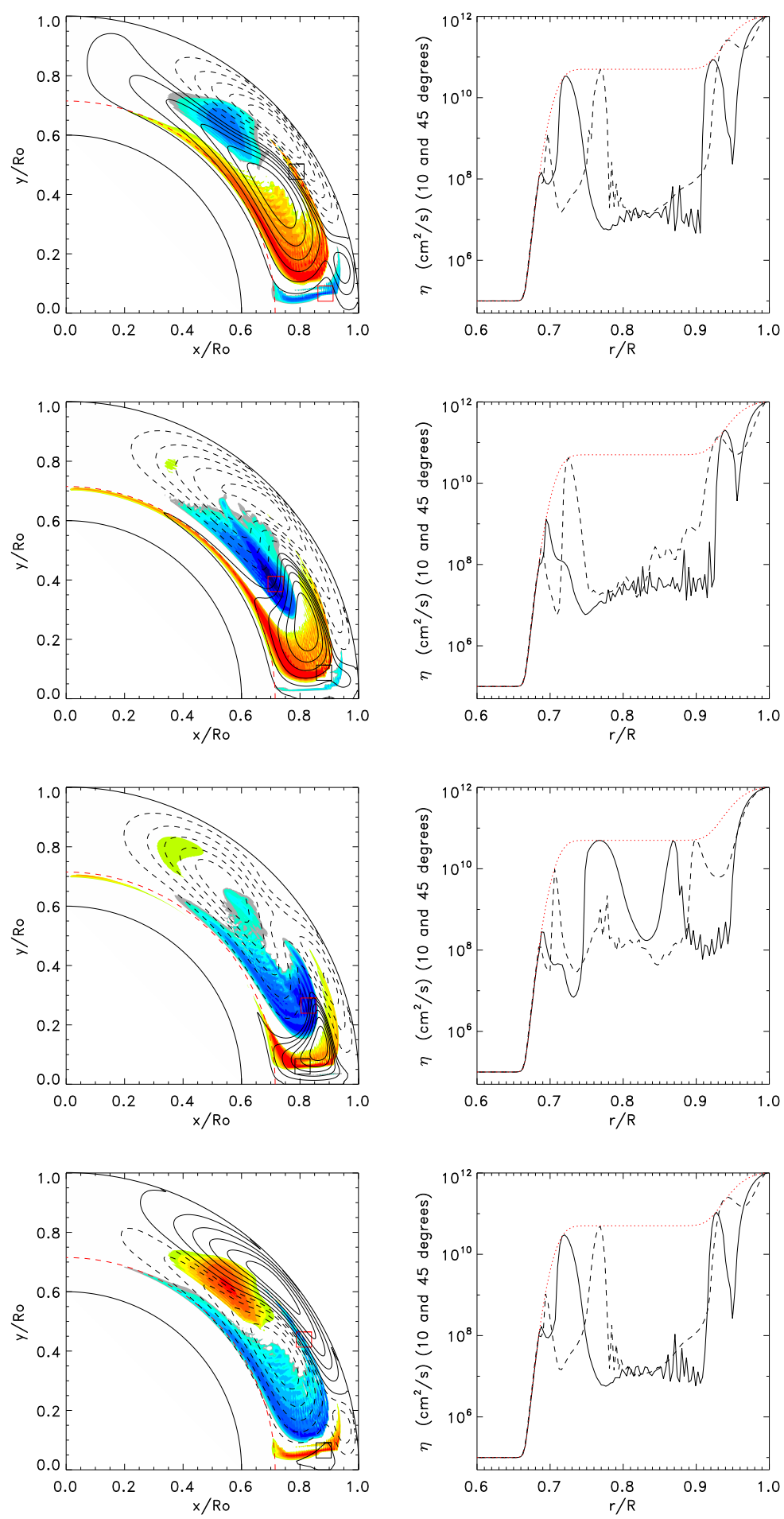

Figura 7.6: O mesmo que na Fig. 7.5, mas para $B_{q}=10^{3}$ G. 
frações de campo separam-se da parte em grande escala e reconectam-se localmente. Isto acontece principalmente no lado equatorial dos campos em grande escala, fazendo com que aconteça cada vez mais fragmentação, dando lugar à formação dessas pequenas estruturas. Por outro lado, se o amortecimento de $\eta$ não é tão grande, como no caso da Fig. 7.5, a advecção vence da amplificação, formando-se então um padrão melhor organizado de campo toroidal.

\subsubsection{Influência do amortecimento de $\eta$ na amplificação do campo}

Com a intenção de quantificar a efetividade do processo de supressão de $\eta$ em amplificar os campos toroidais, na Fig. 7.7 graficamos o valor máximo do campo magnético gerado pelo dínamo em função de $B_{q}$. Da mesma forma que na Fig. 7.4, mostramos os resultados para três latitudes diferentes: $10^{\circ}$ (linha contínua), $45^{\circ}$ (linha tracejada) e $80^{\circ}$ (linha pontilhada), para dois raios diferentes: $0.7 R_{\odot}$ (o centro da tacoclina) e $0.8 R_{\odot}$ (a parte inferior da zona de convecção).

Na tacoclina (painel superior da Fig. 7.7), as curvas mostram um comportamento interessante. Em latitudes próximas dos pólos (linhas pontilhadas), o campo toroidal aumenta com a diminuição de $B_{q}$ (i.e., aumentando o amortecimento). O fator de amplificação é de até $\sim 2.5$. Esse resultado é compreensível já que o fluxo toroidal produzido na tacoclina ou próximo dela, é alimentado por um tempo mais prolongado graças à ação do alongamento das linhas de campo poloidal. No entanto, para as latitudes baixas (linhas contínuas) obtemos um resultado não intuitivo: os valores de $B$ decrescem com o aumento do amortecimento de $\eta$ (menor $B_{q}$ ). Nas latitudes intermediárias, vemos também que $B_{q}$ decresce, mas o efeito não é tão pronunciado, e aparece unicamente para fatores de amortecimento muito eficientes. Nas baixas latitudes $\left(10^{\circ}\right)$ o fator de diminuição pode ser de até $\sim 2.5$.

No centro da zona de convecção (painel inferior da Fig. 7.7), os resultados são diferentes. Os campos magnéticos tanto nas latitudes baixas, quanto nas intermediárias têm o mesmo acréscimo por um fator de até $\sim 2$ com respeito ao caso sem amortecimento de $\eta$. Com

$B_{q}=5 \times 10^{3} \mathrm{G}$, o campo toroidal pode alcançar valores acima de $10^{5} \mathrm{G}$. Já que no meio da zona de convecção não há cisalhamento radial, é o cisalhamento latitudinal que opera nos campos poloidais, de tal forma que vemos uma amplificação similar para campos nas latitudes intermediárias e baixas. No entanto, se os tubos de fluxo, formados desses campos 

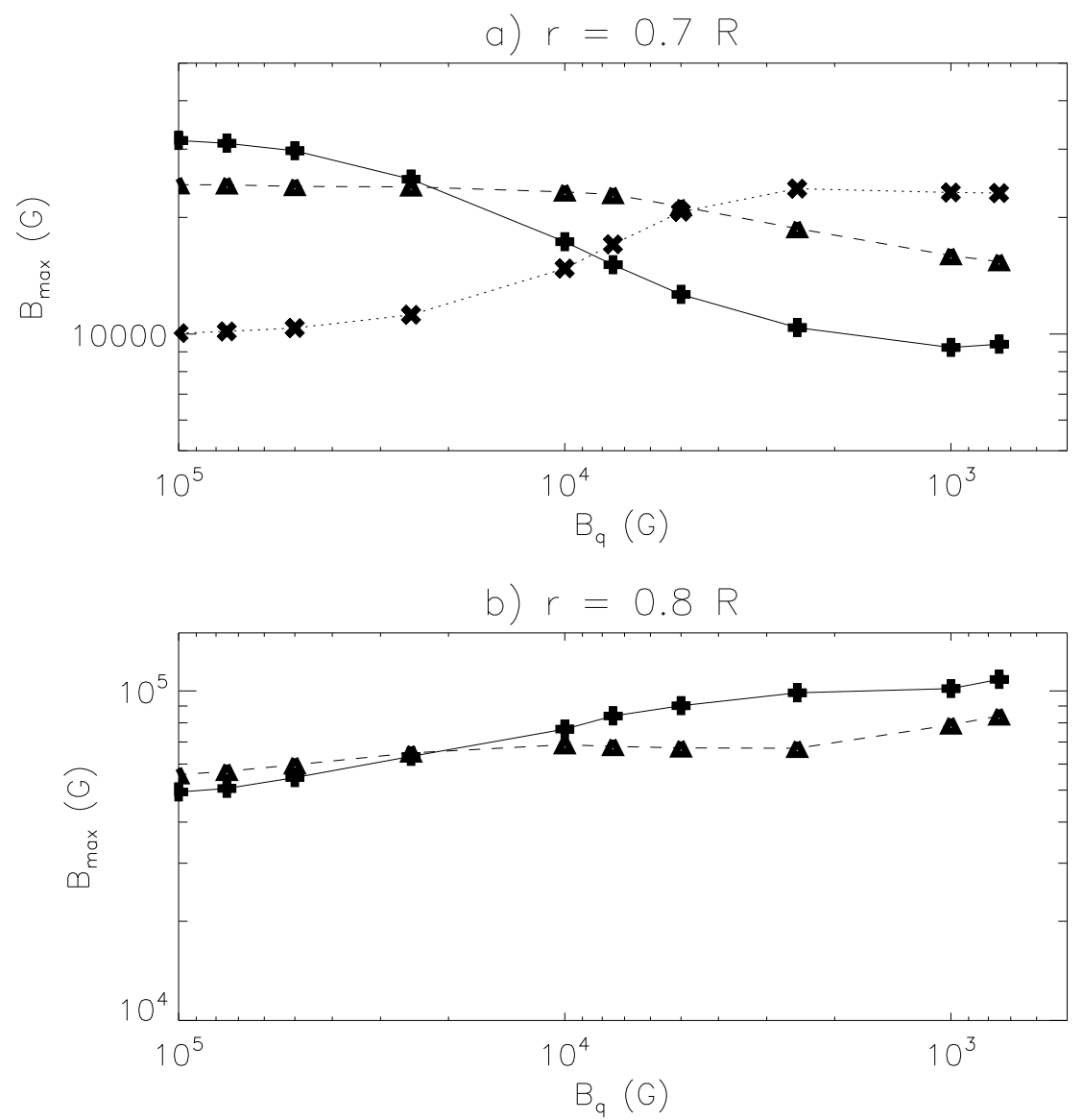

Figura 7.7: Valor máximo do campo toroidal em função de $B_{q}$ (veja a eq. (7.1) para três latitudes diferentes, $10^{\circ}$ (linha contínua, sinal positivo), $45^{\circ}$ (linha tracejada, triângulos), e $80^{\circ}$ (linha pontilhada, símbolo $X)$. Na figura inferior são apresentados unicamente os resultados para $10^{\circ}$ e $45^{\circ}$, os valores máximos de $B$ para $80^{\circ}$ são menores que $10^{4} \mathrm{G}$. 
toroidais intensos, devido ao amortecimento de $\eta$, subissem à superfície, eles certamente não produziriam regiões bipolares conforme a lei de Joy. Isto mostra que provavelmente o efeito de supressão da difusividade não é muito intenso na realidade, ou então que existem outros processos concomitantes inibindo a formação dos tubos de fluxo no meio da zona de convecção.

O contraste existente na amplificação do campo entre as altas e as baixas latitudes na tacoclina (compare as linhas pontilhada e contínua no painel superior da Fig. 7.7) acontece devido à diferença do transporte advectivo entre as altas e as baixas latitudes. Se ele fosse devido unicamente à supressão da difusividade e, portanto, de uma amplificação prolongada dos campos, então deveríamos esperar o aumento na amplitude do campo em todas as latitudes. Porém, neste caso a direção do transporte de fluxo está claramente exercendo algum papel nessa parte do processo. Podemos entender melhor esse mecanismo olhando o diagrama esquemático da Fig. 7.8. Nas altas latitudes, o transporte advectivo é descendente, então os campos poloidais nessa região podem alcançar com maior facilidade a camada de cisalhamento radial produzindo o campo toroidal tanto no caso sem amortecimento de $\eta$, quanto no caso que o inclui. No entanto, no último caso os campos toroidais sofrem menos difusão e permanecem próximos da camada de cisalhamento por um tempo maior que no primeiro caso. No caso com amortecimento de $\eta$, os campos toroidais das altas latitudes (na direção normal ao laço (loop) vermelho na figura) sofrem maior amplificação já que se alimentam localmente de novos campos toroidais criados pelo cisalhamento devido à rotação diferencial. No caso sem amortecimento, os campos sofrem uma difusão maior (veja o laço verde nas altas latitudes que representa uma secção normal ao campo toroidal). Como consequência há um aumento sistemático do campo toroidal nas altas latitudes.

Por outro lado, nas regiões próximas do equador o fluxo advectivo ascendente empurra os campos poloidais para fora, longe da camada de cisalhamento radial, dificultando a criação de campos toroidais em tais latitudes. Mas se os campos poloidais nas baixas latitudes são sempre advectados por um fluxo ascendente, sem importar que o amortecimento de $\eta$ esteja presente ou não, então por que os campos toroidais nas baixas latitudes diminuem com o aumento do amortecimento de $\eta$ e não são independentes desse efeito? O esquema da Fig. 7.8 ajuda novamente a explicar esse processo. Isto acontece devido à 
combinação do transporte ascendente com a diminuição da difusividade da seguinte forma: mesmo que o fluxo meridional nas baixas latitudes afaste sempre o campo poloidal da camada de cisalhamento radial, uma pequena quantidade de campo toroidal é ainda formada na tacoclina, já na zona convectiva é formada uma quantidade maior de campo toroidal devido ao cisalhamento latitudinal. Agora, já que o único mecanismo capaz de transportar campo magnético na direção central nessas latitudes é o transporte difusivo, no caso sem supressão de $\eta$ o campo formado no interior da zona convectiva (laço verde) espalha-se até alcançar a tacoclina onde encontra a quantidade existente de campo toroidal e assim aumenta a sua magnitude. No entanto, no caso com amortecimento de $\eta$ o campo toroidal produzido na zona convectiva permanece confinado em uma pequena região (laço vermelho) e o campo na tacoclina não consegue ser efetivamente amplificado.

\subsubsection{Influencia do amortecimento de $\eta$ no diagrama de borboleta e no período do ciclo}

O acréscimo dos campos toroidais nas altas latitudes e o decréscimo do mesmo nas baixas latitudes, na região da tacoclina e para valores menores que $B_{q}$, irão influenciar da mesma forma o diagrama de borboleta. Vale a pena lembrar que os contornos de campo toroidal que aparecem nesses diagramas são computados a partir de uma média radial feita sobre toda a região de overshoot.

A Fig. 7.9 mostra vários diagramas de borboleta para diferentes valores de $B_{q}$. Podese observar que as asas da borboleta, que estão concentradas principalmente em latitudes $\leq 45^{\circ}$ quando $B_{q}$ é grande (menos amortecimento), deslocam-se para latitudes cada vez maiores com a diminuição de $B_{q}$ (mais amortecimento). Isto se deve à mesma razão explicada em §7.3.3. Note também no painel inferior da Fig. 7.9 que os campos toroidais mostram estruturas em pequena escala similares àquelas encontradas no padrão de campos toroidais da Fig. 7.6. Para valores menores de $B_{q}$ é possível encontrar campos magnéticos ainda mais intensos, no entanto, nesses casos o sistema não consegue atingir um estado estacionário.

As mudanças nos padrões da borboleta indicam que esses diagramas se encontram dentro de um limite aceitável com respeito às observações até um certo aumento da supressão de $\eta$, porém, a influência desse efeito é, de um modo geral, danificar os diagramas de borboleta em comparação com as observações. Em nossos resultados encontramos que 


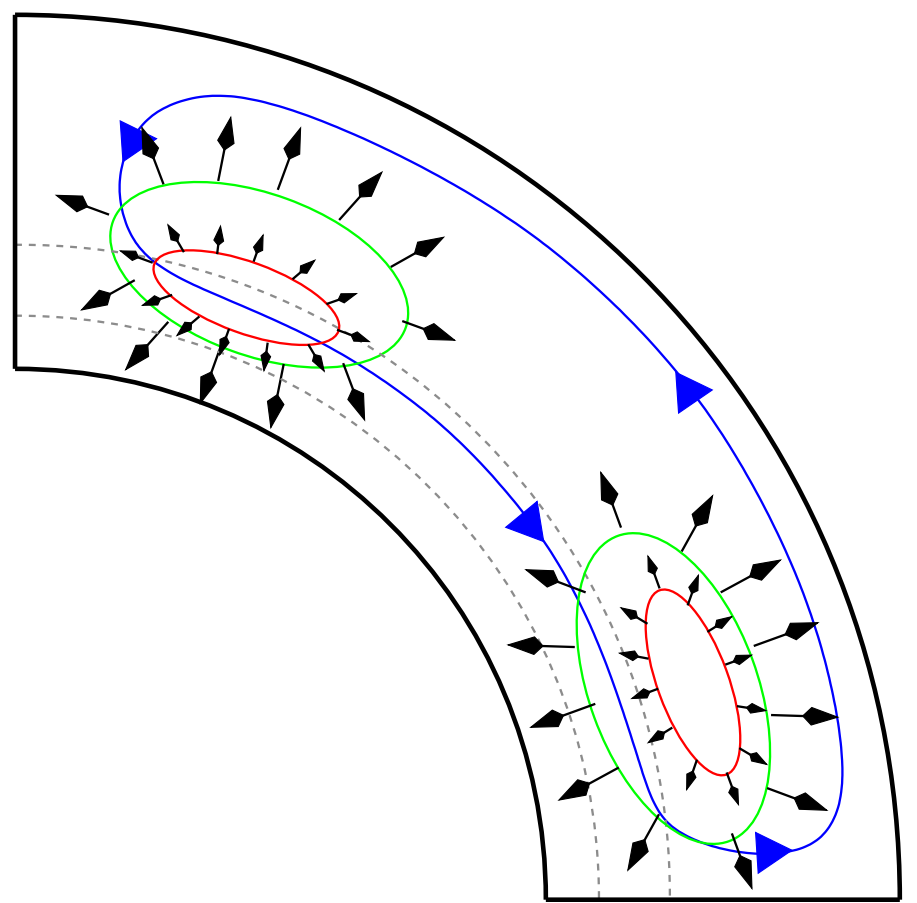

Figura 7.8: Diagrama esquemático mostrando a forma na qual, com a ajuda do transporte advectivo descendente, o campo toroidal nas altas latitudes (normal ao laço vermelho) é amplificado na tacoclina (definida pelas linhas pontilhadas) de forma mais eficiente quando consideramos o amortecimento de $\eta$, do que quando a supressão da difusividade não é levada em conta (laço verde). Em contraste, o fluxo advectivo ascendente nas baixas latitudes faz o campo poloidal se afastar da camada de cisalhamento, de tal forma que quando a difusividade é mais suprimida o campo toroidal (normal ao laço vermelho nas baixas latitudes) permanece retido no interior da zona de convecção, enquanto no caso difusivo, sem supressão, o campo espalha-se com maior facilidade (laço verde) alcançando a camada de cisalhamento radial. 

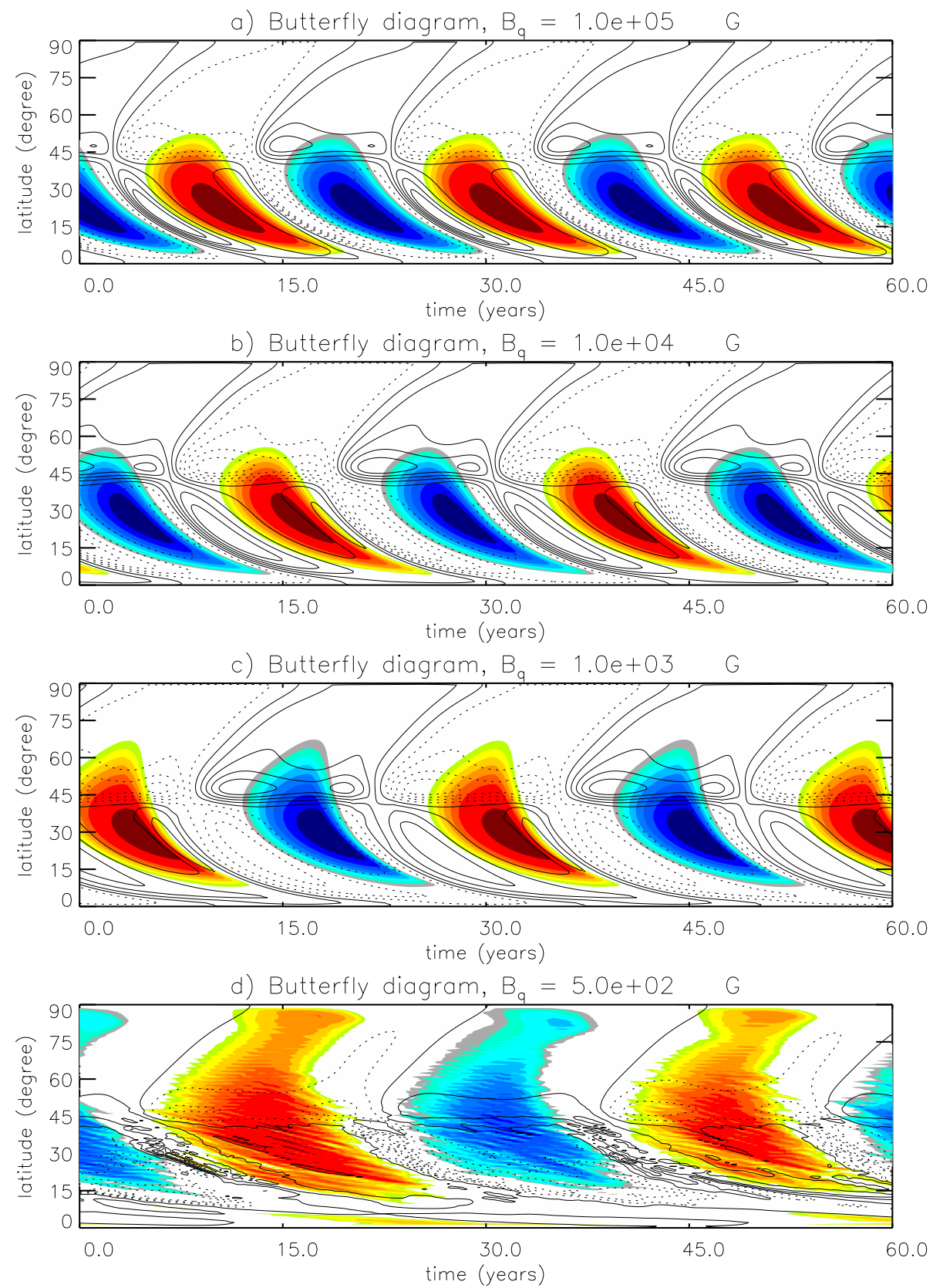

Figura 7.9: Diagramas de borboleta para diferentes valores de $B_{q}$. Acima: $B_{q}=10^{5} \mathrm{G}$; segundo painel (de acima para baixo): $B_{q}=10^{4} \mathrm{G}$; terceiro: $B_{q}=10^{3} \mathrm{G}$ e abaixo: $B_{q}=5 \times 10^{2} \mathrm{G}$. 
modelos com $B_{q}>5 \times 10^{3} \mathrm{G}$ produzem diagramas de borboleta aceitáveis, ao mesmo tempo que amplificam o campo moderadamente. Podemos identificar esse valor como o campo de equipartição $\left(B_{e q}=\sqrt{4 \pi \rho \mathbf{u}^{2}}\right.$, onde $\mathbf{u}$ é a componente turbulenta da velocidade do fluido e $\rho$ é a densidade) e também com o campo de saturação do efeito $\alpha$, ou seja, $B_{e q}=B_{0}=B_{q}$. Na Fig. 7.4 vemos que para $B_{0}=5 \times 10^{3} \mathrm{G}$ o máximo campo toroidal produzido na região equatorial da tacoclina é de $\sim 2 \times 10^{4}$ G. Por outro lado, na Fig. 7.7, obtemos que, no mesmo local, para $B_{q}=5 \times 10^{3} \mathrm{G}$, o fator de amplificação é $\sim 2$, de tal forma que o valor obtido nesse caso seria $B_{\max } \sim 4 \times 10^{4} \mathrm{G}$, o qual é um valor aceitável para tubos de fluxo na base da zona convectiva. Além disso, $B_{q}=5 \times 10^{3} \mathrm{G}$ equivale a uma velocidade turbulenta $\mathbf{u} \sim 4000 \mathrm{~cm} \mathrm{~s}^{-1}$, concordando com as estimativas teóricas para essa velocidade na base da zona de convecção (onde $\rho \sim 0.1 \mathrm{~g} \mathrm{~cm}^{-3}$ ) (Brandenburg e Subramanian, 2005).

O deslocamento das asas de borboleta para as altas latitudes poderia gerar outros problemas no modelo de dínamo, como a perda do acoplamento entre os dois hemisférios através do equador, o que, possivelmente, levaria a uma solução com paridade quadrupolar se o sistema fosse resolvido na esfera completa. Nesse caso, para recuperar a paridade dipolar observada no campo solar em grande escala poderia ser necessária a ajuda de outros mecanismos de transporte na direção do equador, como o bombeamento magnético. Esses estudos carecem ainda ser realizados.

Na Fig. 7.9 observamos, também, que o período do ciclo aumenta com o aumento do amortecimento de $\eta$ (i.e., diminuindo $B_{q}$ ), já que o número de asas de borboleta produzidas em 60 anos decresce. A Fig. 7.10 mostra um gráfico do período do ciclo em função de $B_{q}$, mostrando claramente que o período do ciclo diminui com o aumento da supressão de $\eta$. Isto acontece por causa da competição entre o efeito de congelamento do fluxo magnético, devido à baixa difusão, e o transporte advectivo, devido ao fluxo meridional.

\subsubsection{Dínamos dominados pela advecção versus dínamos dominados pela difusão}

Nos modelos de dínamo de Babcock-Leighton, o fluxo meridional é considerado o mecanismo de transporte (conveyor belt) que leva primeiro o campo magnético poloidal da superfície para os pólos, para assim formar um novo campo polar; em segundo lugar desde a superfície para o interior da camada convectiva e para a tacoclina, onde o fluxo dipolar é convertido em toroidal, conectando assim os locais onde acontecem os efeitos $\alpha$ e $\Omega$; e 


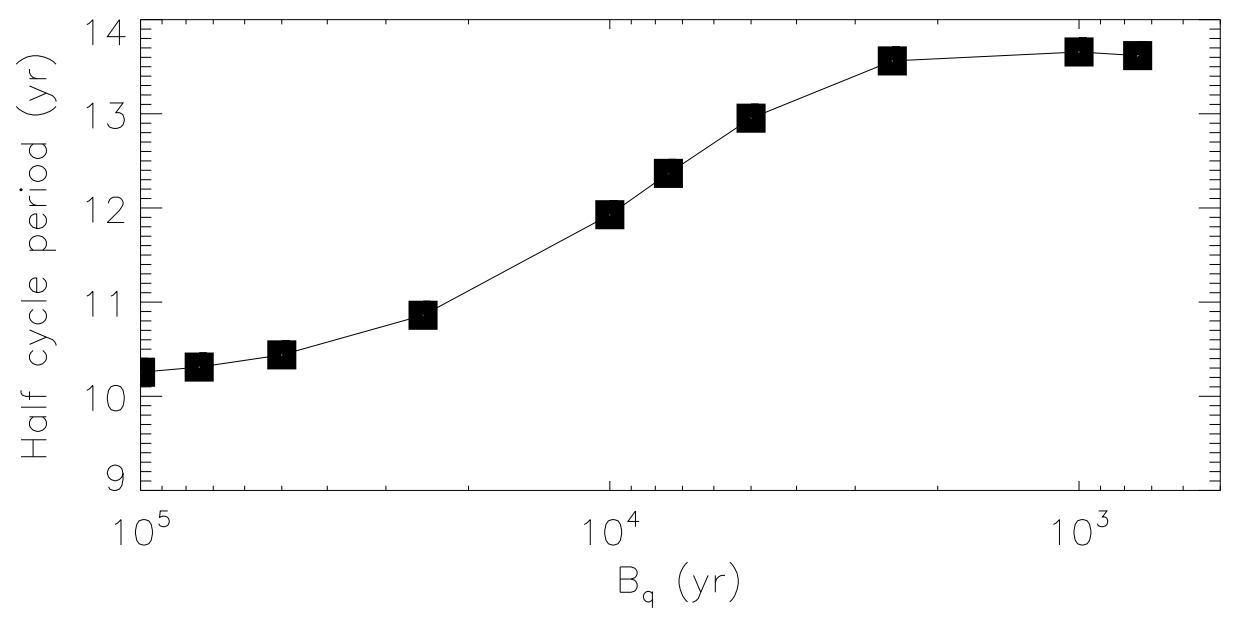

Figura 7.10: Meio-período do ciclo como função de $B_{q}$.

em terceiro lugar, na base da zona de convecção, onde transporta o campo toroidal para o equador, sendo possivelmente responsável pela migração equatorial observada no surgimento das manchas solares. Desta forma, em modelos de BL puros, i.e., sem outros efeitos advectivos adicionais, como o bombeamento magnético, o fluxo meridional domina sobre os outros parâmetros ao determinar o período do ciclo. Porém, para que isso realmente aconteça, o termo advectivo da equação de indução deve dominar sobre o termo difusivo e determinar a escala temporal do sistema. Assim, essa classe de modelos requer valores de $\eta_{c z} \lesssim 2 \times 10^{11} \mathrm{~cm}^{2} \mathrm{~s}^{-1}$. No entanto, os valores obtidos a partir da teoria de comprimento de mistura (§3.7.2) são uma a duas ordens de grandeza maiores do que esse valor. Por isso, embora até agora não exista uma determinação precisa da difusividade magnética na zona de convecção e abaixo dela, essa limitação tem gerado críticas ao modelo dominado pela advecção do fluxo (Charbonneau, 2007; Yousef et al., 2003).

$\mathrm{Na}$ subsseção anterior, descrevemos o efeito do amortecimento de $\eta$ no modelo de dínamo de Babcock-Leighton e econtramos que, dependendo do parâmetro de amortecimento, $B_{q}$, a difusividade pode ser suprimida localmente por até três ordens de grandeza e que esse efeito pode também aumentar o período do ciclo (Fig. 7.10). Isto nos indica que o valor médio de $\eta_{c z}$ está sendo amortecido. Então vale a pena perguntar-se se os dínamos dominados pela difusão, que em geral produzem ciclos mais rápidos, podem mudar para o regime dominado pela advecção graças à diminuição de $\eta$ pelo mecanismo de 


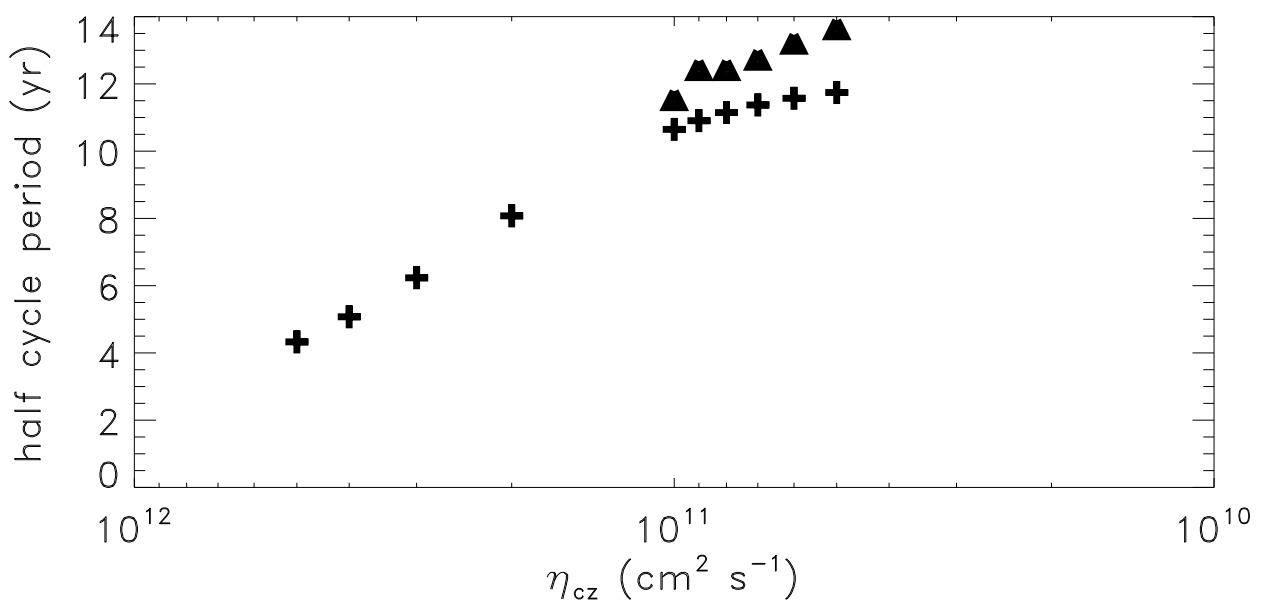

Figura 7.11: Meio-período do ciclo em função de $\eta_{c z}$ para $B_{q}=10^{3} \mathrm{G}$ (triângulos) e $B_{q}=10^{4} \mathrm{G}$ (sinal positivo).

amortecimento, e produzir ciclos com período similar ao observado no ciclo de manchas.

Testamos o mecanismo de amortecimento de $\eta$ procurando uma resposta a essa pergunta. Incrementamos progressivamente a difusividade da camada convectiva desde $5 \times 10^{10}$ $\mathrm{cm}^{2} \mathrm{~s}^{-1}$ (o valor usado nas simulações anteriores) até o máximo valor permitido para obter soluções oscilatórias (que não decaíam devido à grande difusividade), $5 \times 10^{11} \mathrm{~cm}^{2} \mathrm{~s}^{-1}$. Nesse último valor o sistema se encontra no regime dominado pela difusão e o período do ciclo é curto, determinado pelo valor da difusividade. O mesmo experimento numérico foi realizado para dois valores representativos de $B_{q}, 10^{3}$ e $10^{4} \mathrm{G}$, e mantendo-se constante a eficiência do dínamo, definida por $C_{\Omega} C_{\alpha}$, para todas as simulações. Note-se que manter $C_{\Omega} C_{\alpha}=\alpha_{0} \Omega_{e q} R^{3} / \eta_{c z}^{2}=$ cte implica mudar o valor de $\alpha_{0}$ quando $\eta_{c z}$ muda (veja na Tabela 7.2 os valores de $\alpha_{0}$, os valores máximos do campo toroidal médio na base da zona de convecção, $\overline{B_{r_{c}}}$, o campo radial $\left(B_{r}\right)$, na superfície e o período de meio ciclo, $\left.T / 2\right)$.

Na Fig. 7.11 apresentamos o meio-período do ciclo em função da difusividade magnética para dois casos: com $B_{q}=10^{4} \mathrm{G}$ (sinal positivo) e $B_{q}=10^{3} \mathrm{G}$ (triângulos). Os modelos com $B_{q}=10^{4} \mathrm{G}$ apresentam dois regimes diferentes de inclinação da curva. Para valores de $\eta_{c z} \leq 10^{11} \mathrm{~cm}^{2} \mathrm{~s}^{-1}$, o ciclo não muda significativamente com o valor de $\eta$ e é determinado principalmente pela velocidade do fluido. Para $\eta_{c z}>10^{11} \mathrm{~cm}^{2} \mathrm{~s}^{-1}$, o período do ciclo muda mais rapidamente com $\eta_{c z}$, indicando que os modelos se encontram no regime dominado pela difusão. 


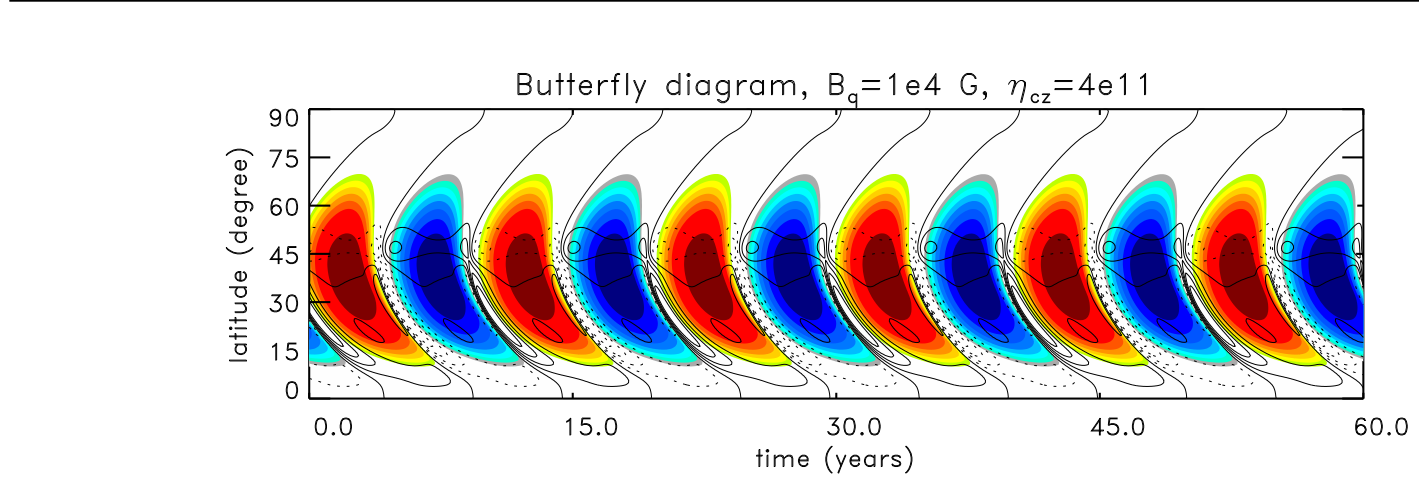

Figura 7.12: Diagrama de borboleta para o modelo com $B_{q}=10^{4} \mathrm{G}$ e $\eta_{c z}=4 \times 10^{11} \mathrm{~cm}^{2} \mathrm{~s}^{-1}$.

Para o caso $B_{q}=10^{3} \mathrm{G}$, o maior valor de $\eta_{c z}$ que converge para um estado estacionário com um período bem definido é $10^{11} \mathrm{~cm}^{2} \mathrm{~s}^{-1}$. Neste caso, a difusividade é altamente intermitente com gradientes maiores que em todas as simulações anteriores. Contudo, encontramos nesse caso (veja a curva em triângulos da Fig. 7.11) uma mudança suave no período em função de $\eta_{c z}$. A Fig. 7.12 mostra um diagrama de borboleta para um dos casos do regime dominado pela difusão. Na mesma figura, vemos que para modelos com valores altos de $\eta_{c z}$, a diferença entre os campos toroidais nas baixas latitudes e os campos radiais próximos dos pólos é $\sim \pi$, portanto maior do que o valor observado de $\pi / 2$.

Esses resultados revelam que um dínamo no regime dominado pela difusão, incluindo circulação meridional, mantém-se nesse regime ainda que a difusividade seja suprimida localmente pela reação do campo magnético. No entanto, lembramos que o perfil da difusividade no interior da zona de convecção é ainda desconhecido.

\subsection{Conclusões parciais deste Capítulo}

Neste Capítulo exploramos os efeitos do amortecimento da difusividade no modelo de dínamo solar de Babcock-Leighton, incluindo o amortecimento de $\eta$ através de uma equação algébrica similar à formula do efeito de amortecimento de $\alpha$, comumente utilizada para saturar o crescimento do campo. Encontramos que depois de alguns anos de evolução o sistema alcança um novo estado estacionário onde as componentes do campo magnético, $A$ e $B$, bem como a difusividade magnética, $\eta$, exibem um comportamento periódico.

No novo perfil de $\eta$ o decréscimo da difusividade pode ser de até três ordens de grandeza, no entanto, ele não é homogêneo em todo o domínio mas apresenta um padrão de cristas e vales que é diferente dependendo do quanto $\eta$ é amortecido. Quanto menor o valor de $B_{q}$, 
Tabela 7.2 - Parâmetros e resultados das simulações da seção 7.3.5.

\begin{tabular}{crrrrr}
\hline \hline$B_{q}(\mathrm{G})$ & $\eta_{c z}\left(\mathrm{~cm}^{2} \mathrm{~s}^{-1}\right)$ & $\alpha_{0}\left(\mathrm{~cm} \mathrm{~s}^{-1}\right)$ & $B_{\max }(\mathrm{G})$ & $B_{r_{\text {max }}}(\mathrm{G})$ & $T / 2(\mathrm{yr})$ \\
\hline $10^{3}$ & $5 \times 10^{10}$ & 50 & $4.8 \times 10^{4}$ & 153.7 & 13.65 \\
$10^{3}$ & $6 \times 10^{10}$ & 72 & $5.0 \times 10^{4}$ & 170.0 & 13.23 \\
$10^{3}$ & $7 \times 10^{10}$ & 98 & $7.5 \times 10^{4}$ & 543.1 & 12.75 \\
$10^{3}$ & $8 \times 10^{10}$ & 128 & $7.9 \times 10^{4}$ & 832.8 & 12.44 \\
$10^{3}$ & $9 \times 10^{10}$ & 162 & - & - & 12.44 \\
$10^{3}$ & $1 \times 10^{11}$ & 200 & $9.3 \times 10^{4}$ & 981.428 & 11.55 \\
\hline \hline $10^{4}$ & $5 \times 10^{10}$ & 50 & $3.6 \times 10^{4}$ & 121.9 & 11.74 \\
$10^{4}$ & $6 \times 10^{10}$ & 72 & $4.5 \times 10^{4}$ & 174.1 & 11.57 \\
$10^{4}$ & $7 \times 10^{10}$ & 98 & $5.3 \times 10^{4}$ & 252.2 & 11.37 \\
$10^{4}$ & $8 \times 10^{10}$ & 128 & $6.1 \times 10^{4}$ & 345.2 & 11.14 \\
$10^{4}$ & $9 \times 10^{10}$ & 162 & $6.7 \times 10^{4}$ & 452.0 & 10.90 \\
$10^{4}$ & $1 \times 10^{11}$ & 200 & $7.2 \times 10^{4}$ & 572.4 & 10.64 \\
$10^{4}$ & $2 \times 10^{11}$ & 800 & $9.5 \times 10^{4}$ & 2547.5 & 8.07 \\
$10^{4}$ & $3 \times 10^{11}$ & 1800 & $1.0 \times 10^{5}$ & 5998.7 & 6.23 \\
$10^{4}$ & $4 \times 10^{11}$ & 3200 & $1.1 \times 10^{5}$ & 10635.7 & 5.07 \\
$10^{4}$ & $5 \times 10^{11}$ & 5000 & $1.2 \times 10^{5}$ & 16515.5 & 4.32 \\
\hline & & & & &
\end{tabular}

${ }^{a}$ A simulação para $B_{q}=10^{3} \mathrm{G}$ e $\eta_{c z}=9 \times 10^{5} \mathrm{~cm}^{2} \mathrm{~s}^{-1}$ não converge para um estado estacionário. Por essa razão, para o gráfico da Fig. 7.11 foi utilizado o mesmo valor do período obtido na simulação com $B_{q}=10^{3} \mathrm{G}$ e $\eta_{c z}=8 \times 10^{5} \mathrm{~cm}^{2} \mathrm{~s}^{-1}$. 
mais irregular é o perfil final de $\eta$ (Figs. 7.5 e 7.6). Essa flutuação espacial na difusividade magnética leva à formação de pequenas regiões de campo magnético intenso com um longo tempo de vida. Tais regiões aparecem, sobretudo, na base da zona de convecção, nas latitudes equatoriais e no meio da zona convectiva. O papel da circulação meridional nestes resultados é muito importante, pois esta irá tentar empurrar os campos toroidais formados e ancorados nas regiões onde $\eta$ é localmente reduzido. Se o fluxo meridional é mais importante que o amortecimento de $\eta$, as regiões de campo mais intenso vão formar-se na base da zona convectiva, porém, se o amortecimento é grande o suficiente, ou o fluxo meridional muito fraco, o campo toroidal pode ficar preso no meio da zona de convecção, onde irá formar tubos de fluxo que ao emergirem para a superfície podem não concordar com a lei de Joy.

Verificamos que, contrariamente ao efeito de amortecimento de $\alpha$, e qual mostra um acoplamento quase linear entre o campo de saturação, $B_{0}$, e o valor final de $\alpha$ (veja a Fig. 7.4), a relação entre o valor de saturação da difusividade, $B_{q}$, e o valor final de $\eta$ é predominantemente não-linear, especialmente na base da zona de convecção, onde o cisalhamento radial compete com a advecção e a difusão. Encontramos que na tacoclina $\left(r=0.7 R_{\odot}\right)$ o campo magnético pode amplificar-se devido à diminuição de $\eta$ por um fator de até $\sim 2.5$ nas altas latitudes. Nas regiões equatoriais o campo magnético diminui por um fator similar. Por outro lado, no centro da camada convectiva $\left(r=0.8 R_{\odot}\right)$ o campo magnético, tanto nas latitudes baixas quanto nas intermediárias, aumenta por um fator de até $\sim 2$ em relação ao caso sem amortecimento da difusividade.

Como consequência desse efeito, o diagrama de borboleta apresenta campos toroidais maiores nas altas latitudes, menores nas baixas latitudes e o aumento do período do ciclo nos modelos onde o amortecimento de $\eta$ é mais efetivo. Essa nova distribuição latitudinal dos campos magnéticos, além de não ser totalmente consistente com as observações poderia levar a outros problemas no modelo, como a perda de acoplamento entre os dois hemisférios no caso de uma simulação na esfera completa, resultando uma paridade quadrupolar mais facilmente.

Já que o período do ciclo diminui quando a eficiência do amortecimento de $\eta$ aumenta, estudamos se esse efeito pode levar um modelo de dínamo dominado pela difusão, caracterizado por um curto período, a um dínamo dominado pela advecção do fluxo. Encontramos 
que os modelos difusivos mantêm-se nesse regime mesmo que a difusividade seja reduzida localmente por causa dos campos magnéticos intensos.

Os resultados sumarizados acima indicam que no cenário de um modelo de BL puro, com a circulação meridional agindo como mecanismo transportador e intensos campos magnéticos emergindo à superfície desde a base da zona de convecção, a difusividade turbulenta é provavelmente fracamente suprimida, i.e. ela é amortecida só para altos valores dos campos magnéticos (segundo os nossos resultados, os valores dos campos magnéticos capazes de diminuir a difusividade devem ser maiores que $5 \times 10^{3} \mathrm{G}$ ). Isto significa que o papel do amortecimento de $\eta$ na amplificação do campo magnético a valores superiores que o campo de equipartição não é significativo o suficiente. Porém, a supressão da difusividade pode ser o mecanismo que fomente a segregação do campo e o leve a uma estrutura mais capilar na base da zona convectiva, similar àquela observada na superfície.

Além disso, outros efeitos, como por exemplo o bombeamento magnético, discutido no Capítulo anterior, podem estar agindo de forma simultânea com o fluxo meridional e a supressão de $\eta$. Isto, possivelmente, formaria um padrão migratório diferente dos campos magnéticos e assim novos perfis de amortecimento da difusividade. Porém, incluir diferentes efeitos turbulentos no mesmo modelo aumenta consideravelmente o número de parâmetros livres a serem considerados, aumentando a complexidade do problema e requerendo, dessa forma, uma quantidade maior de simulações. Por outro lado, é também necessário estudar os efeitos da supressão de $\eta$ em modelos de dínamo operando graças à camada de cisalhamento superficial, como os discutidos em $§ 6.3 .4$. Esses estudos serão realizados no futuro. 


\section{Capítulo 8}

\section{Simulações tridimensionais de efeito dínamo: resultados preliminares}

Os modelos numéricos de dínamo de campo médio (2.5D) apresentados nos capítulos precedentes são uma excelente aproximação para reproduzir as características do ciclo magnético solar. No entanto, como foi discutido ao longo deste trabalho, neles utilizam-se formas paramétricas para ingredientes fundamentais do dínamo, como a contribuição dos campos magnético e de velocidade em pequena escala e, também, do campo de velocidades em grande escala. Por outro lado, as simulações globais do processo de dínamo solar ainda apresentam resultados inconsistentes com as observações devido, sobretudo, as limitações na resolução numérica permitida pelos computadores atuais. Uma aproximação diferente e talvez mais realista foi utilizada no Capítulo 6, na qual complementamos o modelo de campo médio no regime advectivo com a contribuição da pequena escala para o efeito $\gamma$. Tal contribuição foi calculada numericamente por Ossendrijver et al. (2002); Käpylä et al. (2006) em domínios tridimensionais que são pequenas caixas que representam uma fração da zonas convectiva e radiativa. Esses modelos são conhecidos como "modelos locais" e fazem uma abordagem completa dos processos hidro-magnéticos, pois integram todas as equações da MHD (§3.1) e permitem, portanto, investigar a resposta do campo magnético sobre o fluido, inclusive no regime não-linear.

Outras simulações tridimensionais locais (Cattaneo e Hughes, 1996; Ossendrijver et al., 2001) tentaram estabelecer uma relação entre a geração de campo magnético devido à convecção turbulenta com a teoria de dínamo de campo médio e calcularam a variação do efeito $\alpha$ em função do número de Reynolds magnético $(R m)$. Já os trabalhos de Tobias et al. (1998, 2001); Dorch e Nordlund (2001); Ziegler e Rüdiger (2003) estudaram os 
efeitos do bombeamento turbulento (pumping) do campo magnético na região radiativa. Os trabalhos de Ossendrijver et al. (2002); Käpylä et al. (2006) calcularam os perfis radiais e latitudinais dos coeficientes indutivos, $\alpha$, e advectivos, $\gamma$, do dínamo, em caixas tridimensionais localizadas em diferentes latitudes e com diferentes taxas de rotação.

Contudo, a relação que existe entre as simulações tridimensionais de magnetoconvecção e a teoria de dínamo de campo médio ainda não é bem estabelecida. Recentemente, simulações locais de um fluido forçado com turbulência helicoidal (Brandenburg, 2001) foram usadas para verificar o papel da conservação da helicidade magnética na fase não-linear do dínamo. Nesta fase a reação dinâmica do campo magnético sobre o fluido torna-se importante. No processo de dínamo turbulento, o crescimento do campo em grande escala pode ser alcançado através do cascateamento inverso que sofre a helicidade magnética $\left(h_{m}=\mathbf{A} \cdot \mathbf{B}\right.$, onde $\left.\mathbf{B}=\nabla \times \mathbf{A}\right)$ em grande escala. No entanto, como esta é uma quantidade conservativa, à medida que cresce na grande escala, cresce uma componente de helicidade magnética na pequena escala e de sinal contrário levando a saturação do crescimento do campo magnético. Quando o campo magnético evolui em uma região fechada (i.e., com condições de contorno periódicas), a saturação do campo vai depender da eficiência da difusividade magnética em dissipar a helicidade magnética em pequena escala. Porém, se o campo evolui numa região com fronteiras abertas, que permitam o fluxo de helicidade magnética em pequena escala para fora, portanto não conservando essa quantidade dentro do domínio, então o campo magnético em grande escala pode crescer mais facilmente até valores próximos à equipartição de energia (Brandenburg, 2001; Brandenburg e Subramanian, 2005). Esses resultados diferem daqueles encontrados por Vainshtein e Cattaneo (1992); Cattaneo e Hughes (1996) que previam um amortecimento catastrófico de $\alpha$.

No entanto, o cenário mais natural para verificar o crescimento do campo em grande escala não é um meio com turbulência helicoidal forçada, mas sim uma região onde esta evolua naturalmente, estratificada e convectivamente instável, com helicidade cinética induzida através da rotação. Embora simulações de efeito dínamo em meios convectivos existam há aproximadamente duas décadas, a produção de um campo magnético em grande escala e, portanto, a relação entre a teoria de campo médio e as simulações tridimensionais, é ainda discutida.

De fato, as primeiras simulações de convecção turbulenta, mesmo no caso sem rotação, 
já mostraram que a convecção atua como um dínamo que produz campos em pequena escala (Meneguzzi e Pouquet, 1989; Nordlund et al., 1992; Brandenburg et al., 1996; Cattaneo, 1999). Nessas simulações verifica-se um crescimento exponencial do campo magnético como conseqüência do cisalhamento (shearing) e esticamento (stretching) que as linhas de campo sofrem nos contornos dos turbilhões convectivos. Como nenhum campo magnético em grande escala é encontrado, a origem desse efeito dínamo não pode ser atribuída ao efeito $\alpha$ turbulento (embora, de acordo com a teoria, esse efeito esteja presente) mas, possivelmente, a um efeito de dínamo conhecido como $\alpha$-cisalhamento-incoerente (Vishniac e Brandenburg, 1997) ou ao efeito corrente-cisalhamento (Rogachevskii e Kleeorin, 2004, e.g.). Ambos os efeitos são o resultado das componentes não-difusivas do tensor $b_{i j k}$ (eq. $3.27)$.

Mais recentemente, o campo magnético em larga escala foi encontrado em simulações que combinam convecção, rotação e cisalhamento em grande escala (Käpylä et al., 2008b; Hughes e Proctor, 2009), enquanto que Tobias et al. (2008) em simulações similares encontram unicamente dínamo em pequena escala. Hughes e Proctor (2009) argumentam que em seus resultados o processo é independente dos efeitos $\alpha$ e $\Omega$ da teoria de campo médio e, por outro lado, Käpylä et al. (2008b) dizem que os campos em grande escala são produzidos devido à existência de fronteiras abertas que permitem o fluxo da componente em pequena escala da helicidade magnética através dos contornos do domínio computacional. Nos seus resultados o máximo valor alcançado pelo campo magnético é relativamente independente do número de Reynolds magnético, em concordância com os resultados de Blackman e Field (2001); Field e Blackman (2002); Blackman e Field (2002); Brandenburg (2001), suportando assim a existência de um dínamo de tipo $\alpha \Omega$. Os resultados de Tobias et al. (2008) devem-se aparentemente às condições de contorno periódicas que eles utilizam (Käpylä et al., 2008b).

A mesma discordância existe em simulações que combinam somente convecção e rotação. Por um lado, Cattaneo e Hughes (2006) encontram a amplificação de campo magnético em pequena escala, descartando a possibilidade de ele ser produzido por um efeito $\alpha$ turbulento. Por outro lado, as recentes simulações numéricas de convecção turbulenta totalmente compressível de Käpylä et al. (2009) confirmam a existência de um efeito $\alpha$ e de um dínamo de tipo $\alpha^{2}$. Segundo eles, a emergência do campo magnético em grande escala é possível 
unicamente quando a taxa de rotação é suficientemente alta. Käpylä et al. (2009) calculam também os coeficientes $\alpha, \gamma$ e $\beta$ do dínamo e os incluem em um modelo 1D de campo médio obtendo perfis de amplificação similares aos obtidos nas suas simulações 3D, verificando que correspondem, na verdade, a um dínamo $\alpha^{2}$.

Neste capítulo, vamos apresentar alguns resultados preliminares de simulações numéricas magneto-hidrodinâmicas tridimensionais de convecção turbulenta compressível, desenvolvidas a partir de modificações de um código numérico de tipo Gudunov denominado PLUTO (veja Apêndice B). O nosso objetivo principal com essas simulações é investigar um sistema que mimetize uma pequena região localizada nas camadas radiativa e convectiva de uma estrela do tipo solar. Uma vez estabelecidas as características do sistema inicialmente hidrodinâmico, iremos introduzir um campo magnético semente e estudar o processo de amplificação através do efeito dínamo. Essas simulações vão ajudar a distinguir os mecanismos de amplificação do campo que possam suportar (ou não), o formalismo de dínamo de campo médio baseado na conservação da helicidade magnética. Além disso, o sistema pode ser utilizado para estudar de forma realista a evolução de tubos de fluxo magnético em um meio ambiente convectivo.

Na próxima seção, mostraremos a formulação da condição inicial e as configurações do modelo e faremos uma descrição do código numérico MHD que utilizamos para estas simulações. Em seguida apresentaremos os resultados hidrodinâmicos iniciais, seguidos pelos resultados que incluem o campo magnético. Finalizaremos com as perspectivas para a continuação deste estudo.

\subsection{O modelo}

O domínio computacional adotado corresponde a uma porção de uma estrela modelada através de uma caixa tridimensional de magnitudes $\left(L_{x}, L_{y}, L_{z}\right)=(4 L, 4 L, 2 L)$, onde $L$ é a escala de comprimento em unidades de código. As direções $x$ e $y$ correspondem à latitude e longitude, respectivamente, enquanto que a direção $z$ corresponde a direção radial. A caixa encontra-se dividida em duas regiões $\left(-2=z_{0} \leq z \leq z_{1}=-1\right.$, e $-1=z_{1} \leq z \leq z_{2}=0$ veja a Fig. 8.1): uma camada radiativa (convectivamente estável) e uma camada convectiva. As equações que governam a evolução do fluido e do campo magnético no interior da caixa são as equações da MHD, eqs. (3.7, 3.12, 3.13 e 3.14). 


\subsubsection{Condições inicial, de contorno e parâmetros do modelo}

Como configuração inicial consideraremos um sistema em equilíbrio histrostático que deve obedecer às equações:

$$
\begin{aligned}
\frac{d p}{d z} & =-\rho g \\
F_{0} & =-\kappa \frac{d T}{d z} \\
p & =\frac{k_{B}}{\bar{\mu} m_{u}} \rho T
\end{aligned}
$$

onde $\rho, p$ e $T$ são as variáveis termodinâmicas: densidade, pressão e temperatura, respectivamente, $g$ é a aceleração gravitacional, $F_{0}$ é o fluxo radiativo, $\kappa$ é o coeficiente de condução térmica, $k_{B}$ é a constante de Boltzman, $m_{u}$ é a massa atômica e $\bar{\mu}$ é o peso molecular médio. Os valores de $g$ e de $\kappa$ em interiores estelares são função da profundidade, porém, por simplicidade, em nossos modelos vamos considerar a aceleração da gravidade constante em todo o domínio e para a condução térmica iremos considerar um valor constante distitnto para as camada convectiva e radiativa.

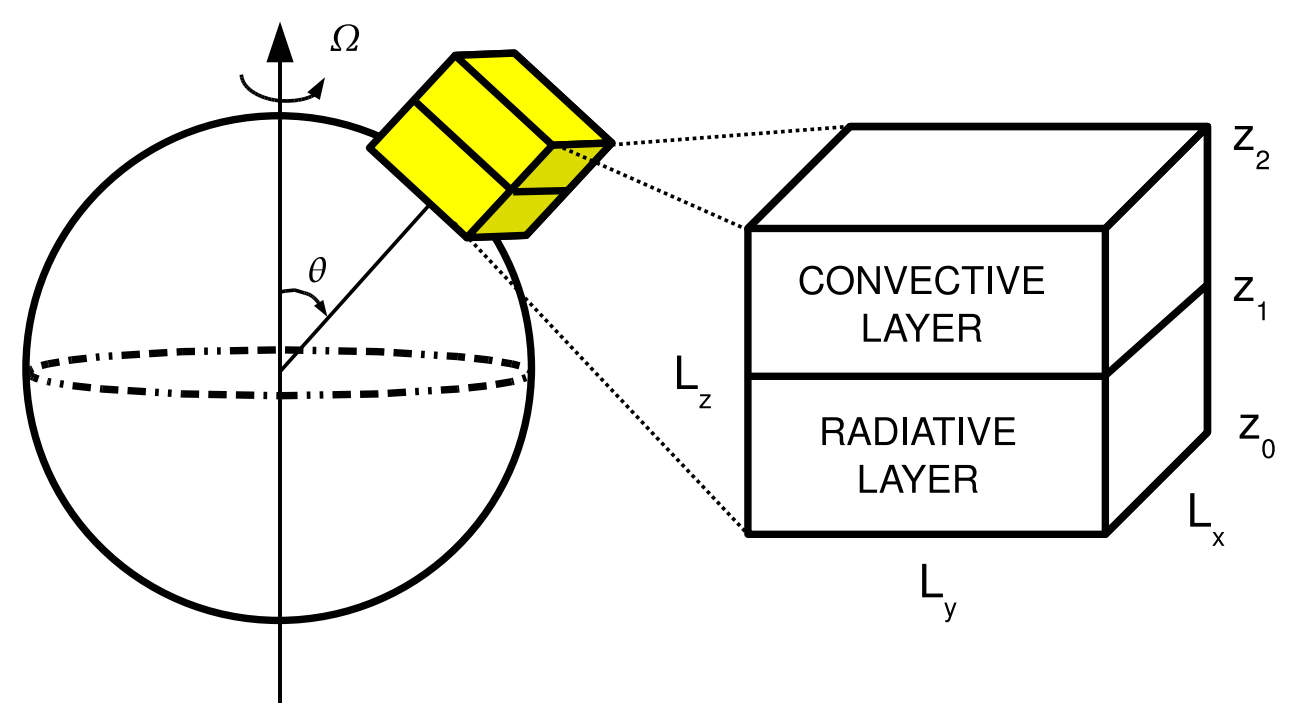

Figura 8.1: Desenho esquemático das diferentes camadas utilizadas na configuração do sistema.

A solução da equação de equilíbrio hidtrostático para uma estratificação politrópica de 
2 camadas é dada por:

$$
\begin{gathered}
T= \begin{cases}\frac{F_{0}}{\kappa_{c}}\left(z_{1}-z\right)+T_{1} & z_{0}<z<z_{1} ; \\
\frac{F_{0}}{\kappa_{s}}\left(z_{2}-z\right)+T_{2} & z_{1}<z<z_{2} ;\end{cases} \\
\rho= \begin{cases}\rho_{1}\left(\frac{T}{T_{1}}\right)^{m_{s}} & z_{0}<z<z_{1} ; \\
\rho_{2}\left(\frac{T}{T_{2}}\right)^{m_{c}} & z_{1}<z<z_{2} ;\end{cases}
\end{gathered}
$$

onde $m_{s}$ e $m_{c}$ estão relacionados com a gravidade e o fluxo radiativo através de:

$$
m_{i}=\frac{\bar{\mu} m_{u}}{k_{B}} \frac{\kappa_{i}}{F_{0}} g-1
$$

neste caso o índice $i$ significa $s$ ou $c$. Finalmente, a pressão pode ser calculada a partir da equação de estado. Os valores de $\rho$ e $T$ nas interfaces $z_{1}$ e $z_{2}$ são calculados considerando que as funções (8.4) e (8.5) devem ser contínuas no ponto $z_{1}$, de tal forma que as seguintes condições devem ser respeitadas:

$$
\begin{aligned}
T_{1} & =\frac{F_{0}}{\kappa_{c}}\left(z_{2}-z_{1}\right)+T_{2}, \\
\rho_{1} & =\rho_{2}\left(\frac{T 1}{T 2}\right)^{m_{c}} .
\end{aligned}
$$

Para garantir valores numéricos razoáveis iremos considerar arbitrariamente $\rho\left(z_{2}\right)=\rho_{c}$ e $T\left(z_{2}\right)=T_{c}$, em unidades de código, tal como se explica mais adiante.

Os sistemas politrópicos que satisfazem $m<m_{a d}$, onde $m_{a d}=1 /(\gamma-1)=1.5$ é o índice politrópico ${ }^{1}$, são convectivamente instáveis; conseqüentemente, estratificações com $m>m_{a d}$ são consideradas estáveis com respeito à convecção e a energia é transportada por radiação (Brandenburg et al., 1996). Para garantir essas duas condições em nosso sistema vamos considerar $m_{s}=9$ e $m_{c}=1$ para as camadas radiativa e convectiva, respectivamente.

Assim, usando a eq. (8.6), só precisamos definir um valor de $g$ para calcular os valores de $F_{0} / \kappa_{c}$ e $F_{0} / \kappa_{s}$ e, então, estabelecer a estratificação em equilíbrio. Em unidades de código definimos $g=20$.

Outra condição que deve ser obedecida para estabelecer que a convecção aconteça em toda a camada instável é que o número de Rayleigh ( $R a$, eq. 3.21) deve ser maior que $10^{3}$ (Chandrasekhar, 1961; Gough et al., 1976). A influência da rotação da esfera no padrão

\footnotetext{
${ }^{1}$ Estamos considerando um índice adiabático $\gamma=5 / 3$ o qual é apropriado para um gás monoatômico ideal.
} 
de convecção é caracterizada pelo número de Taylor (Ta, eq. 3.22), e a importância da dissipação viscosa relativa à difusão térmica e magnética é dada pelos números de Prandtl, Pr, e Prandtl magnético Pm, respectivamente (eqs. 3.19 e 3.20). De tal forma que podemos definir todo o estado do nosso sistema a partir das 7 quantidades adimensionais: $m_{c}, m_{s}, g, R a, T a, \operatorname{Pr}$ e $\operatorname{Pm}$.

O valor da viscosidade, $\nu$ (eq. 3.15), é determinado utilizando-se os valores de $g, R a$ e $\operatorname{Pr}$ e o valor de $T$ na metade da camada convectiva. Por simplicidade, assumiremos também que $\nu$ é constante em todo o domínio. O valor de $\kappa_{c}$ (eq. 3.14) pode ser calculada imediatamente a partir de $\nu, \operatorname{Pr}$ e o valor de $\rho$ na metade da camada estável. Já que o fluxo de temperatura permanece constante, partindo da eq. (8.6) podemos chegar à relação:

$$
\frac{\kappa_{s}}{\kappa_{c}}=\frac{m_{s}+1}{m_{c}+1}
$$

de onde se pode inferir o valor de $\kappa_{s}$. Na interface entre as duas camadas, consideraremos uma variação suave de espessura $0.1 d$. A configuração acima resulta em um contraste máximo de densidade de 50 entre a base e o topo da caixa, e abrange aproximadamente 6 escalas de altura no interior estelar $\left(h_{p}=d \ln p / d z=\mathcal{R} T / \bar{\mu} g\right.$, onde $\mathcal{R}$ é a constante universal dos gases). A taxa de rotação, $\Omega$, é computada a partir do número de Taylor e o vetor de velocidade angular é dado por $\Omega=-\Omega \sin \theta \hat{e_{x}}+\Omega \cos \theta \hat{e_{y}}$.

O código utiliza unidades normalizadas a valores característicos de três variáveis: $U, L$ e $\rho$. Assim, por exemplo, o valor de $U$ em unidades físicas pode ser calculado considerando-se $U^{\prime}=U_{c} U$, onde $U_{c}$ é a velocidade de normalização e $U$ a velocidade do fluido em unidades de código. Dessa forma os valores físicos das outras variáveis podem ser calculados da seguinte maneira:

$$
[t]=\frac{L_{c}}{U_{c}} \quad, \quad[p]=U_{c}^{2} \rho_{c} \quad, \quad[B]=\sqrt{\left(4 \pi \rho U_{c}^{2}\right)} \quad \text { e } \quad[g]=\frac{U_{c}^{2}}{L_{c}}
$$

onde as unidades de normalização escolhidas foram:

$$
\begin{aligned}
U_{c} & =\sqrt{\frac{\gamma k_{B}}{\bar{\mu} m_{p}} T_{c}} \mathrm{~cm} \mathrm{~s}^{-1}, \\
L_{c} & =0.13 R_{\odot} \quad \mathrm{cm}, \\
\rho_{c} & =1 \mathrm{~g} \mathrm{~cm}^{-3} .
\end{aligned}
$$

$\mathrm{O}$ valor de $T_{c}$ pode ser calculado usando as eqs. (8.10 e 8.11) e considerando-se que no 
caso solar $g \simeq 5.4 \times 10^{4} \mathrm{~cm} \mathrm{~s}^{-2}$, o que resulta em $T_{c} \simeq 8.8 \times 10^{4} \mathrm{~K}$. Esse valor corresponde ao topo da camada convectiva do modelo.

Nas fronteiras horizontais da caixa vamos considerar condições de contorno periódicas para todas as variáveis, enquanto que nas fronteiras verticais $\left(z_{0}\right.$ e $\left.z_{2}\right)$ consideraremos as condições de contorno conhecidas como "stress-free", ou seja:

$$
\frac{\partial U_{x}}{\partial z}=\frac{\partial U_{y}}{\partial z}=U_{z}=0
$$

além disso, na fronteira superior a pressão tem um valor fixo dado pela densidade e temperatura, $\rho\left(z_{2}\right)$ e $T\left(z_{2}\right)$, e na fronteira inferior consideraremos um fluxo de calor na direção vertical, assim:

$$
\frac{\partial p}{\partial z}=\rho_{0} \frac{\partial T}{\partial z}=\rho \frac{F_{0}}{\kappa_{s}}
$$

onde usamos a eq. 8.2 para a segunda igualdade. Para o campo magnético existem duas possíveis condições de contorno, a condição "condutora",

$$
\frac{\partial B_{x}}{\partial z}=\frac{\partial B_{y}}{\partial z}=B_{z}=0
$$

e a condição de "campo vertical",

$$
B_{x}=B_{y}=0 .
$$

Essa segunda condição permite o fluxo de helicidade magnética através das fronteiras verticais, portanto, em princípio iremos usar essa condição nas simulações numéricas seguintes para permitir a amplificação de $B$.

\subsubsection{O Código}

A maior parte dos códigos computacionais com os quais se aborda o problema da convecção utilizam métodos de diferenças finitas ou métodos pseudo-espectrais para levar as equações MHD a uma forma discreta. Nos esquemas de diferenças finitas, normalmente são utilizadas seis ordens de precisão na discretização espacial para diminuir a importância da viscosidade numérica, pois no problema da convecção participam termos dissipativos físicos como $\nu, \kappa$ e $\eta$ (Brandenburg et al., 1996; Käpylä et al., 2008b,a).

Em nosso caso vamos utilizar o código de domínio público PLUTO (Mignone et al., 2007) que resolve as equações MHD utilizando volumes finitos e um método de tipo Goudunov (Toro, 1997, veja também o Apêndice B). Este tipo de algorítmo tem a vantagem 
de ser conservativo, ou seja, ele garante que quantidades como a massa, o momento, a energia e o fluxo magnético sejam conservadas no domínio computacional a cada unidade de tempo, além disso é conhecido por apresentar baixa viscosidade numérica, dando assim maior credibilidade à ação dos coeficientes dissipativos físicos $\nu, \kappa$ e $\eta$ (ou seja, $R a, T a$, $\operatorname{Pr}$ e $P m)$. No apêndice B pode-se encontrar uma descrição mais detalhada deste método numérico e do código.

Para este trabalho o código PLUTO foi complementado com a construção de algumas rotinas para calcular os termos de condução térmica, $\nabla \cdot(\kappa \nabla T)$, e a densidade de força viscosa, $\nabla \cdot \tau_{i j}$, nas equações (3.13) e (3.14), e também para configurar a condição inicial de equilíbrio descrita acima bem como as características do modelo convectivo. Os resultados obtidos da evolução temporal desta configuração são apresentados na próxima seção.

\subsection{Resultados}

\subsubsection{Solução hidrodinâmica}

A configuração de equilíbrio hidrostático para a densidade, pressão e temperatura descrita acima, começa a evoluir a partir de uma distribuição randômica de velocidades de baixa amplitude que induzirá a instabilidade convectiva. Como é de nosso interesse estudar soluções MHD realistas precisamos primeiro deixar evoluir o sistema hidrodinâmico até este atingir um estado convectivo estacionário. Isto acontece após algumas vezes o tempo de turnover: $\tau=\ell / u_{r m s}$, onde $\ell$ é o comprimento dos turbilhões convectivos e $u_{r m s}=\sqrt{\ll \mathbf{U}^{2} \gg-\ll \mathbf{U} \gg^{2}}$ é a velocidade turbulenta do fluido (a seguir iremos representar as médias espaciais em 3 dimensões por $\ll \gg$ e as médias espaciais em 2 dimensões por $<>$ ). Todas as quantidades têm uma componente média, $Q_{0}$, e uma componente flutuante, q. Para calcular os valores médios iremos usar as leis de Reynolds, eq. (3.25). A evolução da velocidade $u_{r m s}$ é apresentada no painel esquerdo da Fig. 8.2. Desse mesmo gráfico podemos inferir a velocidade turbulenta $u_{r m s} \sim 0.16$, em unidades de código, de tal forma que o tempo de turnover, considerando $\ell=L$, será: $\tau \sim 6.2$ unidades de código em tempo.

No painel direito da Fig. 8.2 apresentamos o perfil da densidade na direção vertical. A curva é o resultado do cálculo da média espacial em planos bidimensionais (normais a 

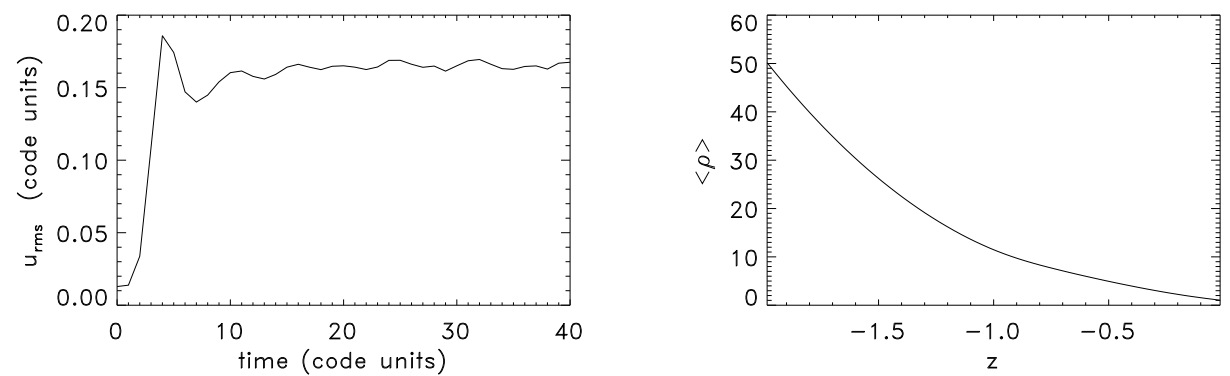

Figura 8.2: Esquerda: Evolução temporal da velocidade rms. Direita: Perfil vertical da densidade calculado considerando-se a média espacial bidimensional e a média temporal sob $\sim 2$ tempos de turnover.

z) e em dois tempos turnover, quando o sistema já atingiu um estado totalmente relaxado (estacionário).

Realizamos alguns experimentos numéricos: um considerando o número de Taylor, $T a=0$ (i.e., sem rotação), o qual chamamos experimento $C 00$, e outro com rotação, $T a=5 \times$ $10^{5}$ para $\theta=0$, ou seja, a caixa está localizada no pólo norte da esfera, o qual denominamos experimento $C 01$. Na simulação que denominamos $C 02$ diminuímos o número de Prandt magnético enquanto que a simulação denominada $C 01_{p c}$ corresponde a mesma configuração de $C 01$, mas considerando condições de contorno condutora (eq. 8.14) para o campo magnético. Já na simulação $C 01_{h r}$ incrementamos a resolução numérica. Os demais parâmetros dessas simulações aparecem. na Tabela 8.2.1.

\begin{tabular}{cccccccc}
\hline Modelo & $N_{x} \times N_{y} \times N_{z}$ & $R a$ & $\operatorname{Pr}$ & $\operatorname{Pm}$ & $R e$ & $R m$ & $T a$ \\
\hline$C 00$ & $50 \times 50 \times 64$ & $10^{6}$ & 0.2 & 5 & $\sim 156$ & $\sim 782$ & 0 \\
$C 01$ & $50 \times 50 \times 64$ & $10^{6}$ & 0.2 & 5 & $\sim 106$ & $\sim 533$ & $5 \times 10^{5}$ \\
$C 02$ & $50 \times 50 \times 64$ & $10^{6}$ & 0.2 & 2 & $\sim 106$ & $\sim 212$ & $5 \times 10^{5}$ \\
$C 01_{p c}$ & $50 \times 50 \times 64$ & $10^{6}$ & 0.2 & 5 & $\sim 106$ & $\sim 533$ & $5 \times 10^{5}$ \\
$C 01_{h r}$ & $128 \times 128 \times 128$ & $10^{6}$ & 0.2 & 5 & $\sim 173$ & $\sim 869$ & $5 \times 10^{5}$ \\
\hline
\end{tabular}

Tabela 8.1 - Valores numéricos dos parâmetros que definem o estado do sistema nas simulações de convecção turbulenta. Os números de Reynolds e de Reynolds magnético são calculados da seguinte maneira: $R e=u_{r m s} \ell / \nu$ e $R m=u_{r m s} \ell P m$, respectivamente, onde $\nu=1.16 \times 10^{-3}$ em unidades de código. $N_{x}, N_{y}$ e $N_{z}$ correspondem aos pontos de grade na direções $x, y$ e $z$, respectivamente. 
Na Fig. 8.3 apresentamos os padrões de convecção representados pela velocidade vertical, $U_{z}$, obtidos para os modelos $C 00$ e $C 01$. Na parte superior da figura são mostrados os resultados para o experimento sem rotação em três alturas diferentes da caixa: o topo, a metade e a base da camada convectiva. Já a parte inferior contém os resultados para a simulação com rotação. Nestas figuras a escala de cores amarela corresponde a fluxos ascendentes e a escala escura indica fluxos descendentes. Podemos observar vários aspectos interessantes da convecção turbulenta como, por exemplo, o fato de as células convectivas terem menor tamanho e fragmentarem-se mais facilmente nas camadas superiores. $\mathrm{Na}$ simulação incluindo rotação, além de observarmos a formação de mais células convectivas que na simulação sem rotação, é possível distinguir-se a presença de vorticidade ciclônica nas interfaces das células de convecção. Esta deve-se à contribuição horizontal da força de Coriolis $(-2 \rho \boldsymbol{\Omega} \times \mathbf{U})$ nos fluxos horizontais convergentes. A vorticidade ciclônica aparece em sentido anti-horário por tratar-se do hemisfério norte. Este comportamento se mantém em quase toda a camada convectiva até a sua base onde os fluxos horizontais são divergentes. A rotação gera, também, uma considerável quantidade de helicidade cinemática, $\omega \cdot \mathbf{U}$, onde $\omega$ é a vorticidade $(\nabla \times \mathbf{U})$, com respeito ao caso sem rotação. Na Fig. 8.4 são mostrados os perfis da helicidade cinemática média em função de $z$ para os dois casos. Note-se que o sinal da helicidade no caso com rotação é negativo na camada convectiva e muda de sinal perto da camada estável. O módulo da amplitude da helicidade cinética é visivelmente maior para o modelo com rotação devido à contribuição da força de Coriolis (veja Miesch et al., 2008).

Outra característica interessante que diferencia a convecção nos modelos com e sem rotação é a penetração do fluxo convectivo na camada estável (Tobias et al., 2008). Como se pode distinguir na barra de cores da Fig. 8.3, a velocidade em direção à base da camada convectiva é maior que a velocidade de emergência do fluxo. De fato, os fluxos ascendentes expandem por espaços amplos enquanto os fluxos descendentes acontecem em espaços muito estreitos (veja Miesch et al., 2008, e as referências contidas). Desta forma, fortes fluxos descendentes em forma de jatos penetram na zona radiativa e formam a região de overshooting. A extensão dessas estruturas é dependente da taxa de rotação, conforme se pode verificar no painel direito da Fig. 8.4, que apresenta os valores, em unidades de 

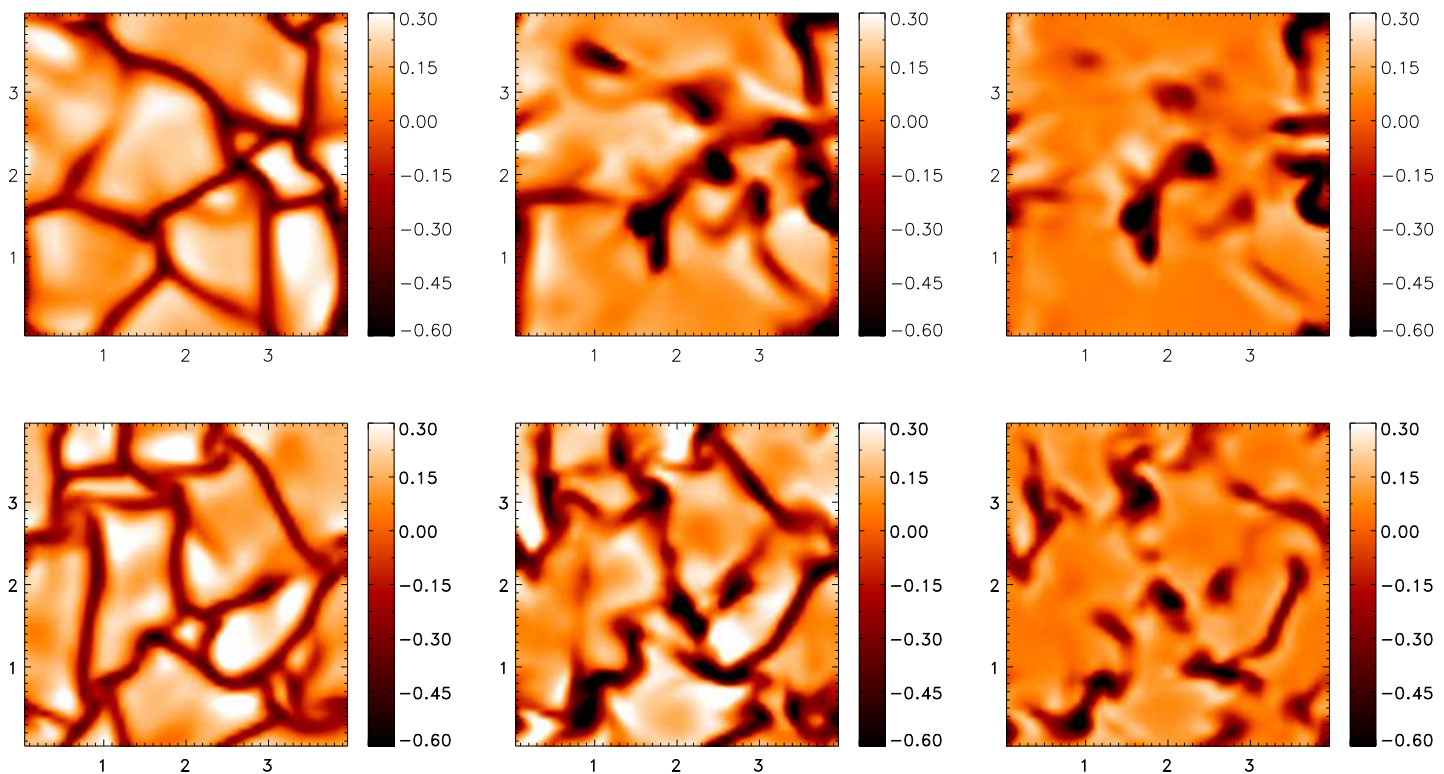

Figura 8.3: Velocidade vertical, $U_{z}$ para os modelos sem rotação (parte superior), e com rotação (parte inferior), para três alturas diferentes da camada convectiva: o topo (esquerda), a metade (meio) e a base (direita).
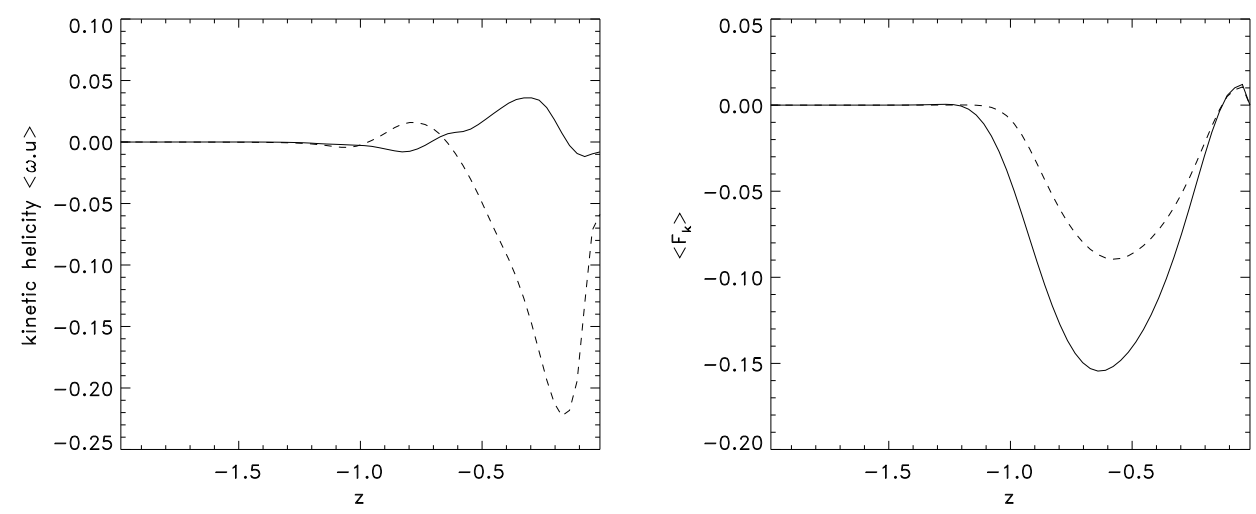

Figura 8.4: Média horizontal e temporal da helicidade cinética (esquerda) e do fluxo de energia cinética (direita) para os modelos C00 (linha contínua) e C01 (linha tracejada).

código, do fluxo de energia cinética definido como;

$$
F_{k}=<\rho \mathbf{u}_{r m s} U_{z}>,
$$

Esse painel mostra que a rotação tende a estabilizar a convecção e reduzir a camada de overshooting. Além da rotação, a penetração na região inferior depende também da valor do fluxo radiativo, definido neste caso pelo valor de $m_{s}=9$ (veja eq. (8.6)). Valores menores 
que essa quantidade permitem maior penetração e mistura entre as duas camadas.

Na Figura 8.5, o espectro de turbulência convectiva, $E_{k}$, é mostrado em função do inverso da escala horizontal dos turbilhões, $\left.k=1 / \ell=\sqrt{(} k_{x}^{2} 2+k_{y}^{2}\right)$, para os modelos com e sem rotação. A energia cinética espectral é definida como:

$$
E_{k}(k)=\frac{<\rho>}{2} \int_{0}^{2 \pi}|\hat{\mathbf{U}}(k, z, t)|^{2} k d \phi_{k}
$$

onde $\phi_{k}=\arctan \left(k_{y} / k_{x}\right)$ e o acento circunflexo denota a transformada de Fourier das três componentes da velocidade.

As características espectrais dos dois sistemas hidrodinâmicos acima mostram que embora a resolução que utilizamos nesses dois casos seja relativamente baixa, devido às exigências computacionais desta classe de simulações, a convecção possui um padrão turbulento, com uma escala de injeção de energia e uma escala inercial na qual o espectro de energia tem uma inclinação aproximada de $-5 / 3$, característica de um espectro de Kolmogorov (Frisch, 1995). Este prevê um cascateamento de energia das grandes para as pequenas escalas, além de uma escala dissipativa, onde a turbulência é amortecida pela ação dos termos difusivos (Veja Fig 8.5).

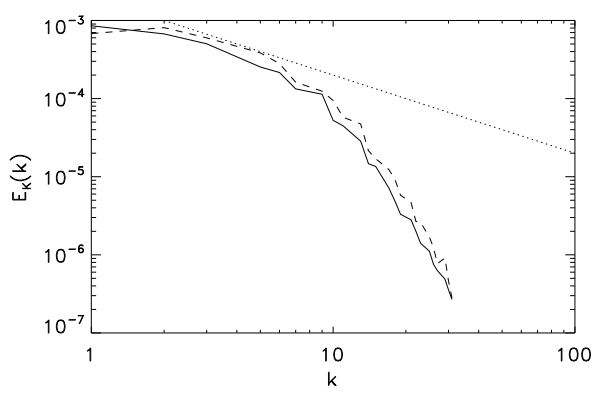

Figura 8.5: Espectro bidimensional da energia cinética correspondente à metade da camada convectiva. As linhas contínua e tracejada correspondem aos casos com $T a=0$ (sem rotação) e $T a=5 \times 10^{5}$ (com rotação), respectivamente. A linha pontilhada com inclinação proporcional a $k^{-5 / 3}$ é mostrada como referência.

\subsubsection{Efeito dínamo}

É de nosso interesse investigar a amplificação do campo magnético em regiões convectivas devido aos efeitos da turbulência, tentando verificar o grau de amplificação devido ao efeito $\alpha$ turbulento ou então a outros processos. 
Para estudar esse efeito, partindo das soluções hidrodinâmicas relaxadas mostradas acima, introduzimos um campo magnético semente homogêneo na direção $\hat{x}$, de valor $10^{-6}$ vezes menor que o valor do campo de equipartição com o movimento turbulento, $B_{q}=\left(\ll \rho \mathbf{u}^{2} \gg\right)^{1 / 2}$ (em unidades de código), e deixamos o sistema evoluir por um período adicional de $\sim 20$ tempos de turnover $(\sim 20 \tau)$.

A Figura 8.6 mostra a evolução temporal do campo magnético. Os painéis da esquerda mostram as densidades de energia cinética (linha contínua) e de energia magnética multiplicada por 2 (linha tracejada), avaliadas tomando-se médias volumétricas sobre todo o domínio computacional, para os modelos (a) C00, (b) C01, (c) C02 e (d) $C 01_{p c}$. Já os painéis da direita apresentam a evolução do campo magnético total, $\mathbf{B}_{r m s}$, em escala logarítmica. Vemos que no caso sem rotação o crescimento é suave, alcançando valores próximos da equipartição somente depois de $\sim 10 \tau$, enquanto que no caso com rotação o crescimento exponencial acontece bem mais rápido em $\sim 3 \tau$. Para comparação, incluímos o modelo $C 02$, que tem a mesma taxa de rotação que o modelo $C 01$, porém com diferente número de Prandtl magnético, $P m=2$ (o que implica um $R m \simeq 212$ ). Neste último caso observa-se que o crescimento do campo é mais suave que no caso com maior $R m$, alcançando valores dinamicamente importantes para o fluido em $\sim 5 \tau$. Verificamos que a dependência da taxa de crescimento do campo com $R m$ obtida nos modelos com rotação (Fig. 8.6 b e c) concorda com aquela encontrada por Brandenburg (2001) em modelos fluidos com turbulência helicoidal forçada, ou seja, verificamos que quanto maior o número de Reynolds, maior a taxa de crescimento. Já a menor taxa de crescimento no modelo sem rotação deve-se possivelmente à existência de diferentes processos de amplificação. O caso com fronteiras condutoras para o campo magnético (Fig. $8.6 d$ ) não apresenta sinais de amplificação. Este efeito poderia ser devido à combinação de dois fatores: as condições de contorno que tendem a eliminar os termos de amplificação do campo magnético em pequena escala e a alta difusividade numérica, a qual está associada a uma baixa resolução e pode levar os termos difusivos a dominar sobre os termos indutivos.

Enquanto as simulações com condições de contorno de campo vertical apresentam resultados satisfatórios no sentido de amplificar o campo magnético semente, verifica-se que, apesar da diferença no tempo de excitação do dínamo, o comportamento da evolução da energia magnética é similar em todos os casos, mostrando surtos de rápido crescimento 

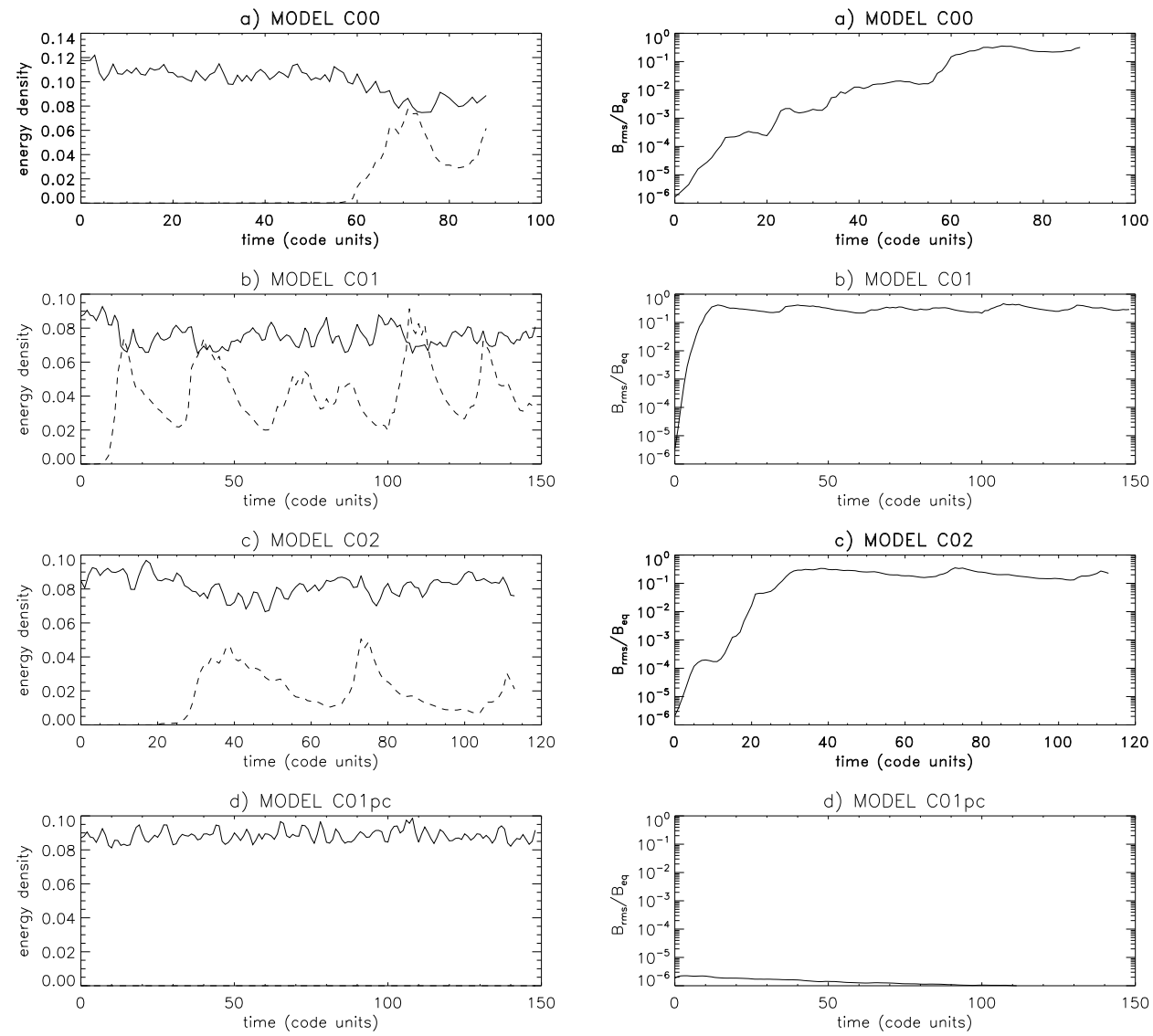

Figura 8.6: Evolução temporal da densidade de energia cinética (linha contínua) e magnética multiplicada por 2 (linha tracejada) em escala linear (esquerda), e da magnitude do campo magnético em relação ao campo de equipartição $B_{e q}($ direita).

acompanhados de um decaimento suave. Contudo, espera-se que a rotação introduza diferenças fundamentais entre os dois casos. Especificamente, a helicidade cinemática do fluido em rotação deve induzir um efeito $\alpha$ (veja Capítulo 3) e, portanto, um campo magnético em grande escala (Cattaneo e Hughes, 2006). Para investigar com maior detalhe esse problema, iremos examinar qual é a componente predominante do campo magnético total na Fig. 8.6. Nessa figura vemos que existem 3 regimes distintos para a evolução do campo magnético: há uma fase de crescimento (correspondente ao intervalo no qual a energia magnética não é dinamicamente importante); uma fase de saturação correspondente às cristas dos painéis a, b e c, da Fig. 8.6, onde a amplitude do campo fica máxima (nestes intervalos a energia magnética se aproxima mais da energia cinética); e uma fase de decaimento suave (onde o campo ainda tem energias da ordem da equipartição, mas diminui sua intensidade). Na Fig. 8.7 mostramos perfis da média horizontal do campo magnético total, $\sqrt{\ll} \mathbf{B}^{2} \gg$ (li- 
nha contínua), médio, $\sqrt{\ll} \mathbf{B} \gg^{2}$ (linha tracejada) e flutuante, $\left.\ll \mathbf{b} \gg=\sqrt{(} \ll \mathbf{B} \gg-\ll \overline{\mathbf{B}} \gg\right)$ (linha ponto-tracejada), para os casos sem rotação $(C 00)$ e com rotação $(C 01)$, integrados sobre o intervalo de tempo correspondente a cada uma dessas três fases.
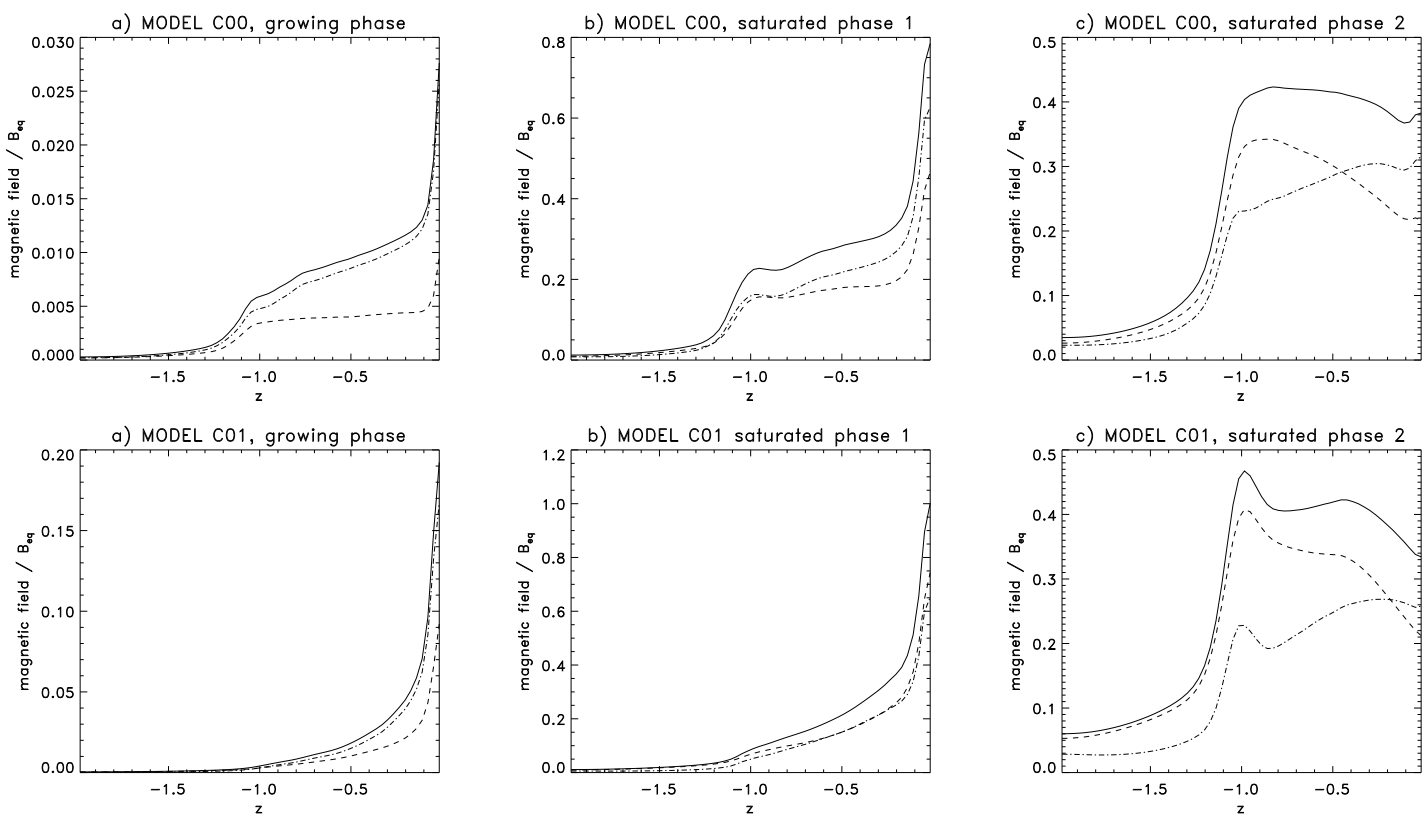

Figura 8.7: Médias tomadas em planos horizontais (normais a $z$ ) do campo magnético total (linha contínua), médio (linha tracejada) e flutuante (linha ponto-tracejada), para três fases diferentes da sua evolução: a) fase cinemática ou de crescimento; b) fase saturada 1; e c) fase saturada 2 (veja explicação no texto), para os modelos C00 (painéis superiores), e C01, (painéis inferiores).

Na Fig. 8.7 vemos que na fase de crescimento (painéis esquerdos) o campo magnético total é dominado pela componente flutuante. Esta começa a formar-se na região mais externa da camada convectiva. As condições de contorno sobre os campos de velocidades e magnético nessa região podem estar atuando de forma decisiva, pois favorecem a formação de fluxos horizontais em grande escala próximos à fronteira superior, que podem operar sobre a componente vertical do campo. Na fase saturada 1, quando a energia magnética mais se aproxima da energia cinética, ambos os campos, médio e em pequena escala, possuem aproximadamente a mesma amplitude. Finalmente, no que chamamos fase saturada 2, podemos distinguir dois fatos interessantes. O primeiro é que a energia encontra-se distribuída de forma mais uniforme na zona convectiva, contendo uma pequena fração de campo na zona radiativa. Isto é um fato notável já que tanto a rotação, quanto o campo 
magnético devem inibir o transporte devido ao bombeamento magnético. Porém, nota-se que o modelo com rotação (C01) tem uma maior fração de campo na camada radiativa. O segundo ponto a se distinguir é a nova distribuição das componentes média e flutuante do campo magnético. No modelo sem rotação o campo magnético médio domina na base da região convectiva e o campo flutuante domina na metade superior da mesma região. No entanto, no modelo com rotação o campo médio domina visivelmente em quase toda a região convectiva, à exceção de uma pequena fração sub-superficial onde o campo em pequena escala é ligeiramente maior.

Isto sugere a existência de um efeito $\alpha$ induzido graças à rotação. Contudo, novamente ressaltamos a necessidade de se considerar ainda um maior número de testes, com diferentes taxas de rotação, bem como diferentes comprimentos horizontais da caixa 3D, maior resolução numérica e uma varredura mais extensa de valores dos parâmetros livres do modelo (Re, Rm, Pr, Pm e Ta).

\subsubsection{Alta resolução: resultados preliminares}

Para testar a validade dos resultados apresentados na seção precedente, nesta seção apresentaremos os resultados de simulações do efeito dínamo com uma resolução numérica maior, com $128^{3}$ pontos de grade. Inicialmente, consideramos uma configuração similar ao modelo $C 01$. Com a resolução maior, a simulação numérica é capaz de resolver escalas menores com maior detalhe. Porém, o custo computacional destas simulações é muito elevado (i.e., uma simulação em baixa resolução, $50 \times 50 \times 64$, leva 12 horas de tempo de computação em 64 processadores para evoluir 200 passos temporais, enquanto que uma simulação do mesmo número de passos com a maior resolução, $128^{3}$, demanda cerca de 90 horas de computação, em 256 processadores.

Na Figura 8.8 apresentamos os contornos da velocidade vertical do estado convectivo estacionário do modelo $C 01_{h r}$ (após $12 \tau$ ). Tal como na Fig. 8.3, os painéis esquerdo, central e direito, correspondem ao topo, ao meio e à base da camada convectiva do modelo $C 01_{h r}$, respectivamente. Neste caso, observam-se com maior detalhe os vórtices formados nas interfaces entre as células convectivas. Comparado ao caso com menor resolução, esta vorticidade é mais evidente nas camadas mais internas. Como esperado, ao aumentar a resolução numérica, aumenta também o número de Reynolds e portanto, o nível de 

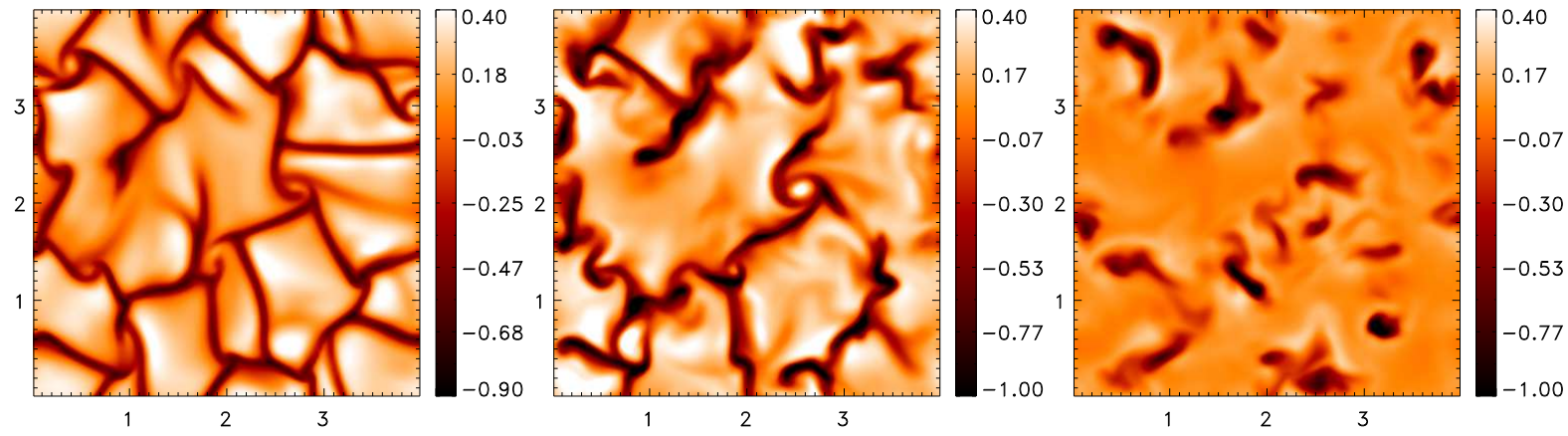

Figura 8.8: Velocidade vertical, $U_{z}$ para o modelo $C 01_{h r}$, para três alturas diferentes da camada convectiva: o topo (esquerda), a metade (meio) e a base (direita).

turbulência. A velocidade turbulenta $(\mathrm{rms})$ desta simulação é $\sim 0.2$, o que resulta $\tau \sim 5$, ambas as quantidades em unidades de código. Essa configuração estacionária é utilizada como condição inicial para a simulação na qual examinaremos a seguir a evolução de um campo magnético semente.

No espectro de energia cinética deste modelo, mostrado na Fig. 8.9, verifica-se novamente a presencia das escalas de injeção, inercial e dissipativa. No entanto, desta vez verifica-se que a escala dissipativa corresponde a valores maiores de $k(\sim 20)$. Isso significa que as escalas do sistema nas quais a viscosidade se torna importante são menores neste caso. Por comparação, na mesma figura graficamos o espectro de energia cinética para o tempo final desta simulação como o campo magnético já presente $(t=120$, linha tracejada) . Esses dois perfis não apresentam diferenças significativas.

A evolução temporal do campo magnético na Fig. 8.10 apresenta algumas diferenças em relação ao caso com baixa resolução (Fig. 8.6). No caso com alta resolução o campo magnético mostra um crescimento exponencial inicial (em aproximadamente $4 \tau$ ) que não chega a atingir o valor do campo de equipartição. Contudo, observa-se que o crescimento do campo magnético continua de forma suave durante os passos temporais seguintes. Até o passo temporal que evoluiu o modelo (i.e., $t=124$ ), a energia do campo magnético atingiu aproximadamente $5 \%$ da energia cinética (note que no painel esquerdo da Fig. 8.10 a energia magnética foi multiplicada por 10 para facilitar a comparação). No painel direito da Fig. 8.10, graficamos separadamente o crescimento do campo total (linha contínua), do médio (linha tracejada) e do flutuante (linha pontilhada). Nessa figura vemos que na fase inicial de amplificação, o campo total é dominado pela componente flutuante (de pequena 


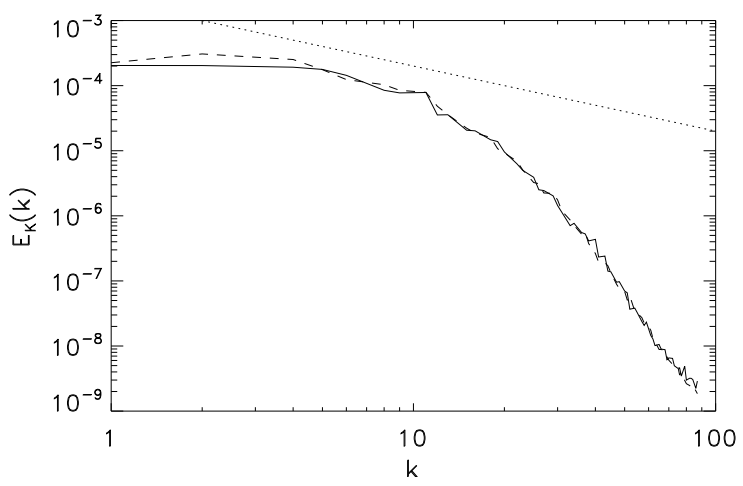

Figura 8.9: Espectro bidimensional da energia cinética correspondente à metade da camada convectiva para o modelo $C 01_{h r}$. As linhas contínua e tracejada correspondem aos passos temporais $t=0$ (sem campo magnético) e $t=120$ (com campo magnético), respectivamente. A linha pontilhada com inclinação proporcional a $k^{-5 / 3}$ é mostrada como referência.

escala). Por outro lado, o campo médio amplifica apenas alguns passos temporais depois. Observa-se também que para $t \gtrsim 40$, o campo em pequena escala começa a decrescer.
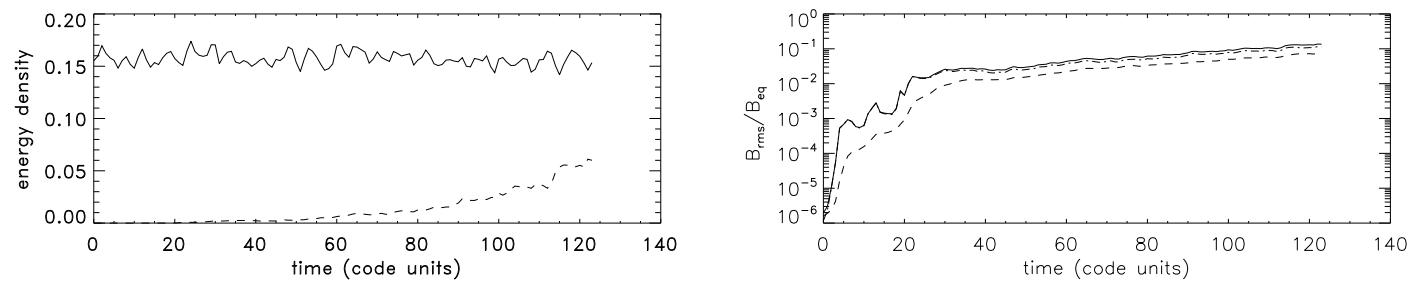

Figura 8.10: Evolução temporal da densidade de energia cinética (linha contínua) e magnética multiplicada por 10 (linha tracejada) em escala linear (esquerda), e da magnitude do campo magnético total (linha contínua), médio (linha tracejada) e flutuante (linha pontilhada), em relação ao campo de equipartição $B_{e q}$ (direita).

Esse comportamento é também observado na Fig. 8.11 que apresenta os perfis da média horizontal do campo magnético total (linha contínua), médio (linha tracejada), e flutuante (linha ponto-tracejada), para o modelo $C 01_{h r}$, integrados sobre os intervalos de tempo correspondentes à fase de crescimento exponencial (i.e., $t=20$ a $t=30$ na Fig. 8.10), e à fase de crescimento suave (i.e., $t=114$ a $t=124$ ) na Fig. 8.10). Nessas figuras é evidente que na fase de crescimento exponencial quase todo o campo magnético corresponde a campo flutuante. Já na fase de crescimento suave, tal como no caso de baixa resolução, o campo 
médio é dominante nas camadas mais internas da zona de convecção e o campo flutuante é dominante nas camadas mais externas. Como a simulação de alta resolução ainda não atingiu o estado final de saturação, não é possível distinguir nesse modelo a fase de surtos de crescimento de energia que observamos nos casos de baixa resolução. Contudo, espera-se que essa fase apareça em estágios temporais posteriores.
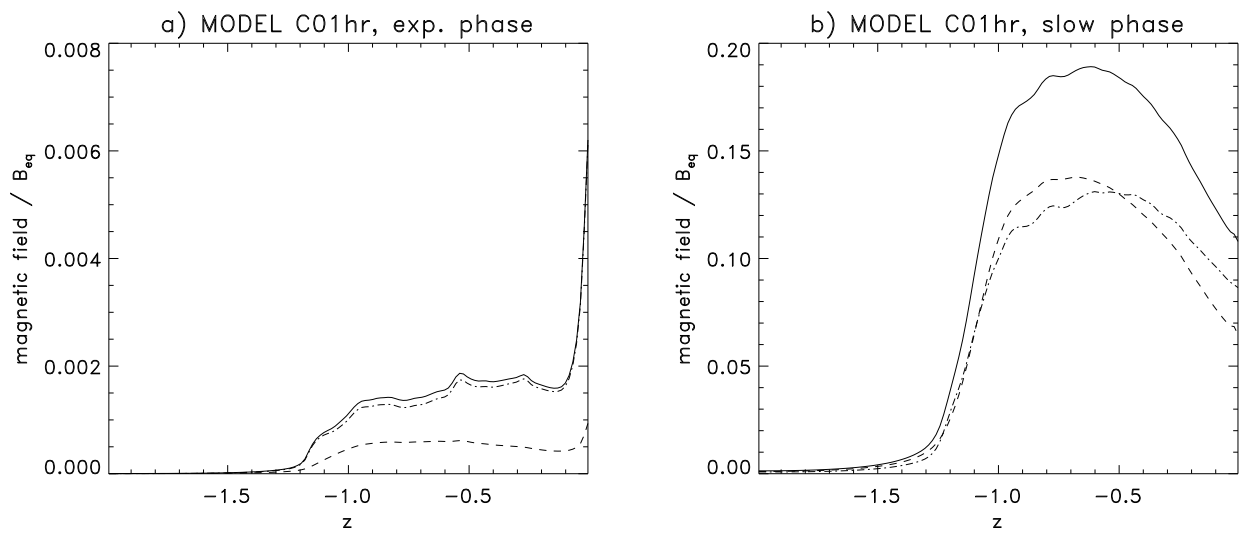

Figura 8.11: Médias tomadas em planos horizontais (normais a $z$ ) do campo magnético total (linha contínua), médio (linha tracejada), e flutuante (linha ponto-tracejada), para duas fases diferentes da sua evolução: a) fase cinemática ou de crescimento exponencial; e b) fase de crescimento suave, para o modelo $C 01_{h r}$.

Espera-se também que a transferência de energia das pequenas para as grandes escalas continue nos passos seguintes. Essa espectativa baseia-se no comportamento dos espectros da energia magnética para os passos temporais $t=40$ (linha contínua) e $t=120$ (linha tracejada) mostrados na Fig. 8.12. Verifica-se que o crescimento da energia magnética é ligeiramente maior para as grandes escalas (i.e., $k<2$ ), do que para escalas com $k>10$.

Finalmente, na Figura 8.13 apresentamos a componente vertical do campo magnético, $B_{z}$, no topo (esquerda) e na metade (direita) da camada convectiva, para dois tempos diferentes, $t=40$ (painéis superiores) e $t=120$ (painéis inferiores). Nessa figura os contornos de campo magnético foram normalizados à metade do valor do campo de eqüipartição para maior clareza dos contornos. Pode-se observar que no topo do domínio computacional o campo se organiza nas interfaces das células convectivas. já na metade da camada convectiva a sua distribuição é mais randômica. Pode-se distinguir também que tanto a intensidade do campo, como o tamanho das suas estruturas magnéticas é maior para $t=120$. Isso indica o crescimento do campo magnético médio. Notamos novamente, que essa 


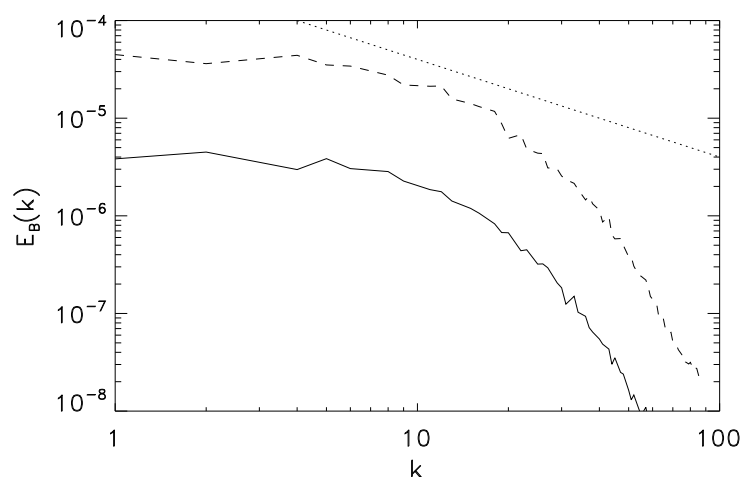

Figura 8.12: Espectro bidimensional da energia magnética correspondente à metade da camada convectiva para o modelo $C 01_{h r}$. As linhas contínua e tracejada correspondem aos passos temporais $t=40$ e $t=120$ na Fig. 8.10. A linha pontilhada com inclinação proporcional a $k^{-5 / 3}$ é mostrada como referência.

simulação por si só não corresponde a uma evidência da presença de um efeito $\alpha$ turbulento intrínseco. Para confirmar esse fato é ainda necessário considerar-se uma configuração similar mas sem incluir a rotação.

\subsection{Discussão}

Neste Capítulo, apresentamos os resultados preliminares de simulações dinâmicas tridimensionais MHD de convecção turbulenta e do efeito de dínamo. Em relação aos resultados obtidos nos modelos convectivos puramente hidrodinâmicos, com e sem rotação, podemos dizer que eles concordam muito bem com aqueles já publicados na literatura (e.g. Brandenburg et al., 1996; Brummell et al., 1996; Ziegler e Rüdiger, 2003). Existem duas diferenças importantes entre as simulações com e sem rotação. No caso com rotação, há formação de vórtices horizontais em sentido anti-horário devidos à ação da força de Coriolis que leva à geração de helicidade cinemática $(\nabla \times \mathbf{U} \cdot \mathbf{U})$. Em segundo lugar, ocorre uma mudança na penetração do fluxo de velocidades na camada estável, a qual, como foi verificado em trabalhos anteriores (Tobias et al., 2008, e.g), diminui com o aumento do número de Taylor, ou seja, com a presença de rotação.

Partindo de um estado convectivo estacionário, incluímos um campo magnético homogêneo semente e, graças aos alongamentos causados por fluxos turbulentos movendo-se 

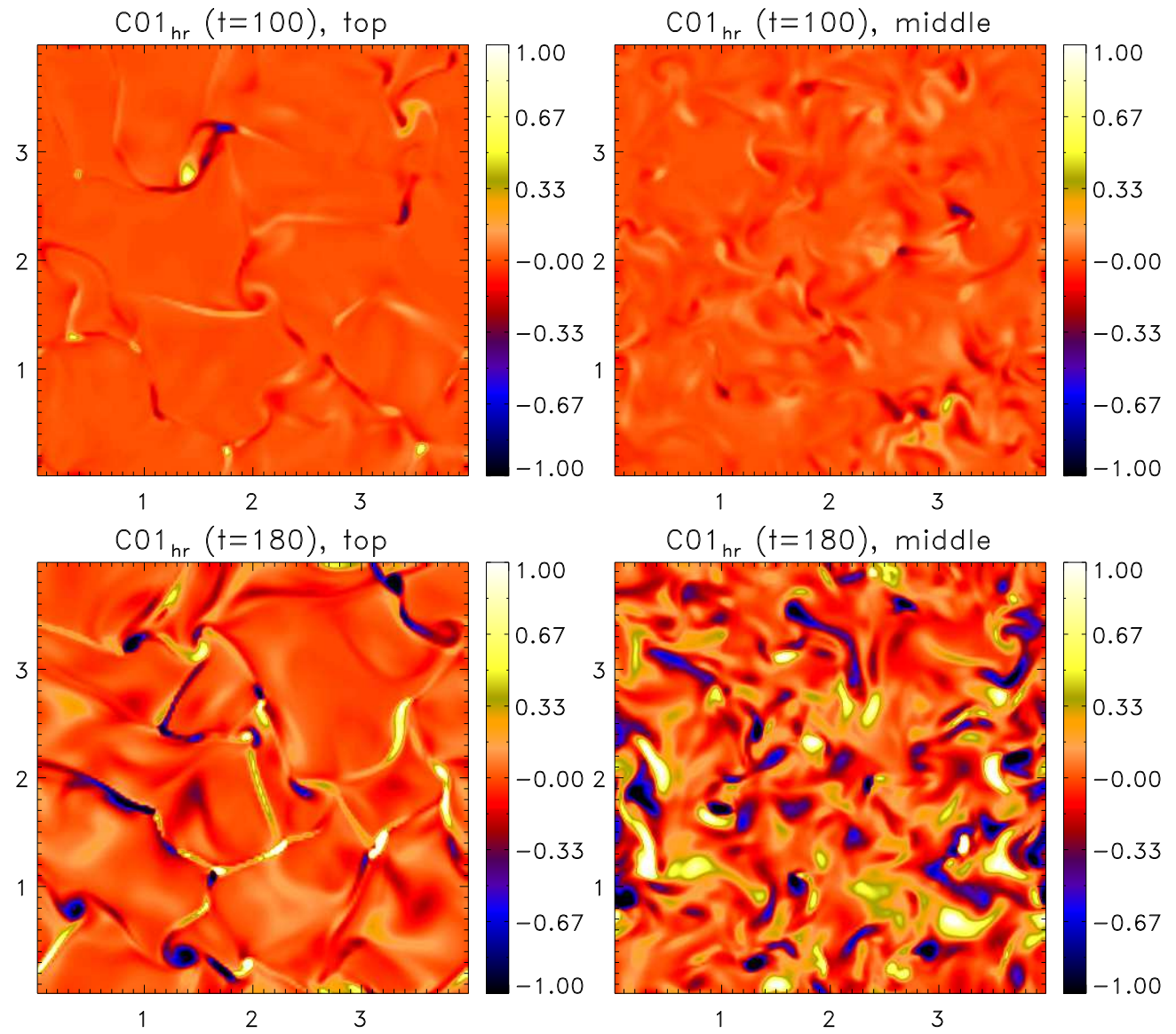

Figura 8.13: Componente vertical do campo magnético, $2 B_{z} / B_{e q}$, para o modelo $C 01_{h r}$, em duas alturas distintas da camada convectiva: o topo (esquerda), e a metade (direita), e para dois tempos distintos: $t=40$ (painéis superiores) e $t=120$ (painéis inferiores).

em direções opostas, este campo magnético começa a amplificar até o sistema alcançar um novo estado estacionário e saturar num valor próximo ao de equipartição. Encontramos que na fase de crescimento a componente flutuante do campo magnético domina sobre a componente média. Já no estado saturado, distinguem-se duas fases, uma na qual a energia magnética aproxima-se consideravelmente da energia cinética. Nesta fase, tanto no modelo sem rotação quanto no modelo com rotação, os campos médio e flutuante têm magnitude similar.

Na segunda fase de saturação há um decaimento suave da energia magnética. Enquanto que no modelo com $T a=0$ (sem rotação) as componentes média e flutuante do campo possuem magnitude similar, no modelo com $T a=5 \times 10^{5}$ (com rotação) a componente média domina claramente. A diferença entre os dois modelos pode depender da existência de 
um efeito $\alpha$ turbulento que aparece na presença da rotação. Realizamos também uma simulação para o caso com rotação (C01) aumentando a resolução numérica. Como esperado, esta simulação consegue definir as pequenas escalas com maior detalhe que o modelo de baixa resolução. Porém, a distribuição dos campos magnéticos, total, médio e flutuante, no interior da zona convectiva, é similar nos dois casos. Contudo, esses últimos resultados são ainda preliminares e exigem um avanço temporal mais completo, até a fase de saturação, bem como uma análise mais detalhada do processo, explorando-se a dependência desses resultados com os parâmetros livres do modelo, a fim de se obter um claro cenário dos processos que estão levando à amplificação dos campo magnéticos na larga escala. 
Capítulo 9

\section{Conclusões gerais e Perspectivas}

Neste trabalho de tese construímos um código numérico de dínamo cinemático de campo médio, que pode ser aplicado de forma geral a qualquer modelo fenomenológico de dínamo solar ou estelar, i.e., a dínamos distribuídos, de overshoot de interface, etc., sempre que os ingredientes necessários para o dínamo (campo de velocidades, efeito $\alpha$ e difusividade magnética) sejam adequadamente definidos. Baseados nas evidências observacionais que sugerem que o campo poloidal superficial resulta do decaimento difusivo das regiões bipolares ativas e do transporte de fluxo pela circulação meridional, incluímos no código o modelo de Babcock-Leighton (BL) o qual é dominado pela advecção. Além disso, discutimos criticamente os demais modelos existentes na literatura e também as limitações atuais do modelo de BL, as quais incluem dificuldades teóricas bem como certa carência observacional de alguns perfis necessários para o modelo.

O nosso principal objetivo nesta tese foi estudar tais limitações e propor possíveis soluções que levem a um cenário mais realista e a um modelo cujos resultados concordem com as observações. Para isso investigamos primeiramente i) a influência da espessura da tacoclina e a participação efetiva das componentes do cisalhamento (i.e., da rotação diferencial) na amplificação do campo magnético, depois ii) estudamos os efeitos do fenômeno turbulento conhecido como bombeamento magnético em diferentes cenários de dínamo dominado pela advecção, e finalmente iii) estudamos os efeitos dinâmicos do campo magnético na sua fase saturada sobre a difusividade magnética, bem como a forma em que as características das soluções do dínamo são alteradas por esse processo conhecido como amortecimento de $\eta$.

Na primeira parte (Capítulo 5), um de nossos principais resultados foi verificar que a 
componente latitudinal do shear, $B_{\theta} / r \partial \Omega / \partial \theta$, domina sobre a componente radial, $B_{r} \partial \Omega / \partial r$, de tal forma que a maior parte do campo toroidal é produzido na zona convectiva e não na tacoclina, como havia sido assumido em modelos anteriores. Encontrou-se também que o campo toroidal que é produzido na tacoclina nas altas latitudes, o qual constitui um dos principais problemas dos modelos de dínamo que utilizam o perfil observado da rotação diferencial, depende sensivelmente da espessura da tacoclina e também do perfil adotado para a difusividade magnética. Assim, numa análise de parâmetros, um diagrama do campo toroidal numa latitude de $60^{\circ}$, em função da difusividade na camada convectiva, e para diferentes valores da espessura da tacoclina, mostrou que os campos toroidais mais intensos nas altas latitudes podem ser eliminados para tacoclinas com larguras $\omega_{1} \gtrsim 0.08 R_{\odot}$ (para $\eta_{c z} \simeq 2 \times 10^{9}-1 \times 10^{10} \mathrm{~cm}^{2} \mathrm{~s}^{-1}$ ), ou para $\omega_{1} \lesssim 0.02 R_{\odot}$ para quase todos os valores possíveis de $\eta_{c z}$ permitidos pelos modelos dominados pela advecção. Para larguras intermediárias, $\omega_{1} \simeq 0.04 R_{\odot}-0.06 R_{\odot}$, campos toroidais intensos sobrevivem nas altas latitudes no diagrama de borboleta. Já uma análise mais detalhada dos campos magnéticos em cortes meridionais do interior solar revelam que a redução efetiva de produção de campo toroidal acontece para as tacoclinas mais finas contidas inteiramente na camada estável (abaixo de $r=0.715 R_{\odot}$ ) (Guerrero e de Gouveia Dal Pino, 2007a,b).

Considerando os resultados acima, na segunda parte de nosso trabalho (Capítulo 6) introduzimos no modelo a contribuição da turbulência para o transporte do fluxo magnético, i.e., o bombeamento magnético. Os resultados revelaram a importância deste mecanismo para solucionar problemas antigos do modelo de dínamo solar tais como, o armazenamento do fluxo magnético na camada estável, abaixo da zona de convecção, e também a distribuição latitudinal de manchas solares. Consideramos ainda o caso em que o fluxo meridional em grande escala está presente somente na parte superior da camada convectiva, como foi reportado por recentes observações de héliossismologia (Mitra-Kraev e Thompson, 2007). Nesse caso, o bombeamento turbulento é o fator que determina o período do ciclo e também a distribuição dos campos toroidais. Isso revela que o papel da circulação meridional poderia não ser tão importante como se pensava até agora (e.g., Dikpati e Charbonneau, 1999), pois existem outros mecanismos de advecção de fluxo que podem vincular os locais onde acontecem a produção de campo toroidal e poloidal. Desta forma o perfil de circulação meridional altamente coerente, adotado na maioria dos modelos advectivos, 
embora não observado, já não é mais necessário (Guerrero e de Gouveia Dal Pino, 2008).

No mesmo Capítulo consideramos também modelos de dínamo operando na camada de cisalhamento radial superficial encontrada recentemente por Corbard e Thompson (2002). Verificamos que, juntamente com a camada de campo toroidal que se forma na metade inferior da zona convectiva, forma-se uma nova camada de campo toroidal próxima da superfície, $r \sim 0.95 R_{\odot}$, em todas as latitudes. Porém se o bombeamento magnético é considerado, os campos formados no pólo são advectados para baixo, de tal forma que o campo toroidal sobrevive unicamente nas latitudes observadas, próximas do equador. Esse resultado não concorda com outros modelos publicados na literatura que descartam a possibilidade de um efeito de dínamo no regime advectivo operando nessa parte da zona convectiva (e.g., Dikpati et al., 2002), mas concorda com outros trabalhos recentes que, apesar de não apresentar um modelo quantitativo, expõem as características favoráveis desse cenário (Brandenburg e Subramanian, 2005; Brandenburg, 2005). Estes porém, argumentam que o modelo mais provável para o dínamo é aquele com efeito $\alpha$ turbulento distribuído em toda a zona convectiva.

Com esse mesmo grupo de simulações numéricas exploramos também o problema da simetria dos campos magnéticos resultantes nos dois hemisférios. A paridade observada no Sol é anti-simétrica, no entanto, a maioria dos modelos de dínamo advectivos, com o efeito $\alpha$ concentrado próximo da superfície, resultam em paridades simétricas através do equador. Em nossas simulações numéricas, examinamos a paridade resultante de modelos com condições iniciais simétricas, anti-simétricas e randômicas, com e sem bombeamento e também incluindo em alguns casos a camada de cisalhamento superficial. Nossos resultados sustentam a idéia proposta por Charbonneau (2007) de que o perfil simétrico (quadrupolar) obtido nas simulações anteriores de dínamo, deve-se principalmente à assinatura quadrupolar que o fluxo meridional imprime sobre o campo dipolar. Ou dito de outra forma, linhas fechadas do campo de velocidades meridional obriga as linhas de campo poloidal a se fecharem em cada hemisfério, dificultando o seu acoplamento com o campo do outro hemisfério na região do equador. Isto resulta em campos poloidais de polaridade oposta nos dois lados do equador e, portanto, em campos toroidais de igual polaridade. Em nosso modelo, a inclusão dos termos de bombeamento ajuda a apagar o perfil quadrupolar do fluxo meridional, fazendo com que as simulações conservem a sua paridade 
inicial, ou, em alguns casos, mudem da paridade quadrupolar à observada (Guerrero e de Gouveia Dal Pino, 2008). No entanto, existem ainda outras possibilidades que poderiam resolver o problema da paridade, como por exemplo, considerar um termo fonte de campo poloidal na base da zona convectiva (Dikpati e Gilman, 2001a; Bonanno et al., 2002) que permita a reconexão das linhas de campo poloidal numa região onde o fluxo meridional é suficientemente fraco. Outra opção é considerar um valor grande para a difusividade magnética na camada convectiva (Chatterjee et al., 2004), só que nesse caso o dínamo deverá ser dominado por um regime difusivo, ao invés do advectivo.

No terceiro conjunto de simulações numéricas do dínamo de campo médio (Capítulo 7), incluímos o efeito da reação dinâmica do campo magnético sobre a difusividade turbulenta. Na fase de saturação do campo magnético, o nível de turbulência diminui, o qual leva à supressão tanto da amplificação do campo magnético, quanto da difusividade. Os efeitos de saturação do crescimento do campo magnético (amortecimento de $\alpha$ ) vêm sendo estudados exaustivamente através de abordagens teóricas e de simulações computacionais de campo médio e também dinâmicas tridimensionais (3D). Já o mecanismo do amortecimento da difusividade ( $\eta$-quenching) vem sendo estudado em simulações numéricas 3D, e a relação entre o amortecimento de $\eta$ e o campo $B$ é relativamente bem conhecida. Porém, os efeitos desse amortecimento em modelos de dínamo de campo médio foram estudados anteriormente somente em problemas específicos (Ruediger et al., 1994; Tobias, 1996; Rüdiger e Kitchatinov, 2000; Gilman e Rempel, 2005). Em nosso modelo, que já continha um termo de amortecimento de $\alpha$, incluímos o amortecimento de $\eta$ através de um termo algébrico similar. Nossos resultados indicam que, embora a dependência de $\alpha$ com o fator de amortecimento seja aproximadamente linear, a resposta do campo magnético ao amortecimento de $\eta$ é não-linear e é espacialmente não-uniforme.

Uma das principais motivações ao incluir-se o amortecimento de $\eta$ foi verificar se seria possível amplificar os campos magnéticos a valores acima da equipartição através desse efeito, pois no cenário no qual as manchas solares são resultado da emergência de tubos de fluxo magnéticos formados na base da zona convectiva, esses tubos precisam ter uma magnitude de $\sim 10^{5}$ G. No entanto, o campo de equipartição é de apenas $10^{4}$ G. Graças a supressão da difusividade encontramos que o campo magnético pode ser amplificado localmente, formando estruturas magnéticas de longa vida e com amplitudes que são até $\sim 2.5$ 
vezes maiores na tacoclina, e $\sim 2$ vezes maiores no centro da zona de convecção, do que em simulações sem amortecimento de $\eta$. No entanto, quando essa amplificação é mais efetiva, ela leva a efeitos que não são observados como, por exemplo, uma distribuição espacial dos campos e que não concorda com o diagrama de borboleta observado. Estudando as propriedades dos modelos com amortecimento de $\eta$ distinguimos um valor provável de campo de saturação, cuja energia concorda com a energia mecânica do movimento, e fornece uma amplificação razoável do campo magnético $\left(B_{\max } \sim 4 \times 10^{4} \mathrm{G}\right)$, a qual, contudo, não chega a ser suficiente para sustentar definitivamente o cenário de tubos de fluxo. Por outro lado, a formação dessas regiões intensas e de longa vida no meio e na base da camada convectiva devido à supressão da difusividade poderia ajudar a entender porque o campo toroidal na superfície encontra-se, principalmente, em forma de estruturas isoladas e não em forma difusa.

Uma vez que o período do ciclo é maior quando a eficiência do amortecimento de $\eta$ aumenta, consideramos também uma difusividade magnética na zona de convecção com valores acima de $5 \times 10^{11} \mathrm{~cm}^{2} \mathrm{~s}^{-1}$, ou seja, adotamos um modelo dominado pela difusão e estudamos a possibilidade de este mudar para o regime advectivo graças à supressão da difusividade. Verificamos que em modelos nos quais o amortecimento de $\eta$ é grande, os campos magnéticos aparecem fortemente segregados, resultando em soluções de dínamo não-estacionarias. Por outro lado, em modelos dominados pela difusão que sofrem pouco amortecimento da difusividade, o sistema permanece sempre nesse regime (Guerrero et al., 2009).

Finalmente, na ultima parte da tese iniciamos a exploração de modelos numéricos dinâmicos do efeito dínamo, devido à turbulência desenvolvida naturalmente pela convecção, adotando domínios tridimensionais que correspondem a uma fração das camadas convectiva e radiativa de uma estrela de tipo solar. Após modificar o código magnetohidrodinâmico PLUTO (veja Apêndice B), e de configurar apropriadamente as condições iniciais e de contorno, encontramos um sistema estacionário de conveç̧ão térmica, na aproximação hidrodinâmica, que se aproxima do que poderia ser a camada convectiva solar. Consideramos dois casos representativos: um modelo sem rotação e outro com rotação. Para esses sistemas calculamos quantidades físicas relevantes para o processo de dínamo, como a velocidade rms (i.e. o número de Reynolds), a helicidade cinemática, o perfil do fluxo de energia 
e o espectro de turbulência convectiva. Partindo de soluções hidrodinâmicas estacionárias, introduzimos um campo magnético semente e verificamos o desenvolvimento de um dínamo para ambos os casos. Já no caso com rotação, verificamos que a componente média do campo magnético domina sobre a componente em pequena escala, indicando a possível existência de um efeito $\alpha$. Embora o tipo de dínamo encontrado nessas simulações não corresponda ao mecanismo idealizado de Babcock-Leighton discutido nos capítulos anteriores e, tampouco, os resultados sejam inteiramente inéditos na literatura, esse novo estudo do dínamo dinâmico abre o caminho para explorar de forma ab-initio processos magnéticos nos interiores estelares que ainda não são bem compreendidos (como, por exemplo, no caso do Sol, a determinação do verdadeiro local no seu interior onde realmente se desenvolve o dínamo que dá origem as manchas solares) e dessa forma avançar na concepção de um modelo mais realista do dínamo solar.

\subsection{Considerações finais e perspectivas}

Ao longo desta tese, mostramos que algumas das maiores dificuldades do cenário de dínamo solar de Babcock-Leighton no regime advectivo podem ser aliviadas, quando são considerados ingredientes físicos plausíveis. Além disso, devem ser consideradas também algumas modificações importantes do modelo tradicional. Por exemplo, o campo magnético produzido nas altas latitudes pode ser reduzido com a escolha apropriada da espessura da tacoclina. Porém, é possível que a maior fração do campo toroidal é produzida na zona convectiva, de modo que tanto o transporte advectivo quanto o transporte difusivo levam esse campo às baixas latitudes e à profundidade necessária para encontrar a fração de campo toroidal produzido na tacoclina e formar, assim, o fluxo de campo toroidal intenso que irá produzir manchas solares unicamente nessas latitudes. O bombeamento magnético, como visto, certamente contribui também nesse processo.

O formalismo de Babcock-Leighton considera que o campo produzido no interior solar, tal como aquele observado na fotosfera, é de natureza capilar, com regiões isoladas onde o campo se encontra muito concentrado, rodeadas de um plasma menos magnetizado. Mas para essas estruturas isoladas conseguirem emergir à superfície precisam ser suficientemente intensas e ter um alto grau de enrolamento, o qual ainda não é fácil de se explicar. Contudo, encontramos que o bombeamento magnético e o amortecimento da 
difusividade podem contribuir para resolver esse problema, empurrando o fluxo para as camadas profundas mais estáveis e fazendo que esse fluxo magnético possua maior tempo de vida para ser amplificado. No entanto, uma resposta definitiva a essa questão será possível somente através de simulações que considerem todos os processos físicos envolvidos de forma dinâmica e em três dimensões. Uma de nossas principais perspectivas futuras é desenvolver simulações tridimensionais realistas direcionadas a resolver estas questões.

A simetria das soluções é um problema que depende do perfil da velocidade meridional e da sua importância frente à difusão, pois limita o acoplamento dos campos poloidais nos dois hemisférios. Esse fluxo meridional é observado somente na superfície e é ainda indeterminado nas camadas mais profundas, o que dificulta a escolha de um perfil realista. Mas, ainda na superfície, observa-se que esse fluxo não conserva uma coerência temporal através do ciclo como o faz, por exemplo, a rotação diferencial. Ao contrário, é muito flutuante. Isto sugere que contribuição da circulação meridional para o ciclo solar deve acontecer predominantemente na superfície, empurrando o campo dipolar na direção dos pólos, e em menor medida, para o interior da zona convectiva, onde o bombeamento magnético pode ser mais importante em advectar o campo nas direções desejadas, influenciando positivamente no acoplamento dos campos poloidais.

Um dos problemas que ainda persiste refere-se ao valor que a difusividade turbulenta tem no interior da camada convectiva. Segundo aproximações lineares esse valor deveria ser similar àquele observado na superfície, acima dos $10^{12} \mathrm{~cm}^{2} \mathrm{~s}^{-1}$. No entanto, segundo os modelos dominados pela advecção, esse valor deveria ser menor de $2 \times 10^{11} \mathrm{~cm}^{2} \mathrm{~s}^{-1}$. Esta discordância dos modelos advectivos com a teoria linear existe também nos modelos de dínamo turbulento em regime difusivo, os quais resultam em períodos do ciclo bem menores que o observado. Verificamos que o amortecimento da difusividade devido à reação dinâmica do campo magnético aumenta o período do ciclo, porém esse não é um efeito capaz de levar um sistema do regime difusivo ao regime advectivo. Acredita-se que outros processos, como por exemplo a conservação da helicidade magnética (Brandenburg e Subramanian, 2005) ou a competição entre as velocidades da onda dínamo e do fluxo meridional em modelos operando devido ao cisalhamento próximo da superfície (veja §6.3.4, e também Guerrero e de Gouveia Dal Pino, 2008), possam incrementar o período do ciclo. No entanto, ambas as soluções correspondem a cenários de dínamo diferentes do modelo 
de Babcock-Leighton, e que precisam ainda ser estudadas em detalhe. Estes estudos serão realizados em um futuro próximo.

Com respeito à possibilidade de o dínamo solar encontrar-se operando nas camadas mais superficiais do Sol em virtude do cisalhamento radial descoberto nessa região, vale a pena mencionar que, de fato, isso funciona no cenário advectivo, com o efeito $\alpha$ operando nas camadas mais externas, como foi mostrado em $§ 6.3 .4$ (veja também Guerrero e de Gouveia Dal Pino, 2008). No entanto, os avanços teóricos e numéricos recentes que têm dado nova vida aos modelos de dínamo turbulento apontam para um processo de dínamo de tipo distribuído (i.e., com um efeito $\alpha$ turbulento operando em toda a zona convectiva, Brandenburg, 2005). Porém, embora as pesquisas teóricas e numéricas referentes ao efeito $\alpha$ turbulento (cuja saturação é determinada pela conservação da helicidade magnética), venham tendo sucesso em modelos com turbulência helicoidal forçada, a existência do efeito $\alpha$ em sistemas convectivos ainda é discutível (como apresentado no Capítulo 8); além disso, até o presente não há modelos de campo médio que reproduzam as observações e o diagrama de borboleta com esse cenário. Outra das grandes limitações da proposta de um dínamo sub-superficial é que nele ainda falta uma explicação para a formação de manchas tal como são observadas, e embora existam na literatura propostas alternativas à emergência de tubos de fluxo para reduzir esse problema (veja Rogachevskii e Kleeorin, 2007, e as referências ali contidas), sugere-se nelas que os eventos observados na superfície seriam sobretudo um resultado do processo de dínamo, e não parte efetiva dele (como é assumido no mecanismo de BL).

Talvez essa seja a grande questão a ser respondida: quanto do que consideramos atividade magnética solar é parte do processo de dínamo e quanto é um efeito secundário do mesmo? Quem sabe respondendo a essa pergunta, com ajuda de observações, teoria e simulações numéricas, poderemos no futuro próximo formular uma resposta definitiva para o processo que governa o ciclo magnético solar, ainda tão evasiva. 


\section{Referências Bibliográficas}

Antia H. M., Basu S., Chitre S. M., Solar internal rotation rate and the latitudinal variation of the tachocline, MNRAS, 1998, vol. 298, p. 543

Arlt R., Sule A., Filter R., Stability of the solar tachocline with magnetic fields, Astronomische Nachrichten, 2007, vol. 328, p. 1142

Babcock H. W., The Topology of the Sun's Magnetic Field and the 22-YEAR Cycle., ApJ, 1961, vol. 133 , p. 572

Baliunas S. L., Donahue R. A., Soon e. a., Chromospheric variations in main-sequence stars, ApJ, 1995, vol. 438, p. 269

Balthasar H., Vazquez M., Woehl H., Differential rotation of sunspot groups in the period from 1874 through 1976 and changes of the rotation velocity within the solar cycle, A\&A, 1986, vol. 155, p. 87

Basu S., Seismology of the base of the solar convection zone, MNRAS, 1997, vol. 288, p. 572

Beck R., Measuring interstellar magnetic fields by radio synchrotron emission, ArXiv eprints, 2008

Berdyugina S. V., Starspots: A Key to the Stellar Dynamo, Living Reviews in Solar Physics, 2005, vol. 2, p. 8

Blackman E. G., Field G. B., How astrophysical mean field dynamos can circumvent existing quenching constraints, Physics of Plasmas, 2001, vol. 8, p. 2407 
Blackman E. G., Field G. B., New Dynamical Mean-Field Dynamo Theory and Closure Approach, Physical Review Letters, 2002, vol. 89, p. 265007

Bonanno A., Elstner D., Belvedere G., Advection-dominated solar dynamo model with twocell meridional flow and a positive $\alpha$-effect in the tachocline, Astronomische Nachrichten, 2006, vol. 327, p. 680

Bonanno A., Elstner D., Rüdiger G., Belvedere G., Parity properties of an advectiondominated solar alpha² Omega-dynamo, A\&A, 2002, vol. 390, p. 673

Brandenburg A., The Inverse Cascade and Nonlinear Alpha-Effect in Simulations of Isotropic Helical Hydromagnetic Turbulence, ApJ, 2001, vol. 550, p. 824

Brandenburg A., The Case for a Distributed Solar Dynamo Shaped by Near-Surface Shear, ApJ, 2005, vol. 625, p. 539

Brandenburg A., Jennings R. L., Nordlund Å., Rieutord M., Stein R. F., Tuominen I., Magnetic structures in a dynamo simulation, Journal of Fluid Mechanics, 1996, vol. 306, p. 325

Brandenburg A., Krause F., Meinel R., Moss D., Tuominen I., The stability of nonlinear dynamos and the limited role of kinematic growth rates, A\&A, 1989, vol. 213, p. 411

Brandenburg A., Moss D., Tuominen I., Turbulent Pumping in the Solar Dynamo. In The Solar Cycle , vol. 27 of Astronomical Society of the Pacific Conference Series, 1992, p. 536

Brandenburg A., Subramanian K., Astrophysical magnetic fields and nonlinear dynamo theory, Phys. Rep., 2005, vol. 417, p. 1

Brandenburg A., Tuominen I., Variation of magnetic fields and flows during the solar cycle, Advances in Space Research, 1988, vol. 8, p. 185

Braun D. C., Birch A. C., Prospects for the Detection of the Deep Solar Meridional Circulation, ApJ, 2008, vol. 689, p. L161

Braun D. C., Fan Y., Helioseismic Measurements of the Subsurface Meridional Flow, ApJ, 1998, vol. 508, p. L105 
Bray R. J., Loughhead R. E., Sunspots. The International Astrophysics Series, London: Chapman \& Hall, 1964

Brown T. M., Christensen-Dalsgaard J., Dziembowski W. A., Goode P., Gough D. O., Morrow C. A., Inferring the sun's internal angular velocity from observed p-mode frequency splittings, ApJ, 1989, vol. 343, p. 526

Brummell N. H., Hurlburt N. E., Toomre J., Turbulent Compressible Convection with Rotation. I. Flow Structure and Evolution, ApJ, 1996, vol. 473, p. 494

Brun A. S., Antia H. M., Chitre S. M., Zahn J.-P., Seismic tests for solar models with tachocline mixing, A\&A, 2002, vol. 391, p. 725

Brun A. S., Miesch M. S., Toomre J., Global-Scale Turbulent Convection and Magnetic Dynamo Action in the Solar Envelope, ApJ, 2004, vol. 614, p. 1073

Caligari P., Moreno-Insertis F., Schussler M., Emerging flux tubes in the solar convection zone. 1: Asymmetry, tilt, and emergence latitude, ApJ, 1995, vol. 441, p. 886

Caligari P., Schussler M., Moreno-Insertis F., Emerging Flux Tubes in the Solar Convection Zone. II. The Influence of Initial Conditions, ApJ, 1998, vol. 502, p. 481

Cally P. S., Dikpati M., Gilman P. A., Clamshell and Tipping Instabilities in a Twodimensional Magnetohydrodynamic Tachocline, ApJ, 2003, vol. 582, p. 1190

Cattaneo F., On the Origin of Magnetic Fields in the Quiet Photosphere, ApJ, 1999, vol. 515, p. L39

Cattaneo F., Hughes D. W., Nonlinear saturation of the turbulent $\alpha$ effect, Phys. Rev. E, 1996, vol. 54 , p. 4532

Cattaneo F., Hughes D. W., Dynamo action in a rotating convective layer, Journal of Fluid Mechanics, 2006, vol. 553, p. 401

Chandrasekhar S., Hydrodynamic and hydromagnetic stability. International Series of Monographs on Physics, Oxford: Clarendon, 1961, 1961 
Charbonneau P., Dynamo Models of the Solar Cycle, Living Reviews in Solar Physics, 2005, vol. 2, p. 2

Charbonneau P., Babcock Leighton models of the solar cycle: Questions and issues, Advances in Space Research, 2007, vol. 39, p. 1661

Charbonneau P., Christensen-Dalsgaard J., Hening R., Larsen R. M., Schou J., Thompson M. J., omczy S. T., Helioseismic sconstrains on the structure of the solar tachocline, ApJ, 1999, vol. 527, p. 445

Charbonneau P., MacGregor K. B., On the Generation of Equipartition-Strength Magnetic Fields by Turbulent Hydromagnetic Dynamos, ApJ, 1996, vol. 473, p. L59+

Charbonneau P., MacGregor K. B., Solar Interface Dynamos. II. Linear, Kinematic Models in Spherical Geometry, ApJ, 1997, vol. 486, p. 502

Chatterjee P., Nandy D., Choudhuri A. R., Full-sphere simulations of a circulationdominated solar dynamo: Exploring the parity issue, A\&A, 2004, vol. 427, p. 1019

Choudhuri A. R., On the Connection Between Mean Field Dynamo Theory and Flux Tubes, Sol. Phys., 2003, vol. 215, p. 31

Choudhuri A. R., Schussler M., Dikpati M., The solar dynamo with meridional circulation., A\&A, 1995, vol. 303, p. L29+

Christensen-Dalsgaard J., Helioseismology, Reviews of Modern Physics, 2002, vol. 74, p. 1073

Corbard T., Berthomieu G., Provost J., Morel P., Inferring the equatorial solar tachocline from frequency splittings, A\&A, 1998, vol. 330, p. 1149

Corbard T., Blanc-Féraud L., Berthomieu G., Provost J., Non linear regularization for helioseismic inversions. Application for the study of the solar tachocline, A\&A, 1999, vol. 344 , p. 696

Corbard T., Jiménez-Reyes S. J., Tomczyk S., Dikpati M., Gilman P., The solar tachocline and its variation (?). In ESA SP-464: SOHO 10/GONG 2000 Workshop: Helio- and Asteroseismology at the Dawn of the Millennium , 2001, p. 265 
Corbard T., Thompson M. J., The subsurface radial gradient of solar angular velocity from MDI f-mode observations, Sol. Phys., 2002, vol. 205, p. 211

Cowling T. G., Magnetohydrodynamics. Monographs on Astronomical Subjects, Bristol: Adam Hilger, 1976, 1976

de Gouveia Dal Pino E. M., Apostila: Astrofísica de Plasmas, 1995

Deluca E. E., Gilman P. A., Dynamo Theory for the Interface Between the Convection Zone and the Radiative Interior of a Star. I. Model Equations and Exact Solutions, Geophysical and Astrophysical Fluid Dynamics, 1986, vol. 37, p. 85

Dikpati M., Charbonneau P., A Babcock-Leighton Flux Transport Dynamo with Solar-like Differential Rotation, ApJ, 1999, vol. 518, p. 508

Dikpati M., Choudhuri A. R., On the Large-Scale Diffuse Magnetic Field of the Sun, Sol. Phys., 1995, vol. 161, p. 9

Dikpati M., Choudhuri R. A., The evolution of the Sun's Poloidal Field, A\&A, 1994, vol. 291 , p. 975

Dikpati M., Corbard T., Thompson M. J., Gilman P. A., Flux Transport Solar Dynamos with Near-Surface Radial Shear, ApJ, 2002, vol. 575, p. L41

Dikpati M., de Toma G., Gilman P. A., Predicting the strength of solar cycle 24 using a flux-transport dynamo-based tool, Geophys. Res. Lett., 2006, vol. 33, p. 5102

Dikpati M., de Toma G., Gilman P. A., Arge C. N., White O. R., Diagnostics of Polar Field Reversal in Solar Cycle 23 Using a Flux Transport Dynamo Model, ApJ, 2004, vol. 601 , p. 1136

Dikpati M., Gilman P. A., Flux-Transport Dynamos with $\alpha$-Effect from Global Instability of Tachocline Differential Rotation: A Solution for Magnetic Parity Selection in the Sun, ApJ, 2001a, vol. 559, p. 428

Dikpati M., Gilman P. A., Prolateness of the Solar Tachocline Inferred from Latitudinal Force Balance in a Magnetohydrodynamic Shallow-Water Model, ApJ, 2001b, vol. 552, p. 348 
Dikpati M., Gilman P. A., Rempel M., Stability Analysis of Tachocline Latitudinal Differential Rotation and Coexisting Toroidal Band Using a Shallow-Water Model, ApJ, 2003, vol. 596, p. 680

Dorch S. B. F., Nordlund $\AA$., On the transport of magnetic fields by solar-like stratified convection, A\&A, 2001, vol. 365, p. 562

D'Silva S., Choudhuri A. R., A theoretical model for tilts of bipolar magnetic regions, A\&A, 1993, vol. 272, p. 621

Durney B. R., On a Babcock-Leighton dynamo model with a deep-seated generating layer for the toroidal magnetic field, Sol. Phys., 1995, vol. 160, p. 213

Durney B. R., On a Babcock-Leighton Dynamo Model with a Deep-Seated Generating Layer for the Toroidal Magnetic Field, II, Sol. Phys., 1996, vol. 166, p. 231

Durney B. R., On a Babcock-Leighton Solar Dynamo Model with a Deep-seated Generating Layer for the Toroidal Magnetic Field. IV., ApJ, 1997, vol. 486, p. 1065

Eddy J. A., The Maunder Minimum, Science, 1976, vol. 192, p. 1189

Fan Y., The Three-dimensional Evolution of Buoyant Magnetic Flux Tubes in a Model Solar Convective Envelope, ApJ, 2008, vol. 676, p. 680

Fan Y., Fisher G. H., Radiative Heating and the Buoyant Rise of Magnetic Flux Tubes in the Solar interior, Sol. Phys., 1996, vol. 166, p. 17

Fan Y., Fisher G. H., Deluca E. E., The origin of morphological asymmetries in bipolar active regions, ApJ, 1993, vol. 405, p. 390

Ferriz-Mas A., Schmitt D., Schuessler M., A dynamo effect due to instability of magnetic flux tubes, A\&A, 1994, vol. 289, p. 949

Field G. B., Blackman E. G., Dynamical Quenching of the $\alpha^{2}$ Dynamo, ApJ, 2002, vol. 572, p. 685

Foukal P., Solar astrophysics. New York, Wiley-Interscience, 1990, 492 p., 1990 
Frisch U., Turbulence. The legacy of A.N. Kolmogorov. Cambridge: Cambridge University Press, —c1995, 1995

Giles P. M., Duvall Jr. T. L., Scherrer P. H., Bogart R. S., A Flow of Material from the Suns Equator to its Poles, Nature, 1997, vol. 390, p. 52

Gilman P. A., Dynamically consistent nonlinear dynamos driven by convection in a rotating spherical shell. II - Dynamos with cycles and strong feedbacks, ApJS, 1983, vol. 53, p. 243

Gilman P. A., Miesch M. S., Limits to Penetration of Meridional Circulation below the Solar Convection Zone, ApJ, 2004, vol. 611, p. 568

Gilman P. A., Miller J., Dynamically consistent nonlinear dynamos driven by convection in a rotating spherical shell, ApJS, 1981, vol. 46, p. 211

Gilman P. A., Rempel M., Concentration of Toroidal Magnetic Field in the Solar Tachocline by $\eta$-Quenching, ApJ, 2005, vol. 630, p. 615

Gizon L., Birch A. C., Local Helioseismology, Living Reviews in Solar Physics, 2005, vol. 2, p. 6

Glatzmaier G. A., Numerical simulations of stellar convective dynamos. II - Field propagation in the convection zone, ApJ, 1985a, vol. 291, p. 300

Glatzmaier G. A., Numerical simulations of stellar convective dynamos. III - At the base of the convection zone, Geophysical and Astrophysical Fluid Dynamics, 1985b, vol. 31, p. 137

Goode P. R., Dziembowski W. A., Korzennik S. G., Rhodes Jr. E. J., What we know about the sun's internal rotation from solar oscillations, ApJ, 1991, vol. 367, p. 649

Gough D. O., Moore D. R., Spiegel E. A., Weiss N. O., Convective Instability in a Compressible Atmosphere. II, ApJ, 1976, vol. 206, p. 536

Granzer T., Schüssler M., Caligari P., Strassmeier K. G., Distribution of starspots on cool stars. II. Pre-main-sequence and ZAMS stars between 0.4 Mo and 1.7 Mo, A\&A, 2000, vol. 355 , p. 1087 
Guerrero G., de Gouveia Dal Pino E. M., How does the shape and thickness of the tachocline affect the distribution of the toroidal magnetic fields in the solar dynamo?, A\&A, 2007a, vol. 464, p. 341

Guerrero G., de Gouveia Dal Pino E. M., Turbulent magnetic pumping in a BabcockLeighton solar dynamo model, A\&A, 2008, vol. 485, p. 267

Guerrero G. A., de Gouveia Dal Pino E. M., Flux-dominated solar dynamo model with a thin shear layer, Astronomische Nachrichten, 2007b, vol. 328, p. 1122

Guerrero G. A., Dikpati M., de Gouveia Dal Pino E. M., The role of difusivity quenching in flux-transport dynamo models, ApJ, 2009, vol. in press.

Guerrero G. A., Muñoz J. D., Kinematic solar dynamo models with a deep meridional flow, MNRAS, 2004, vol. 350, p. 317

Haber D. A., Hindman B. W., Toomre J., Bogart R. S., Larsen R. M., Hill F., Evolving Submerged Meridional Circulation Cells within the Upper Convection Zone Revealed by Ring-Diagram Analysis, ApJ, 2002, vol. 570, p. 855

Haigh J. D., The Sun and the Earth's Climate, Living Reviews in Solar Physics, 2007, vol. 4 , p. 2

Hale G. E., On the Probable Existence of a Magnetic Field in Sun-Spots, ApJ, 1908, vol. 28 , p. 315

Hale G. E., Ellerman F., Nicholson S. B., Joy A. H., The Magnetic Polarity of Sun-Spots, ApJ, 1919, vol. 49, p. 153

Hathaway D., Gilman P., Harvey J. W., Hill F., Howard R. B., Jones H. P., Kasher J., Leibacher J. B., Pintar J., Simon G. W., GONG Observations of Solar Surface Flows, Science, 1996, vol. 272, p. 1306

Hathaway D. H., Doppler Measurements of the Sun's Meridional Flow, ApJ, 1996, vol. 460, p. 1027

Holzwarth V., Mackay D. H., Jardine M., The impact of meridional circulation on stellar butterfly diagrams and polar caps, MNRAS, 2006, vol. 369, p. 1703 
Hughes D. W., Proctor M. R. E., Large-Scale Dynamo Action Driven by Velocity Shear and Rotating Convection, Physical Review Letters, 2009, vol. 102, p. 044501

Jouve L., Brun A. S., On the role of meridional flows in flux transport dynamo models, A\&A, 2007, vol. 474, p. 239

Jouve L., Brun A. S., Arlt R., Brandenburg A., Dikpati M., Bonanno A., Käpylä P. J., Moss D., Rempel M., Gilman P., Korpi M. J., Kosovichev A. G., A solar mean field dynamo benchmark, A\&A, 2008, vol. 483, p. 949

Käpylä P. J., Korpi M. J., Brandenburg A., Alpha effect and turbulent diffusion from convection, ArXiv e-prints, 2008a

Käpylä P. J., Korpi M. J., Brandenburg A., Large-scale dynamos in turbulent convection with shear, A\&A, 2008b, vol. 491, p. 353

Käpylä P. J., Korpi M. J., Brandenburg A., Large-scale Dynamos in Rigidly Rotating Turbulent Convection, ApJ, 2009, vol. 697, p. 1153

Käpylä P. J., Korpi M. J., Ossendrijver M., Stix M., Magnetoconvection and dynamo coefficients. III. $\alpha$-effect and magnetic pumping in the rapid rotation regime, A\&A, 2006, vol. 455, p. 401

Käpylä P. J., Korpi M. J., Tuominen I., Solar dynamo models with $\alpha$-effect and turbulent pumping from local 3D convection calculations, Astronomische Nachrichten, 2006, vol. 327, p. 884

Kichatinov L. L., Turbulent transport of magnetic fields in a highly conducting rotating fluid and the solar cycle, A\&A, 1991, vol. 243, p. 483

Kichatinov L. L., Ruediger G., Magnetic-field advection in inhomogeneous turbulence, A\&A, 1992, vol. 260, p. 494

Komm R. W., Howard R. F., Harvey J. W., Meridional Flow of Small Photospheric Magnetic Features, Sol. Phys., 1993a, vol. 147, p. 207

Komm R. W., Howard R. F., Harvey J. W., Torsional oscillation patterns in photospheric magnetic features, Sol. Phys., 1993b, vol. 143, p. 19 
Kosovichev A. G., Helioseismic Constraints on the Gradient of Angular Velocity at the Base of the Solar Convection Zone, ApJ, 1996, vol. 469, p. L61+

Kosovichev A. G., Subsurface structure of sunspots, Astronomische Nachrichten, 2002, vol. 323 , p. 186

Krause F., Raedler K. H., Mean-field magnetohydrodynamics and dynamo theory. Oxford: Pergamon Press, 1980, 1980

Küker M., Rüdiger G., Schultz M., Circulation-dominated solar shell dynamo models with positive alpha-effect, A\&A, 2001, vol. 374, p. 301

Latushko S., Meridional Drift of the Large-Scale Solar Magnetic Fields in Different Phases of Solar Activity, Sol. Phys., 1996, vol. 163, p. 241

Leighton R. B., Transport of Magnetic Fields on the Sun., ApJ, 1964, vol. 140, p. 1547

Leighton R. B., A Magneto-Kinematic Model of the Solar Cycle, ApJ, 1969, vol. 156, p. 1

Markiel J. A., Thomas J. H., Solar Interface Dynamo Models with a Realistic Rotation Profile, ApJ, 1999, vol. 523, p. 827

Mason J., Hughes D. W., Tobias S. M., The Competition in the Solar Dynamo between Surface and Deep-seated $\alpha$-Effects, ApJ, 2002, vol. 580, p. L89

Maunder E. W., note on the Sun-spots, MNRAS, 1890, vol. 50, p. 251

Meneguzzi M., Pouquet A., Turbulent dynamos driven by convection, Journal of Fluid Mechanics, 1989, vol. 205, p. 297

Miesch M. S., Large-Scale Dynamics of the Convection Zone and Tachocline, Living Reviews in Solar Physics, 2005, vol. 2, p. 1

Miesch M. S., Brun A. S., DeRosa M. L., Toomre J., Structure and Evolution of Giant Cells in Global Models of Solar Convection, ApJ, 2008, vol. 673, p. 557

Mignone A., Bodo G., Massaglia S., Matsakos T., Tesileanu O., Zanni C., Ferrari A., PLUTO: A Numerical Code for Computational Astrophysics, ApJS, 2007, vol. 170, p. 
Mitra-Kraev U., Thompson M. J., Meridional flow profile measurements with SOHO/MDI, Astronomische Nachrichten, 2007, vol. 328, p. 1009

Nandy D., Choudhuri A. R., Toward a Mean Field Formulation of the Babcock-Leighton Type Solar Dynamo. I. $\alpha$-Coefficient versus Durney's Double-Ring Approach, ApJ, 2001, vol. 551, p. 576

Nandy D., Choudhuri A. R., Explaining the Latitudinal Distribution of Sunspots with Deep Meridional Flow, Science, 2002, vol. 296, p. 1671

Newton H. W., Nunn M. L., The Sun's rotation derived from sunspots 1934-1944 and additional results, MNRAS, 1951, vol. 111, p. 413

Nordlund A., Brandenburg A., Jennings R. L., Rieutord M., Ruokolainen J., Stein R. F., Tuominen I., Dynamo action in stratified convection with overshoot, ApJ, 1992, vol. 392, p. 647

Ossendrijver M., Stix M., Brandenburg A., Magnetoconvection and dynamo coefficients:. Dependence of the alpha effect on rotation and magnetic field, A\&A, 2001, vol. 376, p. 713

Ossendrijver M., Stix M., Brandenburg A., Rüdiger G., Magnetoconvection and dynamo coefficients. II. Field-direction dependent pumping of magnetic field, A\&A, 2002, vol. 394 , p. 735

Ossendrijver M. A. J. H., Grand minima in a buoyancy-driven solar dynamo, A\&A, 2000, vol. 359 , p. 364

Parker E. N., Hydromagnetic Dynamo Models., ApJ, 1955, vol. 122, p. 293

Parker E. N., A solar dynamo surface wave at the interface between convection and nonuniform rotation, ApJ, 1993, vol. 408, p. 707

Pierce A. K., Lopresto J. C., Solar rotation from a number of Fraunhofer lines, Sol. Phys., 1984, vol. 93, p. 155

Pouquet A., Frisch U., Leorat J., Strong MHD helical turbulence and the nonlinear dynamo effect, Journal of fluid mechanics, 1976, vol. 77, p. 321 
Press W. H., Teukolsky S. A., Vetterling W. T., Flannery B. P., Numerical recipes in FORTRAN. The art of scientific computing. Cambridge: University Press, - c1992, 2nd ed., 1992

Raedler K.-H., Mean-field approach to spherical dynamo models, Astronomische Nachrichten, 1980, vol. 301, p. 101

Rempel M., Flux-Transport Dynamos with Lorentz Force Feedback on Differential Rotation and Meridional Flow: Saturation Mechanism and Torsional Oscillations, ApJ, 2006, vol. 647 , p. 662

Roberts P. H., Soward A. M., A unified approach to mean field electrodynamics, Astronomische Nachrichten, 1975, vol. 296, p. 49

Rogachevskii I., Kleeorin N., Nonlinear theory of a shear-current effect and mean-field magnetic dynamos, Phys. Rev. E, 2004, vol. 70, p. 046310

Rogachevskii I., Kleeorin N., Magnetic fluctuations and formation of large-scale inhomogeneous magnetic structures in a turbulent convection, Phys. Rev. E, 2007, vol. 76, p. 056307

Rogers T. M., Glatzmaier G. A., Jones C. A., Numerical simulations on penetration and overshoot in the sun, astro-ph/0601668v1, 2006

Rüdiger G., Kitchatinov L. L., Sunspot decay as a test of the eta-quenching concept, Astronomische Nachrichten, 2000, vol. 321, p. 75

Rüdiger G., Kitchatinov L. L., Arlt R., The penetration of meridional flow into the tachocline and its meaning for the solar dynamo, A\&A, 2005, vol. 444, p. L53

Ruediger G., Brandenburg A., A solar dynamo in the overshoot layer: cycle period and butterfly diagram., A\&A, 1995, vol. 296, p. 557

Ruediger G., Kitchatinov L. L., Kueker M., Schultz M., Dynamo models with magnetic diffusivity-quenching, Geophysical and Astrophysical Fluid Dynamics, 1994, vol. 78, p. 
Schmitt D., Schuessler M., Ferriz-Mas A., Intermittent solar activity by an on-off dynamo., A\&A, 1996, vol. 311, p. L1

Schove D. J., Sunspot cycles, NASA STI/Recon Technical Report A, 1983, vol. 84, p. 29019

Schrijver C. J., Zwaan C., Solar and Stellar Magnetic Activity. Solar and stellar magnetic activity / Carolus J. Schrijver, Cornelius Zwaan. New York : Cambridge University Press, 2000. (Cambridge astrophysics series ; 34), 2000

Schuessler M., Caligari P., Ferriz-Mas A., Solanki S. K., Stix M., Distribution of starspots on cool stars. I. Young and main sequence stars of one solar mass., A\&A, 1996, vol. 314, p. 503

Schuessler M., Solanki S. K., Why rapid rotators have polar spots, A\&A, 1992, vol. 264, p. L13

Schüssler M., Flux tubes, surface magnetism, and the solar dynamo: constraints and open problems, Astronomische Nachrichten, 2005, vol. 326, p. 194

Schwabe M., Die Sonne. Von Herrn Hofrath Schwabe, Astronomische Nachrichten, 1843, vol. 20 , p. 283

Snodgrass H. B., Separation of large-scale photospheric Doppler patterns, Sol. Phys., 1984, vol. 94, p. 13

Snodgrass H. B., Dailey S. B., Meridional Motions of Magnetic Features in the Solar Photosphere, Sol. Phys., 1996, vol. 163, p. 21

Spiegel E. A., Zahn J.-P., The solar tachocline, A\&A, 1992, vol. 265, p. 106

Steenbeck M., Krause F., On the Dynamo Theory of Stellar and Planetary Magnetic Fields. I. AC Dynamos of Solar Type, Astronomische Nachrichten, 1969, vol. 291, p. 49

Stix M., Non-Linear Dynamo Waves, A\&A, 1972, vol. 20, p. 9

Stix M., Differential rotation and the solar dynamo, A\&A, 1976, vol. 47, p. 243 
Thompson M. J., Christensen-Dalsgaard J., Miesch M. S., Toomre J., The Internal Rotation of the Sun, ARA\&A, 2003, vol. 41, p. 599

Tobias S. M., Diffusivity Quenching as a Mechanism for Parker's Surface Dynamo, ApJ, 1996, vol. 467 , p. 870

Tobias S. M., Brummell N. H., Clune T. L., Toomre J., Pumping of Magnetic Fields by Turbulent Penetrative Convection, ApJ, 1998, vol. 502, p. L177+

Tobias S. M., Brummell N. H., Clune T. L., Toomre J., Transport and Storage of Magnetic Field by Overshooting Turbulent Compressible Convection, ApJ, 2001, vol. 549, p. 1183

Tobias S. M., Cattaneo F., Brummell N. H., Convective Dynamos with Penetration, Rotation, and Shear, ApJ, 2008, vol. 685, p. 596

Tomczyk S., Schou J., Thompson M. J., Measurement of the Rotation Rate in the Deep Solar Interior, ApJ, 1995, vol. 448, p. L57+

Toro E. F., Riemman solvers and numerical methods for fluid dynamics. Springer-Verlag, Berlin, 1997

Ulrich R. K., The controversial sun. In IAU Colloq. 137: Inside the Stars, vol. 40 of Astronomical Society of the Pacific Conference Series, 1993, p. 25

Vainshtein S. I., Cattaneo F., Nonlinear restrictions on dynamo action, ApJ, 1992, vol. 393, p. 165

van Ballegooijen A. A., Choudhuri A. R., The possible role of meridional flows in suppressing magnetic buoyancy, ApJ, 1988, vol. 333, p. 965

Vishniac E. T., Brandenburg A., An Incoherent alpha - Omega Dynamo in Accretion Disks, ApJ, 1997, vol. 475, p. 263

Wang Y.-M., Nash A. G., Sheeley Jr. N. R., Magnetic flux transport on the sun, Science, 1989, vol. 245 , p. 712

Wang Y.-M., Sheeley Jr. N. R., Magnetic flux transport and the sun's dipole moment New twists to the Babcock-Leighton model, ApJ, 1991, vol. 375, p. 761 
Wang Y.-M., Sheeley Jr. N. R., Nash A. G., A new solar cycle model including meridional circulation, ApJ, 1991, vol. 383, p. 431

Yoshimura H., Solar-cycle dynamo wave propagation, ApJ, 1975, vol. 201, p. 740

Yoshimura H., Nonlinear astrophysical dynamos - Multiple-period dynamo wave oscillations and long-term modulations of the 22 year solar cycle, ApJ, 1978a, vol. 226, p. 706

Yoshimura H., Nonlinear astrophysical dynamos - The solar cycle as a nonlinear oscillation of the general magnetic field driven by the nonlinear dynamo and the associated modulation of the differential-rotation-global-convection system, ApJ, 1978b, vol. 220, p. 692

Yousef T. A., Brandenburg A., Rüdiger G., Turbulent magnetic Prandtl number and magnetic diffusivity quenching from simulations, A\&A, 2003, vol. 411, p. 321

Zhao J., Kosovichev A. G., Torsional Oscillation, Meridional Flows, and Vorticity Inferred in the Upper Convection Zone of the Sun by Time-Distance Helioseismology, ApJ, 2004, vol. 603 , p. 776

Ziegler U., Rüdiger G., Box simulations of rotating magnetoconvection. Effects of penetration and turbulent pumping, A\&A, 2003, vol. 401, p. 433 
Apêndices 

Apêndice A

\section{Métodos numéricos,}

\section{modelo de dínamo de campo médio}

Esse apêndice contém os métodos numéricos empregados na construção do código de dínamo de campo médio descrito no Capítulo 4. Primeiramente, iremos descrever os esquemas de diferenças finitas implementados para a discretização espacial das equações, seguido pelo método ADI, implementado para a evolução temporal. Finalmente, discutiremos o tratamento numérico das condições de contorno.

\section{A.1 Diferenças finitas}

As equações diferenciais parciais são usualmente classificadas em três categorias: $h i$ perbólicas, parabólicas e elípticas (Press et al., 1992). Exemplos destas equações são as equações de onda, de difusão e a equação de Poisson, respectivamente. Em uma dimensão, a equação de onda

$$
\frac{\partial^{2} u}{\partial t^{2}}=v^{2} \frac{\partial^{2} u}{\partial x^{2}}
$$

pode ser escrita como um conjunto de equações diferenciais de primeira ordem:

$$
\begin{aligned}
& \frac{\partial r}{\partial t}=v \frac{\partial s}{\partial x} \\
& \frac{\partial s}{\partial t}=v \frac{\partial r}{\partial x}
\end{aligned}
$$

onde

$$
\begin{aligned}
r & \equiv v \frac{\partial u}{\partial x} \\
s & \equiv \frac{\partial u}{\partial t}
\end{aligned}
$$


As equações acima são conhecidas como equações de fluxo conservativo, já que a sua solução é geralmente uma onda que viaja na direção $x$ com velocidade $v$, tal que a taxa de variação temporal da quantidade $u$ no interior do domínio é igual ao fluxo de $u$ através das fronteiras. Na equação de indução, sem considerar os termos de segunda ordem, temos por exemplo que,

$$
\frac{\partial B}{\partial t}=-a \frac{\partial B}{\partial \theta}
$$

é uma equação de fluxo conservativo, e pode ser chamada também de equação advectiva pois $B$ é transportado no fluido com uma velocidade $a$. Se considerar-mos a evolução temporal discreta de $B$ ao longo do eixo $\theta$, tal que

$$
\begin{aligned}
& \theta_{j}=\theta_{0}+j \Delta \theta, \\
& t_{n}=t_{0}+n \Delta t,
\end{aligned}
$$

onde $j=0,1, \ldots, J$ and $n=0,1,2, \ldots, N$, é possível escrever o termo do lado direito da eq. (A.4) na forma discreta

$$
\frac{\partial B}{\partial t}=\frac{B_{j}^{n+1}-B_{j}^{n}}{\Delta t}
$$

a qual é chamada diferenciação de Euler, e permite calcular os valores de $B_{j}$ no passo temporal $n+1$ a partir dos valores de $B_{j}$ no passo $n$. Infelizmente, a equação de Euler têm só primeira ordem de precisão em $t$. A derivada espacial em $\theta$ também pode escrever-se em uma forma discreta usando segunda ordem de precisão, e considerando-se unicamente os valores conhecidos de $B^{n}$ (ou seja, valores no passo temporal $n$ ), assim:

$$
\frac{\partial B}{\partial x}=\frac{B_{j+1}^{n}-B_{j-1}^{n}}{2 \Delta \theta} .
$$

Combinando as eqs. (A.6) e (A.7) obtemos a aproximação de diferenças finitas da equação advectiva conhecida como representação FTCS (Forward Time Centered Space),

$$
\frac{B_{j}^{n+1}-B_{j}^{n}}{\Delta t}=-a \frac{B_{j+1}^{n}-B_{j-1}^{n}}{2 \Delta \theta} .
$$

Assumindo que a solução da equação diferencial tem a forma

$$
B_{j}^{n}=\zeta^{n} \mathrm{e}^{i k j \Delta \theta}
$$

onde $k$ é o número de onda espacial e $\zeta=\zeta(k)$ é um número complexo que depende de $k$, podemos fazer uma análise de estabilidade desta equação (conhecida como análise de Von 
Neumman Press et al., 1992). Para isto, substituímos a eq. (A.9) na eq. (A.8) e dividimos por $\zeta^{n}$, o que resulta em:

$$
\zeta(k)=1-i \frac{a \Delta t}{\Delta \theta} \sin (k) \Delta \theta
$$

Na equação acima, temos que $|\zeta(k)|>1$ para todos os valores possíveis de $k$, o que implica que sempre obteremos o crescimento exponencial, instável, de $B$. Por essa razão o esquema FTCS é considerado incondicionalmente instável.

Uma forma simples de eliminar essa instabilidade foi introduzida por Lax (Press et al., 1992) substituindo o termo $B_{j}^{n}$ no lado esquerdo da eq. (A.8) por seu valor médio

$$
B_{j}^{n} \rightarrow \frac{1}{2}\left(B_{j+1}^{n}+B_{j-1}^{n}\right)
$$

a qual leva a

$$
B_{j}^{n+1}=\frac{1}{2}\left(B_{j+1}^{n}+B_{j-1}^{n}\right)-\frac{a \Delta t}{2 \Delta \theta}\left(B_{j+1}^{n}-B_{j-1}^{n}\right) .
$$

Uma análise similar à apresentada acima para este esquema leva à condição $|\zeta|^{2} \leq 1$, o que implica:

$$
\frac{|a| \Delta t}{\Delta \theta} \leq 1
$$

A eq. A.13 é uma condição conhecida como o critério de estabilidade de CourantFriedrich-Lewy (CFL), do qual fazemos uso na eq. (A.13) para calcular o valor do passo temporal nas nossas simulações. O esquema de Lax têm primeira ordem de precisão no tempo e segunda ordem de precisão no espaço. O mecanismo de discretização conhecido como Lax-Wendroff de dois passos é capaz de oferecer segunda ordem de precisão tanto no espaço, quanto no tempo. Nele é necessário definirem-se os valores das variáveis em pontos intermediários do passo temporal e das pontos de grade, $B_{j+1 / 2}^{n+1 / 2}$. Esses pontos intermediários são calculados com o esquema de Lax dado pela eq. (A.11), de tal forma que teremos:

$$
B_{j+1 / 2}^{n+1 / 2}=\frac{1}{2}\left(B_{j+1}^{n}+B_{j}^{n}\right)-\frac{a \Delta t}{2 \Delta \theta}\left(B_{j+1}^{n}-B_{j-1}^{n}\right),
$$

e uma equação similar para $B_{j-1 / 2}^{n+1 / 2}$. Finalmente, os valores atualizados no ponto central $B_{j}^{n+1}$ são computados usando o esquema FCTC, o qual resulta em (veja a Fig. A.1)

$$
B_{j}^{n+1}=B_{j}^{n}-\frac{\Delta t}{\Delta \theta}\left(B_{j+1 / 2}^{n+1 / 2}-B_{j-1 / 2}^{n+1 / 2}\right)
$$




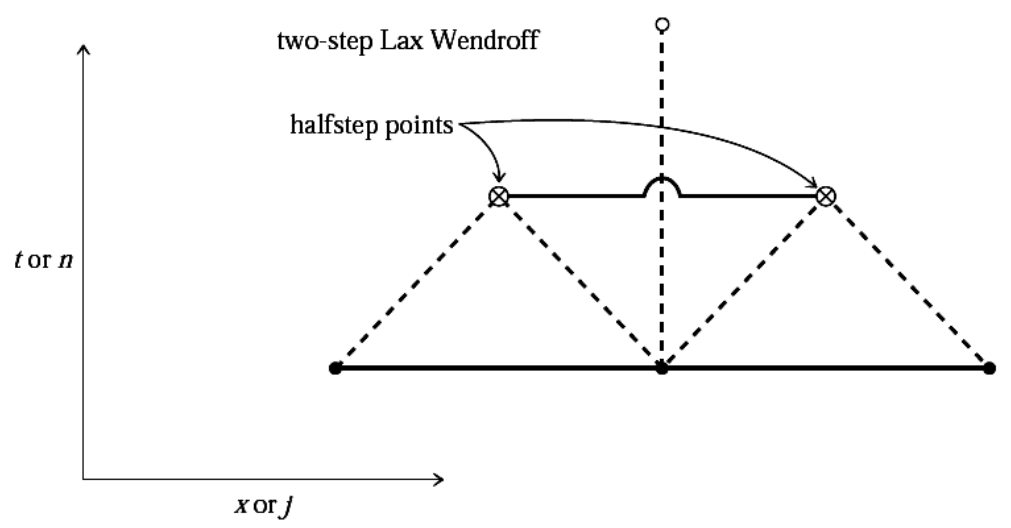

Figura A.1: Representação esquemática do mecanismo de diferenças finitas de Lax-Wendroff de doispassos. O dois passos temporais meios, assim como os valores nos pontos intermediários da grade, marcados com $(\otimes)$ são calculados com o método de Lax da eq. eq. (A.11). Os valores atualizados $B_{j}^{n+1}$ são computados com esses dois pontos mais o ponto central original. Adaptada de Press et al. (1992).

A parte da equação de indução para as componentes $B$ e $A$ do campo magnético correspondente à segunda derivada constitui uma equação de difusão. No caso de $B$ ela é

$$
\frac{\partial B}{\partial t}=\eta \frac{\partial^{2} B}{\partial \theta^{2}}
$$

onde $\eta$ é o coeficiente de difusividade. Essa equação pode ser escrita em termos das diferencias finitas na forma simples:

$$
\frac{B_{j}^{n+1}-B_{j}^{n}}{\Delta t}=\eta \frac{B_{j+1}^{n}-2 B_{j}^{n}+B_{j-1}^{n}}{\Delta \theta^{2}},
$$

que corresponde ao esquema FTCS, mas contrario à equação hiperbólica, o critério de estabilidade para a equação de difusão, $\zeta \leq 1$ leva a

$$
\frac{2 \eta \Delta t}{(\Delta \theta)^{2}} \leq 1
$$

o que significa que a restrição do passo temporal é definida pelo tempo de difusão a traves de um ponto de grade, $t_{d}=(\Delta \theta)^{2} / \eta$. As equações acima são também validas e podem se expandir automaticamente para a coordenada $r$ e a variável $A$.

\section{A.2 Método ADI}

Existem duas formas possíveis de se fazer um sistema de equações diferenciais evoluir no tempo: os métodos explícitos e implícitos. Nos primeiros, os valores das variáveis no 
passo temporal $n+1$ são calculados a partir dos valores das variáveis no passo $n$. Já nos segundos, as equações discretizadas se organizam de tal forma que todos os termos do lado direito correspondem ao passo temporal $n+1$. Por exemplo, podemos escrever a equação de difusão (A.17) assim:

$$
\frac{B_{j}^{n+1}-B_{j}^{n}}{\Delta t}=\eta \frac{B_{j+1}^{n+1}-2 B_{j}^{n+1}+B_{j-1}^{n+1}}{\Delta \theta^{2}}
$$

podemos agrupar os termos de forma apropriada para ter:

$$
-\lambda B_{j-1}^{n+1}+(1+2 \lambda) B_{j}^{n+1}-\lambda B_{j+1}^{n+1}=B_{j}^{n},
$$

onde $\lambda \equiv \eta \Delta t / \Delta \theta^{2}$, e $j=1,2, \ldots, N-1$. Essa fórmula corresponde a um sistema tridiagonal de equações que pode ser resolvido utilizando-se um algorítmo tridiagonal padrão para esse tipo de sistemas (veja por exemplo Press et al., 1992).

A estratégia que utilizamos neste trabalho para a evolução temporal do sistema 2.5D é conhecida como método ADI (alternating direction implicit). A idéia básica é separar o passo temporal em dois passos de tamanho $\Delta t / 2$, e a cada sub-passo uma das coordenadas espaciais é tratada implicitamente e a outra de forma explícita.

Assim, partindo das eqs. (4.4) e (4.5), a coordenada $\theta$ é considerada implicitamente e a coordenada $r$ explicitamente, de tal forma que obtemos:

$$
\begin{aligned}
& \frac{A_{i j}^{n+1 / 2}-A_{i j}^{n}}{\Delta t / 2}=L_{\theta} A^{n+1 / 2}+L_{r} A^{n}+S_{1}^{n} \\
& \frac{B_{i j}^{n+1 / 2}-B_{i j}^{n}}{\Delta t / 2}=L_{\theta} B^{n+1 / 2}+L_{r} B^{n}+S_{2}^{n},
\end{aligned}
$$

onde os índices $i=j=0,1,2, \ldots$, representam as direções espaciais, $n$ a dimensão temporal, e os operadores $L_{\theta}$ e $L_{r}$ de $A$ e $B$ correspondem àqueles definidos nas eqs. 4.6 a 4.9, mas dessa vez expressos em uma forma discretizada utilizando-se os dispositivos de Lax-Wendrof e FTCS. Então, todos os termos no passo $n+1 / 2$ são organizados no lado esquerdo, como na eq. (A.20), para formar um sistema tridiagonal de equações para as variáveis nas posições $j-1, j$ e $j+1$. Finalmente resolvemos esse sistema com um algorítmo tridiagonal de tipo Gaussiano (Press et al., 1992). Para o segundo meio-passo temporal, a coordenada $r$ é resolvida implicitamente e a coordenada $\theta$ de forma explicita, assim:

$$
\begin{aligned}
& \frac{A_{i j}^{n+1}-A_{i j}^{n+1 / 2}}{\Delta t / 2}=L_{\theta} A^{n+1 / 2}+L_{r} A^{n+1}+S_{1}^{n+1 / 2} \\
& \frac{B_{i j}^{n+1}-B_{i j}^{n+1 / 2}}{\Delta t / 2}=L_{\theta} B^{n+1 / 2}+L_{r} B^{n+1}+S_{2}^{n+1 / 2} .
\end{aligned}
$$


então, como no passo anterior, formamos o novo sistema tridiagonal e resolvemos para encontrar os valores atualizados das variáveis $A_{n+1}$ e $B_{n+1}$. Note que os termos fonte $S_{1}$ e $S_{2}$ são sempre considerados explicitamente.

\section{A.3 Tratamento numérico das condições de contorno}

Existem dois tipos de condições de contorno utilizadas freqüentemente em simulações numéricas: as condições de contorno de Dirichlet e as de Neumann. Nas primeiras, a variável, no nosso caso o campo magnético ou o potencial vetor, assume um valor fixo na fronteira, por exemplo, na fronteira do pólo norte solar temos que $A=B=0$, de tal forma que no código isto pode ser escrito da seguinte maneira:

$$
A[i][0]=B[i][0]=0 \quad \text { para } \quad i=0, \ldots, N .
$$

Por outro lado, nas condições de contorno de Neumann, é a primeira derivada de uma variável que assume um valor conhecido. Então, novamente é necessário usar o esquema de diferenças finitas para calcular o valor na fronteira. Porém, já que nesse caso não dispomos de todos os vizinhos do ponto em questão (pois ele é o primeiro ou o último ponto da grade computacional), então devemos usar diferenças finitas tomando pontos consecutivos à frente atrás, o que significa que os valores das primeiras derivadas nesse ponto da grade são calculados com os valores dos seus vizinhos à direita ou à esquerda, respectivamente. Por exemplo, a condição $\partial f / \partial x=0$ num ponto ao final do domínio pode ser expressa em diferenças finitas para trás como:

$$
\frac{\partial f_{N}}{\partial x}=\frac{3 f_{N}-4 f_{N-1}+f_{N-2}}{2 \Delta x}=0,
$$

tal que

$$
f_{N}=\frac{4 f_{N-1}-f_{N-2}}{3},
$$

e de forma similar para um ponto no começo do domínio.

Em nosso código, a condição de contorno usada para $A$ em $r=R_{\odot}$ permite o acoplamento do campo poloidal do interior do domínio com um campo magnético no vácuo. A equação que governa a evolução do campo no vácuo é a equação de Laplace: $\left(\nabla^{2}+1 / s\right) A=0$, onde $s=r \sin (\theta)$, a qual tem uma solução analítica conhecida dada por:

$$
A\left(r>R_{\odot}, \theta, t\right)=\sum_{m} \frac{a_{m}(t)}{r^{m+1}} P_{m}^{l}(\cos \theta)
$$


onde $P_{m}^{l}(\cos \theta)$ são os polinômios associados de Legendre e $a_{m}$ são coeficientes que podem ser calculados dos valores dos valores de $A$ em $R_{\odot}$. Assim:

$$
a_{m}(t)=\frac{(2 m+1) R_{\odot}^{m+1}}{m(m+1)} \int_{0}^{2 \pi} A\left(R_{\odot}, \theta, t\right) P_{m}^{l}(\cos \theta) \sin \theta d \theta
$$

Para acoplar de forma suave as soluções interna (calculadas numéricamente em nosso modelo) e externa (equação de Laplace) consideramos uma condição de tipo Neumann de tal forma que em $r=R_{\odot}$ tem-se:

$$
\frac{\partial A\left(R_{\odot}, \theta, t\right)}{\partial \theta}=-\sum_{m} \frac{(m+1) a_{m}(t)}{R_{\odot}^{m+2}} P_{m}^{l}(\cos \theta)
$$

então, usando as eqs. (A.26) e (A.27), obtemos:

$$
A_{N, j}=\frac{1}{3}\left(4 A_{N-1, j}-A_{N-2, j}-2 \Delta \theta \sum_{m} \frac{(m+1) a_{m}(t)}{R_{\odot}^{m+2}} P_{m}^{l}(\cos \theta)\right) .
$$

Os valores de $A$ neste contorno são avaliados calculando os coeficientes $a_{m}(t)$ do passo temporal anterior. Porém, o acoplamento das equações externa e interna não acontece imediatamente e é necessário repetir o processo, corrigindo de forma iterativa os valores de $A\left(R_{\odot}, \theta, t\right)$ e $a_{m}(t)$ durante algumas vezes até alcançar a convergência. Normalmente um loop de 15 a 20 iterações é suficiente.

Vale notar que nos modelos que cobrem só um hemisfério, para respeitar a condição de contorno no equador $\partial A / \partial \theta=0$, é preciso somar unicamente os polinômios nos quais $m$ é ímpar. Já no caso dos dois hemisférios, todos os termos dos polinômios de Legendre até ordem $m$ são somados. Em nossos modelos usamos $m_{\max }=32$.

\section{A.4 Fluxograma do código do dínamo de campo médio}

O código que modela o dínamo de campo médio está organizado segundo a ordem mostrada no fluxograma da Fig. A.2:

1. O programa principal, escrito na linguagem $\mathrm{C}++$ encontra-se no arquivo chamado dynamo.C, ele chama inicialmente o arquivo de configuração Num.h que contém a definição do domínio computacional, a resolução, e os valores de algumas quantidades importantes. Logo após é chamada a classe velocity que se encontra no arquivo velocity.C que contém a definição de todos os perfis (ou ingredientes) do modelo de 


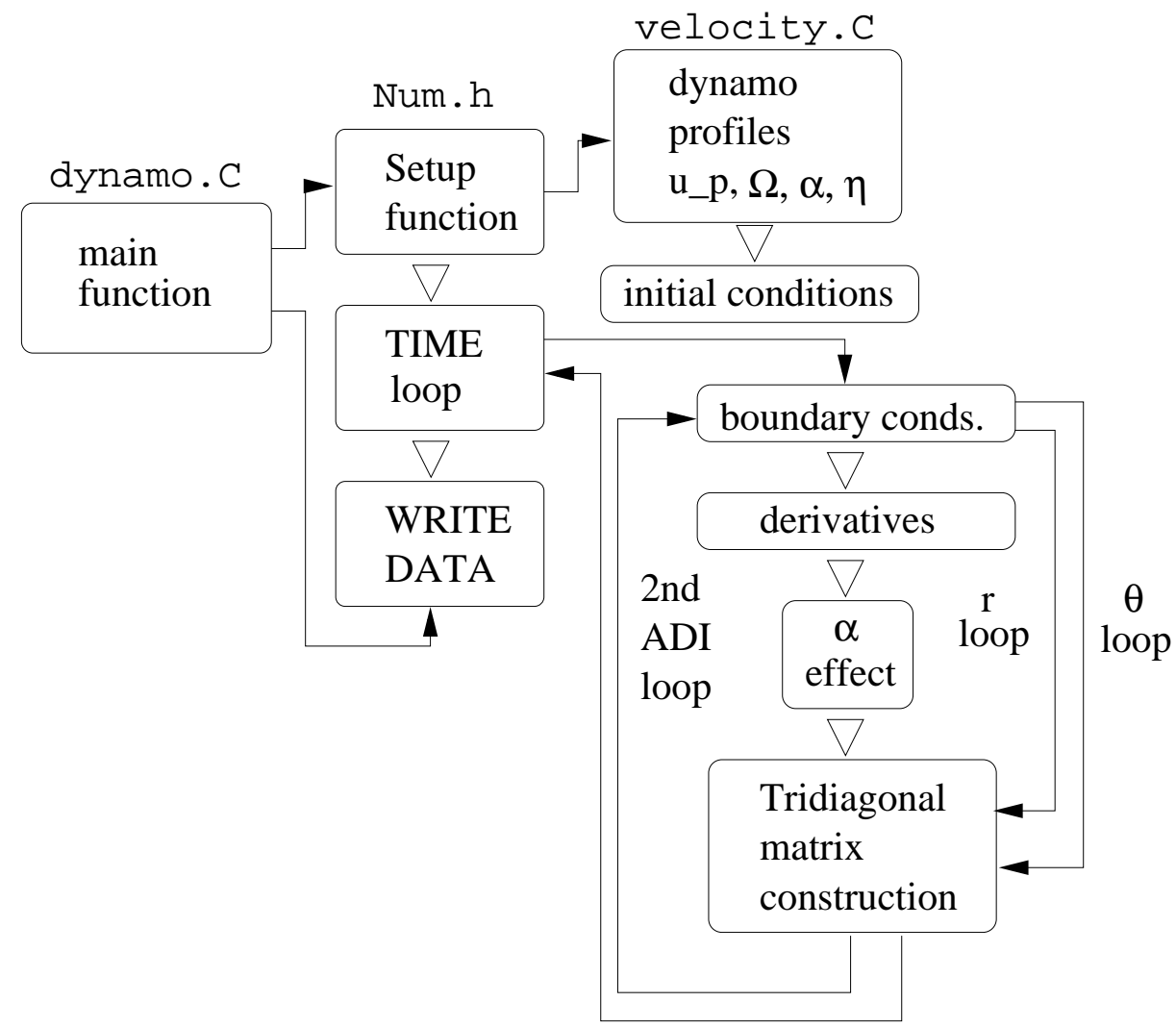

Figura A.2: Fluxograma do código DYNAMOiag indicando os passos seguidos para resolver as equações do dínamo de campo médio com os métodos de diferenças finitas e ADI para o avanço temporal.

dínamo, a saber: perfil de rotação diferencial, perfil de circulação meridional, e os perfis radial e latitudinal do efeito $\alpha$, da difusividade $\eta$ e do bombeamento magnético. Vários perfis adotados na literatura desses ingredientes do dínamo (tanto no cenário de Babcock-Leighton quanto no cenário turbulento nos modelos distribuído e de interface) foram testados no código e alguns deles encontram-se disponíveis no programa e podem ser chamados nas instruções do pre-processamento localizadas no começo do arquivo velocity.C.

2. Uma vez definidos os perfis necessários são definidas no arquivo dynamo.C, na função IC, as condições iniciais. Dentre as opções disponíveis encontram-se as condições simétrica, antisimétrica, randômica e também a possibilidade de iniciar-se com um arquivo de dados.

3. começo do loop temporal

Depois de algumas definições convenientes, e de se iniciar e se configurar o parale- 
lismo, começa o loop de avanço temporal. De acordo com o método ADI, ele começa a integração implícita em uma direção espacial (p.ex. a variável $r$ ) e segue a seguinte ordem:

- definição das condições de contorno chamando a rotina BoundCond;

- cálculo das derivadas de primeira e segunda ordem com os métodos de diferenças finitas descritos acima chamando a rotina Deriv,

- cálculo do efeito $\alpha$ e construção das matrizes tridiagonais que a seguir são resolvidas chamando a rotina tridiag.

- Então são adicionados os termos fonte e o mesmo loop começa novamente, mas dessa vez integrando implicitamente na segunda direção espacial (i.e., variável $\theta)$;

- novamente são adicionados os termos fonte e calculados os valores das variáveis para um novo passo temporal.

4. Finalmente o programa escreve os arquivos de saída com os resultados da simulação. Estes podem ter o formato necessário para construir um diagrama de borboleta ou para construir um corte meridional (ou os dois simultaneamente).

Os dados são visualizados utilizando rotinas construídas no programa IDL. O código do modelo de dínamo de campo médio encontra-se disponível para descarga no site: www.astro.iag.usp.br/ guerrero/code/ . Ele pode ser utilizado, modificado e distribuído livremente. 
Apêndice B

\section{O código PLUTO}

Nos cálculos tridimensionais do Capítulo 8 utilizamos o código de domínio público PLUTO (Mignone et al., 2007). Esse código resolve as equações da hidrodinâmica (HD) e também da magnetohidrodinâmica (MHD) usando volumes finitos e um algorítmo de tipo Goudunov. Já que o código tem uma documentação muito completa ${ }^{1}$, iremos aqui descrever unicamente alguns detalhes do método numérico utilizado, bem como o fluxograma do código e as diferentes possibilidades que ele tem.

\section{B.1 Método de Gudunov}

Ao contrario dos métodos de diferenças finitas, que calculam o valor das variáveis nas arestas da grade computacional, os métodos de volumes finitos calculam o fluxo das quantidades conservativas: $\rho, \mathbf{m}, E$ e $\mathbf{B}$, densidade, momentum, energia e campo magnético, respectivamente. Então as equações da HD (ou MHD) podem ser escritas na forma:

$$
\frac{\partial \mathbf{U}}{\partial t}=-\nabla \cdot \mathbf{T}(\mathbf{U})+\mathbf{S}(\mathbf{U})
$$

onde $\mathbf{U}$ é um vetor que contém as quantidades conservativas do sistema, $\mathbf{T}$ é um tensor de segunda ordem que contém nas suas linhas os fluxos de cada componente de $\mathbf{U}$, e $\mathbf{S}$ contém os termos fonte, tais quais a aceleração da gravidade, a forca de Coriolis, termos de resfriamento, etc. Em um caso unidimensional simples em que $\mathbf{S}=0$, resolver a eq. B.1 numa região separada do resto do domínio por uma descontinuidade (i.e., por uma brusca variação no valor das variáveis), e com a condição inicial $\mathbf{U}(x, 0)=U_{0}(x)$, é chamado problema de Riemann. O problema de Riemann resolve-se considerando-se os valores à

\footnotetext{
${ }^{1}$ http://plutocode.to.astro.it/
} 
direita, $\mathbf{U}^{+}$, e à esquerda $\mathbf{U}^{-}$, dessa região. Já que a eq. B.1 é de tipo hiperbólico, a sua solução é um conjunto de $m$ ondas (uma para cada variável), que se propagam no plano $x-t$.

Já no caso de uma grade unidimensional abrangendo o intervalo $[0, L]$, é necessário resolver-se o problema de Riemann $(R P)$ localmente para cada par de arestas. Por exemplo, para os pontos $i-1$ e $i$, resolve-se $R P\left(\mathbf{U}_{i-1}^{n}, \mathbf{U}_{i}^{n}\right)$ e para os pontos $i$ e $i+1$, resolve-se $R P\left(\mathbf{U}_{i}^{n}, \mathbf{U}_{i+1}^{n}\right)$, o qual gera um padrão de ondas como o apresentado no diagrama esquemático da Fig. B.1, emergindo dos pontos intermediários da grade, $i-1 / 2$ e $i+1 / 2$, que neste caso correspondem à região onde se encontra a descontinuidade. Os novos valores de $\mathbf{U}$ nos pontos intermediários das arestas permitem calcular os valores dos fluxos $\mathbf{F}_{i-1 / 2}$ e $\mathbf{F}_{i+1 / 2}$.

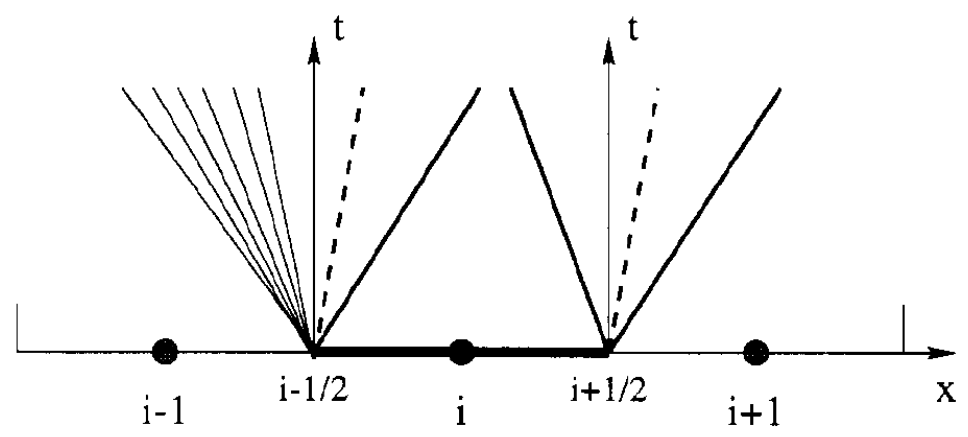

Figura B.1: Padrão de ondas emergentes típico de soluções de problemas de Riemann locais nos pontos intermediários da grade, $i-1 / 2$ e $i+1 / 2$ (figura extraída de Toro, 1997).

O passo seguinte é calcular o operador

$$
\mathcal{L}=-\frac{1}{\Delta x}\left(\mathbf{F}_{i+1 / 2}-\mathbf{F}_{i-1 / 2}\right)+\mathbf{S}
$$

onde os fluxos F são calculados resolvendo-se o problema de Riemann para cada ponto (e.g., $\left.F_{i-1 / 2}=R P\left(\mathbf{U}_{i-1}^{n}, \mathbf{U}_{i}^{n}\right)\right)$. $\mathcal{L}$ pode substituir o lado direito da eq. B.1, levando a uma formulação discreta das equações em volumes finitos:

$$
\mathbf{U}^{n+1}-\mathbf{U}^{n}=\Delta t \mathcal{L}
$$

Finalmente se resolve-se a eq. B.3 para encontrar os valores de $\mathbf{U}$ no passo temporal $n+1$. Essa solução é feita através de um mecanismo explícito (de tipo Runge-Kutta, 
por exemplo) ou implícito (veja acima), mas considerando-se que o passo temporal deve obedecer à restrição

$$
\Delta t \leq \frac{\frac{1}{2} \Delta x}{S_{\max }^{n}},
$$

onde $S_{\max }^{n}$ é a máxima das velocidades das ondas emergentes das descontinuidades em todo o domínio no tempo $t$. Essa condição implica que não podem existir interações entre as ondas no interior de uma célula da grade. Essa relação é equivalente à condição de Courant-Friedrich-Lewy descrita anteriormente.

Um algorítmo contendo os passos anteriores: interpolação, solução do problema de Riemann e avanço temporal é conhecido como de tipo Gudunov, por ter sido ele quem em 1959, propôs uma primeira versão desse método (Toro, 1997). A seguir apresentaremos um fluxograma indicando a forma como o código PLUTO implementa esse método.

\section{B.2 Fluxograma e opções do código PLUTO}

O código pluto, escrito na linguagem $C$, está construído de forma modular, permitindo resolver as equações da HD ou da MHD usando um método de tipo Goudunov, conforme ressaltado acima. Ele segue o fluxograma mostrado na Fig. B.2. Ele contém uma rotina principal main.c que chama os diferentes módulos do código na seguinte ordem:

1. Inicio (initialize.c): essa rotina lê os arquivos de configuração do código, definitions.h e pluto.ini os quais definem as características do problema físico a ser considerado, i.e., dimensão, geometria, intervalos, resolução, técnica de interpolação, resolvedor do problema de Riemann e mecanismo de avanço temporal. Posteriormente lê a rotina init.c que contém as condições iniciais. Desta forma establecem-se todas as características do problema hidro ou magnetohidrodinâmico que ira ser resolvido. Esse passo é feito uma única vez.

2. Inicio do loop temporal: Leitura das condições de contorno nos arquivos pluto.ini e init.c. Já que algumas das condições de contorno, que podem ser dos tipos Neumann ou Dirichlet, como foi visto acima, dependem dos valores internos do domínio, a atualização dessas condições deve se fazer a cada passo temporal.

3. O módulo Interpolate contém uma coleção de rotinas com diferentes mecanismos 


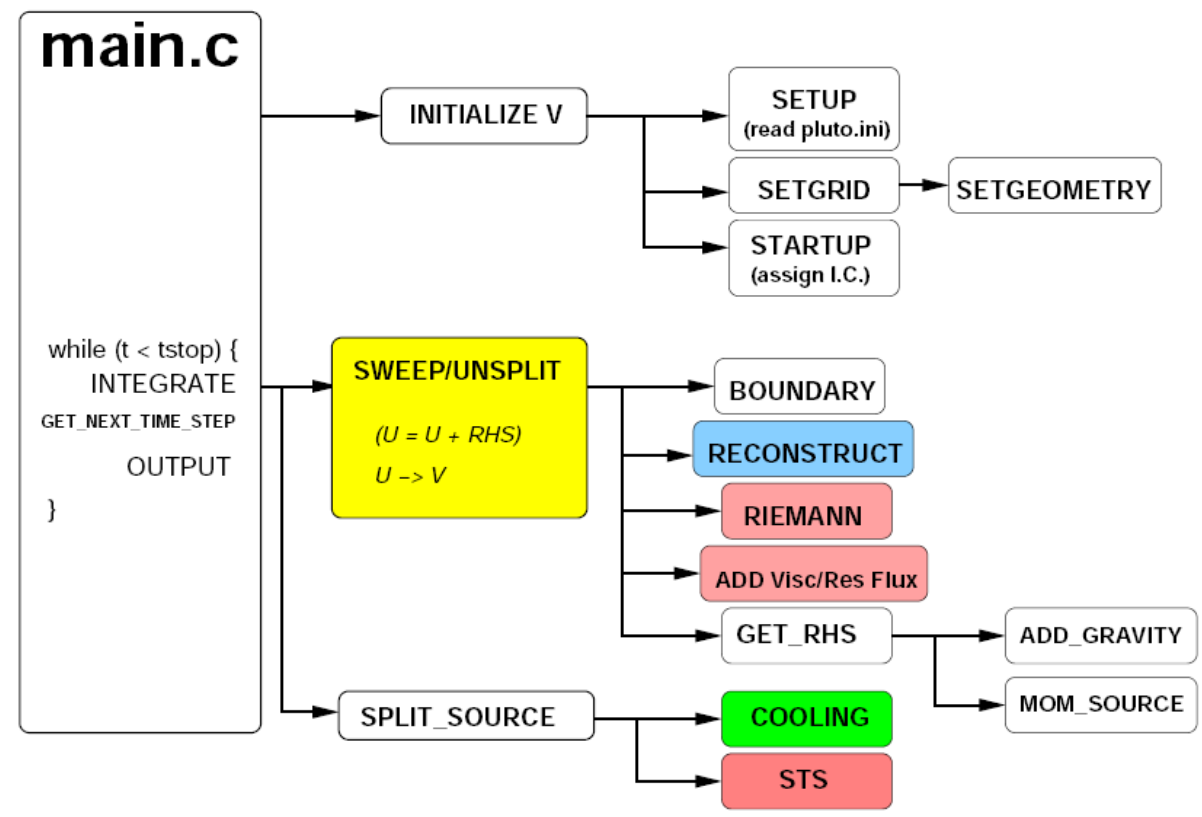

Figura B.2: Fluxograma do código PLUTO indicando os passo seguidos na resolução das equações da hidrodinâmica e da magnetohidrodinâmica com um algorítmo de volumes finitos e seguindo o método de Gudunov

de interpolação: flat, linear, ceno3, parabolic e weno5. Essas rotinas lêem os valores das variáveis nas arestas e calculam os seus valores intermediários (e.g. em $i \pm 1 / 2$ ).

4. Resolução do problema de Riemann: Os módulos HD e MHD contém uma série de rotinas, as quais utilizam os valores das variáveis nos pontos intermediários para calcular os fluxos e o operador $\mathcal{L}$ (eq. B.2). Dentre as diferentes possibilidades estão os métodos (ordenados de acordo com o grau de sua difusividade numérica, de menor para maior): two chock, roe, ausm+, hlld, hllc, hll e tvdlf.

5. Adição de termos parabólicos: os termos de tipo parabólico como a condutividade térmica (modificada para o Capítulo 8 desta tese), viscosidade física (implementada no código para o Capítulo 8 desta tese) e difusividade magnética, não são calculados juntamente com o problema de Riemann, porém uma vez calculados os valor atualizados das variáveis, estes são corrigido com a contribuição parabólica.

6. O lado direito da eq. B.3 é também corrigido com as contribuições de forças como a força de gravidade e a força de Coriolis, chamadas na rotina body_force.c, e também 
com possíveis efeitos de resfriamento implementados no módulo Cooling, que oferece as seguintes possibilidades: power-law cooling, tabulated cooling, Raymond cooling e multi ion non_equilibrium cooling (em nossa modelagem do sistema convectivo essas rotinas não são necessárias).

7. Evolução temporal das variáveis usando alguma das técnicas contidas no módulo Time_Stepping: Euler, RK2, RK3, Hancock ou Characteristic tracing.

8. Escritura dos dados.

Aqui se fecha o loop temporal e se retorna ao item 2

A escolha da técnica de interpolação, do resolvedor do problema de Riemann e do mecanismo de avanço temporal é efetuada, em parte, considerando-se as características de cada técnica e do problema específico que se está examinando. Porém essa escolha é, em geral, realizada de forma empírica, procurando-se a melhor relação entre velocidade de cômputo, precisão e difusividade numérica. Uma informação mais completa sobre as técnicas de interpolação pode ser encontrada na documentação do código (http://plutocode.to.astro.it/), bem como em comentários dentro das rotinas do código. Já os detalhes dos resolvedores do problema de Riemann encontram-se explicados de forma simples e completa em Toro (1997). Para os métodos de avanço temporal veja Press et al. (1992); Toro (1997). 
Apêndice C

Efeitos da forma e espessura da tacoclina, Artigos 1 e 2 
Apêndice D

Bombeamento magnético turbulento, Artigo 3 
Apêndice $\mathrm{E}$

O papel do amortecimento da difusividade, Artigo 4 